\title{
PARTICIPAÇÃO DO ESTRESSE E ANSIEDADE NA ALTERAÇÃO DO LIMIAR DE DOR À PRESSÃO (LDP) EM PACIENTES COM DTM MIOGÊNICA:
}

\section{UM ESTUDO COMPARATIVO}
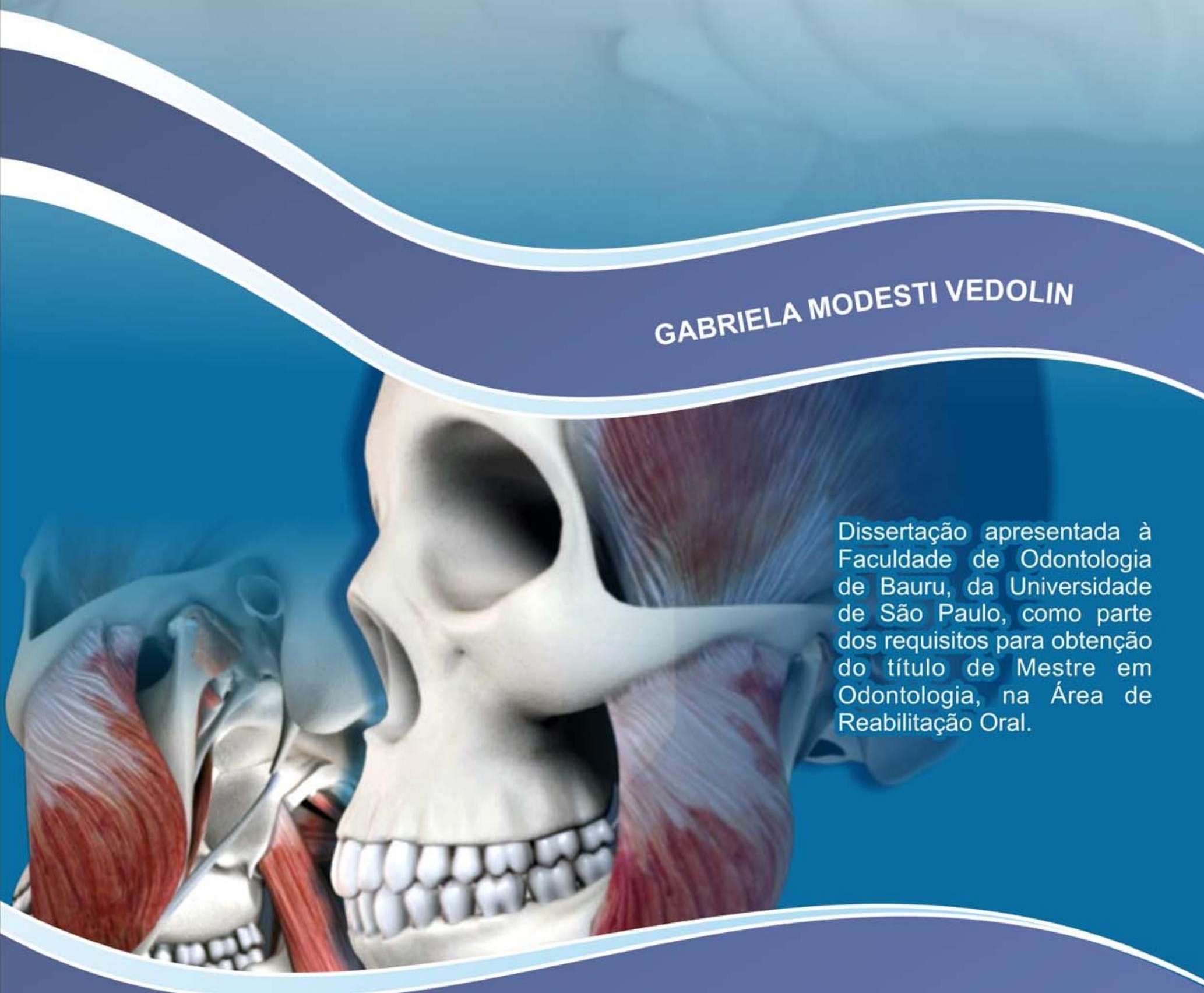


\section{PARTICIPAÇÃO DO ESTRESSE E ANSIEDADE NA ALTERAÇÃO DO LIMIAR DE DOR À PRESSÃO (LDP) EM PACIENTES COM DTM MIOGÊNICA: UM ESTUDO COMPARATIVO}

\section{GABRIELA MODESTI VEDOLIN}

Tese apresentada à Faculdade de Odontologia de Bauru, da Universidade de São Paulo, como parte dos requisitos para obtenção do título de Mestre em Odontologia, na Área de Reabilitação Oral.

Orientador: Prof. Dr. Paulo César Rodrigues Conti 


\begin{tabular}{|l} 
VEDOLIN, Gabriela Modesti \\
Participação do estresse e ansiedade na alteração do \\
Limiar de dor à pressão (LDP) em pacientes com DTM \\
miogênica: um estudo comparativo / Gabriela Modesti \\
Vedolin. - Bauru, 2006. \\
189 p. : il. ; $30 \mathrm{~cm}$ \\
Dissertação (Mestrado) - Faculdade de Odontologia \\
de Bauru. USP \\
Orientador: Prof. Dr. Paulo César Rodrigues Conti
\end{tabular}

\section{Autorizo, exclusivamente para fins acadêmicos e} científicos, a reprodução total ou parcial desta dissertação, por processos fotocopiadores elou meios eletrônicos.

Assinatura do autor (a):

Data:

Projeto aprovado pelo Comitê de Ética em Pesquisa da Faculdade de Odontologia de Bauru - USP. Protocolo de pesquisa no 162/2004. 
17 de janeiro de 1979 - NASCIMENTO - IJUÍ - RS

Filiação: ADRIANA MODESTI VEDOLIN

CELSO VEDOLIN

1997-2002

Curso de Graduação em Odontologia na Universidade de Passo Fundo - RS.

2002-2004

Curso de Especialização em Prótese Dentária na Faculdade de Odontologia de Bauru - USP

2003-2003

Curso de Aperfeiçoamento em Periodontia promovido pelo Instituto de Ensino Odontológico - IEO

2003-2004

Curso de Aperfeiçoamento em Prótese Sobre Implante promovido pelo Instituto de Ensino Odontológico - IEO

2004-2006

Curso de Pós-Graduação em Odontologia, área de concentração Reabilitação Oral, em nível de Mestrado, na Faculdade de Odontologia de Bauru - USP

\section{ASSOCIAÇÕES DE CLASSE E SOCIEDADES CIENTÍFICAS}

SBPqO - Sociedade Brasileira de Pesquisa Odontológica 
“SE sua mente pude conceber E $\square$ SEU CDRAÇÃ̃ ACREDITAR, .... VICÉ PUDE ALCANÇAR." 


\section{DEDICATǴRIA}

ADS MEUS PAIS

PURTADIRES DAS MAIDRES VIRTUDES - INTEGRIDADE E HINESTIDADE - E RESPINSÁVEIS PELD MEU CARÁTER E DIGNIDADE, ENSINARAM-ME QS PRINCÍPIDS BÁSILDS DE UM SER HUMAND, PUSSIBILITANDL-ME DISTINGUIR VALDRES QLE ME LEVARAM Aं CAPACIDADE DE SEGUIR SDZINHA. PRDTEGERAM-ME SEM SEREM EGUÍSTAS, AMARAM-ME SEM NADA CDBRAR E DUARAM-SE INLDNDICIONALMENTE, SEMPRE! MINHA ADMIRAÇÃA É INDESCRITÍVEL; MEU AGRADECIMENTD, ETERND E MEU AMDR... INCALCULÁVEL. ADS DOIS, DEDICD ESTE TRABALHD

“SÚ 口 AMDR PUDE SER DIVIDIDD INFINITAMENTE E AINDA ASSIM NÃロ DIMINUIR" 


\title{
A DEUS
}

\author{
PロR ter ME CDNLEDID A VIDA, A \\ ロPロRTUNIDADE EM DESCDBRI-LA
}

E PELDS BDNS CAMINHDS PDR $\square$ NDE ME

TEM CDNDUZIDD. 


\section{AGRADELIMENTDS}

\section{Ag Prgfessar dr. PAUla césar Rodrigues canti,}

PRIMEIRD, MEU PRDFEsSDR; DEPDIS, MEU DRIENTADDR E, ETERNAMENTE, MEU AMIGD.

SEL PRDFISSIONALISMD, DEDICAÇÃ̈ CDNSTANTE E SABEDLRIA D TIRNAM UM VERDADEIRL PRDFESSDR.

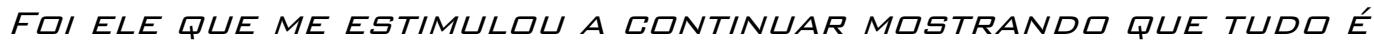
PDSSÍVEL. SUA DRIENTAÇÃ INTEGRAL E SEGURA INSPIRA A BUSLA PELD DESAFID. MUITU DBRIGADA PELA CDNFIANÇA EM MIM DEPDSITADA, PELA SINLERIDADE, AMIZADE E PELD APDID E INLENTIVD CDNSTANTE. MEUS MAIS SINLERDS AGRADECIMENTDS PDR TUDD; SEMPRE! 


\section{AGRADELIMENTDS}

À faculdade de adontqlogia de bauru, que possibilitud A CINCRETIZAÇÃ́ DE MEUS PRIJETIS PRIFISSIONAIS.

Ags Membrgs da Banca examinadora, pela disponibilidade e PRESTEZA EM AVALIAR MEU TRABALHם.

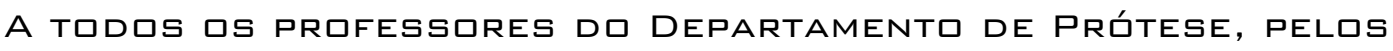
ENSINAMENTIS, ATENÇÃa E cINVívio.

Aa Prof. lauris, pela atençãa constante.

ALS FUNCIINÁRIOS DI DEPARTAMENTI DE PRÓTESE, EM ESPECIAL EdNa, cláudia, Valquíria, Marcelo e Rivanildo pela ajuda PERMANENTE, CARINHם E DEDICAÇÃ

A Débgrah, amiga e conselheira, que sempre esteve dispgsta a ME AJUDAR CIM CARINHI, ALEGRIA E CIMPETÊNCIA.

Ags funcianárigs da clínica de Pós-graduaçãa, cleuza, Hebe e DU PELA DISPINIBILIDADE, CARINHI E COMPETÊNCIA.

A todas MEUS fAMILIARES, ESPECIALMENTE MEU IRMÃ LEDNARDa, PELA INSPIRAÇÃa, PELI APRII INCGNDICIONAL E CARINHם. MINHA ETERNA ADMIRAÇÃa!

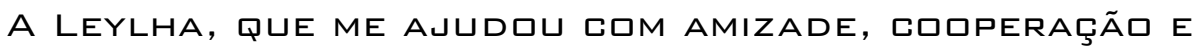

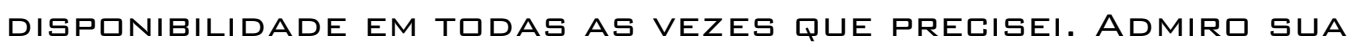
SABEDIRIA, PACIÊNCIA E AMLR PELI TRABALHQ.

A TIDIS as VILUNTÁRIGS ALUNGS DA GRADUAÇÃ́ DA FIB/USP, PELA PARTICIPAÇÃ̃ E CONTRIBUIÇÃ̃ FUNDAMENTAL PARA EXECUÇÃa DE MEU PRIJETR.

Ags meus colegas de turma: ana paula, Ramãa, Thiaga, luis Eduardo, flqra, Valéria, lugiana, rafael, daniel c., daniel b., Pagla, Fernanda, JefFErsan e Adriana, pelas mamentas COMPARTILHADIS, COMPANHEIRISMI E AMIZADE. 
Aq estagiárig FÁbig, pela ajuda gratuita e agradável Na REALizaçÃ̃ deste trabalho.

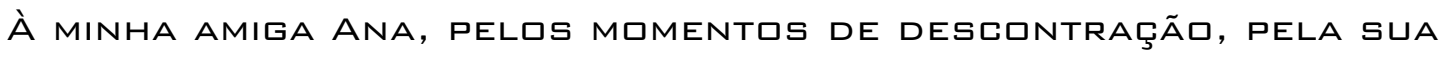

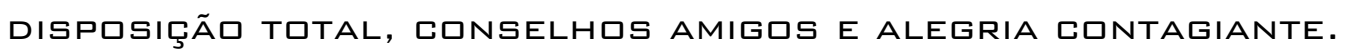

À minha amiga e companheIRA de pesquisas VALÉria, pela amizade, SLlidariedade, alegria, risadas e conversas. Sermas grientadas

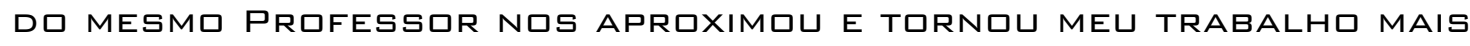

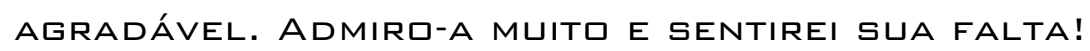

À minha eterna amiga flora, pela cumplicidade, carinha e PRESENÇA EM TIDIS IS MIMENTIS DE MINHA VIDA. Aם SEGUIRMIS NOSSRS CAMINHIS JUNTAS, TUDG FICLU MAIS FÁCIL. BAURU NÃם SERIA

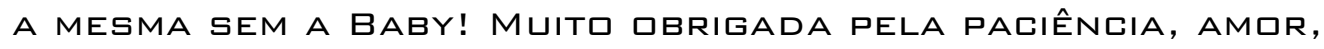

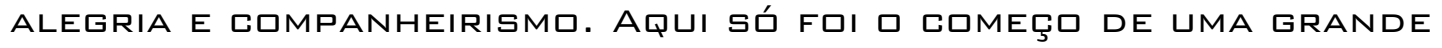
AMIZADE!

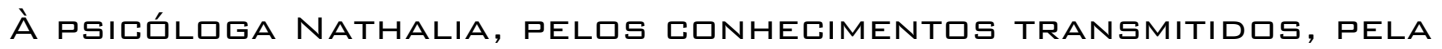
AJUDA FUNDAMENTAL NA REALIZAÇÃ̃ DESTE TRABALHם, SEJA ATRAVÉS DIS EXAMES DIS PACIENTES QU MESMI PELA qBTENÇÃם D INSTRUMENTI IMPRESCINDÍVEL PARA TAL FINALIDADE. MAIS D QUE ISSD, HIJE TENHI SUA AMIZADE, PARCERIA E CARINHI.

À minha grande amiga Aline, pela contribuiçãa constante NA REALIZAÇÃ̃ DI MEU PRロJETa E DISPGSIÇÃa ADMIRÁVEL. FUI PRIVILEGIADA EM TÊ-LA COMI PARCEIRA DE TRABALHO, UMA AMIGA TÃ ESPECIAL!!! FII UM PRAZER ENIRME CLMPARTILHAR DE SUA ALEGRIA,

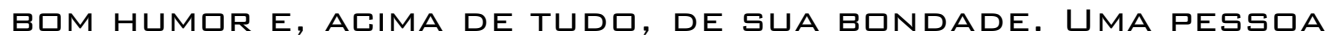
EXCEPCIINAL. CINHECÊ-LA FロI UMA BENÇÃ̃ qUE JAMAIS ESqUECEREI!

Às MINHAS AMIGAS E COMPANHEIRAS CLÁ, DANI E RÊ qUE PARTICIPARAM DA MINHA VIDA EM BAURU COM CARINHI E ALEGRIA. 


\section{SUMÁRIO}

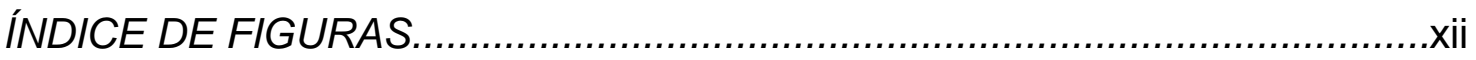

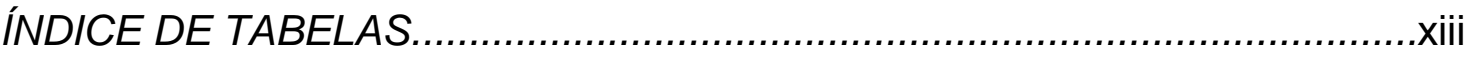

LISTA DE ABREVIATURAS E SÍMBOLOS.............................................

RESUMO

1 - INTRODUÇÃO

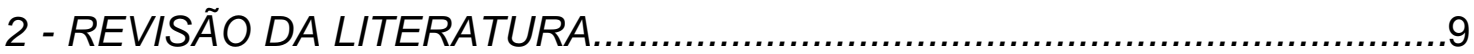

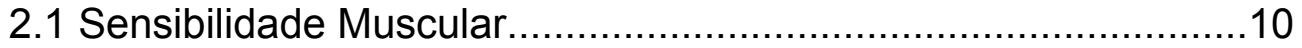

2.2 Aspectos psicológicos e as DTMs............................................32

3 - PROPOSIÇÃO

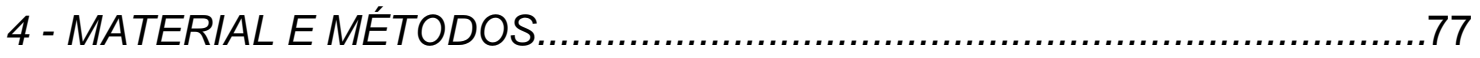

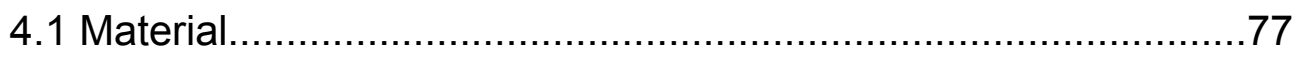

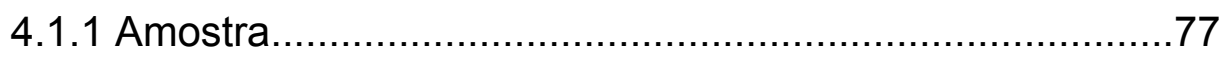

4.1.1.1 Estabelecimento dos Grupos..................................77

4.1.1.1.1 Grupo Experimental (com DTM)..................................... 80

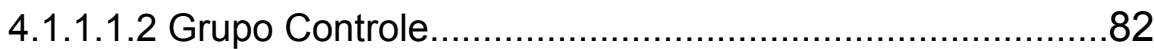

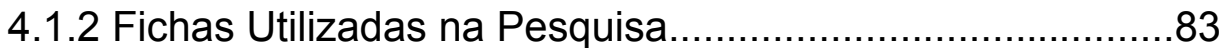

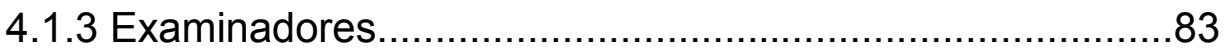

4.1.4. Material utilizado nas diferentes avaliações.......................84

4.1.4.1. Algômetro para mensuração do limiar de dor à pressão...84

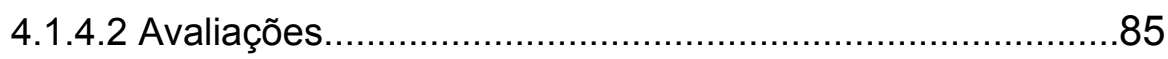

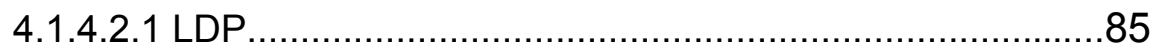

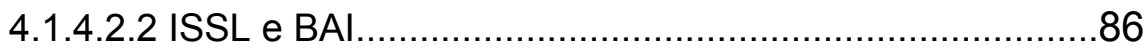

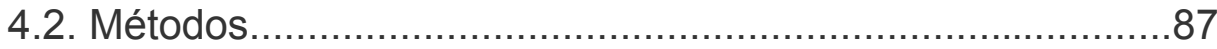

4.2.1 Avaliação do limiar de dor à pressão............................87

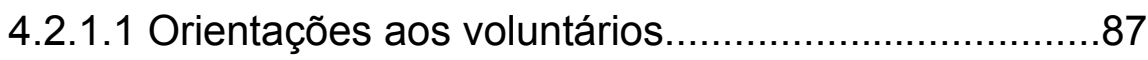

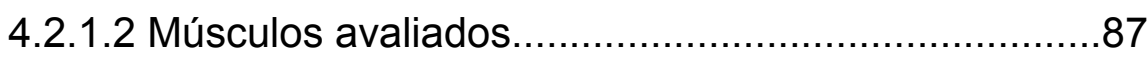

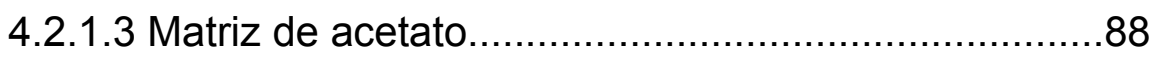

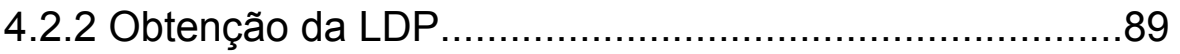

4.2.3 Avaliação do estresse e ansiedade................................91 
4.2.3.1 ISSL ........................................................... 92

4.2.3.2 BAI.........................................................93

4.2.4 Períodos de avaliação............................................94

4.2.4.1 Análise estatística dos resultados.........................95

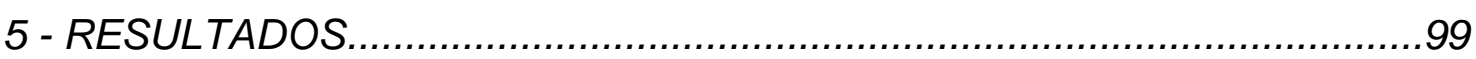

5.1 Limiar de dor à pressão..............................................99

5.2 Escala de Análise Visual (EAV).....................................109

5.3 Estresse e Ansiedade...............................................110

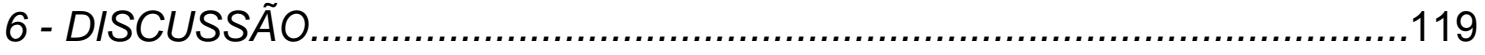

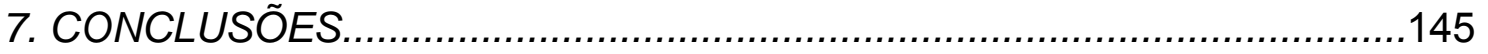

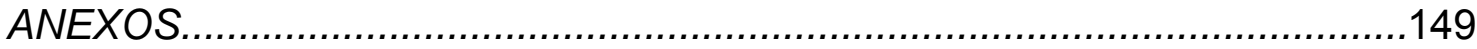

REFERÊNCIAS BIBLIOGRÁFICAS.................................................. 173

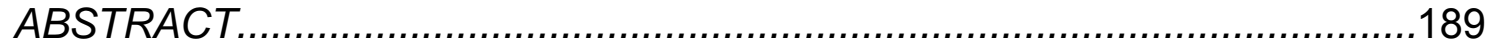




\section{ÍNDICE DE FIGURAS}

Figura 1 - Algômetro KRATOS ${ }^{\circledR}$ utilizado para o exame de palpação.

Figura 2 - Ponta circular achatada com silicone adaptada para entrar em contato com pele do

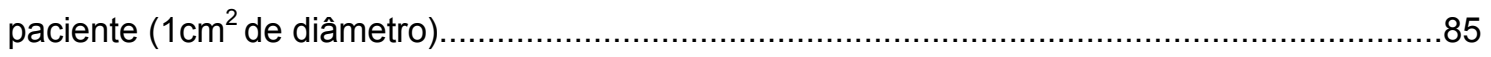

Figura 3 - Controle Manual que permite o registro pelo próprio paciente …............................85

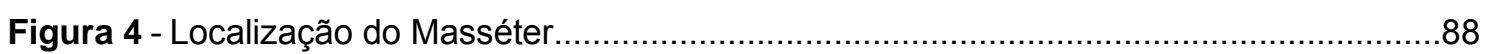

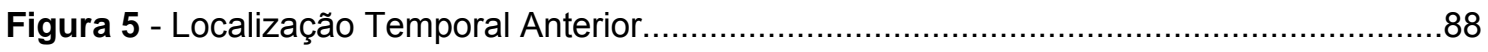

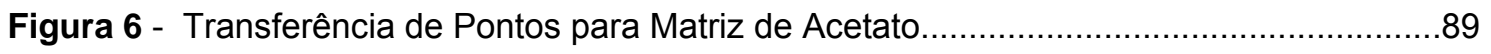

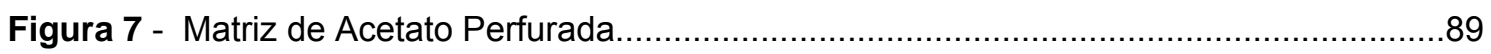

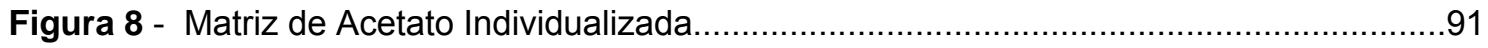

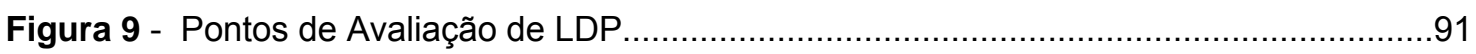

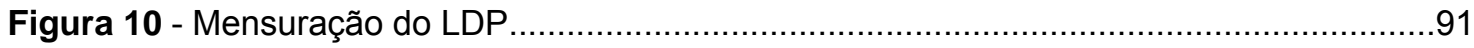

Figura 11 - Valores dos LDPs (valores em $\mathrm{Kg} / \mathrm{cm}^{2}$ ) do músculo masséter em cada tempo do estudo (1, 2, 3 e 4).

Figura 12 - Valores dos LDPs (valores em $\mathrm{Kg} / \mathrm{cm}^{2}$ ) do músculo temporal anterior em cada tempo do estudo (1, 2, 3 e 4).

Figura 13 - Valores dos LDPs (valores em $\mathrm{Kg} / \mathrm{cm}^{2}$ ) do músculo temporal médio em cada tempo do estudo (1, 2, 3 e 4$)$. 106

Figura 14 - Valores dos LDPs (valores em $\mathrm{Kg} / \mathrm{cm}^{2}$ ) do músculo temporal posterior em cada tempo do estudo (1, 2, 3 e 4).....

Figura 15 - Valores dos LDPs (valores em $\mathrm{Kg} / \mathrm{cm}^{2}$ ) do tendão de Aquiles em cada tempo do estudo (1, 2, 3 e 4$)$. 108

Figura 16 - Valores da EAV (valores em centímetros) de ambos os grupos em cada tempo do estudo (1, 2, 3 e 4).

Figura 17 - Gráfico demonstrativo da presença e ausência do estresse (valor percentual), segundo o ISSL, em cada grupo do estudo no período pré-provas 110

Figura 18 - Gráfico demonstrativo da presença e ausência do estresse (valor percentual), segundo o ISSL, em cada grupo do estudo no período de provas

Figura 19 - Gráfico demonstrativo da presença e ausência do estresse (valor percentual), segundo o ISSL, em cada grupo do estudo no período pós-provas.

Figura 20 - Gráfico demonstrativo da presença e ausência do estresse (valor percentual), segundo o ISSL, em cada grupo do estudo no período pós-férias

Figura 21 - Valores percentuais de indivíduos com estresse, segundo o ISSL, em cada grupo nos diferentes períodos do estudo.

Figura 22 - Valores de ansiedade (escala numérica), segundo o BAI, em cada grupo nos diferentes tempos do estudo 


\section{ÍNDICE DE TABELAS}

Tabela 1 - Idade média dos grupos de indivíduos analisados em anos .99

Tabela 2 - Médias e desvio padrão do LDP de cada músculo em cada grupo nos diferentes tempos de avaliação (valores em $\mathrm{Kgf} / \mathrm{cm}^{2}$ ). 100

Tabela 3 - Análise de variância (ANOVA) a 3 critérios para mensurações repetidas dos LDP $(p<0,05)$

Tabela 4 - Médias e desvio padrão do LDP de cada músculo em cada grupo no período préprovas (valores em $\mathrm{Kgf} / \mathrm{cm}^{2}$ ) 102

Tabela 5 - Médias e desvio padrão do LDP de cada músculo em cada grupo no período de provas (valores em $\mathrm{Kgf} / \mathrm{cm}^{2}$ ) 102

Tabela 6 - Médias e desvio padrão do LDP de cada músculo em cada grupo no período de pós- provas (valores em $\mathrm{Kgf} / \mathrm{cm}^{2}$ ).

Tabela 7 - Médias e desvio padrão do LDP de cada músculo em cada grupo no período de pós- férias (valores em $\mathrm{Kgf} / \mathrm{cm}^{2}$ ).

Tabela 8 - Média dos LDPs do músculo masseter em cada grupo em todos os períodos do estudo (valores em Kgf/ $/ \mathrm{cm}^{2}$ )

Tabela 9 - Média dos LDPs do músculo temporal anterior em cada grupo em todos os períodos do estudo (valores em $\mathrm{Kgf} / \mathrm{cm}^{2}$ ) 105

Tabela 10 - Média dos LDPs do músculo temporal médio em cada grupo em todos os períodos do estudo (valores em $\mathrm{Kgf} / \mathrm{cm}^{2}$ ) 106

Tabela 11 - Média dos LDPs do músculo temporal posterior em cada grupo em todos os períodos do estudo (valores em $\mathrm{Kgf} / \mathrm{cm}^{2}$ ).

Tabela 12 - Média dos LDPs do tendão de Aquiles em cada grupo em todos os períodos do estudo (valores em Kgf/ $/ \mathrm{cm}^{2}$ ) 108

Tabela 13 - Média e desvio padrão de dor na Escala de Análise Visual (EAV) de cada grupo em todos os períodos do estudo (valores em $\mathrm{cm}$ ).

Tabela 14 - Número e valores percentuais de indivíduos com presença ou ausência de estresse segundo o ISSL de cada grupo no período Pré-Provas do estudo. 110

Tabela 15 - Número e valores percentuais de indivíduos com presença ou ausência de estresse segundo o ISSL de cada grupo no período de Provas do estudo

Tabela 16 - Número e valores percentuais de indivíduos com presença ou ausência de estresse segundo o ISSL de cada grupo no período Pós-Provas do estudo

Tabela 17 - Número e valores percentuais de indivíduos com presença ou ausência de estresse segundo o Inventário de Sintomas de Stress de Lipp (ISSL) de cada grupo no período

Pós- Férias do estudo

Tabela 18 - Número e valores percentuais de indivíduos com presença de estresse segundo o Inventário de Sintomas de Stress de Lipp (ISSL) de cada grupo em todos os períodos do estudo. 
Tabela 19 - Médias dos valores de ansiedade e desvio padrão segundo o Inventário de Ansiedade de Beck (BAl) de cada grupo em todos os períodos do estudo (escala numérica de 0 a 63)....... 


\section{LISTA DE ABREVIATURAS E SÍMBOLOS}

\%: $\quad$ Porcentagem

ANOVA: Análise de Variância

ATM: Articulação Temporomandibular

BAl: Inventário de Ansiedade de Beck

cm: Centímetro

$\mathrm{cm}^{2}$ : $\quad$ Centímetro quadrado

CVM: $\quad$ Contração Voluntária Máxima

DTM: Disfunção Temporomandibular

DMF: Disfunção Miofascial

EAV: $\quad$ Escala de Análise Visual

EMG: Eletromiografia

ISSL: Inventário de Sintomas de Stress de Lipp

Kg: Quilograma

$\mathrm{Kgf} / \mathrm{cm}^{2}$ : Quilogramaforça por centímetro quadrado

$\mathrm{Kgf} / \mathrm{cm}^{2} / \mathrm{s}$ : Quilogramaforça por centímetro quadrado a cada segundo

KPa/s: Quilograma Pascal por segundo

LDP: $\quad$ Limiar de Dor à Pressão

N/seg: Newton por segundo

RDC/TMD: Research Diagnostic Criteria for Temporomandibular Disorders

SNC: $\quad$ Sistema Nervoso Central

USP: $\quad$ Universidade de São Paulo 
Resumo 


\section{RESUMO}

O objetivo deste trabalho foi analisar a influência da ansiedade e do estresse no limiar de dor à pressão (LDP) de músculos mastigatórios, numa amostra de estudantes universitários em diferentes períodos do ano letivo. Para este propósito, foram selecionados 45 indivíduos, sendo 29 estudantes, que apresentavam DTM de origem miogênica seguindo critérios de inclusão propostos pelo Research Diagnostic Criteria (RDC) e 16 que não apresentavam características de DTM, do gênero feminino, equilibrados em relação à idade. Utilizando um algômetro (KRATOS ${ }^{\circledR}$ ) foram realizadas tomadas bilaterais dos limiares de dor à pressão (LDP) dos indivíduos da amostra nos músculos masseter, temporal anterior, médio e posterior. Além disso, os participantes foram solicitados a responder questionários multidimensionais, através do Inventário de Ansiedade de Beck (BAI) e o Inventário de Sintomas de Stress de Lipp (ISSL), para mensurar reações emocionais ou afetivas em situações que causem estresse e/ou ansiedade. Também, o nível de dor foi registrado pela Escala de Análise Visual (EAV). Todos os exames foram realizados em quatro momentos distintos (T1, T2, T3 e T4) tendo como parâmetro o período de avaliações acadêmicas da Faculdade de Odontologia de Bauru. Os dados obtidos foram submetidos à análise estatística (ANOVA, Teste de Tukey, Teste de Friedman e Mann-Whitney), em um nível de significância de 5\%. A comparação entre os diferentes tempos do estudo nos 2 grupos mostrou diferença estatisticamente significativa $(p<0,05)$, sendo que o período das avaliações mostrou maiores níveis de estresse e ansiedade e menores valores de LDP. Sob o ponto de vista do músculo nos diferentes grupos e nos diferentes tempos, foram encontradas diferenças estatisticamente significativas $(p<0,05)$. Os resultados da Escala de Análise Visual mostraram diferenças estatisticamente significantes entre o grupo sintomático e o grupo assintomático em T1, T2, T3 e T4. Com relação ao estresse e ansiedade, não houve diferenças estatisticamente significante entre os grupos. Houve, no entanto, uma associação entre o aumento do estresse e da ansiedade e diminuição dos valores de LDP em cada tempo. Concluiu-se que existe relação entre estresse e ansiedade e LDP tanto para indivíduos assintomáticos quanto para sintomáticos com DTM de origem miogênica.

Palavras-chave: Disfunção Temporomandibular. Dor Orofacial. Músculos da Mastigação. Dor Experimental. Limiar de Dor à Pressão. Estresse. Ansiedade. 
Introducão 


\section{1 - INTRODUÇÃO}

Dentre as patologias que acometem a região orofacial, há uma grande prevalência daqueevi (DTMs) são as mais comuns Atualmente, o termo Disfunção Temporomandibular (DTM) refere-se aos sinais e sintomas associados à dor e distúrbios funcionais e estruturais do sistema mastigatório, especialmente das Articulações Temporomandibulares (ATM), dos músculos mastigatórios ou ambos ${ }^{118,142}$. Os sinais e sintomas mais freqüentes das DTMs são: dor localizada na musculatura mastigatória, na ATM e/ou área préauricular, limitação e/ou assimetria dos movimentos mandibulares e sons articulares (estalos ou criptações). As DTMs podem ser divididas em três grupos básicos: desordens dos músculos mastigatórios, desordens articulares (incluindo deslocamento de disco, artralgia, artrite e artrose) e desordens dos ossos cranianos e mandibulares, que incluem desordens congênitas e adquiridas $^{142}$.

Apesar de estudadas há muito tempo, muitas controvérsias ainda existem em relação à etiologia, diagnóstico e tratamento desses processos. $O$ modelo etiológico multifatorial aceita a participação de vários fatores etiológicos na determinação da patologia. Entre os fatores iniciantes estão os traumáticos, anatômicos, patofisiológicos e psicológicos ${ }^{40,118,142}$.

Ao considerar os fatores psicológicos, os mais estudados na literatura são a ansiedade e o estresse ${ }^{18,97,157,158}$. Ambos podem influenciar as DTMs e outras condições dolorosas de várias formas. Da mesma forma, várias condições emocionais podem ser resultantes de dores agudas ou crônicas. Os fatores psicológicos são subdivididos em cognitivos, comportamentais e emocionais.

Os fatores emocionais ou afetivos, que são o objetivo de estudo desse trabalho, são aqueles que incluem a subjetividade da experiência, os processos emocionais e as diferenças individuais na percepção da dor. Os fenômenos mais freqüentes relacionados aos quadros dolorosos são o estresse, a ansiedade, o medo e a depressão. 
O conceito de estresse foi introduzido por Hans Selye ${ }^{166} \mathrm{em} 1936$, expressando o processo de adaptação realizado pelo organismo ao enfrentar situações percebidas como ameaçadoras à sua vida e ao seu equilíbrio interior. Atualmente, aceita-se que o estresse é a soma das reações biológicas a qualquer estímulo adverso físico, mental, emocional, interno ou externo que tende a perturbar a homeostase do organismo. Estas reações compensatórias adequadas ou inadequadas podem levar às desordens funcionais ${ }^{14,98}$.

Os agentes estimulantes ou as situações excitadoras do organismo são chamados de estressores, podendo ser de origem psicológica ou fisiológica, intrínseca ou extrínseca. Os estressores externos são representados pelos fatos do cotidiano ocorridos no meio em que o indivíduo vive. As causas internas referem-se aos processos cognitivos, à personalidade e à forma particular de reagir a eventos da vida ${ }^{98}$.

A relação entre estresse e ansiedade é muito grande. A rigor, o estresse nada mais é do que o componente físico da ansiedade. Assim como no estresse, a ansiedade torna-se inadequada quando deixa de desempenhar uma forma de alerta sobre o perigo iminente ou do estímulo para as atividades do indivíduo, passando a prejudicar acentuadamente seu desempenho ${ }^{98}$.

A ansiedade também pode ser definida como uma sensação difusa e desagradável de apreensão e inquietação, acompanhada por sintomas corporais como taquicardia, sudorese, tonturas, náuseas, cólicas, cefaléias, parestesias, tensão muscular e tremores. É um sinal de alerta sobre o perigo, possibilitando que sejam tomadas medidas para lidar com a ameaça, sendo um fator de preservação da vida. Neste sentido, pode ser uma resposta normal ou patológica, dependendo de sua intensidade e duração".

A distinção entre ansiedade e medo é dificultada pela estreita relação entre esses estados emocionais. No campo das alterações biológicas, tanto o medo como a ansiedade são condições estressantes. Em geral, considera-se o medo como provocado por um estímulo ou uma situação bem 
definida. A ansiedade, ao contrário, teria causas intrapsíquicas mais difíceis de especificar $^{66}$.

Com base nas evidências atuais da literatura, não é claro se os fatores emocionais poderiam ser conceitualmente causadores ou conseqüentes dos quadros dolorosos. Vários instrumentos de avaliação têm sido desenvolvidos para investigar aspectos físicos ou psicológicos das DTMs. Muitos conceitos foram propostos para formular teorias embasadas na busca de um sítio do sistema estomatognático responsáveis pelos múltiplos sinais e sintomas relatados na literatura. A comunidade científica busca um melhor entendimento da relação causa e efeito de tal patologia ${ }^{176-178}$.

Entre os sinais clínicos mais característicos da DTM está a sensibilidade muscular. A detecção e a correta interpretação da dor muscular passam a ser, então, uma necessidade para a elaboração de um correto diagnóstico e plano de tratamento. Buscando o sucesso da terapia, a avaliação do Limiar de dor à pressão (LDP) deve ser considerada um meio capaz de avaliar os indivíduos doentes com maior precisão e diferenciá-los, quando necessário, de não doentes. O método de mensuração não manual do LDP através da algometria é válido e confiável para esta detecção e diferenciação de indivíduos ${ }^{76,139,140 .}$.

Muitos pacientes de DTM relatam aumento da dor muscular diante de alterações emocionas ${ }^{176}$. Por outro lado, diversas modalidades de terapia para DTM podem ser modificadas por fatores psicológicos como estresse, ansiedade e depressão ${ }^{56}$. Tem sido discutida com bastante relevância na literatura a relação entre os fatores emocionais e as alterações das respostas musculares em pacientes com DTM miogênica ${ }^{53,125}$. Em muitos estudos, a interpretação do agente estressor foi feita experimentalmente em laboratórios ${ }^{31}$, 53, 87. Entretanto, provavelmente, esta não seria a forma ideal de avaliar o estresse já que os desequilíbrios psicológicos naturais são significativamente diferentes.

Baseado no acima exposto, a proposta deste estudo foi avaliar as alterações do LDP na presença de um agente estressor natural, considerando 
a possível influência do estresse e ansiedade na alteração da sensibilidade muscular. 
Revisão de literatura 


\section{2 - REVISÃO DE LITERATURA}

Disfunção Temporomandibular é um termo genérico empregado a um conjunto de problemas musculoesqueletais do sistema mastigatório ${ }^{142}$. Muito embora a etiologia precisa da DTM ainda não seja conhecida, a literatura sustenta a hipótese multifatorial, sintetizada pela ação conjunta de fatores estruturais (oclusão, anatomia das articulações temporomandibulares e estrutura esquelética); funcionais (neuromuscular) e psicológicos ${ }^{103}$.

LASKIN $^{95}$, em 1969, propôs uma teoria psicofisiológica para a etiologia das DTMs, onde sugere que os espasmos musculares são os principais fatores para ocorrência dos sinais e sintomas de DTM. Esta teoria colocou a dor temporomandibular no contexto de uma disfunção muscular ampla e defendeu a hipótese de que o fator primário era o espasmo muscular desencadeado por distúrbios emocionais. Atualmente, a dor e a disfunção são sintomas consideravelmente relacionados com condições somáticas baseadas em aspectos comportamentais e psicológicos, que desenvolvem dor miofascial ou DTM miogênica ${ }^{172}$. O termo Dor Miofascial é abordado como um subtipo ou subgrupo das DTMs 40,103, 149 e refere-se à dor muscular regional de qualquer origem de tecido mole, associada à sensibilidade muscular, podendo ou não estar relacionado com pontos gatilhos (trigger points), segundo os critérios para Diagnóstico em Pesquisa sobre Disfunções Temporomandibulares $(\mathrm{RDC} / \mathrm{TMD})^{40}$.

Para fins didáticos, dividiu-se a revisão de literatura em dois tópicos: Sensibilidade Muscular e Manifestações Psicológicas. 


\subsection{Sensibilidade Muscular}

Os estudos que discutem sensibilidade dolorosa e métodos objetivos de mensuração de sintomatologia são bastante antigos. Já em 1952, HARDY, WOLFF E GOODELLI ${ }^{72}$ discutiram resumidamente os requisitos de um método adequado de mensuração do limiar de dor, entre os quais: mensurabilidade do estímulo com reprodutibilidade, controle adequado do limiar e do limite máximo, não causar danos ao tecido, produção de uma percepção nítida de dor, simplicidade do aparelho e do método de aplicação. Segundo os autores, foi possível concluir que o uso do dedo oferece amplamente essas condições, com exceção da mensuração da dor, que pode ser realizada com auxílio do algômetro.

De acordo com KEELE ${ }^{88}$, em 1954, é necessário dar condições de tranqüilidade e relaxamento para a medição do limiar de dor à pressão (LDP), evitando, dessa forma, que o procedimento ou instrumento transmita qualquer impressão de ameaça ao paciente. Além disso, na aplicação de um estímulo de pressão, o fator tempo deve ser padronizado a fim de que a taxa de aumento seja constante, evitando fadiga, tanto do examinador quanto do local palpado. Segundo o autor, a pressão ideal é aplicada a uma taxa de $1 \mathrm{~kg}$ por segundo, aumentando esse valor gradativamente. $O$ autor utilizou o teste de Libman, o qual faz uso dos dedos, e o teste que avalia quantitativamente o LDP através do algômetro, em 260 indivíduos. Após aplicação dos testes foi possível classificar a amostra como: hipersensíveis (sensibilidade com força até 1,5kg); normo-sensíveis (pressão de 2,0 - 4,0kg); hipo-sensíveis (pressão com valores acima de $4,0 \mathrm{~kg}$ ). O autor concluiu que a principal deficiência do teste de Libman para a sensibilidade de dor foi a falta de mensuração do estímulo, o que foi superado pelo uso do algômetro.

DAVENPORT ${ }^{33}$, em 1969, estudou os limiares de dor à pressão na cavidade oral do homem. Para tal estudo, foram utilizados 10 indivíduos (estudantes de odontologia) com idade média de 20,7 anos. Os testes foram sempre executados pelo mesmo operador, utilizando um algômetro. A medição de tecido mucoperiósteo foi feita com uma sonda. As mensurações 
foram repetidas em intervalos semanais de 4 semanas. Os limiares de dor à pressão variaram significativamente entre os indivíduos, mas não no mesmo indivíduo em diferentes ocasiões. Foi descoberto que a taxa de aplicação e a espessura do tecido influenciam consideravelmente os limiares de dor à pressão. Uma taxa uniforme de aplicação do estímulo não necessariamente garante, portanto, o controle desse fator quando os limiares de dor à pressão dos indivíduos estão sendo comparados.

De acordo com JIMENEZ; LANE ${ }^{83}$, em 1985, uma das dificuldades no tratamento dos pacientes com dor crônica é a avaliação da severidade da dor. Para tal objetivo, os autores avaliaram a tolerância de pressão e o limiar de pressão em pacientes com dor crônica. Foram admitidos 21 pacientes consecutivamente em um programa de dor multidisciplinar de janeiro a março de 1985, foram incluídos nesse estudo e avaliados em 21 dias. Usando um algômetro, as mensurações do limiar e tolerância de pressão foram reavaliadas pelo examinador no primeiro dia do estudo e em intervalos semanais. Duas leituras foram registradas e expressadas em $\mathrm{kgf} / \mathrm{cm}^{2}$, representando o limiar e a tolerância de pressão. Em 19 dos 21 pacientes, um aumento em ambos os valores foi descoberto sob alta pressão. Leituras em seqüências de acompanhamento foram obtidas um mês após a alta de 12 pacientes, em 9 dos quais não foram observadas mudanças. Uma diminuição leve em ambos os valores foi descoberta nos 3 pacientes remanescentes; porém, as leituras foram ainda maiores que na primeira mensuração. Portanto, um aumento do limiar de dor à pressão foi proporcional à diminuição dos relatos de dor, confirmando que as determinações do limiar de dor à pressão e da tolerância de pressão são úteis como indicadores da severidade de dor durante tratamento de pacientes com dor crônica.

Em 1986, SOLBERG ${ }^{169}$, questionou a aceitação da palpação como um método diagnóstico da dor muscular. Segundo o autor, a palpação permanece como um exame físico essencial apesar da dificuldade de reproduzir os resultados. O autor relata que o diagnóstico controverso é comum devido à hipersensibilidade de algumas estruturas anatômicas, à presença de nódulos inflamados e, hiperalgia prolongada à dor referida. 
Portanto, o risco de interpretação de sensibilidade exagerada sugere que a palpação deva ser usada mais apropriadamente para reiterar observações oriundas de testes funcionais do que como um critério isolado para se detectar a Disfunção Temporomandibular. Afirmou-se ainda que a palpação da articulação temporomandibular seja mais confiável como um indicador de sensibilidade e inflamação da articulação.

Em 1986, JAEGER; REEVES ${ }^{80}$, buscando determinar a relação entre sensibilidade dos pontos de gatilho e os sintomas referidos da dor miofascial, as graduações de intensidade de dor referidas e medidas pela escala de analise visual e miofasciais, examinaram pacientes antes e depois de tratamento muscular. Foram selecionados 20 indivíduos apresentando sinais e sintomas de dor miofascial, dos quais 15 possuíam dor referida primária unilateral localizada na região cervical, occipital, temporal e frontal, e 5 descreviam queixas bilaterais. Os autores demonstraram que a sensibilidade dos pontos de gatilho diminuía em resposta ao estiramento passivo quando avaliada pelo algômetro e que diminuições na sensibilidade dos pontos de gatilho local eram acompanhadas por diminuição nos relatos subjetivos de intensidade de dor referida. Além disso, uma análise no grupo de dor unilateral demonstrou que os pontos gatilho ativos foram mais sensíveis do que seus pontos gatilho latente. Subseqüências ao alongamento e ao spray, os pontos de gatilho tornaram-se menos sensíveis do que o controle não estirado (latente). Resultados similares foram encontrados com o grupo que continham pontos de gatilhos bilaterais. Portanto, os autores concluíram que o uso do algômetro de pressão não está restrito à região da cabeça e pescoço, podendo também ser útil na avaliação da sensibilidade de pontos de gatilho em outras partes do corpo.

Ainda em 1986, REEVES; JAEGER; GRAFF-RADFORD ${ }^{151}$ investigaram a confiabilidade do algômetro na avaliação da sensibilidade dos pontos gatilho (trigger points) em pacientes com dor miofascial da cabeça e pescoço. Para tal pesquisa, foram desenvolvidos 3 estudos com o propósito de testar a confiabilidade intra e interexaminador com o uso do algômetro, usando pontos gatilho previamente marcados; testar, com a mesma finalidade, 
a confiabilidade interexaminadores em pontos de gatilho não marcados e verificar se os pontos gatilho representam um área discreta dentro do músculo. Foram avaliados 15 pacientes (11 mulheres e 4 homens, com idade de 24 a 60 anos). O primeiro estudo demonstrou alta confiabilidade nos examinadores, tanto na obtenção do limiar quanto na localização dos pontos de gatilho. No segundo, demonstrou-se confiabilidade significante entre os examinadores na localização e medida do limiar, enquanto que o terceiro levou à conclusão de que os pontos gatilho são pontos discretos de sensibilidade no músculo. Os autores concluíram que a habilidade de quantificar e medir confiavelmente a sensibilidade dos pontos gatilho amplia a discussão das possibilidades clínicas e cirúrgicas dos problemas miofasciais e dolorosos músculoesqueletais relacionados.

Para avaliarem a reprodutibilidade do teste de palpação para o sistema estomatognático, DUINKERKE et al. ${ }^{37}$, em 1986, utilizaram dois dentistas experientes e dois estudantes de odontologia, após um programa de treinamento. Foram examinados 58 indivíduos (25 mulheres e 33 homens idade 18 a 65 anos) assintomáticos. Concluíram que a reprodutibilidade intra e interexaminadores para ambos dentistas e estudantes, em relação à palpação dos músculos, foi satisfatória, variando entre 0.73 e 0.95 , como também em relação à abertura bucal.

Em 1986, JENSEN et al. ${ }^{81}$ avaliaram o limiar de dor à pressão (LDP) na região temporal com uso de um algômetro. Foram realizadas 4 etapas que resultou em 4 diferentes estudos. A primeira etapa utilizou 12 homens e 12 mulheres (24 a 69 anos) e nele o LDP foi determinado na região temporal direita usando 3 diferentes taxas de aplicação de pressão, com a mesma extremidade do algômetro, tendo este uma área de 0,503 $\mathrm{cm}^{2}$. Em seguida, 0 LDP foi determinado no lado esquerdo usando 3 diferentes áreas da extremidade do algômetro, mantendo uma pressão constante (0,34N/seg). Dos 24 indivíduos, 11 retornaram para uma segunda aplicação de pressão no lado direito após 3 semanas, usando a mesma taxa de pressão, com a área de $0,503 \mathrm{~cm}^{2}$. Na segunda etapa uma taxa maior de pressão foi aplicada em ambos os lados. Foram avaliados 4 mulheres e 4 homens (20 a 29 anos) e 4 
diferentes áreas foram usadas. Todos retornaram para 5 repetidos testes com intervalos de 1 semana, sendo que na última semana os pacientes receberam uma aplicação de anestésico em um lado e, no outro, uma aplicação de $9 \mathrm{mg} / \mathrm{ml}$ de solução salina. Na terceira etapa, o LDP de 2 mulheres e 4 homens (21-36 anos ) foram medidos através de 50 tentativas consecutivas, numa força de 0,68N/seg, com uma área de 0,503 $\mathrm{cm}^{2}$. Na quarta etapa, o LDP de 17 mulheres e 13 homens (19 a 46 anos) foi determinado nos dois lados com a mesma taxa e área anterior. Todos retornaram em 45 minutos para uma segunda determinação. Os autores verificaram que no estudo 1 houve uma diminuição do LDP quando a área foi aumentada e que, usando uma mesma área na extremidade do algômetro, com aplicação de três cargas diferentes, houve um aumento do LDP com a taxa aumentada. Houve, também, uma correlação positiva entre o LDP em ambos os lados. No estudo 2 não houve diferença no LDP nas 4 áreas analisadas. Houve um gradual aumento do LDP nas diversas investigações realizadas. Não houve diferença do LDP após a injeção do anestésico e da solução salina nos dois lados, mas ambos LDP aumentaram significativamente. No estudo 3 não houve alteração do LDP após 50 medições consecutivas. No estudo 4 não houve diferença significante entre os dois lados, entre o primeiro e o segundo exame. Também não houve uma correlação significante em relação ao gênero e idade na obtenção do LDP.

LIST; HELKIMO ${ }^{100}$, em 1987, avaliaram a confiabilidade da medida do limiar da pressão no registro da sensibilidade no músculo masseter. Para tal propósito, 15 indivíduos (14 mulheres e 1 homem), com uma média de idade de 35 anos, foram incluídos neste estudo. Um algômetro foi usado para registrar o grau de sensibilidade muscular e 2 examinadores registraram independentemente 5 pontos bem definidos, previamente marcados na pele sobre o músculo masseter. De acordo com os autores, o desvio máximo para uma mensuração repetida foi menor que $4 \mathrm{~mm}$, indicando que foi possível localizar os pontos de mensuração com boa precisão em registros repetidos. Os registros repetidos do grau de sensibilidade muscular com a ajuda do algômetro mostraram altas correlações em comparações intra e interindivíduos. Os valores médios das mensurações do limiar da dor em 
diferentes pontos de mensuração variaram entre $1.95 \mathrm{kgf} / \mathrm{cm}^{2}$ (a origem do músculo masseter superficial) e $2.95 \mathrm{kgf} / \mathrm{cm}^{2}$ (a porção profunda do músculo masseter). O estudo mostrou que a sensibilidade no músculo masseter pode ser registrada com boa precisão com o auxílio de um algômetro.

Em 1987, FISHER ${ }^{52}$ procurou estabelecer, em seu estudo, valores normais para os Limiares de Dor à Pressão em músculos freqüentemente acometidos por trigger points. Para a realização das tomadas dos LDPs, 0 autor utilizou um algômetro. Foram selecionados para esse estudo 24 homens (idade média de 35,9 anos) e 26 mulheres (idade média de 28,6 anos) para serem examinados, sendo todos sem sinais e sintomas de DTM. Primeiramente os trigger points foram detectados (8 áreas acometidas com freqüência) pela palpação usando os dedos. Após a detecção da área afetada, o algômetro era utilizado. Após a infiltração de anestésico nos trigger points, nova medição foi feita com o uso do algômetro. Comparando um lado com o outro, o autor não encontrou diferenças estatisticamente significativas. Portanto, atribuiu a semelhança dos resultados entre os lados à excelente reprodutibilidade e validade da medição do LDP. Além disso, recomendou como referência para o diagnóstico clínico de dor muscular e para documentação de eficácia de tratamento, concluindo que o algômetro pode ser usado para monitorar sensibilidade e inflamação.

SCHIFFMAN et al. ${ }^{160}$, em 1988, compararam o LDP de 15 locais da cabeça e pescoço em 45 pacientes que tinham "síndrome de dor miofascial" com 45 controles combinados por idade e sexo. Esse estudo foi planejado para comparar a confiabilidade do uso do algômetro e da palpação muscular manual e para examinar a confiabilidade interexaminadores em ambas as técnicas. Os resultados obtidos pela palpação manual foram realizados através de respostas verbais do paciente para a seguinte questão: "isto dói ou apenas pressiona?". Uma resposta positiva indicava que a palpação feita era dolorida e uma resposta negativa indicava que era apenas pressão. O LDP foi registrado e repetido em 5 segundos para obter a média para cada um dos 15 locais palpados. O teste de KAPPA, usado para avaliar a confiabilidade entre dois examinadores, com o algômetro demonstrou valores maiores que 0,40 
em 13 dos 15 locais, com exceção do músculo masseter profundo e temporal posterior. Para a palpação manual, somente 2 dos 15 locais (o temporal anterior e esternocleidomastóideo) alcançaram este nível de confiabilidade. Os autores concluíram que a confiabilidade do algômetro é adequada e superior ao uso da palpação manual. Eles também observaram que a confiabilidade adequada da palpação manual pode ser possível para locais específicos com examinadores experientes e técnicas padronizadas.

No mesmo ano, DWORKIN; LE RESCHE; DE ROUBEN ${ }^{39}$ avaliaram a confiabilidade interexaminadores na mensuração clínica das Disfunções Temporomandibulares. Para tal objetivo, analisaram, primeiramente, 48 pacientes, 18 com sintomas de DTM e 30 assintomáticos, distribuídos em idade e gênero. Quatro examinadores treinados e três sem treinamento examinaram cada paciente. Foi avaliado medições de abertura bucal, interarcos, padrões oclusais, palpação muscular e sons da ATM. Com relação à palpação dos músculos extra-orais, intra-orais e ATM, os valores iniciais de KAPPA foram $0.47,0.27$ e 0.47 para os examinadores treinados e $0.39,0.13$ e 0.25 para os não treinados, respectivamente. Após um treinamento adicional, os examinadores treinados passaram de 0.47 para 0.65 , de 0.27 para $0.61 \mathrm{e}$ de 0.47 para 0.52 respectivamente. Os autores verificaram que as respostas de dor à palpação mudaram após o curso do exame de confiabilidade e que poderiam, pelo menos, explicar parcialmente a baixa concordância dos interexaminadores. Portanto, os autores concluíram que o treino dos examinadores é extremamente importante para uma avaliação confiável dos sinais das DTMs.

A confiabilidade e a validade do uso do algômetro no registro de sensibilidade no músculo masseter e temporal anterior foram avaliadas por LIST; HELKIMO; FALK ${ }^{101}$, em 1989, Para tal estudo, usaram 45 indivíduos (40 mulheres e 5 homens), sendo 25 voluntários saudáveis e 20 pacientes sintomáticos. Nesse estudo, 2 tipos de algômetro foram utilizados. A sensibilidade à palpação foi medida em 6 pontos localizados no músculo masseter, temporal anterior e sobre o arco zigomático para avaliar: (parte 1) a validade do LDP por comparação com a técnica da palpação convencional, 
limite de dor de pressão nos indivíduos sintomáticos e assintomáticos; (parte 2) - a reprodutibilidade do algômetro por medições repetidas no limite de dor de pressão em 6 pontos definidos, observando se os valores do algômetro alteram significativamente com o erro de localização; (parte 3) - se a razão da aplicação de pressão pelo algômetro afetou o limite de dor e pressão. $\mathrm{Na} 1^{a}$ parte, os registros foram feitos por 3 examinadores independentes com algômetro, com uma força de $1 \mathrm{kgf} / \mathrm{cm}^{2}$, e por outro, que palpou manualmente os 6 pontos marcados, sendo o registro feito por relato do paciente: 0 (sem sensibilidade); 1 (sentimentos de dor forte); e 2 (reflexo palpebral ou um sinal de pulo). Na $2^{\mathrm{a}}$ parte, os 6 pontos eram marcados pelo examinador 1 sobre a pele e transferidos para análise, depois apagados e repetidos pelo examinador 2. $\mathrm{Na} 3^{\mathrm{a}}$ parte foram utilizados 2 algômetros: um aplicando uma pressão de $1 \mathrm{kgf} / \mathrm{cm}^{2}$ e o outro $2 \mathrm{kgf} / \mathrm{cm}^{2}$. Pelos resultados, os autores verificaram que houve uma correlação estatisticamente significante entre a técnica com 0 algômetro e a palpação com os dedos e que uma diferença estatisticamente significante do limiar de dor á pressão foi obtida para o grupo sintomático e para o grupo assintomático. Houve ótima confiabilidade na localização dos locais marcados, sendo que os autores afirmaram ainda que se os pontos forem localizados com certa imprecisão, os coeficientes de confiabilidade seriam ainda de mesma grandeza. Portanto, o uso do algômetro pode ser recomendado para a avaliação dos limites de dor e pressão no sistema mastigatório em estudos clínicos e experimentais.

De acordo com GALLAGHER; DAL SANTO; RUGH ${ }^{58}$, em 1989, o algômetro de pressão tem sido usado para determinar a limiar de dor à pressão em situações clinicas, método esse considerado subjetivo na determinação de dor. De acordo com os autores, se a dor é detectada pela palpação, o algômetro pode ser aplicado na área para medir a quantidade da força capaz de causar dor, ou seja, o algômetro é colocado no ponto mais sensível e a pressão é lentamente aumentada até os sinais do paciente anunciarem qualquer alteração de dor. Nesse momento, o examinador olhará para o mostrador indicando, assim, a pressão que leva o paciente a sentir dor. Essa alteração no limiar ou tolerância poderá ser registrada e comparada em futuras visitas. 
OHRBACH; GALE ${ }^{140}$, em 1989, testaram 4 hipóteses num trabalho de confiabilidade e validade em pacientes com dor miogênica: $1^{a}$ ) existe confiabilidade e validade do limiar de dor a pressão (LDP) em pacientes sintomáticos e assintomáticos; $2^{\mathrm{a}}$ ) as medidas do LDP entre testes e entre sessões são confiáveis; $3^{a}$ ) o LDP nos locais que produzem dor local são menores do que aqueles que produzem dor referida; $4^{a}$ ) a qualidade do local seria relacionado ao relatório da palpação e ao examinador seria confiável em sua avaliação. Para responder a essas questões foram selecionados 45 indivíduos com idade entre 17 e 77 anos, média de 38,6 (89\% eram mulheres) com queixas de DTM. Os exames foram feitos em 2 etapas. $\mathrm{Na} 1^{\text {a }}$ etapa, utilizando-se o grupo sintomático foi feito um relato dos sintomas e a aplicação da escala de análise visual (EAV). A palpação dos músculos foi realizada para selecionar os locais de medição do LDP (doloridos) utilizando uma pressão consistente de 1,47 a $1,68 \mathrm{~kg}$ por $4-5$ segundos, com o dedo indicador. Os autores, portanto, concluíram que o $1^{\circ}$ estudo demonstrou forte validade na medida do LDP entre sintomáticos e assintomáticos; o LDP não foi significativamente diferente entre o local de dor primária e o local de controle de dor no mesmo músculo; o LDP foi bem menor no local de dor comparado ao local de controle sem dor; o $2^{\circ}$ estudo indicou uma confiabilidade adequada na obtenção do LDP; no $3^{\circ}$ estudo o LDP foi bem menor em locais que produziam dor referida do que nos locai que produziam dores localizadas pela palpação; o $4^{\circ}$ estudo apresentou evidências de áreas de nódulos e feixes palpáveis comumente associados a regiões musculares que produziam dor. Além disso, a confiabilidade intra-examinador na reavaliação desses locais foi apenas razoável. A dor referida teve uma pobre associação com uma dor padrão e achados físicos.

Ainda em 1989, OHRBACH; GALE ${ }^{139}$ utilizaram o algômetro para verificar o limiar de dor à pressão (LDP) em músculos normais verificando sua confiabilidade, efeitos de medição e diferenças topográficas. Para tal objetivo, foram utilizados 5 homens e 5 mulheres assintomáticos. Os músculos masseter e atemporal anterior foram selecionados quanto à medição por causa do freqüente envolvimento dos mesmos, em disfunções temporomandibulares, acessibilidade, planificação e apoio uniforme pelo 
tecido subjacente. Para localizar com precisão o local dos músculos a serem palpados foi utilizado um molde de plástico. Isso era realizado 10 minutos antes do procedimento de palpação, período em que os indivíduos recebiam todas as instruções para pesquisa, O limiar de dor para pressão (LDP) foi definido como aquele ponto em que a força lentamente crescente aplicada sobre a pele do indivíduo (pelo algômetro) mudava de sensação de pressão para dor. Foram realizados dois estudos: o primeiro, com intervalo de 3 segundos entre os locais e de $4-5$ minutos entre os 5 testes realizados; e, no segundo, as medidas foram feitas em intervalos semanais de 4 semanas e 5 sessões em 8 semanas. Considerando os testes estatísticos, houve um aumento do LDP em alguns locais, diminuição ou manutenção de níveis iniciais em outros. A interpretação de informações pelos testes estatísticos indicou que o LDP foi significativamente maior no músculo temporal que no masseter, obtendo-se um índice de confiabilidade que variou de 0,55 a 0,93. Os LDPs obtidos através de múltiplas seções foram confiáveis e sem diferenças. Ainda, de acordo com os autores, mais que 3 testes para a obtenção do LDP não são justificados, considerando uma redução crescente em erro contra o aumento de tempo. Concluiu-se, então, que uma média de 2 testes seria ideal para a tomada do LDP.

Em 1991, LIST; HELKIMO; KARLSSON ${ }^{102}$ discutiram a relação entre a taxa de aplicação de pressão no músculo masseter e o LDP obtido com o auxílio de um algômetro. Para o estudo foram analisados 20 pacientes (16 mulheres e 14 homens) com idade média de 44 anos e com diferentes graus de DTM. Em 10 pacientes, foram obtidas 10 tomadas dos LDPs no masseter superficial direito com taxas de pressão variadas, sem uma seqüência lógica, variando de baixa a alta $\left(0,5\right.$ a $\left.2,8 \mathrm{Kgf} / \mathrm{cm}^{2} / \mathrm{s}\right)$. A correlação entre a taxa de aplicação de pressão e o LDP obtido foi alta. Nos outros 10 pacientes, as tomadas repetidas sob uma mesma taxa de pressão não influenciaram os valores dos LDPs significativamente.

JENSEN et. al. ${ }^{82}$, em 1992, estudaram a sensibilidade e o limiar de dor nos músculos cefálicos em uma população geral. Para tal estudo, foram utilizados 740 indivíduos (383 homens e 352 mulheres, com idade entre 25-64 
anos). Primeiramente, foram feitos exames dentários, da saúde geral e a sensibilidade registrada através de uma escala de 0 a 3 pela palpação executada pelos $2^{\circ}$ e $3^{\circ}$ dedos, fazendo uma pressão firme e com pequenos movimentos rotativos, realizados por um dentista experiente e treinado. Depois, o exame de limiar de dor à pressão (LDP) foi realizado em outra sala por uma enfermeira treinada com uso de algômetro eletrônico. Ambos os examinadores desconheciam as reclamações de dor de cabeça dos envolvidos na pesquisa. Como resultado, os autores verificaram que os músculos mais sensíveis à palpação foram o pterigóideo lateral (55\%), o trapézio (52\%) e o esternocleidomastóideo (51\%), sendo os músculos frontal e temporal posterior os menos sensíveis nos indivíduos normais. As mulheres foram mais sensíveis que os homens em todos os músculos examinados pela palpação manual. No total, o grupo de jovens foi mais sensível do que o grupo mais velho. Os LDPs nos músculos temporais mostraram-se mais baixos nas mulheres do que nos homens e, de uma maneira geral, os limiares aumentaram com a idade. Portanto, os autores verificaram que num exame clínico de rotina de pacientes com dor de cabeça, talvez os músculos masseter superficial, frontal e posterior possam ser excluídos porque exibiram pouca sensibilidade e que os músculos trapézio, esternocleidomastóideo e temporal anterior poderão ser incluídos, devido a sua alta sensibilidade.

DWORKIN; LERESCHE ${ }^{40}$, em 1992, propuseram um conjunto de critérios de diagnóstico para pesquisa das DTMs, rotulada de RDC/TMD, com o propósito de permitir uma padronização e reprodução de resultados entre os pesquisadores. Para isso, incluíram nesse estudo alguns critérios em relação à palpação muscular e da articulação como: a) pressionar sobre o local selecionado usando as extremidades dos dedos indicador e o médio, usando uma pressão de 2 libras para os músculos extra-orais e 1 libra para a articulação e os músculos intra-orais; b) durante a palpação, deve-se usar a mão oposta para apoiar cabeça fornecendo assim uma maior estabilidade; c) o paciente deverá estar em posição de repouso; d) para assegurar a palpação no lugar correto, deve-se orientar o paciente a apertar os dentes e, então, relaxar; e) deve-se palpar numa extensa área para detectar o local exato da sensibilidade; f) antes de começar a palpação, o examinador deverá falar ao 
paciente para registrar a dor sentida durante a palpação, ou seja, caso o paciente sinta dor, o mesmo deverá marcar se essa dor é suave, moderada ou severa. Além disso, os autores descreveram algumas especificações sobre os locais que deverão ser palpados: a) Temporal Posterior: deverão ser palpadas as fibras posteriores, atrás das orelhas, diretamente acima das mesmas; b) Temporal Médio: deverão ser palpadas as fibras localizadas $2 \mathrm{~cm}$ lateralmente ao bordo lateral da sobrancelha; c) Temporal Anterior: deverão ser palpadas as fibras acima da fossa infratemporal, imediatamente acima do processo zigomático; d) Origem do Masseter: deverão ser palpadas as fibras localizadas em uma área $1 \mathrm{~cm}$ imediatamente à frente da ATM e abaixo do arco zigomático; e) Corpo do Masseter: deverão ser palpadas as fibras logo abaixo do arco zigomático, na borda anterior do músculo; f) Inserção do Masseter: deverão ser palpadas as fibras em uma área localizada $1 \mathrm{~cm}$ superior $\mathrm{e}$ anterior ao ângulo da mandíbula. Foram feitas também especificações para outros músculos como digástrico, pterigóideo medial, lateral, etc.

Em 1992, CHUNG; UM; KIM ${ }^{21}$ avaliaram a confiabilidade intra e interexaminadores na obtenção do limiar de dor à pressão nos músculos da cabeça e pescoço. Para tal estudo, foram utilizados 40 estudantes de odontologia (20 a 27 anos). Foram feitos duas medições com intervalos de 5 minutos por examinadores, a uma força de $40 \mathrm{KPa} / \mathrm{s}$. Os seguintes músculos foram medidos: temporal anterior, médio e posterior, masseter profundo, anterior e inferior, pterigóideo medial, digástrico posterior, esternocleidomastóideo (superior e médio) e trapézio. Uma comparação com informações obtidas dos músculos contralaterais não demonstram diferenças estatisticamente significantes. Houve obtenção de uma excelente confiabilidade entre os examinadores em todos os músculos, com exceção do pterigóideo medial e do esternocleidomastóideo médio, medidos nos homens. Os autores demonstraram que o algômetro eletrônico poderia ser indicado para avaliação dos LDPs dos músculos da cabeça e pescoço em estudos clínicos e experimentais.

No mesmo ano, MURPHY; MICKINNEY; GROSS ${ }^{131}$ realizaram um estudo a fim de verificar a existência ou não de uma constância nos valores do 
LDP nos músculos de indivíduos saudáveis. A confiabilidade intra e inter examinadores também foi analisada com o intuito de facilitar a metodologia de pesquisas futuras. Para o propósito do estudo, foram selecionados 20 indivíduos do gênero feminino, com idade média de 24,8 anos e livres de sinais e sintomas de DTMs. Foi usado um algômetro para a coleta dos valores de palpação nos músculos temporal (anterior), masseter (corpo) e aspecto lateral da cápsula da ATM. O exame foi realizado inicialmente por um clínico experiente e depois por uma auxiliar treinada. Os autores concluíram que uma pressão padrão pode ser estabelecida para indivíduos normais $\left(1,5 \mathrm{Kgf} / \mathrm{cm}^{2}\right)$ e que uma boa concordância intra e interexaminadores foi alcançada.

GOULET; CLARK; FLACK ${ }^{63}$, em 1993, com o propósito de desenvolverem um treinamento e um protocolo de calibração entre os examinadores a fim de permitir uma consistência de achados clínicos durante exame repetido, avaliaram a habilidade de 4 examinadores treinados e calibrados para aplicar consistentemente pressão com os dedos dentro de 2 limites de pressão: alta $(1,5-2,1 \mathrm{~kg})$ em 4 músculos: frontal, masseter superficial, profundo e temporal anterior e baixa $(0,5-1,1 \mathrm{~kg})$ para a ATM e testaram a habilidade de examinadores para localizar precisamente os mesmos locais de palpação. Anterior ao estudo, cada examinador recebeu um protocolo escrito com todas as instruções, além de participarem de um programa de calibração realizado com ajuda de um algômetro, com o propósito de obter o mesmo padrão de aplicação de força, além de como localizar precisamente os locais previamente determinados para palpação. Esse processo de calibração durou cerca de 3 meses. Os autores verificaram que somente 1 examinador falhou na realização do limite de pressão alta solicitada (79\%), comparado a um índice de sucesso global de 89,5\%; em relação à aplicação de pressão no limite baixo, os resultados foram mais satisfatórios ainda, variando numa taxa de 0,12 a $0,22 \mathrm{kgf} / \mathrm{cm}^{2}$. A reprodutibilidade das posições marcadas foi avaliada medindo com a escala a distância entre os locais selecionados. Exceto para o masseter superficial e temporal anterior, examinadores selecionaram os locais de palpação dentro de uma distância de $7 \mathrm{~mm}$ em mais de $85 \%$ das vezes. Portanto, os autores mostraram, nesse estudo, a capacidade de examinadores 
treinados em desempenhar consistentemente tarefas técnicas para a reprodutibilidade dos procedimentos de palpação manual.

No mesmo ano, CHUNG; KIM; KIM ${ }^{20}$ avaliaram o LDP de 39 indivíduos (20 homens e 19 mulheres) com idade média de 23,8 anos e sem sinais e sintomas de DTM, e 30 mulheres com idade média de 23,5 anos e com diagnóstico de capsulite na ATM. Para realizar as medições, fizeram uso de um algômetro. Além disso, avaliaram também a confiabilidade intra e interexaminadores, as diferenças entre os gêneros e entre os lados (direito e esquerdo) e a validade do algômetro utilizado. Foi obtida uma alta confiabilidade intra e interexaminadores. No grupo assintomático, o LDP dos homens se mostrou significativamente superiores, assim como no grupo com DTM. Os autores concluíram também que o algômetro é um bom instrumento para medir os LDPs na região da ATM.

Ainda em 1993, de acordo com CLARK; DELCANHO; GOULET ${ }^{24}$ dados colhidos pelo exame clínico tradicional indicaram que a sensibilidade dos músculos mastigatórios e da ATM são os aspectos mais consistentes numa avaliação de DTM, embora esses dados sejam bastante questionados em se tratando de pesquisas clínicas. Segundo os autores, o método de pressão digital (isto é, ponta do dedo) permanece como um gold standard e quaisquer novos métodos que surjam devem ser comparados a ele, para que todas suas vantagens e possíveis dificuldades sejam identificadas.

Em 1994, BENDSTSEN et al. ${ }^{8}$ ressaltaram a importância da palpação digital no diagnóstico das DTMs e a dificuldade de se quantificar a pressão ideal. Muitos são os estudos que determinam tais valores, entretanto precisar a pressão digital exata é impossível. Para suprir tais deficiências, o algômetro é o aparelho que torna possíveis valores padronizados, apesar de suas limitações. Os autores propuseram, com este estudo, apresentar o instrumento denominado palpômetro com o intuito de quantificar a pressão exercida durante o exame de palpação. O palpômetro consiste numa resistência sensível à força, em forma de um filme de polímero fino de 0,33 $\mathrm{mm}$ de espessura e $10 \mathrm{~mm}$ de diâmetro, que é posicionado na parte mole da 
extremidade do dedo indicador e é conectado a um medidor de pressão/força. Foi possível obter resultados importantes nos diversos testes realizados com o palpômetro; porém, ressaltaram suas limitações, entre elas a falta de percepção do aparelho no que diz respeito à textura do músculo e o fato da palpação ser realizada apenas com um dedo unilateralmente. Concluíram, portanto, que o palpômetro pode melhorar a qualidade do exame de palpação, tornando-o indispensável para a realização de pesquisas e para o treinamento de profissionais.

Ainda em 1994, McMILLAN; LAWSON ${ }^{117}$ mediram o LDP em várias regiões dos músculos masseter e temporal, em várias intensidades de apertamento dental e abertura bucal com o auxílio de um algômetro. Para essa finalidade, foram selecionados 10 indivíduos homens, alunos de graduação de Odontologia, com idade variando de 22 a 30 anos, com dentição completa e sem sinais e sintomas compatíveis com DTM. O masseter foi palpado em três pontos (origem, corpo e inserção) e o temporal em três pontos de seu feixe anterior. Eletrodos foram posicionados nas fibras superficiais do masseter (corpo) para posterior dos pontos anteriormente determinados. Os pacientes foram solicitados a apertar os dentes com a força máxima, em $\mathrm{MIH}$, força correspondente à Contração Voluntária Máxima (CVM). A escala eletromiográfica foi então ajustada, considerando a CVM como força 10 e cada paciente; a partir dessa determinação, foi treinado a apertar os dentes com força de 10\%, 20\%,40\%, 60\% e $80 \%$ da CVM. Os diferentes graus de abertura solicitados aos pacientes foram de 10, 20 e $40 \mathrm{~mm}$, medidos pela distância interincisivos. Quanto maior foi a força de apertamento, maior foi o LDP encontrado em todos os pontos examinados. $O$ LDP não se alterou nos diferentes graus de abertura. Não foram encontradas diferenças intra e intermúsculo dos LDPs nas diferentes forças de apertamento e em todas as aberturas testadas. Os LDPs do temporal foram consistentemente maiores em relação ao masseter.

McMILLAN; BLASBERG ${ }^{116}$, nesse mesmo ano, fizeram uma medição do LDP em trigger points ativos nos músculos masseter e temporal antes e depois da injeção de anestésico nesses pontos, utilizando um 
algômetro. Foram selecionadas, para esse estudo, 20 mulheres com idade entre 21 e 54 anos, sendo 10 com sinais e sintomas de DTM de origem miogência com a presença de trigger points ativos, que seriam infiltrados com anestésico e 10 controles livres de DTM e com dentição completa que receberiam anestesia no ponto S6 (acupuntura) apenas no masseter. Os LDPs se mostraram significativamente menores nos pacientes com dor miofascial em relação aos controles. Depois de infiltrados, o LDP nos trigger points do masseter aumentou minimamente enquanto no temporal se manteve inalterado. No grupo controle, o LDP aumentou significativamente após a injeção de anestésico no ponto S6 de acupuntura em todos os pontos testados do masseter. Os autores concluíram que, apesar da anestesia local atuar perifericamente nos pontos de dor e centralmente onde a dor é mantida, os LDPs não aumentaram significativamente nos pacientes com dor miofascial, contrastando com os do grupo controle. Disseram ainda que esse fato sugere que nos indivíduos com dor miofascial ocorre uma excitabilidade continuada nos tecidos da periferia e/ou nas áreas neurais centrais, o que pode contribuir para a persistência da sensibilidade dolorosa muscular.

GRAY; DAVIES; QUAYLE ${ }^{67}$, em 1994, fazendo uma abordagem da necessidade do exame dos músculos mastigatórios, afirmam que o exame de sensibilidade dos músculos é importante porque permite detectar um possível sinal de parafunção. Segundo os autores, a sensibilidade muscular pode ser devida, tanto à alteração na oclusão quanto a uma mudança subconsciente no padrão de mastigação do paciente, para evitar a interferência. Essa sensibilidade pode variar com o estágio e o progresso da desordem. Com relação à sensibilidade, os autores acham que todos os músculos devem ser palpados onde se ligam ao osso, sendo que raramente o corpo do músculo é sensível. Afirmaram, também, que o masseter é sensível em pacientes que tenham o hábito de apertar os dentes e o temporal em pacientes que tenham bruxismo, pois os pacientes que reclamam de dor de cabeça temporal, freqüentemente demonstram sensibilidade neste músculo. A sensibilidade do pterigóideo lateral e medial pode ser difícil de detectar devido a sua difícil acessibilidade. 
REID; GRACELY; DUBNEN ${ }^{152}$, em 1994, avaliaram a relação do limiar de dor à pressão através do algômetro nos músculos masseter profundo, masseter superficial (origem e inserção) e temporal anterior em pacientes com Disfunções Temporomandibulares de origem miogênica. Além disso, a influência do tempo, o lado e o local de maior dor indicados pelo relato do paciente, o local e o lado facial na medida do limiar de dor à pressão (LDP) foram avaliados. Para tal estudo, utilizaram 29 pacientes (28 mulheres, 1 homem; média de idade 28,5 anos), e 11 no grupo controle (11 mulheres; média de idade 39 anos). Os pacientes foram diagnosticados com DTM, com dor muscular por pelo menos 3 meses. Os pacientes do grupo controle não possuíam sinais e sintomas de DTM. Cada paciente participou de 2 sessões separadas por um intervalo de 1 semana. A localização dos locais dos músculos sensíveis foi detectada manualmente e registrada num guia transparente, usando para localizar novamente essas áreas em cada sessão. Foi solicitado aos pacientes para identificar seu "lado mais doloroso" antes de se obter a medição do limiar de dor à pressão (LDP). Cada medição do LDP foi definida pela média de 3 tentativas usando um algômetro de pressão. As medidas foram repetidas após 30 minutos para avaliar a confiabilidade intrasessões. Obtiveram como resultado que o LDP médios dos pacientes, não dos controles, diferiram significativamente após 4 sessões $(p<0.05)$. Os LDPs médios também diferiram entre os grupos $(p<0.02)$. Os LDPs diferiram significativamente entre todas as localizações $(p<0.0001)$, mas não diferiram entre os lados esquerdo e direito. A comparação dos valores de LDP obtidos nos lados mais dolorosos designados pelos pacientes não revelou diferenças significativas ( $p=0.51)$. Os LDPs no grupo controle diferiram bastante entre os vários locais examinados, mas, como nos pacientes, não diferiram entre os lados esquerdo e direito. A confiabilidade do LDP obtido com o algômetro na mesma sessão (intervalo de 30 minutos) e entre sessões (intervalos de 1 semana) foi satisfatório e similar entre pacientes e controle. Por outro lado, a confiabilidade do LDP lado a lado em pacientes foi menor do que no grupo controle, apesar dessa diferença não ser significativa. Portanto, o algômetro foi capaz de controlar o índice de aplicação de pressão em uma população de pacientes com DTM de origem miogência. Também os LDPs foram altamente 
reproduzíveis intra e entre sessões e significativamente mais baixos em pacientes quando comparados ao grupo controles.

No ano seguinte, em 1995, SVENSSON et al. ${ }^{180}$ analisou 11 voluntárias com dor muscular crônica (pelo menos 6 meses de dor) e 11 voluntários com controle assintomáticos, quanto ao limiar de dor à pressão (LDP) e curvas estímulo-resposta (E-R) nos músculos masseter e dedos indicadores. Foram induzidos, por meio de injeção intramuscular de solução salina $5 \%$ e anestesia local, condições de hiper e hipoalgesia experimental nos músculos masseter do grupo controle. Foi aplicada uma pressão constante por 5 segundos e a intensidade de dor foi pontuada através da escala de análise visual (EAV), que foram mostrados na tela do computador. Cinco diferentes intensidades de pressão foram aplicadas, com 2 minutos de intervalo entre estímulos sucessivos. Os autores observaram que os LDPs obtidos nos músculos masseter dos pacientes com dor foram significativamente menores em relação ao grupo controle. As rampas médias das curvas S-R foram bem mais íngremes para os pacientes com dor nos músculos masseter do que no grupo controle, mas não houve diferenças estaticamente significativas nos LPD ou curvas S-R para o dedo indicador. Os LPD nos músculos masseter do grupo controle não foram afetados pela injeção de solução salina $5 \%$, entretanto as rampas das curvas S-R para os músculos masseter foram bem mais íngremes para os valores de injeção salina comparadas aos valores básicos. A injeção de anestesia local nos músculos masseter do grupo controle aumentou os LPD e reduziu as rampas das curvas S-R significativamente quando comparadas aos valores básicos. Os autores sugerem que o LDP e as curvas S-R são instrumentos valiosos para a descrição quantitativa da dor muscular crônica e experimental.

Em 1997, ISSELÉE et al. ${ }^{78}$ também avaliaram o limiar de dor à pressão dos músculos masseter e temporal num único dia, com duas sessões separadas por 15 minutos pela manhã e 2 sessões à tarde, com o mesmo intervalo, e entre 2 dias por um mesmo examinador, com auxílio de um algômetro eletrônico em 11 homens e 11 mulheres livres de sintomas. Verificaram que para cada músculo, a primeira medida do LDP de uma sessão 
foi notadamente mais alta do que a última da mesma sessão. Os dados também demonstraram uma boa reprodutibilidade entre sessões e entre os dias. Em conclusão, o presente estudo não encontrou nenhuma influência sistemática na medida LDP com referência ao tempo de registro (manhã/tarde) ou entre 2 consecutivos.

Em 1998, ainda ISSELÉE et al. ${ }^{76}$ avaliaram o limiar de dor à pressão (LDP) dos músculos masseter e temporal durante quatro sessões (manhã e tarde dos dias 1 e 3), para testar o desempenho clínico de um novo medidor de dor (algômetro) na medição a curto prazo do LDP. Durante cada sessão, cada ponto de palpação dos músculos mastigatórios foram medidos 4 vezes. Existia um intervalo de poucos segundos entre as medições 1 e 2 e, 3 e 4 e, 5 minutos entre 2 e 3 . Para tal estudo foram utilizados 20 homens (idade de 22 - 36 anos) e 9 mulheres (idade 21 - 34 anos) livres de DTM. Foi utilizado um molde transparente colocado sobre a face dos indivíduos com o propósito de localizar os pontos destinados à palpação. A força de aplicação exercida com o algômetro foi entre 37 e 43KPa/s. Para cada palpação realizada, o primeiro LDP da sessão foi significativamente menor que o segundo na mesma sessão. Similarmente, o terceiro era menor que o quarto. Os valores do LDP entre as sessões da manhã e tarde e entre os dias 1 e 3 não foram significativamente diferentes. Entretanto, quando os valores do LDP foram considerados diferentes, análises de variação mostraram que a variabilidade entre indivíduos do LDP foi 1,4 a 6,8 vezes mais altas que a variabilidade observada intra ou entre sessões e dias. Nenhuma diferença em relação ao gênero foi encontrada. Os autores comprovaram o bom desempenho clínico desse novo tipo de algômetro.

SVENSSON; ARENDT-NIELSEN; $\operatorname{HOUE}^{179}$, em 1998, induziram dor no músculo masseter através da infusão de solução salina hipertônica (5\%) por até 800 segundos, em 12 homens saudáveis. Os indivíduos marcaram constantemente a intensidade de dor numa escala de análise visual de $10 \mathrm{~cm}$. A mastigação ipsilateral e contralateral, em relação ao lado da infusão, foram quantitativamente avaliadas antes, durante e após os períodos de constante intensidade de dor muscular, por meio de registros de 
fechamento mandibular eletromiográficos e traçados mandibulares. Em um número significante de ciclos mastigatórios de fechamento, durante sua função agonista, foi diminuída tanto para mastigação dolorosa ipsilateral como para a contralateral $(p<0,05)$. Estas alterações eletromiográficas são provavelmente um reflexo do padrão de recrutamento natural bilateral dos músculos de fechamento durante a mastigação. Dentro das limitações do estudo, a dor muscular experimental, induzida pela infusão de solução salina hipertônica, causou uma diminuição da capacidade dos músculos mastigatórios de trabalhar contra uma carga, o que está de acordo com a adaptação funcional da dor muscular. O objetivo biológico de tal adaptação pode permitir a cicatrização da área lesada.

Em 1998, GOULET et al. ${ }^{64}$ avaliaram: 1) reprodutibilidade dos métodos de detecção da sensibilidade de dois músculos mastigatórios e da articulação; 2) reprodutibilidade das mensurações do movimento mandibular máximo; 3) fatores que influenciam a concordância dos examinadores. Os autores utilizaram uma pressão padrão por 2 segundos sobre quatro locais dos músculos mastigatórios definidos anatomicamente: um local na frontal (testa), como controle, e dois locais da ATM em cada lado da face. Uma técnica utilizava o algômetro de pressão enquanto a outra técnica foi aplicada através de um examinador treinado que exercia a pressão com a ponta do dedo indicador. Foram avaliados 72 indivíduos (36 pacientes e 36 controle) em um tipo de estudo cego. Idade, gênero e raça foram consideradas. Cada indivíduo foi examinado 2 vezes com cada um dos métodos descritos, numa seqüência aleatória completamente equilibrada por examinadores regulados. Os níveis de sensibilidade foram determinados pelo indivíduo através do autorelato de dor sob pressão. Os autores verificaram que os coeficientes de correlação intraclasse (ICC) para os métodos de avaliação da sensibilidade alcançaram de 0,220 a 0,739 para a pressão manual e de 0,391 a 0,880 para o algômetro. Os ICC para a mensuração do movimento mandibular foram muito menos variáveis, alcançando de 0,59 a 0,68 para movimentos laterais e de 0,78 a 0,93 para movimento de abertura. Esses resultados são indicativos de boa a excelente concordância entre examinadores ajustados para mensuração do movimento mandibular e para os métodos de avaliação da 
sensibilidade nos dois locais do masseter (superficial e profundo) e os temporais anteriores. Somente uma concordância razoável foi descoberta para os temporais mediais e cápsula lateral da ATM usando esses métodos.

Em 2000, FREDRIKSSON; ALSTERGREN; KOPP ${ }^{54}$ realizaram um estudo que teve o propósito de investigar e comparar os LDPs em pontos testes (masseter, temporal anterior e aspecto lateral da ATM) e em pontos de referência (protuberância mental, osso metacarpo e $1 \mathrm{~cm}$ acima da glabela), utilizando um algômetro. Foram selecionados 12 homens (idade média de 29 anos) e 12 mulheres (idade média de 35 anos) para essa finalidade, sendo todos livres de sinais e sintomas de DTM. Foram feitos 5 exames consecutivos em cada indivíduo, e outro após 6 meses. Os LDPs diminuíram significativamente para todos os pontos teste durante as 5 medições e aumentaram significativamente de uma sessão pra outra. Os homens apresentaram limiares significativamente maiores em relação às mulheres. Os autores concluíram que os LDPs em indivíduos saudáveis variaram significativamente durante as tomadas consecutivas e após 6 meses.

Segundo um estudo desenvolvido por FARELLA et al. ${ }^{43}$, em 2000, cuja finalidade foi analisar a sensibilidade, especificidade e os valores preditivos positivos do diagnóstico com algômetro em dores musculares miofasciais, a obtenção do LDP é questionável. Os autores concluíram que a palpação com algômetro serve somente como uma pequena ajuda no diagnóstico das dores miofasciais e por isso este tipo de diagnóstico, como uma única ferramenta, deveria sempre ser interpretado com precaução.

Entretanto, a literatura descreve a confiabilidade da obtenção do LDP através do algômetro manual desde que alguns fatores sejam determinados: 1) tamanho da ponta ativa; 2) velocidade de aplicação da pressão; 3) grau de contração muscular; 4) tempo de reação do indivíduo e do examinador; 5) subjetividade do relato de dor. Além disso, o LDP sofre variações individuais assim como segundo o gênero e grupos musculares. Apesar da suscetibilidade das variações da determinação do LDP, os índices 
de concordância intra e interexaminadores descritos na literatura estão entre bons e excelentes ${ }^{64,116}$.

Em 2002, CONTI, SANTOS, LAURIS ${ }^{28}$ avaliaram a concordância interexaminadores para o exame de palpação muscular após um programa de calibração. Avaliaram diferenças considerando o tempo, o grupo de músculos e o lado examinado. Foram selecionados 32 indivíduos (16 homens e 16 mulheres). $\mathrm{O}$ grupo sintomático foi composto por 16 pacientes com sinais $\mathrm{e}$ sintomas de DTM miogênica. No grupo controle, os 16 indivíduos não apresentavam qualquer sinal ou sintomatologia dolorosa compatível com DTM. A palpação foi realizada em três sessões (inicial, após 30 dias e após 40 dias), por 4 examinadores previamente calibrados, na musculatura e cervical. A quantificação da resposta dolorosa foi feita através de uma escala ordinal (de 0 a 3). A concordância foi medida através do teste de Kendall. Para o músculo esternocleidomastóideo, houve a maior concordância $(0,84)$, enquanto o pior valor foi encontrado para a palpação da origem do masseter $(0,56)$. Os níveis de concordância para todos os músculos foram considerados justos e excelentes, independentes do tempo e lado analisado.

Em 2005, SILVA et al. ${ }^{168}$ desenvolveram um estudo com o objetivo de comparar o limiar de dor à pressão (LDP) dos músculos mastigatórios entre pacientes com sinais e sintomas de dor miofascial e indivíduos assintomáticos. Foram selecionadas 50 mulheres com sinais e sintomas de DTM de origem miogência e 49 livres de qualquer queixa dolorosa compatível com DTM. Os voluntários dos dois grupos foram palpados por único examinador nos seguintes pontos: corpo do masseter, temporal anterior, temporal médio e temporal posterior. O masseter apresentou LDP significativamente menor, seguido pelo temporal anterior, médio e posterior $(p>0,001)$. Foi obtida uma especificidade de $90.8 \%$ para valores de LDP de $1,5 \mathrm{Kgf} / \mathrm{cm}^{2}$ para o masseter, $2,47 \mathrm{Kgf} / \mathrm{cm}^{2}$ para o temporal anterior, $2,75 \mathrm{Kgf} / \mathrm{cm}^{2}$ para o temporal médio e $2,77 \mathrm{Kgf} / \mathrm{cm}^{2}$ para o temporal posterior. Os autores concluíram que a palpação mostrou ser um exame confiável para se detectar sensibilidade muscular em pacientes de DTM. 


\subsection{Aspectos Psicológicos e as DTMs}

Segundo RAPPAPORT ${ }^{150}$, em 1984, foi Reich, na década de 20, o primeiro autor dentro da psicologia que começou a dar importância à unidade mente-corpo, ou seja, a psiquê não estaria desvinculada da parte biológica e, sim, sofreria e causaria influências sobre a mesma e vice-versa, surgindo, então, o conceito que daria origem à medicina psicossomática. O autor propôs uma idéia na qual, dentro dessa unidade, não haveria supremacia de um em relação ao outro, pois tanto o biológico poderia afetar o psicológico como o inverso.

Os primeiros trabalhos que apontaram uma possível etiologia psicológica para DTM surgiram no ano de 1955, com MOULTON ${ }^{129}$, um psiquiatra que desenvolveu seus trabalhos com um cirurgião-dentista avaliando 35 pacientes com DTM através de entrevistas. Concluiu que esses pacientes, além de extremamente ansiosos, tendiam a expressar essa ansiedade através de sintomas físicos. A partir da análise psiquiátrica, somente 4 foram considerados normais, 20 extremamente ansiosos e 11 psicóticos ou prépsicóticos. Como conclusão diante de tais observações, o autor afirmou que a tensão e ansiedade foram construídas durante toda a vida e, em um determinado momento crítico, os sintomas dentais apareceram. O paciente, freqüentemente acompanhado apenas pelo profissional da área odontológica, tenderia, então, a focalizar apenas o problema dentário como uma fuga ou substituição para os problemas de sua vida considerados insolúveis. Tais pacientes se tornariam propensos a criar dependência crônica do profissional e não apresentariam melhoras significativas na sintomatologia, porque isto significaria o abandono por parte do cirurgião-dentista, e em tais casos, o tratamento indicado seria a abordagem conjugada entre odontologia e psiquiatria.

$\mathrm{Na}$ tentativa de analisar os aspectos psicossomáticos das DTMs, $\mathrm{KYDD}^{94}$, em 1959, avaliou 30 pacientes com DTM através de exame eletromiográfico, oclusal e psicológico, sendo, este último, realizado através da história descrita pelo paciente sobre a origem e progressão da dor, entrevista 
na tentativa de se determinar a existência de incidentes emocionalmente estressantes que pudessem estar relacionados com o aparecimento inicial dos sintomas e 3 testes psicológicos: "Cornell Medical Index", "Minnesota Multiphasic Personality Inventory" (MMPI) e "Edwards Personality Profile". A avaliação psicológica mostrou que dos 30 pacientes, 23 (76\%) se apresentaram emocionalmente perturbados. Nesses pacientes foi possível demonstrar uma relação entre exacerbação dos sintomas e dificuldades no ajuste social e interpessoal, envolvendo reações de conflito e ansiedade.

De acordo com MOULTON ${ }^{130}$, em 1966, o papel dos estados emocionais na etiologia das cefaléias, dores nas costas, úlceras gástricas e asma, entre outras doenças psicossomáticas, é mais bem aceito e compreendido do que no caso de sintomas bucais e dentais. Embora os dentes tenham uma finalidade aparentemente mecânica, não seria surpresa alguma que, fatores emocionais desempenhassem uma significante influência na etiologia de alguns distúrbios, já que a face e a cavidade bucal têm um profundo significado psicológico para o homem, desde a infância até a idade adulta. A boca é a primeira fonte de prazer corporal, o que poderia ser uma das razões pelas qual a dor nessa região é tão especialmente sentida. Dessa forma, alterações orais e faciais estéticas ou funcionais podem apresentar conseqüências que iriam além dos fatores físicos.

Freqüentemente a DTM é um distúrbio difícil de ser tratado, principalmente em função de sua etiologia multifatorial e de compreensão muitas vezes limitada. Para investigar a relevância de fatores psicológicos na etiologia da DTM, FINE ${ }^{50}$, em 1971, comparou dois grupos: grupo I com 50 pacientes com DTM e grupo 2 com 50 pacientes com dores relacionadas a cáries, dentes impactados ou uso de próteses totais. A avaliação psicológica constituiu-se de uma detalhada entrevista a respeito da história familiar, saúde geral, problemas no trabalho, infância, doenças psiquiátricas, estado civil e história relacionada, nível de instrução, ansiedade e depressão e qualquer mudança no estilo de vida dentro de um período de 5 anos, previamente ao aparecimento dos sintomas. Os sintomas relacionados à ansiedade mais comumente observados foram: tensão muscular, incapacidade de relaxar, 
respiração excessiva, palpitações, desmaios e tremores nas mãos. No grupo 1, $76 \%$ dos pacientes apresentaram envolvimento psicológicos enquanto que no grupo 2 apenas 20\%. A maioria dos pacientes do grupo 1, com um diagnóstico psicológico confirmado, apresentaram distúrbios caracterizados pós-sintomas típicos de depressão moderada ou severa, associada com altos sintomas de ansiedade. O autor sugeriu que os sinais e sintomas reconhecidos como características da DTM poderiam ser adicionadas à longa lista de sintomas somáticos que freqüentemente predominam em pacientes acometidos por depressão e ansiedade.

Com o objetivo de medir o estresse e seu envolvimento com a etiologia das DTMs, de uma maneira mais objetiva ou bioquímica, EVASKUS; LASKIN $^{42}$, em 1972, realizaram uma análise comparativa entre 32 pacientes com DTM e 34 controles, através da medida dos níveis urinários de catecolaminas e esteróides, que são substâncias com índices aumentados em indivíduos submetidos a situações estressantes. A quantidade de esteróides mostrou-se 33\% maior no grupo com DTM quando comparado ao grupo controle, enquanto que os níveis de catecolaminas mostraram-se $118 \%$ mais altos no grupo com disfunções quando comparado com o grupo controle. Os resultados desse estudo ofereceram evidências bioquímicas que pacientes com DTM estão sob maior estresse psicológico que indivíduos normais. É reconhecido que indivíduos submetidos a situações estressantes freqüentemente desenvolveram mecanismos de alívio das tensões, os quais podem ser os bucais parafuncionais, como o bruxismo cêntrico ou excêntrico. É proposto que esse mecanismo de alívio de tensões pode levar à fadiga muscular com conseqüente mioespasmo, dor e disfunção articular, sintomas características da DTM.

No mesmo ano, ROTHWELL ${ }^{155}$ avaliou 70 pacientes com DTM através do "Eyesenck Personality Inventory" e, após uma comparação com uma amostra controle, concluiu que a principal diferença, estatisticamente significante observada, foi a maior escala de ansiedade observada no grupo com DTM quando comparada ao controle. 
Em um extenso estudo sobre as implicações psicológicas nas DTM, RUGH; SOLBERG ${ }^{157}$, em 1976, puderam chegar às seguintes conclusões: embora os fatores psicológicos tenham um importante papel na etiologia das DTMs, uma abordagem mais confiável seria considerar a etiologia como sendo de natureza multifatorial; os fatores psicológicos operantes nas DTMs não podem ser entendidos dentro de uma única linha de pensamentos, e sim, deveriam ser sempre considerados os fatores emocionais, comportamentais e sociais em conjunto; fatores emocionais (ansiedade, medo, frustração e raiva) desempenham um papel significado na etiologia das DTMs, gerando tensão muscular e hábitos parafuncionais e, embora pareça improvável que a atividade muscular emocionalmente induzida seja um fator necessário, é provável que ela seja suficiente para causar a DTM; a avaliação do paciente deveria incluir, também, uma determinação dos fatores emocionais, como a ansiedade.

Um fator particularmente interessante no estudo da personalidade é a ansiedade, comentou LUNDIN ${ }^{109}$, em 1977, e definiu a operação para a produção da ansiedade como um estímulo neutro ser seguido por um estímulo aversivo, por exemplo, uma campainha tocar e em seguida o animal tomar um choque elétrico. Quando essa operação é repetida, o estímulo neutro adquire papel de estímulo aversivo, através do pareamento. As conseqüências comportamentais dessa operação são denominadas de ansiedade. No entanto, para que haja realmente a caracterização da ansiedade, a separação temporal dos dois estímulos deve ser de duração suficiente para permitir a ocorrência de mudanças comportamentais. Em segundo lugar, há o fato da inevitabilidade do estímulo aversivo que segue o estímulo neutro. Se o organismo puder fazer alguma coisa para eliminá-lo, a condição se torna de esquiva e não de ansiedade, portanto, sendo necessária também a impossibilidade de fuga para se caracterizar a operação de ansiedade.

Em um estudo sobre o papel do estresse nas DTMs, WEINBERG ${ }^{190}$, no mesmo ano, afirmou que as pesquisas sobre diferenças de gênero em resposta ao estresse emocional, em todos os mamíferos, indicam que o macho é muito mais sensível ao estresse que as fêmeas e, sendo assim, a razão pela 
qual um maior número de homens não possui sinais e sintomas de DTM, embora eles tenham uma sensibilidade maior ao estresse, isso se explica porque estes possuem maior número de mecanismos disponíveis de escape ou alívio das tensões não orais do que as mulheres em nossa sociedade e ainda, a DTM não seria uma doença do estresse unicamente, mas sim um sistema de alívio tensional através da cavidade bucal socialmente induzido, não sendo o estresse em si, mas sim a maneira que os indivíduos lidam com ele que seria destrutivo ou danoso.

Ao aplicar psicoterapia em 23 pacientes com DTM que não haviam respondido a terapias convencionais, $\mathrm{POMP}^{148}$, em 1977, observou que a remissão dos sintomas ocorreu em 17 pacientes, dados que coincidiram com experiências de emoções negativas, reconhecimento e mudanças de uma auto-imagem negativa, desenvolvimento de um sentimento de competência ou uma mudança específica no ambiente do paciente. De uma maneira geral, concluiu que os fatores emocionais desempenharam papel no aparecimento, progressão e remissão dos sintomas de DTM, e ainda, pacientes com DTM que não responderam a terapias convencionais, poderiam se beneficiar de uma psicoterapia de curto prazo, direcionada para o aprendizado de estratégias para lidar melhor com os problemas da vida diários.

Através da análise psicológica "Taylor Manifest Anxiety Scale" de 44 pacientes portadores de DTM e 10 de dores faciais não relacionadas ao diagnóstico de disfunção, GALÉ ${ }^{57}$, em 1978, concluiu que existiram duas possibilidades para explicar a relação da ansiedade com a DTM. A primeira e mais provável, segundo o autor, é que esses pacientes teriam o seu nível de ansiedade elevado como conseqüência da disfunção, pois, após o tratamento adequado da DTM, o nível de ansiedade diminuiu. A segunda, considera os pacientes com DTM como sendo mais ansiosos que a população normal e que a dor aumentaria ainda mais essa ansiedade, num ciclo vicioso onde o fenômeno doloroso aumentaria a ansiedade e a ansiedade aumentaria a dor.

No mesmo ano, avaliando 105 pacientes que receberam diversas modalidades de tratamento conservador para DTM, COHEN ${ }^{27}$, concluiu que 
fatores psicológicos e musculares desempenham fortes papéis na etiologia da disfunção e que, apesar de existirem controvérsias a respeito do papel da oclusão como fator etiológico único e principal, existiram certas questões quanto a isso.

Ainda em 1978, MARBACH; LIPTON ${ }^{114}$ discutiram que numerosos estudos descrevem as condições clínicas e psicológicas dos pacientes com DTM, porém poucos consideram os aspectos sociais da disfunção, os quais poderiam ser os verdadeiros determinantes do porque os pacientes buscam tratamento. Dois fatores sociais poderiam ser determinados: a estrutura do grupo social ou comunidade ao qual o paciente pertence e a orientação de saúde ou sistemas de valores ao qual ele se adere. No que se refere ao comportamento da doença, poderíamos perceber diferenças na extensão que as pessoas identificam ou percebem a existência da doença, avaliam ou se tornam conscientes da mesma, procuram ou não procuram assistência e respondem a tratamentos médicos ou não. Esse comportamento depende da maneira pela qual a doença se manifesta, ou seja, sua severidade, do ambiente sócio-cultural das pessoas envolvidas e das relações familiares e comunitárias. Sendo assim, o alívio da sintomatologia ou tratamento da disfunção poderia ser mais bem abordado, provendo ao paciente uma interpretação de sua condição que fosse digna de crédito. Isso significa que o clínico deve apresentar um diagnóstico que seja culturalmente e psicologicamente aceito pelo indivíduo. Por exemplo, se o ambiente sóciocultural enfatiza que uma expressão psicológica não é aceitável, tal interpretação dos sintomas pelo profissional será de pouca utilidade para o paciente. Na verdade, tal atribuição irá aumentar a ansiedade e romper com a relação profissional-paciente. Por outro lado, pacientes que aprenderam previamente que a somatização de problemas emocionais é aceitável, irão responder favoravelmente a uma explicação psicofisiológica para a etiologia de seus sintomas.

Considerando a literatura a respeito dos aspectos psicológicos e DTM, SCOTT ${ }^{164}$, em 1980, afirmou existirem falhas no que se relaciona ao tratamento da disfunção. Entre elas, refere-se à escassa literatura a respeito 
dos aspectos psicológicos na etiologia da DTM e ainda a falta de esclarecimentos quanto à real função dos profissionais da área da psicologia com os pacientes acometidos pela disfunção.

Em 1980, CLARK; RUGH; HANDELMAN ${ }^{25}$, no intuito de testar a hipótese de que o bruxismo noturno está diretamente relacionado a períodos de estresse diários, mediram o nível desse estresse através das catecolaminas urinárias. Para medir a atividade do masseter, um sistema portátil de eletromiografia, o qual utilizava atividade elétrica cumulativa, foi utilizado para avaliar o bruxismo noturno. Uma correlação positiva foi encontrada entre o bruxismo noturno e estresse diário. Estes resultados suportam a teoria do estresse emocional como fator etiológico do bruxismo noturno.

A importância do estresse e da ansiedade como fatores contribuintes à complexa etiologia das disfunções temporomandibulares está cada vez mais difundida, comentou LOWENTAL ${ }^{105}$, em 1981 e que, apesar disso, habilidades psiquiátricas ou psicológicas especializadas não seriam sempre necessárias para o cirurgião-dentista lidar com tais pacientes. O próprio interesse na situação de vida do paciente e conflitos atuais, saber ouvi-lo atentamente, a experiência de vida do profissional e sua compreensão humana são freqüentemente suficientes. A mesma atenção dada pelo profissional aos dados colhidos no exame físico deveria ser ministrada ao componente emocional ou psicológico do paciente.

MOODY et al. ${ }^{126}$, em 1981, estudaram dois grupos de indivíduos. O primeiro composto de 52 pacientes sendo $84,6 \%$ mulheres, com idade média de 34,4 anos, com síndrome de dor e disfunção em tratamento na Universidade de Kentucky, Estados Unidos, e um grupo controle composto de 52 indivíduos selecionados da população geral, sendo 61,5\% mulheres com idade média de 27,4 anos. A proposta dos autores foi comparar o nível de estresse entre os dois grupos e a presença de dor subjetiva. Foi utilizado o teste Subjclive Stress Scale e respondido um questionário avaliando a presença de dor. A presença de dor objetiva foi avaliada por intermédio de palpação muscular. Como resultados, obtiveram índices mais elevados de 
estresse no grupo de pacientes com disfunção. Este grupo também apresentou significativamente maiores índices de dor subjetiva e objetiva. Os autores realçam que um dado importante obtido, embora estatisticamente não significante, foi a falta de relação entre nível de estresse com o nível de dor relacionadas com disfunção.

Com o propósito de mostrar a relação entre o estresse emocional e as DTMs, STEIN et al. ${ }^{173}$, em 1982, compararam através da Escala de Reajustamento Social de Homes e Rale, 16 pacientes com DTM e 8 controles e puderam observar que os pacientes com difusão obtiveram escores mais alto ( média de 161,8 ) que os do grupo controle ( média de 93,4 ) e também, à medida que o número de sintomas aumentava, ou seja, a disfunção se tornava mais severa, havia uma tendência do aumento do escore do teste para todos os pacientes. Não se pode afirmar se os pacientes tiveram os eventos da vida estressantes antes ou depois da manifestação da disfunção, entretanto existe uma relação com certeza, entre os eventos de vida estressantes e o número de sintomas presentes.

Também na tentativa de avaliar o estresse emocional na etiologia das DTMs, FEARON; SERWATKA ${ }^{46}$, em 1983, compararam 28 pacientes portadores de disfunção com 28 pacientes com outros problemas odontológicos (grupo controle), em relação aos fatores psicológicos, através da Escala de Reajuste Social ou Social Readjustment Rating, um inventário que mede em escores as situações estressantes na vida do indivíduo. Puderam observar que o grupo com DTM apresentou escores significantemente mais altos que o grupo controle, concluindo que o estresse emocional teria um papel significante na etiologia da DTM não orgânica, ou seja, naqueles casos em que não existia uma alteração física óbvia, como a confecção de próteses ou restaurações, trauma, doença articular degenerativa ou luxações mandibulares, e que a existência do estresse deveria ser avaliada na vida do paciente com DTM, para promover um tratamento adequado.

SALTER et al. ${ }^{159}$, em 1983, com a finalidade de investigar a influência da ansiedade e outras características emocionais na cronicidade 
dos sintomas de síndrome de dor e disfunção temporomandibular, avaliaram 103 indivíduos, sendo 73 pacientes portadores desta síndrome, subdivididos em dois subgrupos de acordo com o tempo de duração dos sintomas: (grupo A) 31 indivíduos com duração de sintomas de disfunção de no máximo 6 meses e 42 pessoas que apresentavam os sintomas há mais de 6 meses. Este segundo subgrupo incluía alguns pacientes com lesões ou alterações patofisiológicas, como neuralgia do trigêmeo, enxaqueca, otite crônica, etc. A média de idade foi de 29,2 anos e $86 \%$ eram pessoas do sexo feminino. Foram comparados com outros dois grupos: B) 17 indivíduos também com dor crônica há mais de seis meses, mas de diagnóstico desconhecido e C) 13 indivíduos normais. Todos foram submetidos ao Questionário Geral de Saúde de Goldberg e por um outro teste denominado Crown-Crisp Experimental Index. Como resultado, observaram que o perfil psicológico dos grupos de pacientes com dor são semelhantes entre si e aos do grupo controle. Estes resultados levam à conclusão de que é questionável se a síndrome de dor e disfunção temporomandibular sejam de origem primariamente psicológica.

No ano de 1984, buscando características específicas relacionadas à ansiedade e personalidade, em pacientes com DTM, MOSS; ADAMS ${ }^{128}$ avaliaram comparativamente através do " MMPI " ( características de personalidade ), do STAI - State Trait Anxiety Inventory (ansiedade) e do Beck Depression Inventory (depressão) 10 pacientes com história de DTM, 10 pacientes assintomáticos e 10 apenas com sons articulares e sem dor. Os resultados indicaram que os grupos não apresentaram diferenças em nenhuma das variáveis estudadas, levando a uma possível conclusão de que o alto nível de ansiedade apresentado pelo paciente com DTM pode apenas ser uma conseqüência da própria disfunção e não a causa da mesma, podendo, assim, essa ansiedade desaparecer após o tratamento ter sido realizado.

DUINKERKE et al. ${ }^{36}$, em 1985, estudando um grupo de 211 pacientes com dentição natural completa, através de exame clínico e aplicação das escalas somática e psicológica do Hopkins Symptomns Check List (HSCL), pôde observar que o estresse foi um importante fator na etiologia 
da DTM. Sintomas tanto psicológicos quanto somáticos não só provaram estarem altamente correlacionados entre si, mas também com os sinais e sintomas da DTM; além disso, as mulheres obtiveram um maior escore na escala somática, mas não na psicológica, em comparação com os homens. Isto poderia explicar, ao menos parcialmente, por que a DTM incide mais no sexo feminino que no masculino. Tornar-se-ia, então, importante a identificação dos pacientes que somatizam estresse, a fim de excluí-los de procedimentos oclusais extensivos ou desnecessários, cirurgias ou outras intervenções invasivas. Também adquirida suma importância o papel do cirurgião - dentista como ouvinte do paciente, estabelecendo o diagnóstico também com a ajuda da anamnese e adotando procedimentos mais conservadores.

No mesmo ano, FRICTON et al. ${ }^{55}$, avaliando 164 pacientes portadores de DTM, concluíram que fatores emocionais, posturais e comportamentais estavam associados à etiologia da disfunção e que estes comumente levavam os clínicos a rotularem a dor como de origem psicogênica. Este diagnóstico errôneo era particularmente danoso aos pacientes, podendo levá-los a procurar medidas mais drásticas, como intervenções cirúrgicas para provar a existência da dor. Na verdade, uma vez estabelecido o diagnóstico da disfunção, é importante que o paciente seja conscientizado da origem psicológica do problema e que, mesmo quando fatores psicológicos estiverem envolvidos, a dor do paciente é real.

BRAND; LLOYD; GLUCMAN ${ }^{11}$ comentaram, em 1985, que ao questionar se certos estados emocionais, como a depressão, ansiedade ou histeria, poderia causar dor crônica ou susceptibilidade à dor crônica após microtraumas ou injúrias menores, pareceu estar evidente que estados emocionais resultassem da dor crônica. Entretanto, na opinião dos autores, fatores emocionas podem causar ou agravar a dor, como tal, seria importante documentar a natureza de tais emoções e influencia comportamental das maneiras nos pacientes com DTM. 
Ainda em 1985, SPECULAND; GOSS ${ }^{171}$, numa revisão da literatura, comentaram que muitos estudos tentaram identificar traços específicos de personalidade que estariam relacionados com pacientes portadores de DTM, normalmente através da análise de respostas a um questionário. Pelo menos 10 estudos entre 1959 e 1980 mostraram que uma grande variedade de características de personalidade seria impossível; isso provavelmente ocorreu em função de que um grupo com DTM não é homogêneo e mesmo se um traço específico de personalidade fosse identificado, não haveria prova de nem uma relação causal, assim como a ansiedade é relatada na literatura em vários trabalhos, porém uma relação causal é difícil de ser demonstrada. O mecanismo pelo qual a ansiedade poderia estar relacionada às DTMs seria resumido da seguinte forma: estados emocionais tais como a ansiedade causaria tensão muscular; a tensão muscular persistente resultaria em dor e essa seqüência de eventos levaria aos sinais e sintomas relatados pelos pacientes acometidos pela disfunção. Um outro grande número de estudos mostra que cerca de $50 \%$ a $75 \%$ dos pacientes com DTM enfrentaram eventos estressantes ou ansiogênicos anteriormente ao aparecimento dos sintomas. Eles relataram problemas relacionados ao trabalho, conflitos familiares, responsabilidade por familiares doentes e problemas econômicos e, geralmente, a proporção de dor á palpação muscular aumentavam de forma diretamente proporcional á freqüência dos eventos estressante.

HIJEZEN; SLANGEN ${ }^{74}$, em 1985, tiveram como propósito neste estudo, avaliar características de psicológicas como o estresse e hábitos parafuncionais que pudessem discriminar pacientes com dor e disfunção miofascial de um grupo controle sem disfunção. O grupo experimental era composto de 58 pacientes com disfunção e 64 sem disfunção. Os grupos tiveram uma distribuição quanto ao gênero, aproximadamente $80 \%$ mulheres, e de faixa etária semelhantes, a maioria entre vinte e trinta anos. Responderam um questionário indagando sobre sintomas físicos e fatores emocionais que pudessem ser desencadeantes das queixas somáticas. Tiveram como resultado uma semelhança entre os dois grupos ao estresse sofrido no ambiente de trabalho. Numa auto-avaliação, $40 \%$ de ambos os grupos relacionavam o desencadeamento de suas queixas somáticas com tensão. 0 
grupo com disfunção relatou, significantemente, mais bruxismo noturno com a presença de sintomas relacionados. Outros hábitos parafuncionais, como morder objetos, língua etc., não foram significativamente diferentes em ambos os grupos.

KLEINKNECHT et al. ${ }^{90}$, em 1986, examinaram a relação entre o relato de sintomas coletados em uma pesquisa de comunidade com as descobertas num exame clinico, como também as discrepâncias em termos de características psicossociais dos pacientes e a confiabilidade interexaminadores. Para isso, foi feita uma seleção de 65 indivíduos, abrangendo tanto pacientes com sintomas de DTM como assintomáticos. Toda a amostra respondeu a um questionário de sintomas de DTM, onde relataram a presença ou ausência de 14 itens relacionados a tais patologias. Esse questionário também continha várias escalas, com o intuito de avaliar psicologicamente o paciente, além de uma pesquisa de experiência de vida com relato de eventos que os pacientes experimentaram no ultimo ano que influenciaram suas vidas. Os exames clínicos foram realizados por quatro dentistas que não sabiam da situação clinica e nem das características psicossociais do paciente. O exame incluiu palpação dos músculos da cabeça, pescoço, mastigação e ATM. A palpação foi conduzida, aplicando-se uma pressão digital firme na área examinada, sendo os músculos palpados externamente (temporal, frontal, esternocleidomastóideo, supra e infra-hióide e masseter). O pterigóideo lateral foi palpado intra-oralmente. Os sons da articulação e o movimento da mandíbula também foram avaliados. Treinamento de padronização foi utilizado até que o protocolo estivesse concordante entre os participantes. Os sintomas relatados pelo questionário foram cruzados com os números de sinas de dor encontrados durante o exame. Os resultados demonstraram uma relação direta entre o número de sintomas relatados e o numero de sintomas encontrados durante o exame. Dentre os indivíduos que relataram zero, um ou dois sintomas, $27 \%$ acusaram um sinal durante o exame. Porém quando mais de dois sintomas eram relatados, a porcentagem dos casos com sinais aumentaram. Dentre os 8 indivíduos que relataram todos os sintomas, em 7 foram descobertos 2 ou mais sinais de dor durante o exame $(87,5 \%)$. Os resultados desse estudo 
indicam que o método do relato do indivíduo ou relato do paciente na identificação de sintomas pode ser de grande utilidade para que os sinais possam ser descobertos durante o exame. Essa relação é particularmente forte para aqueles indivíduos que relatam vários sintomas.

O bruxismo e as DTMs estão intimamente relacionados, ambos sendo influenciados por fatores psicológicos, segundo CANNISTRACI; FRIEDRICH ${ }^{15}$, em 1987, quando comentaram que o bruxismo é uma desordem de sono relacionada com expressões de estados emocionais durante o dia, principalmente situações estressantes ou então relacionadas com a ansiedade. Pacientes com DTM têm dificuldade em lidar com eventos estressantes da vida cotidiana e, como resultado, ficam submetidos às conseqüências da ansiedade e frustração. Algumas indicações de que o paciente estaria sendo acometido por essas conseqüências e, portanto, poderia se beneficiar de uma abordagem psicológica, seria uma má adaptação às mudanças de vida (âmbito pessoal, social ou profissional), insônia, comportamento agressivo ou impaciente, dificuldades emocionais, dores de cabeça freqüentes, dores musculares ou articulares, mudanças na aparência física, higiene pessoal ou auto - estima, mudanças na pressão sanguínea, alergias e resfriados constantes, dificuldades sexuais e incapacidade de relaxar. Em tal caso, o ensino ao paciente de técnicas de lidar com o estresse - como reconhecê-lo, técnicas de relaxamento muscular, aconselhamento nutricional e mudanças no estilo de vida - são meios de aliviar a tensão e o estresse relacionado com o bruxismo e outros sintomas da DTM.

O estresse foi apontado como um fator etiológico da hiperatividade muscular e, conseqüentemente, dos sinais e sintomas de DTM, comentaram LUNDEEN; STURDEVANT; GEORGE ${ }^{107}$ em1988. 52 pacientes com dores musculares ou articulares foram avaliados psicologicamente, através do Derogatis Stress Profile (DSP). O grupo com dores musculares $(n=24)$ apresentou escores mais altos no teste, relato de dor mais intensa e uma maior inabilidade conseqüente à dor, quando comparado com o grupo de dor articular $(n=28)$. Os autores concluíram que os pacientes acometidos pela DTM sofrem de uma desordem complexa e multidimensional, sendo que, 
apenas o exame ou análise física pode levar a um diagnóstico incorreto e conseqüente tratamento inadequado, e ainda, que quando a dor ocorre apenas na ATM, independente das dores na musculatura mastigatória, a dor articular não é provavelmente o resultado da hiperatividade muscular.

No ano seguinte, 1988, GRZESIAK ${ }^{69}$, na segunda parte de um artigo sobre aspectos psicológicos das dores crônicas orofaciais, concluiu que, de uma maneira geral, os pacientes com DTM se apresentam como sendo rígidos, obsessivos, perfeccionistas, exigentes e inclinados a interiorizar conflitos e ansiedade através de sintomas físicos. Porém um dos maiores problemas em revisão de pesquisa psicológica em pacientes com disfunção é a quase impossibilidade de realização de análises comparativas. Diferentes pesquisadoras fazem perguntas diferentes, focalizam a atenção em diferentes questões psicossociais, utilizam as mais variadas formas de instrumentos de medida e negligenciam ou emitem dados que poderiam ser úteis. Uma possível solução seria que mais Clínicas e Centros Médicos, especializados em dores crônicas orofaciais, adotassem, um ou mais, recentes e bem estruturados testes psicossociais.

MARBACH; LENNON; DOHRENWEND ${ }^{113}$, em 1988, tiveram como proposta, identificar fatores com potencial de risco para o desenvolvimento de síndrome de dor e disfunção temporomandibular. Avaliaram 151 indivíduos do gênero feminino com sintomas de disfunção que apresentavam uma média de nível de escolaridade, idade e estado geral de saúde semelhantes, mas que não estavam naquele momento sob tratamento de dor crônica. Compararam este grupo com 39 mulheres saudáveis, com fatores sócios-demográficos semelhantes. Foram submetidos aos testes psicológicos: Rotter's Locus of Control Scale, Masculinity and Feminity Scales, Behavioral Style Scale, Sensation-Seeking Scale e Needlor Approval Scale. Os resultados mostraram que o grupo de pacientes com dor estavam muito mais estressados que 0 grupo controle. Os pacientes mostraram ter menos suporte emocional para seus problemas que o grupo controle. Apresentaram também uma taxa de natalidade significantemente menor e maiores sintomas pré-menstruais que as mulheres do grupo controle, interpretados pelos autores como possíveis 
comportamentos à dor ou anormalidades biológicas. O grupo de pacientes com dor apresenta significantemente mais queixas de doenças físicas, podendo ser conseqüentes à própria experiência de dor, como distúrbio do sono. As características de personalidade dos pacientes não diferem das do grupo controle.

A habilidade do dentista em detectar problemas psicológicos através de exame foi avaliada por OAKLEY et al. ${ }^{136}$, em 1989. Para tal objetivo, 107 pacientes com DTM foram submetidos, primeiramente a testes psicológicos, e depois submetidos a exames conduzidos pelos dentistas, através do uso de uma escala onde eram solicitados a indicar a presença ou ausência de depressão, ansiedade ou estresse. Os resultados dos testes psicológicos permaneciam desconhecidos para os dentistas. Os autores concluíram que o procedimento do exame baseado nas impressões do profissional em um exame inicial não identifica adequadamente os problemas psicológicos do paciente com DTM.

KATZ et al. ${ }^{87}$, em 1989, realizaram um estudo com o objetivo de avaliar a influência do estresse induzido experimentalmente sobre a atividade eletromiográfica superficial dos músculos temporal e masseter, de respostas autonômicas fisiológicas e temperatura do dedo da mão, em pacientes com disfunções temporomandibulares (DTM). Avaliou 20 mulheres entre 18 e 52 anos, com média de idade de 31,2 anos que apresentavam sinais e sintomas característicos de DTM. Estes indivíduos relacionaram a ocorrência de seus sintomas a períodos de estresse. Foi comparado com um grupo controle, composto por 20 mulheres assintomáticas, entre 20 e 55 anos, com média de idade de 30,1 anos. O estresse induzido compreendia repetição rápida, sobre um teclado, de seqüências numéricas apresentadas com diferentes graus de dificuldade, sendo que as respostas incorretas eram penalizadas com o som de uma forte sirene. Os resultados alcançados demonstraram que as reações fisiológicas foram expressivas em ambos os grupos, provando terem sido manipuladas com sucesso. A eletromiografia do músculo temporal mostrou uma magnitude significantemente maior para o grupo de pacientes. Concluíram que os resultados suportam a hipótese psicofisiológica de que os pacientes 
com desordens temporomandibulares respondem, sob estresse, de forma diferente de indivíduos assintomáticos.

FARKAS; FARKAS ${ }^{44}$, no ano de 1990, comparam 25 pacientes com DTM (grupo 1) com um grupo controle (grupo 2) nos aspectos psicológicos e puderam observar que os pacientes com disfunção apresentaram escores mais altos nas escalas de superdramatização e autocrítica que o grupo controle. $O$ medo de rejeição pode motivar esses pacientes a serem perfeccionistas, de tal maneira que tenham maiores dificuldades em lidar com frustrações e desenvolvendo maiores índices de ansiedade em situações estressantes, bem como serem muito mais autocríticos.

SCHNURR; BROOKE; ROLLMAN ${ }^{162}$, em 1990, tiveram como objetivo avaliar as diferenças psicológicas entre diferentes grupos: a) grupo I, pacientes que: apresentavam dor e disfunção temporomandibular, composto por 202 pessoas subdivididas, de acordo com o diagnóstico diferencial do tipo de disfunção - 42 pacientes com dor miogênica, 69 com desarranjos internos do tipo I (presença de ruídos articulares), 85 com desarranjos internos do tipo II (história de travamento transitório) e seis do tipo III (travamento permanente); b) grupo II, pacientes com dor em conseqüência a traumatismos, composto por 79 indivíduos de uma clínica fisioterápica; c) grupo III, composto por 71 estudantes saudáveis. Responderam a uma série de questionários referentes aos seguintes testes psicológicos: Basic Personality Inventory, Multidimentional Health Locus of Control, Behavior Questionnaire, Perceived Stress Scale e Ways of Coping Scale. Os resultados indicaram um relacionamento significativo entre a intensidade e cronicidade de dor e características de personalidade no grupo II, mas não no grupo de pacientes com disfunção. Os grupos I e II apresentaram, embora sem relevância estatística, uma maior ansiedade e foram mais hipocondríacos que os indivíduos saudáveis. Para outros tipos de personalidade, respostas a doenças, preocupações com o cuidado à saúde, e forma de administrar o estresse, os três grupos não mostraram diferenças relevantes. 
SOUTHWELL; DEARY; GEISSLER ${ }^{170}$, em 1990, tiveram como objetivo neste estudo avaliar se a relação da ansiedade com a síndrome da articulação temporomandibular é de causa ou de efeito. Analisaram 32 pacientes, 24 mulheres e 8 homens, com média de idade de 36 anos que sofriam de disfunção. Compararam com um grupo controle composto de 32 indivíduos, 22 mulheres e 10 homens, com idade média de 36,2 anos, sem sinais e sintomas de disfunção. Foram submetidos aos testes: Eyseneck Personality Questionnaire, Spielberger State-Trait Anxiety Inventory, e Pennybaker Inventory of Limbic Languidness. Os resultados indicaram que os pacientes com disfunção eram significantemente mais introvertidos e tinham níveis de neuroticismo também maiores do que o grupo controle. Os resultados sugerem que os pacientes com disfunção tinham uma personalidade mais vulnerável ao estresse, mas não um estado de ansiedade. Quando subdivididos em gênero, as mulheres do grupo com disfunção apresentaram mais ansiedade do que os homens. Concluem que os pacientes com disfunção parecem ter uma propensão à ansiedade.

FLOR et al. ${ }^{53}$, em 1991, tiveram como proposição avaliar as diferenças do auto-relato de estresse com respostas eletromiográficas em dois subgrupos de pacientes com disfunção: indivíduos com dor e disfunção miofascial sem alterações articulares e indivíduos com sintomas musculares e alterações articulares. Analisaram 10 pacientes com DTM, 12 com dor lombar crônica e 12 indivíduos saudáveis. Foi realizado exame clínico do sistema mastigatório e teste psicofisiológico, que compreendia a eletromiografia dos músculos masseter e bíceps em condições neutras e sob pensamento em fatores individualmente estressantes. Foram submetidos aos seguintes testes psicológicos: State-Trait Anxiely Inventory e Multidimentional Pain Inventory e Daily Hassles Scale. Os resultados demonstraram que o grupo de pacientes com disfunção apresentou significantemente mais atividade eletromiográfica no músculo masseter do que os outros dois grupos. Os indivíduos com síndrome de dor e disfunção miofascial indicaram maior presença de estresse.

MCCREARY et al. ${ }^{115}$, em 1991, tiveram como proposição avaliar a natureza e extensão de possíveis diferenças psicológicas entre subgrupos de 
pacientes com diferentes diagnósticos de Desordens Temporomandibulares. Examinaram e classificaram 112 pacientes consecutivos da clínica de dor facial de Universidade de Los Angeles. A idade destes indivíduos era de 39 anos e $86 \%$ do sexo feminino. Os subgrupos foram divididos de acordo com o tipo de disfunção apresentada: a) pacientes com mialgia; b) pacientes com problema articular (principalmente) e c) combinação de sintomas muscular e articular. A intensidade de dor e as características psicológicas foram avaliadas por intermédio dos seguintes testes: McGill Pain Questionnaire, Beck Depression Inventory, State-Trait Anxiety Inventory e Minnesota Multiphasic Personality Inventory. Os pacientes com mialgia foram os que apresentaram os maiores índices de intensidade de dor e de níveis de estresse, seguidos pelo grupo de sintomas combinados. Altos graus de depressão e ansiedade, entretanto, não foram associados com níveis altos de dor.

SCHNURR; ROOLMAN; BROOKE ${ }^{163}$, em 1991, tiveram como proposição explorar o relacionamento entre diversos fatores psicológicos com o resultado de tratamento de pacientes que apresentavam dor e disfunção temporomandibular, com a finalidade de poder estabelecer uma possível previsibilidade dos resultados. Avaliaram 178 pacientes do centro de dor facial de Universidade de Toronto, Canadá, com idade média de 27,4 anos, sendo $86,5 \%$ pessoas do gênero feminino. Esta amostra foi subdividida de acordo com o diagnóstico diferencial dos casos clínico em: 39 casos com dor miogênica, 58 com desarranjos internos do tipo I (presença de ruídos articulares), 75 com desarranjos internos do tipo II (travamento transitório), e seis do tipo IU (travamento permanente). Responderam a uma série de questionários referentes aos seguintes testes psicológicos: Basie Personality Inventory, Multidimentional Health Locus of Control, Illness Behavior Questionnaire, Pereeived Stress Seale e Ways of Coping Seale. Foram tratados de forma conservadora por intermédio de exercícios musculares e ultra-som. Foram reavaliados após cinco meses. Os resultados indicaram que os pacientes que apresentaram uma melhora de mais do que $50 \%$ no sintoma dor mostraram-se mais hábeis em se distanciar dos seus problemas. Apenas $12,2 \%$ relataram melhora da disfunção enquanto $43 \%$ relataram melhora da dor. Os resultados não permitem predizer o sucesso dos tratamentos. 
WRIGHT; DEARY; GEISSLER ${ }^{192}$, em 1991, tiveram como objetivo neste trabalho, testar a teoria que o estresse induz à hiperatividade muscular. Avaliaram o nível de estresse em pacientes com síndrome da disfunção mandibular. Avaliaram 37 pacientes com disfunção, sendo 27 mulheres e dez homens com média de 35,4 anos de idade. Selecionaram, como controle, um grupo de 30 indivíduos sem disfunção, 21 mulheres e 9 homens, com idade média de 37,7 anos. Todos foram analisados por intermédio do Hassels Scale, que mede episódios agudos e discretos de estresse e Beck Depression Inventory, para avaliar queixas somáticas de depressão e também pelo Symptom Checklist, que avalia a somatização de desordens psicológicas. Alcançaram, como resultado, um nível de intensidade de depressão maior nos pacientes com disfunção do que no grupo controle. Não houve diferença entre os grupos quanto ao nível de estresse, mas o grupo de pacientes relatou mais somatização.

MARBACH $^{112}$, em 1992, teve como proposta examinar a evidência de que certas características de personalidade podem ser fator de risco importante na etiologia da síndrome dor e disfunção temporomandibular. Relembra que são três as teorias que relacionam o efeito de personalidade psicológica com disfunção: a) psicossomática, considera que certos conflitos pessoais não resolvidos contribuem às modificações patofisiológicas b) a habilidade pessoal em lidar com os problemas, que considera que o indivíduo promove modificações cognitivas e comportamentais para se adaptar a demandas externas e psíquicas; c) teorias psicofisiológicas, em que os fatores de personalidade podem influenciar variáveis biológicas, por exemplo, levando o músculo a um estado de hiperatividade (com aumento do bruxismo) ou a uma modificação imunológica, na presença de episódios de depressão. O autor estudou 151 mulheres, pacientes com disfunção e outras 139, como grupo controle, com média de idade semelhante. Todos foram submetidos a diversos testes psicológicos, específicos para avaliar cada uma das teorias: Rotter's Lócus Control Scale, Masculinity and Feminity Scales, Behavioral Style Scale, Sensation-Seeking Scale e Need for Approval Scale. Os dois grupos não diferiram quanto às características de personalidade, não suportando, portanto, 
a teoria psicossomática. Os dois grupos também mostraram habilidades semelhantes em lidar com seus problemas. Ambos os grupos relataram consciência semelhante quanto à presença de bruxismo. Os dois grupos não apresentaram diferenças nas mensurações realizadas do sistema imunológico. Conclui, por estes resultados, que não há evidências de que pacientes com disfunção tenham uma personalidade específica.

Sendo uma psicóloga estudiosa da área das DTMs, SEGER ${ }^{165}$, em 1992, chamou atenção para a necessidade de se estudar com muita atenção o relato dos pacientes com o objetivo de avaliar em que grau a ansiedade, o estresse e conflitos emocionais interferem na disfunção. Deve-se avaliar de que forma o paciente se relaciona com a sua realidade, quais suas percepções sobre esta, qual sua capacidade de suportar frustrações, se há autocontrole e como ele sente e percebe sua doença. Às vezes, o individuo adota determinados padrões de comportamento, pois não se sente em condições de enxergar a realidade de modo diferente do que ele vem fazendo: não se pode esquecer que, freqüentemente, o psicólogo é visto como alguém que poderá desvendar suas defesas e, portanto, é, muitas vezes, temido e até rejeitado. $\mathrm{O}$ psicólogo deve ter em mente a existência de um dano físico, independente dos problemas emocionais e, portanto, o tratamento deve ser integrado com o cirurgião-dentista. Este, por sua vez, deve lembrar que por trás do dano físico, pode haver um problema emocional interferindo e agravando a disfunção, o que caracterizaria a intervenção ou abordagem integrada.

Ainda considerando o papel do estresse e outros fatores psicológicos na etiologia das DTMs, CAREY ${ }^{16}$, no mesmo ano, afirmou que tanto na experiência do estresse como seus efeitos e conseqüências são muito individuais e variáveis, de tal forma que alguns se tornam mais produtivos em sua presença, enquanto outros podem até mesmo desenvolver doenças psicossomáticas e distúrbios emocionais, dentre os quais a DTM. O estresse emocional parece gerar hiperatividade muscular e uma necessidade de hábitos parafuncionais como uma válvula de escape, de tal maneira que, ele sozinho, poderia causar toda a sintomatologia da disfunção, independentemente do tipo 
de oclusão do paciente. Freqüentemente o paciente exibe uma relação direta entre ciclos de dor e períodos de alta ansiedade ou estresse emocional.

CARLSON et al. ${ }^{17}$, em 1993, estudaram as diferenças psicológicas e fisiológicas entre dois grupos de indivíduos: 34 pacientes com dor nos músculos da mastigação, atendidos no centro de dor orofacial da Universidade de Kentucky, sendo 32 mulheres e 2 homens, com idade média de 34,1 anos e um grupo controle de 18 indivíduos, constando de 17 mulheres e 1 homem com média de idade equivalente ao grupo estudado. Todos os indivíduos foram analisados pelos seguintes testes psicológicos: State-Trait Anxiety Inventory, que avalia grau de ansiedade, Cognitive-Somatie Anxiety Questionnaire, que avalia as respostas conseqüentes à ansiedade, Health Loeus of Control Seale, que mensura a preocupação do paciente com relação à saúde, Tension Manequin, para auto-avaliação da tensão muscular, e o teste Emotion Assesment Seale, para auto-avaliação das emoções. Os participantes foram avaliados quanto a mensurações fisiológicas: eletromiografia do músculo masseter, freqüência cardíaca e pressão sangüínea. Os testes foram realizados em repouso, com o paciente sob estresse mental (cálculos aritméticos mentais) e sob relaxamento. Os resultados obtidos revelaram que, sob estresse, os pacientes tiveram uma freqüência cardíaca e uma pressão sistólica maiores do que o grupo controle. O grupo de pacientes também apresentou maior ansiedade, mais sintomas cognitivos e maior sensação de tensão muscular. A eletromiografia não apresentou diferenças entre os grupos.

RUGH; WOODS; DAHLSTROM ${ }^{158}$, em 1993, em uma revisão da literatura, afirmam que a ansiedade tem sido proposta como um fator etiológico das DTMs, através de hábitos parafuncionais e tensão muscular; mas, na verdade, em alguns casos, a ansiedade pode ser um fator etiológico, em outros casos pode ser conseqüente à DTM finalmente; às vezes, apenas coincidir ou existir, independente da disfunção e não haver uma relação entre eles.

Ainda no ano de 1993, NIEMI; BELL; MOFFETT ${ }^{132}$ compararam 52 pacientes com DTM e 72 indivíduos como grupo controle através do inventário auto-afirmativo Symptoms of Stress (SOS), que é utilizado para medir o estresse nos níveis somático e emocional. O nível médio de estresse na 
população com DTM foi mais alto do que no grupo controle, principalmente na escala somática, sendo a tensão muscular o fator mais característico; entretanto, diferenças estatisticamente significantes não foram observadas entre os sintomas emocionais tais como ansiedade, depressão ou desorganização cognitiva.

OAKLEY et al. ${ }^{137}$, em 1993, tiveram como objetivo determinar se pacientes com desordens temporomandibulares tinham problemas psicológicos e, em caso afirmativo, testar se um questionário, elaborado com poucos quesitos e de aplicação simples e rápida, pudesse proporcionar confiabilidade em comparação com os resultados de outros testes obtidos previamente. Avaliaram 116 pacientes, $85 \%$ mulheres e $25 \%$ homens, com idade média de 37,42 anos, em tratamento na clínica de dor facial da Universidade de Los Angeles. Todos foram submetidos aos seguintes testes psicológicos: Beck Depression Inventory, Schedule of Recent Experience e State-Strait Anxiety Invenfory Também responderam a um questionário de autoavaliação quanto à presença de ansiedade e depressão. O questionário estudado pode ser útil para delinear dificuldades psicológicas em pacientes com desordens temporomandibulares. Sugerem que os casos em que os resultados sejam positivos, um diagnóstico mais completo deva ser realizado, visto serem mais demorados e muito mais onerosos.

PARKER; HOLMES; TEREZHALMY ${ }^{145}$, em 1993, avaliaram 110 pacientes portadores de dor orofacial em decorrência de desordens temporomandibulares, presente por mais de 3 meses por intermédio do Minnesota Multiphasic Personality Inventory Os pacientes estavam distribuídos em 30 homens e 80 mulheres, com idade variando entre 18 a 73 anos. Foram submetidos a um exame clínico por um dentista e a um teste psicológico aplicado por um psiquiatra. Os resultados do teste permitiram subdividir os pacientes em quatro subgrupos: a) $24 \%$ perfil normal b) $52 \%$ com reações psicofisiológicas c) depressão em $11 \%$ e d) reações defensivas em $13 \%$. Os autores concluíram, por este trabalho, que é difícil suportar a teoria de que há uma predisposição psicológica para desenvolver desordens 
temporomandibulares, uma vez que os pacientes que foram avaliados já tinham desenvolvido disfunção.

FIGUEIRÓ; TEIXEIRA ${ }^{49}$, em 1994, estudando os aspectos psicossociais relacionados a dor, afirmaram que o comportamento do doente com dor crônica pode ser influenciado por fatores ambientais. A dor gera padrões de comportamento sensíveis às recompensas, que são modulados pelo ambiente e passiveis de aprendizado. Esses comportamentos aprendidos mantêm-se ou extinguem-se, de acordo com as reações do contexto nos quais eles ocorrem. Assim, quando o ambiente reforça positivamente um comportamento doloroso este tende a persistir e existir mesmo na ausência dos estímulos nociceptivos. Reforços diretos (cuidados médicos, repouso, medicações, maior atenção do cônjuge ou familiares) ou indiretos (evitar situações desagradáveis ou obrigações penosas) podem contribuir para a manutenção da dor, amplificação da percepção dolorosa, incapacidades funcionais e sofrimento psíquico. Não há duvida de que aspectos familiares, sociais e culturais podem participar dessa modificação da expressão das sensações e sentimentos, induzindo os doentes a rotular seu sofrimento psicológico como dor. Deste modo, é fundamental, nos pacientes com dor crônica, ir além do visível e do imediatamente audível e buscar o entendimento de uma linguagem corporal que não pode ganhar representação no campo psíquico, estando, portanto, incapacitada de se manifestar como emoções e palavras. À medida que avança o conhecimento a respeito dos pacientes com dor crônica, fica mais evidente a complexidade deste problema e mais freqüentemente, se recomenda uma avaliação mais compreensiva através de tratamentos múltiplos e integrados, incluindo abordagem dos aspectos psicossociais, ambientais e culturais envolvidos na gênese e perpetuação das algias crônicas.

Fatores emocionais, como a ansiedade e depressão, também podem influenciar a resposta do paciente à dor, de acordo com OAKLEY et al. $^{135}$, em 1994, que aplicaram tratamento comportamental-cognitivo em 56 pacientes com DTM, sendo a grande maioria do gênero feminino (85\%), que não haviam obtido sucesso como tratamento convencional odontológico e 
fisioterápico. O exame clínico foi realizado antes e após o término do tratamento, e se baseou em medidas subjetivas de dor, estresse emocional, grau de abertura bucal, dor à apalpação na ATM. Após um tratamento de 5 semanas, que incluiu técnicas de relaxamento muscular, automonitoramento de estressores e estratégias de comportamento frente ao estresse, puderam observar que o tratamento teve as melhores respostas quanto à diminuição da ansiedade e percepção à dor.

PIERCE et al. ${ }^{147}$, em 1995, examinaram 1) os relacionamentos entre atividade eletromiográfica de bruxismo do sono (BS), auto-relato de estresse e variáveis de personalidade e 2) o relacionamento entre a crença no relacionamento estresse-bruxismo e o auto-relato de estresse. Cem adultos completaram uma bateria de questionários de personalidade (instrumentos psicométricos padronizados: 1) Taylor Manifest Anxiety Scale e Profile of Mood State, 2) Pilowsky Depression Scale e Profile of Mood State; 3) IIIness Behavior Questionnaire e 4) Multidimensional Health Lócus of Control Scales. Também indicaram se acreditavam no relacionamento estresse-bruxismo, foram submetidos a um exame odontológico e moldagens das arcadas dentárias. Subsequentemente, foram realizadas medições eletromiográficas (EMG) da freqüência e duração do BS durante 15 noites consecutivas. Previamente ao registro de cada noite, os indivíduos indicavam seu nível de estresse durante as 24 horas precedentes em uma escala de Likert de 1 a 5, onde 1 indicava nenhum estresse e 5 representava o maior nível de estresse possível. Os autores não encontraram nenhum relacionamento entre as medições EMG e as variáveis de personalidade, nem entre as medições EMG e o auto-relato de estresse. Houve correlação estatisticamente significativa entre as medições EMG e o auto-relato de estresse para oito indivíduos. Ainda, indivíduos com maiores níveis de estresse, relataram maior ansiedade, irritabilidade e depressão e menor comportamento de negação. Indivíduos que relataram acreditar no relacionamento estresse-bruxismo relataram maior estresse. Apesar disso houve relacionamento significativo entre diversas variáveis de personalidade e auto-relato de estresse. Ou seja, indivíduos com relato de autos níveis de estresse eram mais prováveis de relatar altos níveis de 
ansiedade, irritabilidade e depressão, enquanto aqueles que relatavam menores níveis de estresse eram mais prováveis de relatar altos índices de negação.

Em 1996, GATCHEL et al. ${ }^{60}$ compararam psicologicamente 50 pacientes com DTM crônica e 51 pacientes com DTM aguda. Puderam observar que pacientes com DTM crônica apresentaram uma maior porcentagem de desordens afetivas, como depressão - (78\%), quando comparados com pacientes com DTM aguda - (45\%), e com população em geral - (5 a 26\%). Já os pacientes com DTM aguda apresentaram uma maior porcentagem de distúrbios de ansiedade - $(52,9 \%)$, quando comparados ao grupo com DTM crônica - (24\%) e população em geral - (1 a 25\%).

No mesmo ano, FRICTON; OLSEN ${ }^{56}$, afirmaram que os fatores psicossociais são, com freqüência, responsáveis pela recidiva dos pacientes já submetidos a algum tipo de tratamento. Nesse trabalho, os autores avaliaram 94 pacientes com DTM, antes e depois do tratamento realizado, com o propósito de verificar quais fatores estariam mais relacionados com o sucesso da terapia. Puderam observar que os sentimentos de baixa auto-estima, ansiedade e preocupação, depressão e qualidade de sono foram os mais indicativos do sucesso ou não do tratamento, mostrando a necessidade da avaliação dos fatores psicológicos relacionados à ansiedade e depressão, de tal forma que terapias centradas apenas nos aspectos físicos seriam inadequados.

CURRAN; CARLSON; OKESON ${ }^{31}$, em 1996, exploraram os fatores psicológicos e fisiológicos (temperatura da pele, atividade EMG, freqüência cardíaca e pressão sanguínea e freqüência respiratória) que poderiam diferenciar pacientes com DTM miogênica $(n=23)$ de indivíduos controle assintomáticos correspondentes em sexo, idade e peso. Cada indivíduo respondeu a vários questionários psicológicos padronizados e, em seguida, submeteram-se a dois testes laboratoriais de estresse (aritmética mental e estímulo pressão-dor). Os pacientes com DTM apresentaram maiores taxas de 
respiração em repouso e relataram maior ansiedade, tristeza e culpa em relação ao grupo controle. Em resposta ao fator estressante aritmética, pacientes com DTM reagiram com maiores níveis de raiva do que o grupo controle. Não houve diferenças entre os grupos quanto às medidas de dor ou qualquer outra variável medida para o teste de estímulo pressão-dor (no dedo médio da mão não dominante). Não houve diferença entre os grupos nos níveis eletromiográficos dos músculos masseteres e temporais em repouso. Os autores consideraram que a ansiedade tem sido um fator que, consistentemente, diferencia pacientes de dor facial crônica de indivíduos assintomáticos. Sugerem que a verificação do status psicológico do paciente deve ser realizada na avaliação inicial de pacientes com dor facial crônica. Relatam que a reatividade emocional aumentada a fatores estressantes do ambiente pode contribuir para os maiores níveis de estresse, ansiedade e depressão frequentemente encontrados em pacientes de dor facial. Com relação à maior freqüência respiratória em repouso dos pacientes em relação ao grupo controle, os autores discutem que, o aumento crônico da freqüência respiratória pode levar a alterações no $\mathrm{pH}$ sangüíneo, o que está associado com o aumento da excitabilidade neuronal, menor fluxo sangüíneo periférico e hiper-irritabilidade. Os autores atribuem a ausência de diferenças no limiar de dor entre os grupos ao estímulo experimental empregado, bem como ao sitio anatômico, os quais diferiram de outros estudos.

KROGSTAD et al. ${ }^{91}$, em 1996, tiveram como objetivo avaliar as possíveis diferenças entre gêneros referentes ao relato de dor, queixas somáticas e ansiedade, numa amostra de pacientes com desordens temporomandibulares, antes e após dois anos de tratamento. O grupo consistiu de 53 pacientes, 40 mulheres e 13 homens, com idade média de 38 anos referidos ao departamento de fisiologia estomatognática da Universidade de Oslo, Noruega. Todos foram examinados clinicamente e responderam aos questionários: versão norueguesa do McGill Pain Questionnaire (avalia qualitativamente a dor), Present Pain Intensity (avalia quantitativamente a dor), Somatic Complaints Questionnaire (avalia somatização) e o Spielberger StateTrait Anxiety Inventory (avalia ansiedade). Todos os pacientes sofreram 
tratamento conservador de aconselhamento, exercícios de relaxamento e placa oclusal. Após 2 anos, os pacientes responderam novamente aos questionários. Os dados obtidos foram comparados com os de um grupo controle de 35 indivíduos sem sintomas, tratados no departamento de prótese da mesma Universidade. Os resultados mostram que o grupo controle apresentava índices psicológicos significativamente menores do que os dos pacientes. Não houve diferença em gênero, nos 2 anos de controle, quanto à dor relacionada à emoção e à dor sensorial. Após 2 anos, as mulheres relataram diminuição da intensidade de dor. $O$ índice de ansiedade foi praticamente idêntico nos dois grupos. O grupo de pacientes foi caracterizado como levemente estressados em relação ao grupo controle. O tratamento da desordem temporomandibular não afetou a ansiedade de ambos os grupos. Este não foi um achado surpreendente, sendo que o traço de ansiedade é relativamente estável nos adultos e desde que outra modalidade de tratamento, como a terapia comportamental-cognitiva, não foi empregada neste estudo.

Ainda em 1996, CONTI et al. ${ }^{29}$ tiveram como objetivo investigar a prevalência de sinais e sintomas de DTM, sua relação quanto ao gênero e associações aos fatores oclusais e psicológicos, em um grupo de 310 estudantes, residentes em Bauru, São Paulo. A amostra foi composta de $51,61 \%$ de mulheres e 49,39\% de homens, com idade média de 19,79 anos. Os indivíduos foram subdivididos em dois grupos: a) grupo I - 152 estudantes de segundo grau com idade média de 18,47 anos; b) grupo II - universitários com idade média de 21,05 anos. Utilizaram um questionário previamente testado que qualificava os sintomas em graus diferentes de gravidade. Fizeram exame de palpação muscular mastigatória e de pescoço, e analisaram os seguintes fatores oclusais: relação cêntrica, oclusão cêntrica, presença de sobremordida e trespasse horizontal, movimentos excêntricos, e contatos de lado de balanceio. As avaliações do grupo I foram realizadas durante testes escolares pré-vestibulares. O resultado do questionário anamnésico mostrou que $58,71 \%$ dos indivíduos eram assintomáticos, $34,84 \%$ com sinais e sintomas leves, $5,81 \%$ moderados e $0,65 \%$ graves. As mulheres apresentaram significantemente mais sintomas que os homens e com maior gravidade. Aqueles que se consideravam tensos apresentaram significantemente mais 
sintomas e com maior gravidade. A oclusão pareceu não influenciar a presença, nem a gravidade das DTMs.

KUTTILA et al. ${ }^{92}$, em 1997, baseados em observações clínicas das características de flutuação e efemeridade de sinais e sintomas Desordens Temporomandibulares, isto é, do desaparecimento espontâneo e seu reaparecimento, tentaram relacionar, neste estudo, a associação entre sinais e sintomas das desordens temporomandibulares com as seguintes variáveis: idade, gênero, estresse em relação a subgrupos diagnósticos recomendados pela Academia Americana de Dor Orofacial: miogênico, artrogênico, combinado e não classificados. Examinaram um total de 391 indivíduos subdivididos de acordo com a idade de 25, 35, 45, 55 e 65 anos, num controle anual de 2 anos, sem tratamento. A avaliação de sintomas de estresse foi realizada por intermédio do Symptoms of Stress Inventory derivado do Cornel Medical Index e subclassificados em periféricos, cardiopulmorares, neurológico, gastrointestinal, depressão, ansiedade, raiva e desorganização cognitiva. Os resultados demonstram que os indivíduos da faixa dos 35 anos foram os que mais apresentaram sintomas. Pacientes com necessidade ativa de tratamento tinham índices de estresse maiores do que os outros grupos. Os subgrupos diagnósticos foram, no exame inicial, significantemente associado à flutuação da necessidade de tratamento, mas não à idade, gênero e nível de estresse. Nos controles anuais, entretanto, não mostraram associação com os resultados preliminares nem com as variáveis estudadas.

RUF et al. ${ }^{156}$, em 1997, considerando que o estresse experimental não é idêntico ao ambiental, embora as respostas fisiológicas sejam similares, avaliaram o resultado do efeito de situações de estresse emocional não experimental sobre a atividade eletromiográfica dos músculos mastigatórios de 15 estudantes de Odontologia da Universidade de Giessen, Alemanha. Estes fatores foram relacionados com a sensação subjetiva de desamparo. A idade média da amostra foi de 23 anos. Nenhum dos participantes mostrou sinais ou sintomas de disfunção. Os músculos masseter e temporal anterior foram avaliados eletromiograficamente durante a mastigação e apertamento dentário, em uma situação de normalidade e, em outra, sob estresse. A situação de 
estresse foi idêntica para todos os participantes, durante um exame escolar de máxima importância para suas aprovações. O grau de sentimento de desamparo foi avaliado por intermédio do Helplessness Scale, composto de um questionário. Os autores encontraram como resultado, um aumento significativo da atividade eletromiográfica em todos os músculos e em todas as funções executadas. Houve uma associação de moderada à alta entre a função muscular eletromiográfica e o sentimento de desamparo. As mulheres demonstraram valores mais altos do que os homens.

SUVINEN et al. ${ }^{176}$, em 1997, classificam desordens temporomandibulares, baseados em fatores de interação físicos, psicológicos e sociais em 140 pacientes com média de idade de 39,2 anos de idade, todos com diagnóstico confirmado de desordens temporomandibulares por mais de seis meses. As propriedades psicométricas foram avaliadas por intermédio do Coping Strategies Questionnaire, Illness Behavior Questionnaire e o Hospital Anxiety and Depression Scale. Os pacientes com desordens temporomandibulares puderam ser subdivididos em três diferentes grupos: os altamente estressados sendo psicossocialmente mal-adaptados $31 \%$ (maladaptados), comportamentalmente funcionais mostrando-se moderadamente estressados 35\% (adaptados) e um grupo de pacientes com um perfil psicossocial normal 34\% (sem complicações). Os grupos não mostraram diferenças na freqüência de dor, uso de medicamentos ou duração da dor; entretanto, foram estatisticamente diferentes quanto aos fatores psicossociais. Os classificados como mal-adaptados mostraram menor poder de concentração, maior dificuldade em lidar com problemas do dia a dia, hipocondria, ansiedade e relataram maior gravidade dos sintomas. Os pacientes classificados como adaptados mostraram maior capacidade na resolução dos problemas diários, menor nível de estresse psicológico e eram menos hipocondríacos. Nenhum grupo mostrou predominância no uso de medicamentos.

CIMINO et al. $^{23}$, em 1998, tiveram como proposição investigar sintomas comuns e características diferentes entre fibromialgia (FM) e dor miofascial (DMF) da musculatura mastigatória em pacientes afetados por 
Desordens Temporomandibulares. Suas amostras eram compostas de 23 mulheres com disfunção e 23 com fibromialgia. Todos os pacientes foram submetidos a exame clínico por um dentista e por um reumatologista. Utilizaram o Middlesex Hospital Questionnaire para obter o perfil de personalidade destes pacientes. A média de idade destes pacientes foi de 34 anos e eram originários da Universidade Frederico II, em Nápoles, Itália. Os pacientes responderam a um questionário indagando sobre sintomas subjetivos de disfunção e tiveram seus músculos e articulações examinadas clinicamente. Utilizaram como critério diagnóstico de dor miofascial: a) dor na musculatura por mais de três meses; b) aumento da dor muscular sob função e palpação; c) presença de pontos de gatilho; d) presença de dor referida; e) sem dor articular; f) abertura de boca menor que $35 \mathrm{~mm}$. Critério diagnóstico de fibromialgia: a) história de dor muscular generalizada por mais de três meses; b) dor à palpação em pelo menos 11 pontos de um total de 18; c) testes laboratoriais de sangue normais; d) ausência de outras desordens reumatológicas. O teste psicológico utilizado avaliava as seguintes atitudes comportamentais: ansiedade, fobia, obsessão, somatização e histeria. Os resultados mostraram, com significância estatística, que dor no corpo estava presente em todos os pacientes com fibromialgia e, em apenas $27 \%$ dos com dor miofascial. Episódios de forte estresse coincidiam com o desencadeamento da dor em indivíduos com DMF em 50\%, enquanto em apenas $13 \%$ daqueles com FM. Não houve diferença do nível de estresse psicológico entre os dois grupos, embora fossem bem maiores do que quando comparados com populações normais.

CARLSON et al. ${ }^{18}$, ainda em 1998, identificaram, em seu estudo, variáveis psicológicas e fisiológicas que diferenciam pacientes com dor nos músculos da mastigação de indivíduos assintomáticos. Para esse propósito, foram selecionados 35 pacientes com dor facial (média de 30,17 anos), sendo que, 33 eram mulheres. Para o grupo controle, 35 indivíduos foram selecionados (média de 30,14 anos) com a mesma proporção homem/mulher. Toda a amostra completou uma série de questionários padronizados anteriormente a uma avaliação laboratorial da quantificação do estresse e de estimulação através de pressão em determinados pontos do corpo (masseter, 
temporal e dedo médio). Durante a avaliação, a condição emocional e fisiológica dos indivíduos (pressão arterial, respiração, temperatura da pele, atividade muscular) foi monitorada. Os resultados mostraram que pessoas com dor muscular reportaram maior fadiga, distúrbios do sono, depressão, ansiedade, sintomas menstruais e menor auto-estima, em comparação com os indivíduos controle. Além disso, estes pacientes com dor muscular apresentaram menor LDP que o grupo controle no masseter direito e esquerdo e no temporal direito. Não houve diferença estatisticamente significativa do LDP do músculo temporal esquerdo entre os dois grupos.

Em 2000, MICHELOTTI et al. ${ }^{125}$ investigaram o quanto que uma condição estressante pode induzir mudanças nos LDPs dos músculos da mastigação em um grupo de indivíduos assintomáticos. Foram selecionados 16 indivíduos sem sinais e sintomas de DTM, sendo 9 homens e 7 mulheres, com idade média de 22 anos, estudantes de graduação da Faculdade de Odontologia da Universidade de Nápoles e prestes a fazer um exame muito importante. Foram selecionados 16 indivíduos, também livres de DTM (9 homens e 7 mulheres), com idade média de 26 anos, estudantes de pósgraduação também daquela instituição e que não seriam submetidos a nenhum tipo de teste, para fazer parte do grupo controle. Os dois grupos foram monitorados paralelamente em 5 tempos de estudo diferentes durante 0 período de 1 mês: 2 dias antes do exame (T1), no dia do exame (T2), 2 dias depois do exame (T3), 1 mês depois do exame (T4), e depois de passados 2 dias de T4 (T5). No dia do exame (T2), o grupo controle foi solicitado a preencher um questionário. Em cada dia, foram realizados os seguintes procedimentos: LDP do masseter, do temporal anterior e do tendão de Aquiles; estado de ansiedade através do IDATE; medição do estresse através de uma escala de análise visual (EAV). Além disso, no grupo que iria fazer o exame, amostras de sangue foram colhidas para a análise dos níveis de betaendorfinas em T2 e T5. Nos estudantes estressados, os LDPs dos músculos e do tendão de Aquiles foram significativamente menores no dia do exame (T2) e nos dias próximos ao exame (T1 e T3), assim como os níveis de ansiedade e de estresse. Não foram encontradas diferenças significativas nos níveis de beta-endorfina. No grupo controle, os LDPs, a ansiedade e o estresse não 
variaram significativamente. Os autores concluíram que esses resultados sustentam a relação entre estresse psicológico e sensibilidade à pressão nos músculos mastigatórios.

BADER; LAVIGNE ${ }^{5}$, em 2000, lembram que devido à freqüente inconsciência do hábito de bruxismo do sono (BS), a prevalência do mesmo é difícil de ser estimada. Relatam que sua prevalência não difere entre os sexos e que é mais freqüente entre os jovens e tende a reduzir com a idade. Os sintomas reconhecidos na infância podem persistir na idade adulta. Sobre sua etiopatogenia, lembram que o BS pode estar associado a interferências oclusais, fatores psicológicos e ambientais, neurotransmissores e disfunção dos gânglios basais. Relatam que o BS pode estar associado a traços de personalidade, como ansiedade ou vulnerabilidade ao estresse, embora esse assunto seja ainda controverso.

Em 2002, LINDROTH; SCHMIDT; CARLSON ${ }^{97}$ compararam, em um estudo, pacientes com dores musculares mastigatórias e pacientes com manifestações dolorosas intracapsulares e seus comportamentos psicossociais. Tiveram como objetivo identificar diferenças entre os dois grupos de DTM e a influência das alterações emocionais em ambas as patologias. $O$ estudo contou com a participação de 435 pacientes com dor muscular mastigatória e 139 pacientes com dor intracapsular. A média de idade foi de 36,1 anos e $88,2 \%$ dos indivíduos eram do gênero feminino. A avaliação dos fatores emocionais foi realizada através do Inventário Multidimensional SCL-90 o qual questiona 90 itens referentes a depressão, ansiedade, comportamento obsessivo compulsivo, fobias e paranóia. O inventário classifica o estresse em uma escala de $0-4$. Além deste, utilizaram o Índice de Qualidade do Sono de Pitesburgo (PSQI) para qualificar e quantificar o sono dos pacientes; Inventário Multidimensional de Dor (MPI) para determinar a severidade da dor; Índice de Estresse Pós-Traumático (PCL) para mensurar sintomas de estresse e ainda, o Questionário de Atividades de Baecke (BAQ) que determinou os níveis de atividade física tanto no trabalho quanto nas ocasiões de lazer dos indivíduos. Para a avaliação da dor orofacial foi utilizado o Questionário de Dor de McGill 
(MPQ). Os resultados apresentaram uma diferença significativa em relação à severidade e duração da dor entre os dois grupos. O grupo de disfunção miogênica demonstrou maiores níveis de dor que o grupo de disfunção articular. Este último apresentou capacidade adaptativa 2 vezes maior. Por outro lado, o grupo de pacientes com dor intracapsular teve menos sintomas psicológicos, melhor qualidade de sono e menores índices estressores de vida que o grupo muscular. Assim, os autores concluem que os pacientes acometidos por DTM miogênica crônica demonstram comportamento mais propenso ao desenvolvimento de patologia quando comparados ao grupo de DTM articular. Além disso, apresentaram maiores níveis de estresse.

Em estudo bastante semelhante ao anterior, neste mesmo ano de 2002, YATANI et al. ${ }^{193}$ compararam a qualidade do sono e as características psicológicas em um grupo de pacientes com DTM. Participaram da pesquisa 137 pacientes, que buscavam tratamento no Centro de Dor Orofacial da Universidade de Kentucky. Inicialmente, em uma primeira avaliação, todos os indivíduos responderam aos seguintes questionários: Inventário Multidimensional SCL-90; Índice de Qualidade do Sono de Pitesburgo (PSQI) e o Inventário Multidimensional de Dor (MPI). A partir disso, foram divididos em 2 grupos segundo a qualidade do sono: 67 pacientes com má qualidade de sono e 70 com boa qualidade de sono. Os resultados não apresentaram diferenças significativas de gênero e idade entre os grupos. Não houve diferenças quanto à distribuição de gênero e idade entre os grupos. O grupo com sono de má qualidade relatou escores mais altos que o grupo de sono de boa qualidade em todas as 14 escalas do SCL-90R e em 7 das 13 escalas do MPI. A análise de regressão logística demonstrou que o sono de má qualidade poderia ser previsto por maior severidade da dor, maior estresse psicológico e menor percepção de controle. Sugerem futuros estudos para compreensão mais clara dos mecanismos envolvidos nestes fenômenos. Além disso, recomendam especial atenção no tratamento destes pacientes e dedicação a ambos os fatores.

$\mathrm{ELI}^{41}$, em 2003, chama atenção para os fatores psicossociais que participam da etiologia, diagnóstico e tratamento das disfunções. Segundo a 
autora, a dor (crônica e aguda) é uma experiência complexa e de natureza multidisciplinar, subjetiva e quase sempre associada a fatores emocionais, cognitivos e estados psicológicos. Entre estas condições emocionais, considera a ansiedade e o estresse de suma importância nos mecanismos de desencadeamento dos processos dolorosos.

Como já descrito no decorrer desta revisão, os instrumentos utilizados para avaliação do estresse e ansiedade são bastante variados. Neste estudo, a classificação da ansiedade ocorreu através do Inventário de Ansiedade de Beck (BAI) e o estresse foi avaliado através do Inventário de Sintomas de Estresse para adultos (ISSL). Este último foi validado em 1994 por LIPP $^{99}$ e tem sido utilizado pesquisas e trabalhos clínicos na área do estresse ${ }^{13}$, 14,75

Ainda em 2003, CALAIS; ANDRADE; LIPP ${ }^{13}$ pesquisaram sintomas de estresse em adultos jovens, relacionando-os com o gênero e ano escolar em curso. Investigaram também o tipo e a freqüência dos sintomas. Participaram do estudo 295 estudantes de 15 a 28 anos, sendo 150 mulheres e 145 homens, que cursavam o primeiro e terceiro anos do ensino médio da cidade de Campinas, curso pré-vestibular e primeiro e quarto anos de ensino superior da cidade de Bauru. Os participantes foram divididos em 5 grupos de cerca de 60 sujeitos, metade de cada gênero e por grau de escolaridade. A avaliação do estresse foi realizada através do ISSL aplicada na própria instituição de Ensino. Os resultados acusaram correlação significativa entre gênero e nível de estresse $(p<0,0001)$ sendo que as mulheres apresentaram maior nível de estresse em todos os grupos avaliados. Além disso, maior índice de estresse surgiu em estudantes do curso pré-vestibular, seguidos do terceiro ano do ensino médio. A sintomatologia apresentada foi predominantemente psicológica e os sintomas mais prevalentes foram: sensibilidade emotiva excessiva, para as mulheres e, para os homens, pensamento recorrente. Os autores sugerem a realização de novos trabalhos para investigar as fontes de estresse na cultura brasileira e seu efeito diferencial em homens e mulheres em diversas faixas etárias. 
Em 2004, CAMELO; ANGERAMI ${ }^{14}$ realizaram um estudo que objetivou investigar a ocorrência de estresse nos trabalhadores de cinco núcleos de saúde da família, da Faculdade de Medicina de Ribeirão Preto (USP). Foi utilizado o Inventário de Sintomas Stress para Adultos, de Lipp. O instrumentou visou identificar a sintomatologia que o indivíduo apresentava, avaliando a presença de sintomas de estresse, o tipo de sintoma predominante e a fase em que se encontrava. Foi constatada a presença de estresse em $62 \%$ dos trabalhadores, sendo que $83 \%$ deles estavam na fase de resistência, e $17 \%$ na fase de quase-exaustão. Houve predominância de sintomas psicológicos em $48 \%$ dos sujeitos, de sintomas físicos, em $39 \%$, e igualmente de sintomas, em $13 \%$ desse grupo de trabalhadores.

Ainda em 2004, TURNER; DWORKIN ${ }^{184}$ realizaram um levantamento bibliográfico sobre os fatores de risco psicossociais relacionados com a dor orofacial crônica. A pesquisa foi realizada na base de dados MEDLINE e abrangeu estudos entre os anos de 1995 e 2002. O objetivo dos autores foi acessar artigos de relevância científica que abordassem os fatores de risco relacionados com a DTM, especialmente as alterações psicológicas e, através deles, conduzir com melhor qualidade a abordagem do tratamento destes indivíduos. Como já era esperado, o resultado da literatura demonstrou que as alterações psicossociais têm grande influência na dor orofacial crônica. Entre os principais fatores de risco, salientou-se o abuso de álcool e drogas e, principalmente, alterações emocionais como estresse, ansiedade e depressão.

GLAROS; WILLIAMS; LAUSTEN ${ }^{61}$, em 2005, examinaram o grau em que parafunções e estados emocionais poderiam predizer dor mandibular em indivíduos com DTM (DMF, DMF e artralgia ou deslocamento de disco) e em indivíduos controle. Verificou-se que os pacientes de DMF apresentaram medidas mais elevadas do que os demais para dor, tensão nos músculos mastigatórios, tempo e intensidade do contato dentário, humor e estresse.Os autores usaram a tensão nos músculos mastigatórios, e a variável composta (humor e estresse) para predizer a dor mandibular por meio do teste de regressão linear. O modelo foi significativo e respondeu por 69 por cento da 
variação na dor muscular. Devido à alta correlação de tensão com dor mandibular, os autores removeram essa variável e refizeram a análise. 0 segundo modelo foi significativo e respondeu por 46 por cento da variação na dor mandibular. Desse modo, concluiu-se que parafunções, especialmente aquelas relacionadas ao aumento da tensão muscular e aos estados emocionais são bons preditores dos níveis de dor mandibular em pacientes com DTM e em indivíduos controle.

No ano de 2005 , SUVINEN et al. ${ }^{177}$ reavaliaram os subtipos de DTM discutidos em um estudo anterior e compararam sintomas físicos, psicológicos e variações psicossociais em pacientes que buscavam tratamento. Foram analisadas 41 mulheres todas com sinais e sintomas de DTM segundo $\mathrm{RDC} / \mathrm{TMD}$ e que apresentavam alterações tanto musculares quanto articulares. As alterações físicas eram mensuradas considerando tipo, freqüência, localização e duração do sintoma. Para avaliação das alterações emocionais foi utilizado o Inventário de Depressão e Ansiedade, de Beck. Além disso, a condição psicossocial das voluntárias foi analisada através de um Inventário Multidimensional de Dor (MPI) que avalia a interferência da condição dolorosa no trabalho, participação social, satisfação familiar, severidade da dor e estresse. Os resultados demonstraram que os subtipos de DTM estão relacionados com os fatores físicos, psicológicos e psicossociais de acordo com o modelo biopsicossocial. Sugerem ainda que estes três subtipos de fatores relacionados com DTM possam ser incorporados no diagnóstico e classificação desta patologia.

No mesmo ano, SUVINEN et al. ${ }^{178}$ discutiram em uma revisão os conceitos etiológicos das DTM. Entre eles: fatores físicos, psicológicos, psicossociais e suas integrações com o modelo biopsicossocial. Ao discutir as alterações psicológicas, os autores ressaltam que a influência destes fatores tem especial importância no diagnóstico e no sucesso da conduta adotada para tratamento das dores associadas à DTM nestes pacientes. Os componentes sensoriais, incluindo variações psicológicas, são importantes na manifestação, percepção, avaliação e comportamento da dor. A literatura científica sustenta 
com sucesso que os fenômenos emocionais como depressão, ansiedade e estresse participam das disfunções como fatores de risco para o desenvolvimento da patologia ${ }^{38,40,71,162,176 .}$

Por fim, concluem que variações individuais são fundamentais na determinação dos fatores psicológicos e que estes devem ser incluídos em uma abordagem disciplinar das DTM e, além disso, devem ser considerados para uma possível determinação de subtipos desta patologia.

Em 2006, HILGERT et al. ${ }^{75}$ pesquisando sobre a relação entre doença periodontal e fenômenos psiconeuroimunológicos, avaliaram a importância dos níveis de estresse e a relação com doenças orais crônicas. O objetivo dos autores foi avaliar a extensão e severidade das doenças periodontais e os níveis de cortisona salivar e associá-los com os níveis de estresse dos indivíduos. Para a avaliação do estresse foi aplicado em 235 voluntários o Inventário de Sintomas de Stress de Lipp para adultos (ISSL). Os resultados demonstraram uma forte correlação positiva entre os níveis de estresse e os níveis cortisona salivar e, conseqüentemente, com a doença periodontal crônica. Isto demonstra que alterações psicológicas relacionam-se fortemente com doenças crônicas.

Neste mesmo ano, NIEMI et al. ${ }^{133}$ discutiram os fatores psicológicos e seus efeitos sobre interferências artificiais em indivíduos com e sem história de DTM. Esta pesquisa contou com a participação de 47 mulheres sendo que 26 apresentavam história de DTM e idade média de 24 anos; enquanto que 21 não apresentavam nenhum sinal ou sintoma de DTM com idade média de 32 anos. Inicialmente os grupos eram avaliados em relação à condição de depressão e ansiedade, através do Inventário de Depressão de Beck (BDI) e Inventário de Ansiedade de Beck (BAI), e quanto ao estresse, através da Escala de Sintomas de Estresse derivado do Índice Médico de Cornell. Além disso, foram utilizados a Escala de Personalidade de Karolinska e ainda o Inventário de Saúde. Através desses instrumentos, toda a amostra foi analisada quanto à personalidade, comportamento e índices de depressão, ansiedade e estresse. Posteriormente, os grupos foram subdivididos 
aleatoriamente. Enquanto um subgrupo foi submetido à colocação de interferências oclusais artificiais verdadeiras, o outro recebeu interferências falsas. As voluntárias foram avaliadas durante 2 semanas diariamente e 9 sintomas de DTM foram avaliados em relação a intensidade, na Escala de Análise Visual (EAV). Os sintomas eram: desconforto oclusal, dificuldade de mastigação, sensibilidade dentária, cansaço mandibular, dor de cabeça, dor facial, dificuldade de abertura, bruxismo e dor de ouvido. Ao comparar os níveis de ansiedade e estresse obtidos antes da colocação das interferências com os índices da EAV de ambos os grupos os resultados demonstraram uma significativa relação entre condição psicológica e DTM. Além disso, indivíduos sem história de doença e com baixos níveis de estresse e ansiedade alcançaram melhor adaptação às interferências oclusais artificiais.

Em 2006, MICELI, A.V.P.; LEITE, D.M.C. ${ }^{124}$ discutiram o fenômeno dor e seu caráter subjetivo a partir do referencial da psicanálise, revelando alguma semelhança entre o atual conceito de memória somatossensorial e aquele de memória neurônica apresentado por Freud ao explanar sua concepção do aparelho psíquico, que, segundo uma abordagem quantitativa, seria formado por três tipos de neurônios j, y e w, onde circula uma variação de energia Q. Segundo os autores, a psicanálise não apenas ratifica o caráter subjetivo da dor, ao marcar o seu lugar qualitativo na economia psíquica, como também, ao postular a formação do aparelho psíquico freudiano, vem confirmar a existência dessa subjetividade e sua influência sobre aquele que sofre.

Também em 2006, MENEZES et al. ${ }^{121}$, verificaram as diferenças entre as concepções dos descritores de intensidade e qualidade de dor e sua relação com fatores emocionais entre profissionais da área de saúde e leigos. Foram voluntários dez médicos e dez estudantes de ambos os gêneros, escolhidos aleatoriamente. Foram utilizados 38 descritores diferentes relacionados com diagnóstico de dor e de alterações psíquicas. Os métodos utilizados foram: estimação de magnitude e categorias. Foram encontradas altas correlações entre médicos e leigos de 0,85 a 0,80 nos experimentos de estimação de magnitude e categoria dos descritores de intensidade de dor, 
respectivamente. Por outro lado, nos experimentos de estimação de magnitude e categoria de descritores de qualidade, as correlações entre médicos e leigos foram baixas, de 0,52 e 0,67, desta forma podemos concluir que há diferenças nas concepções dos descritores de qualidade. 
Proposicáo 


\section{3 - PROPOSIÇÃO}

Considerando a relação de DTM com fatores psicológicos, dentre os quais a ansiedade e o estresse, como demonstrado na literatura revista, este trabalho se propõe a:

1. Comparar, por meio de algometria, níveis de LDP em mulheres com DTM miogênica (dor miofascial, RDC/TMD) e assintomáticas;

2. Avaliar a participação de diferentes níveis de ansiedade nos valores de LDP dos músculos da mastigação e nos níveis de dor subjetiva (EAV);

3. Avaliar diferenças nas alterações do LDP dos músculos da mastigação de relato de dor subjetiva (EAV) frente a diferentes situações de estresse; 
Material e Métodos 


\section{MATERIAL E MÉTODOS}

\subsection{Material}

\subsubsection{Amostra}

A amostra foi selecionada após a aprovação do Comitê de Ética em Pesquisa (CEP) da Faculdade de Odontologia de Bauru (FOB) - USP (processo $n^{0}$ 162/2004 - Anexo 1), e, de acordo com os critérios de inclusão e exclusão, participaram do estudo voluntárias do gênero feminino, estudantes da FOB - USP dos primeiro, segundo e terceiro anos.

\subsubsection{Estabelecimentos dos grupos}

\section{Critérios de exclusão e inclusão iniciais (ANEXO 4)}

Utilizaram-se os seguintes critérios de exclusão para todos os participantes da pesquisa, baseados nos critérios sugeridos pela AADS (LAVIGNE; ROMPRÉ; MONTPLAISIR, 1996) ${ }^{96 .}$

1. Apresentação de dois ou mais dentes perdidos (excluindo-se os terceiros molares);

2. Utilização de prótese removível;

3. Presença de má-oclusão grosseira, especificamente, mordida aberta anterior, mordida cruzada unilateral, sobrepasse horizontal (overjet) maior que $6 \mathrm{~mm}$ e interferência no arco de fechamento que provocasse um deslize de RC para $\mathrm{MIH}$ maior do que $5 \mathrm{~mm}$ (características oclusais de risco ${ }^{149}$ ).

Esses critérios visaram à exclusão de fatores que pudessem predispor o paciente à DTM.

Também eram excluídos os indivíduos que relatassem:

- História de trauma facial ou cervical;

- Limitação dos movimentos na região cervical;

- Doença periodontal ativa ou cáries; 
- História de distúrbios neurológicos, doenças hormonais, neoplasias ou doenças psiquiátricas (KATO, 2001) ${ }^{86}$.

Após o preenchimento do questionário e a realização da entrevista, se as voluntárias não apresentassem quaisquer das características acima, eram solicitadas a continuar o preenchimento desta ficha que possuia informações pessoais (nome, idade, gênero, telefone, ano de graduação que freqüentavam) e um questionário sobre sintomas relativos às DTM (Anexo 4). Este questionário anamnésico foi desenvolvido baseado em fichas preexistentes ${ }^{29}$ e aplicado aos voluntários sem participação do examinador. As mulheres responderam a 10 perguntas relativas a sintomas de DTM, que permitiram a classificação da disfunção em relação à severidade. Este questionário foi aplicado pelo Examinador 1, que será descrito no item 4.1.3.

\section{QUESTIONÁRIO AVALIAÇÃO OBJETIVA (Anexo 4)}

1. Você sente dificuldade de abrir a boca?

2. Você sente dificuldade de movimentar sua mandíbula para os lados?

3. Você sente desconforto ou dor muscular quando mastiga?

4. Você sente dores de cabeça com freqüência?

5. Você sente dores no pescoço e/ou ombros?

6. Você sente dores de ouvido ou próximo a ele?

7. Você percebe algum ruído na ATM?

8. Você considera sua mordida "anormal"?

9. Você usa apenas um lado de sua boca para mastigar?

10. Você sente dores na face ao acordar?

Havia três possibilidades de resposta: SIM, NÃO e ÀS VEZES. Cada "sim" recebeu o valor 2 , cada "às vezes" recebeu o valor 1 e cada "não" recebeu o valor 0 . As questões 4, 6 e 7 receberam valor 3 para cada resposta "sim" se correspondessem a sintomas bilaterais ou intensos; valor 2, se correspondessem a sintomas unilaterais ou leves; receberam valor 1 para a resposta "às vezes" e valor 0 para a resposta "não", de acordo com CONTI et al. $^{29}, 1996$. 
O somatório dos valores obtidos fornecia a classificação da DTM em intensidade:

Valores de 0 a 3: não portador de DTM

Valores de 4 a 8: portador de DTM leve

Valores de 9 a 14: portador de DTM moderada

Valores de 15 a 23: portador de DTM severa.

\section{QUESTIONÁRIO DE FREQUÊNCIA E INTENSIDADE DA DOR}

Permitiu a determinação da intensidade, freqüência, qualidade e local da dor, ruídos articulares ou limitações da abertura bucal ${ }^{65}$ (Anexo 5)

\section{ANAMNESE}

Foi utilizado o Research Diagnostic Criteria for Temporomandibular Disorders (RDC/TMD) ${ }^{40}$ (Anexo 6)

Após estes exames iniciais, todos os indivíduos foram submetidos ao exame físico, direcionado para investigação e diagnóstico de DTM.

\section{EXAME FÍSICO}

Como parte do exame físico (Anexo 6), os seguintes critérios foram avaliados:

* Localização da dor, lado (nenhum, direito, esquerdo ou ambos) e área (nenhum, ATM, músculos ou ambos);

* Abertura bucal (extensão e trajetória);

* Movimentos excursivos (amplitude, presença de dor e ruídos).

* Palpação dos músculos temporal (porções anterior, média e posterior), músculo masseter (origem, corpo e inserção da porção superficial e porção profunda), pterigóideo medial (inserção) e ventre posterior do digástrico.

Utilizaram-se os escores: "0" para ausência de dor; "1" para relato de dor leve (o paciente relata que doeu um pouco); "2" para dor moderada (paciente responde com reflexo palpebral) e "3" para dor intensa (o paciente reage afastando o rosto). Foi aplicada, durante a palpação muscular, pressão digital aproximada de 1,5 kg. Já para palpação articular, foi aplicado $1 \mathrm{Kg}$ de pressão digital $^{168}$. 
* Inspeção de ruídos articulares (estalido ou crepitação) por meio de inspeção digital. Em situações em que havia dúvida, questionava-se o paciente quanto à percepção do ruído durante o exame.

O Examinador 1 (o qual realizou a primeira etapa do exame inicial em todos os participantes da pesquisa) calibrava a pressão exercida durante a palpação, por meio de um algômetro, que será descrito posteriormente.

\subsection{Grupo Experimental (com DTM)}

As voluntárias do grupo com DTM, ou experimental, foram selecionados entre os alunos da Graduação da Faculdade de Odontologia de Bauru - USP. Todos os indivíduos foram selecionados a partir de 2 classificações relativas a DTM, descritas no item 4.1.1.1. Inicialmente foram classificados a partir do questionário anamnésico como "portadores de DTM leve", "portadores de DTM moderada" e "portadores de DTM severa".

Posteriormente, além do questionário anamnésico, foi utilizado o Research Diagnostic Criteria for Temporomandibular Disorders (RDC/TMD) com o propósito de permitir uma padronização e reprodução de resultados entre os pesquisadores, classificando de maneira clara e objetiva os pacientes de DTM em seus respectivos subgrupos, bem como os assintomáticos. (Anexo 6)

O RDC/TMD estabelece algumas instruções relacionadas a palpação dos músculos e da ATM. São eles:

- Deve-se pressionar um sítio específico, usando-se o polegar e o dedo médio com a pressão padronizada de 2.0 libras $(0,9 \mathrm{~kg})$ para os músculos extra-orais e 1.0 libra $(0,45 \mathrm{~kg})$ para a ATM e os músculos intra-orais. Devem-se palpar os músculos enquanto se apóia a cabeça do paciente com a outra mão a fim de estabilizá-la. A mandíbula do indivíduo deve estar em posição de repouso, sem que os dentes se toquem. Quando necessário, pode-se pedir ao paciente que aperte os dentes para que se localize melhor a área a ser palpada; em seguida, pede-se ao paciente que torne a relaxar, para que a pressão possa ser 
exercida. Como o local de dor máxima pode variar de paciente para paciente, é necessário que várias áreas na região especificada sejam pressionadas a fim de determinar se a dor existe. O paciente é orientado a relatar se a dor é suave, moderada ou severa.

Os critérios de classificação do RDC/TMD foram seguidos criteriosamente, com exceção da palpação do músculo pterigóideo lateral (recomendada pelo instrumento), que foi substituído pela porção profunda do masseter devido às evidências clínicas e anatômicas da impossibilidade de palpação deste músculo ${ }^{84,175,185}$. A palpação da porção profunda do masseter tem sido incluída em diversos estudos de análise da Disfunção Miofascial $(\mathrm{DMF})^{10,189}$. Além disso, a palpação do tendão do músculo temporal não foi incluída. Essa exclusão não afetaria o diagnóstico da DMF, pois foi mantido o critério de pelo menos 3 pontos sensíveis dentre um total de apenas 18 sítios, e não 20 sítios. Ainda, a pressão digital exercida durante à palpação dos músculos foi de aproximadamente $1,5 \mathrm{Kg}$ para os músculos extra-orais e $1 \mathrm{Kg}$ para a ATM e músculos intra-orais ${ }^{168}$.

A partir deste instrumento, os voluntários do grupo experimental deveriam apresentar:

* Dor na face há pelo menos 6 meses;

* Intensidade de dor não inferior a 2, nos últimos 6 meses na Escala de Análise Visual (EAV). Esta escala é representada por um traço horizontal de $100 \mathrm{~mm}$, onde, em seu extremo esquerdo, lê-se "sem dor" e, no direito, lê-se "pior dor imaginável", na qual o paciente assinala com um traço vertical a posição que melhor indica o grau de dor sentida no momento ${ }^{80,143,180}$;

* Classificação, segundo os critérios do RDC/TMD, como portadores de sinais e sintomas de Disfunções Temporomandibulares (DTM) de origem miogênica (dor miofascial, ou seja, relato de dor intermitente ou crônica na região dos músculos mastigatórios, e/ou dor na região dos músculos durante o exame funcional e/ou palpação muscular). A DTM miofascial poderia ou não estar associada com patologias articulares. 


\subsection{Grupo Controle}

Os indivíduos do grupo assintomático, ou controle foram selecionados a partir do questionário anamnésico, sendo aqueles que se enquadraram na classificação de "não portador de DTM". Assim como o grupo com DTM, o grupo controle foi selecionado entre os alunos da Graduação da Faculdade de Odontologia de Bauru - USP.

Todo o protocolo descrito foi também aplicado para os indivíduos assintomáticos. Os critérios de inclusão específicos do grupo controle incluíram:

* Ausência de relato de queixa de dor ou desconforto na mandíbula, face, têmporas ou área pré-auricular;

* A presença de três ou mais sítios musculares sensíveis à palpação (dentre os 18 palpados) era critério de exclusão;

* Não deveriam apresentar queixa de dor ou disfunção articular, tais como: dor ou travamento articular, luxações mandibulares, limitação de abertura bucal ou edema;

* Sinais clínicos de deslocamentos de disco assintomáticos e estalidos assintomáticos não fizeram parte dos critérios de exclusão devido à alta prevalência destes sinais em grupos sem sintomas ${ }^{38,104}$.

A partir desta seleção, os voluntários regularmente matriculados na Faculdade de Odontologia de Bauru - Universidade de São Paulo, foram previamente informados do propósito do estudo através da carta de informação ao paciente (Anexo 3) e, após cientes dos procedimentos a serem realizados, assinaram o termo de consentimento livre e esclarecido, de acordo com as normas da resolução 196/96 do Conselho Nacional de Saúde (Anexo 2). Um total de 45 voluntárias participaram do estudo, distribuídas da seguinte forma:

Grupo Experimental: 29 voluntárias com sinais e sintomas de DTM segundo questionário anamnésico e RDC;

Grupo Controle: 16 voluntárias sem sinais e sintomas de DTM segundo o questionário anamnésico e RDC. 


\subsubsection{Fichas utilizadas na pesquisa}

FICHA A: Termo de Consentimento Livre e Esclarecido (Anexo 2).

FICHA B: Carta de informação ao paciente e termo de consentimento livre e esclarecido (Anexo 3).

FICHA C: Questionário de Avaliação Objetiva - dados referentes às informações pessoais dos voluntários (nome, idade, gênero, endereço, telefone), critérios de inclusão inicial e o questionário anamnésico de DTM (Anexo 4).

FICHA D: Questionário de Freqüência e Intensidade de Dor (Anexo 5)

FICHA E: Questionário RDC/TMD - Anamnese e Exame Físico (Anexo 6).

FICHA F: Inventário de ansiedade de Beck (BAI) - Avaliação de ansiedade (Anexo 7)

FICHA G: Inventário de Sintomas de Stress para Adultos de Lipp (ISSL) Avaliação do estresse (Anexo 8)

FICHA H: Ficha de Exame - específica para cada momento do estudo na qual foram registrados os valores de LDP e EAV (Anexo 9)

\subsubsection{Examinadores}

O contato inicial, os exames de seleção e classificação dos participantes do estudo foram realizados por 2 examinadores, cirurgiõesdentistas, estagiários do Departamento de Prótese da Faculdade de Odontologia de Bauru - USP. Ambos classificados como Examinador 1, durante a descrição da pesquisa. No momento das avaliações específicas de cada momento da pesquisa, as mensurações do LDP foram realizadas por um terceiro examinador, cirurgião-dentista, especialista em Prótese Dentária, aluno de pós-graduação em Reabilitação Oral, em nível de Mestrado, da Faculdade de Odontologia de Bauru - USP. Este foi classificado como Examinador 2 . Foi caracterizado, dessa forma, o mascaramento do examinador. Todos examinadores foram submetidos a um treinamento para realização correta dos exames, e para familiarização dos métodos empregados na pesquisa. 


\subsubsection{Material utilizado nas diferentes avaliações}

\subsubsection{Algômetro para mensuração do Limiar de Dor à Pressão}

O exame de palpação, neste estudo, teve o objetivo de verificar o Limiar de Dor à Pressão (LPD). O LDP $33,52,125,140$ é definido como o ponto a partir do qual uma força aplicada e sentida como pressão passa a ser percebida como dor.

Com o auxílio de um algômetro (KRATOS ${ }^{\circledR}$ ) - aparelho capaz de medir tração e pressão em Kgf ou daN- (Figura 1), foram registrados bilateralmente os Limiares de Dor à Pressão (LDP) dos indivíduos nos músculos masseter, temporal anterior, médio e posterior.

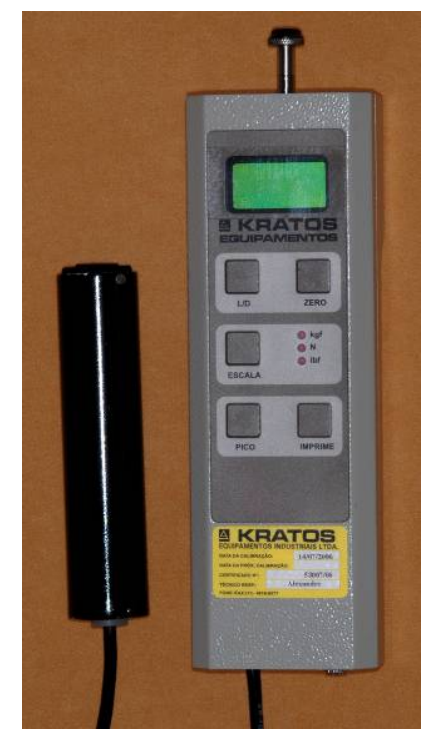

Figura 1 - Algômetro KRATOS ${ }^{\circledR}$ utilizado para o exame de palpação

O algômetro utilizado possui uma haste em uma das extremidades com ponta em forma circular achatada. A parte plana da ponta é a porção do aparelho que entra em contato com a face do indivíduo. Possui uma área de $1 \mathrm{~cm}^{2}$, similar à ponta do dedo indicador, que normalmente é o dedo utilizado no exame de palpação digital. Para maior conforto do paciente foi adaptado uma ponta de silicone nas mesmas dimensões da extremidade da haste circular achatada (Figura 2). Além disso, o aparelho possui um controle manual que 
permite o registro pelo paciente do momento exato no qual a força exercida deixa de ser pressão tornando-se sensação dolorosa. (Figura 3)

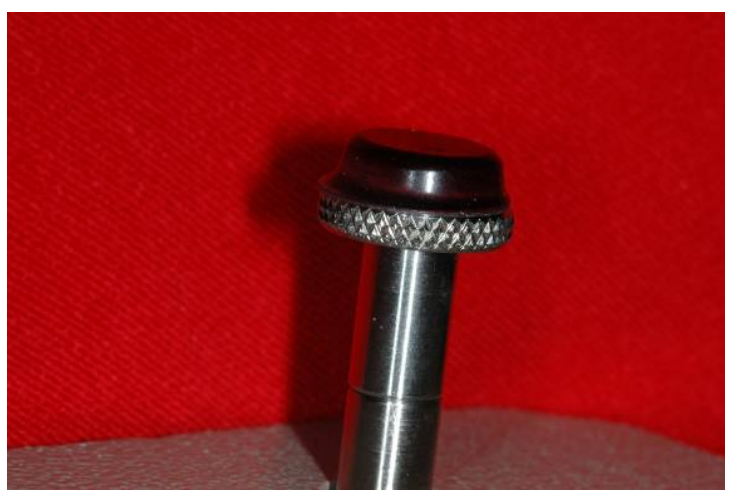

Figura 2 - Ponta circular achatada com silicone adaptada para entrar em contato com pele do paciente $\left(1 \mathrm{~cm}^{2}\right.$ de diâmetro)

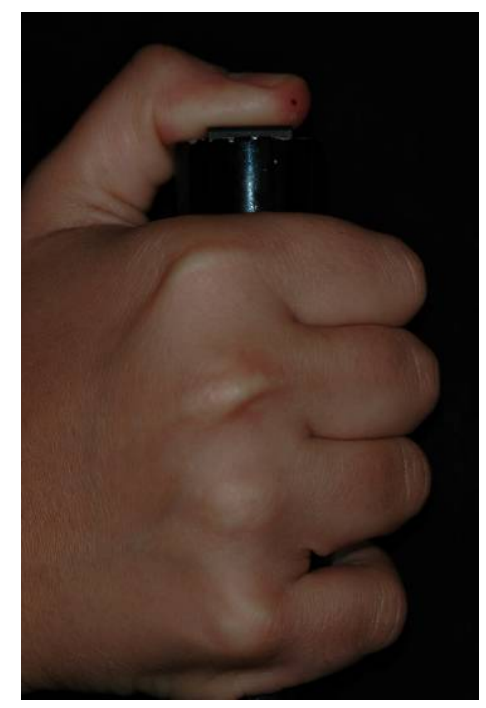

Figura 3 - Controle Manual que permite o registro pelo próprio paciente

\subsubsection{Avaliações}

\subsection{LDP}

Cada ponto determinado para avaliação do Limiar de Dor à Pressão (LDP) foi avaliado em 4 tempos de estudo distintos (T1, T2, T3 e T4). Nestes 4 tempos, os pontos foram mensurados 2 vezes para que fosse possível fazer a média do LDP. Todas as medidas eram registradas na ficha de exame pessoal do voluntário. Essa ficha foi elaborada para registrar os dados coletados em 
cada avaliação e não identificava o indivíduo pelo nome, tampouco classificava quanto ao grupo a que pertencia (Anexo 9).

Antes do início do exame, os voluntários registravam a dor na Escala de Análise Visual (EAV). Após o registro na EAV, as mensurações do LDP eram registradas para cada grupo muscular 2 vezes (Anexo 9). A média foi realizada posteriormente pelo examinador 2 .

A Ficha de Exame possuía as seguintes informações:

- Data do exame (determinante do momento correspondente);

- Número identificador do voluntário;

- Período de avaliação;

- Escala de Análise Visual;

- Tabela dos músculos avaliados que permitia o registro do Limiar de Dor à Pressão de cada lado avaliado (direito e esquerdo) e a média.

\subsection{ISSL e BAI}

O Inventário de ansiedade de Beck (BAI) identifica a presença e ausência de ansiedade da população, através de uma lista de sintomas físicos e emocionais ansiogênicos (Anexo 7).

O Inventário de Sintomas de Stress para Adultos de Lipp (ISSL), quantifica e qualifica sintomas de estresse categorizando em fases (alerta, resistência e exaustão) (Anexo 8).

Além disso, o uso dos testes é privativo do psicólogo no exercício da avaliação psicológica que, de acordo com a Resolução CFP 007/2003, sendo entendida como o processo técnico científico de coleta de dados, estudos e interpretação a respeito de fenômenos psicológicos, que são resultantes da relação do indivíduo com a sociedade, utilizando-se, para tanto, de estratégias psicológicas - métodos, técnicas e instrumentos. Objetivando melhoria da 
pesquisa, os testes foram aplicados regularmente por uma psicóloga habilitada pelo CRP 06/81727.

\subsection{Métodos}

\subsubsection{Avaliação do Limiar de Dor à Pressão}

\subsubsection{Orientações aos voluntários}

Os voluntários foram previamente orientados sobre o tipo de exame que seria realizado, foram atendidos na clínica do Departamento de Prótese da Faculdade de Odontologia de Bauru - USP, sentados em cadeira odontológica com a cabeça e as costas numa posição ligeiramente reclinada. Antes de iniciar as avaliações do limiar de dor à pressão, todos foram orientados a concentrarem-se somente na pressão exercida sobre os músculos e não permitir que a pressão fosse suportada e transformada em sensação dolorosa. Todos esses cuidados tiveram o objetivo de eliminar variáveis que pudessem interferir na detecção do limiar de dor dos voluntários.

\subsubsection{Músculos avaliados}

Os músculos selecionados para a realização do exame de palpação foram os masseteres superficiais (corpo) e os temporais (anterior, médio e posterior), no lado direito e esquerdo.

Masseter Superficial: para palpação do corpo do masseter, solicitou-se ao indivíduo que apertasse os dentes para que pudesse localizar todo o corpo do músculo. Em seguida, localizou-se o ponto médio entre a origem e a inserção. (Figura 4)

\section{Temporal:}

* Temporal Anterior: 30mm posterior ao ponto mais lateral sobre o limite da órbita e $15 \mathrm{~mm}$ acima da extremidade superior do arco zigomático. (Figura 5) 
* Temporal Médio: $60 \mathrm{~mm}$ ao longo de uma linha vertical, desenhado perpendicular a uma linha do canto do tragus ao meio do meato auditivo externo.

* Temporal Posterior: localizado $40 \mathrm{~mm}$ mais para posterior do ponto anteriormente marcado para o temporal médio.

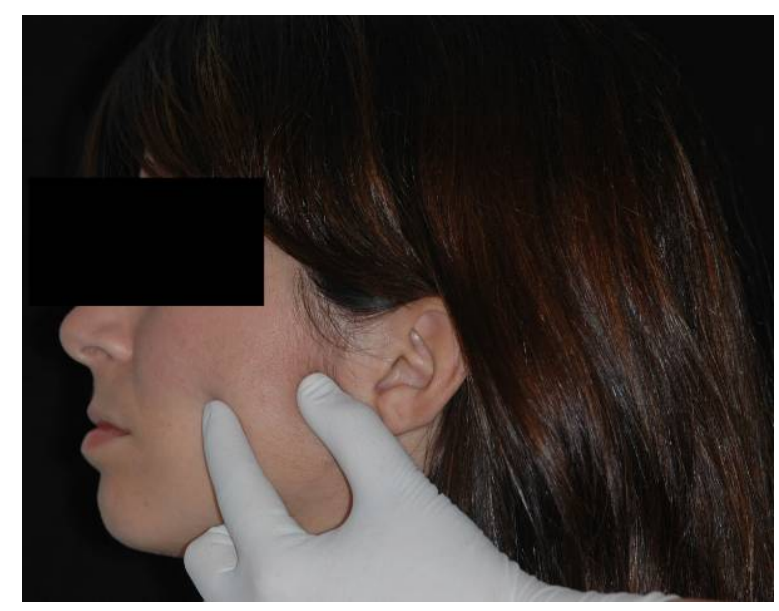

Figura 4 - Localização do Masseter

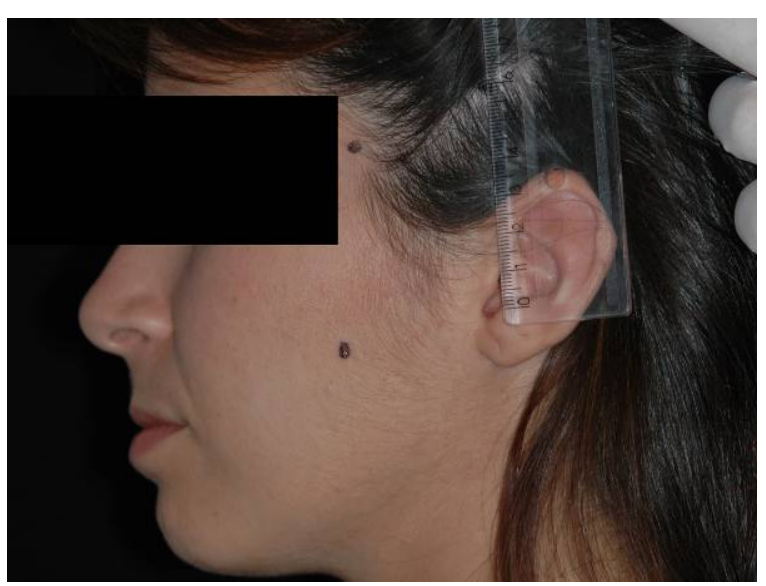

Figura 5 - Localização Temporal Anterior

\subsubsection{Matriz de Acetato}

Buscando maior precisão nas mensurações, foi confeccionada uma matriz de acetato na forma da face dos indivíduos que permitiu a marcação dos pontos a serem pressionados (Figura 8) ${ }^{76,125,} 139$. Inicialmente, foram posicionadas as matrizes de acetato na face dos voluntários e traçadas duas linhas: tragus - canto externo do olho; tragus - comissura labial. Assim, individualizaram-se as matrizes (Figura 6). Após, na ausência das matrizes, 
fazia-se a identificação dos pontos na face do indivíduo e as respectivas marcações com canetas de retro-projetor na pele do voluntário. Posteriormente transferiam-se as marcações para a matriz colocada sobre a face. No local das marcações, foram feitos orifícios. Dessa forma, em todos os momentos distintos, os pontos foram identificados igualmente e a avaliação do LDP ocorreu no mesmo local. (Figura 7)

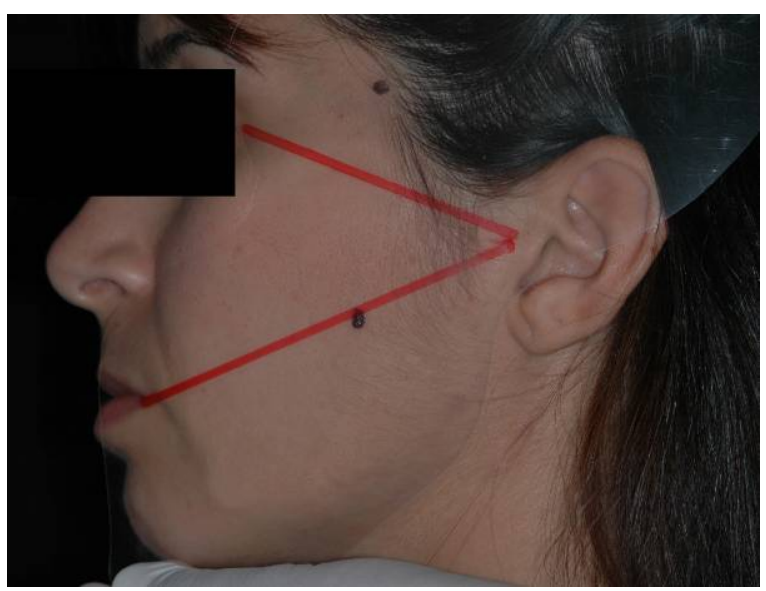

Figura 6 - Transferência de Pontos para Matriz de Acetato

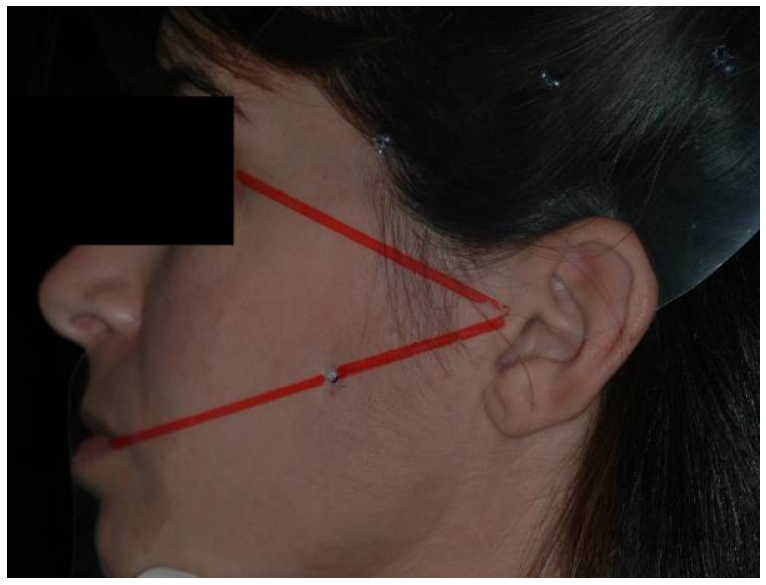

Figura 7 - Matriz de Acetato Perfurada

\subsubsection{Obtenção do LDP}

Antes do início das mensurações através da algometria, avaliou-se a intensidade da dor, através da EAV, em toda a amostra, inclusive no grupo controle, já que os grupos eram desconhecidos pelo examinador (Anexo 9). Em seguida, iniciou-se o exame propriamente dito que possibilitou a avaliação do 
limiar de dor à pressão, através da utilização do algômetro com dispositivo manual já descrito anteriormente.

Antes da avaliação do LDP o voluntário foi orientado a relaxar a musculatura facial durante 1 minuto e a mensuração era iniciada numa seqüência padronizada com intervalos de 10 segundos entre cada ponto: masseter direito, temporais direitos, tendão de Aquiles (foi selecionado como grupo não muscular controle) ${ }^{125}$, masseter esquerdo, e temporais esquerdos (Figura 9). Após 4 minutos, a seqüência foi repetida para evitar sensibilização diferente entre os lados;ou seja, volta-se pelo lado direito e posteriormente 0 lado esquerdo, como na seqüência ${ }^{140}$. A escolha de iniciar a mensuração pelo lado direito foi aleatória e facilitada pelo posicionamento dos participantes nas cadeiras.

A palpação foi realizada com o algômetro perpendicular ao ponto a ser examinado (Figura 10), exercendo uma pressão crescente e constante de aproximadamente $0.5 \mathrm{Kgf} / \mathrm{cm}^{2} / \mathrm{s}$ em cada ponto pré - determinado, até que o voluntário relatasse que a sensação de pressão estava se tornando dor, apertando assim o dispositivo. Nesse momento a pressão deixava de ser aplicada e o algômetro registrava o valor que era anotado na ficha. Todos os músculos foram palpados 2 vezes e a média foi utilizada. Enquanto a palpação era realizada com uma mão, a outra servia de anteparo para que o paciente não retirasse a cabeça e prejudicasse a obtenção dos dados.

Cada indivíduo foi orientado pelo examinador, em relação à palpação, a apertar no controle de mão que permitia a fixação do valor do LDP (registro) no momento exato em que o estímulo crescente exercido na sua face deixava de ser pressão e passava a ser doloroso. Foram orientados a não ficar suportando a dor, e sim registrar através do controle manual o instante em que a dor se iniciou. 


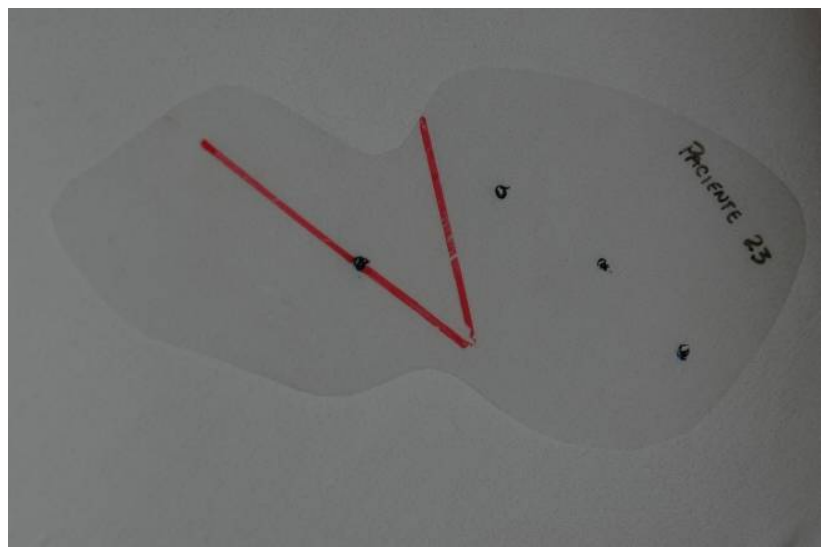

Figura 8 - Matriz de Acetato Individualizada

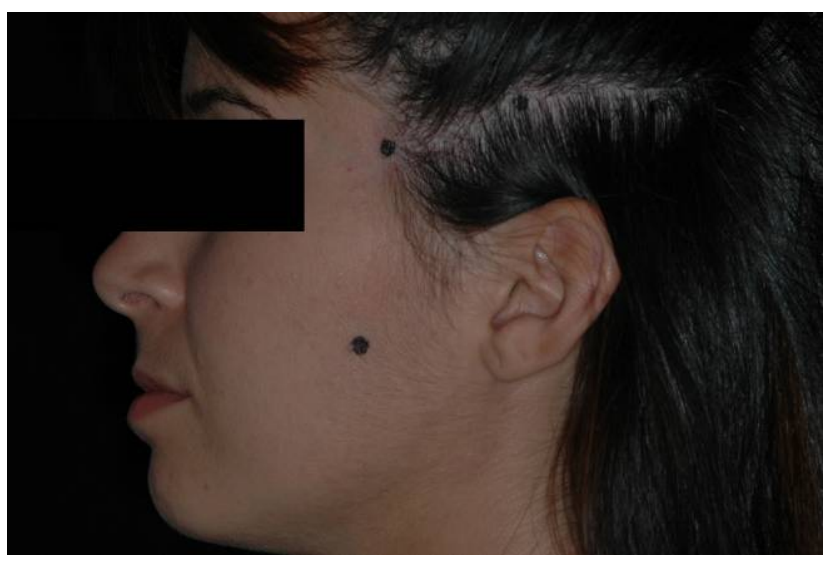

Figura 9 - Pontos de Avaliação de LDP

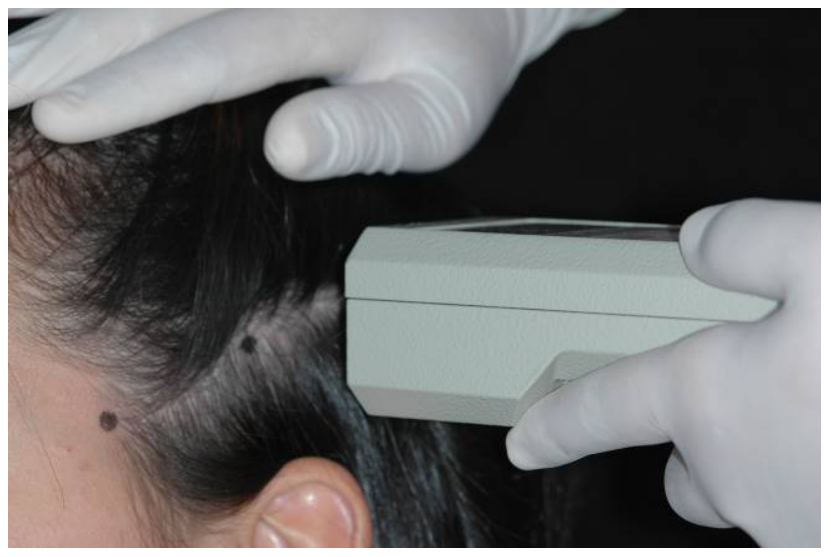

Figura 10 - Mensuração do LDP

\subsubsection{Avaliação do Estresse e Ansiedade}

As avaliações psicológicas foram realizadas em uma sala silenciosa do Departamento de Prótese da Faculdade de Odontologia de Bauru - USP. A ansiedade e o estresse foram avaliados pelo preenchimento de todos os 
participantes dos questionários ISSL e BAI, respectivamente, para avaliar estresse e ansiedade da população em questão. As análises ocorreram simultaneamente às avaliações do LDP e os testes foram aplicados e analisados regularmente por uma psicóloga habilitada pelo CRP 06/81727.

Além disso, os questionários foram aplicados individualmente. Todos os cuidados com o objetivo de eliminar variáveis que pudessem interferir no estresse e ansiedade dos voluntários foram tomados.

\subsubsection{ISSL}

O Inventário de Sintomas de Stress para Adultos de Lipp (ISSL) quantifica e qualifica sintomas físicos e psíquicos de estresse categorizando em fases (alerta, resistência e exaustão).

O ISSL foi validado em $1994^{99}$ e tem sido utilizado em pesquisas e trabalhos clínicos na área do estresse ${ }^{13,} 14,75$. Apresenta um modelo quadrifásico do estresse, baseado, inicialmente, no modelo trifásico de Selye ${ }^{166}$. O instrumento é formado por três quadros que contêm sintomas físicos e psicológicos de cada fase do estresse. O número de sintomas físicos é maior do que os psicológicos e varia de fase para fase. No total, o ISSL inclui 34 itens de natureza somática, e 19, de natureza psicológica.

A aplicação desse inventário foi realizada individualmente em sala isolada e preparada com mesa, cadeira e caneta de forma que permitisse que o indivíduo refletisse sobre seu estado físico e emocional e respondesse ao questionário.

Inicialmente a examinadora se apresentou como Psicóloga da pesquisa e coletou dados como nome, idade, escolaridade e se no dia do exame sentia dor na articulação temporomandibular. Após este momento, o individuo foi orientado a responder às 3 folhas, assinalando com um " $X$ ", qual daqueles sintomas sentiu respectivamente nas últimas 24 horas, última semana e último mês. Ao término o indivíduo entregava a folha e poderia 
realizar comentários espontâneos sobre a avaliação realizada. A examinadora esclarecia as duvidas.

A análise dos dados ocorreu através de um gráfico a partir da somatória dos sintomas físicos e psíquicos do indivíduo em cada um dos estágios de tempo (24 horas, ultima semana e ultimo mês). Uma tabela de convergência padronizada pelo inventário foi utilizada e a partir dos resultados pôde-se classificar quanto a presença ou ausência de estresse.

\subsubsection{BAI}

O Inventário de Ansiedade de Beck (BAI) avalia o nível de ansiedade da população através de uma lista de sintomas físicos e emocionais ansiogênicos. É uma escala sintomática, composta por 21 itens, destinada a medir a gravidade dos sintomas destes sintomas. Sua validação ocorreu no ano de $1961^{6}$.

A aplicação do inventário ocorreu individualmente, em sala isolada, preparada com mesa, cadeira e caneta, após a aplicação do ISSL, onde foi distribuída folha de respostas. Os indivíduos foram orientados a assinalar com um "X" dentre os sintomas descritos com que freqüência os percebiam durante a última semana, incluindo o dia de avaliação. A folha de respostas continha 4 graus de freqüência: Absolutamente não, levemente, moderadamente e gravemente.

Durante a aplicação, a examinadora permaneceu na sala para retirar possíveis dúvidas que os indivíduos pudessem ter. Ao término, os indivíduos entregavam as folhas e poderiam realizar algum comentário sobre seu estado emocional espontaneamente ou retirar duvidas sobre a pesquisa realizada.

A avaliação do inventário ocorreu através da somatória dos pontos atribuídos à freqüência de cada sintoma, sendo que: para absolutamente não, atribuímos pontuação 0 (zero); para levemente, pontuação 1 (um); para 
moderadamente, pontuação 2 (dois); e para gravemente, pontuação 3 (três). Após esta somatória, uma tabela de conversão, padronizada pelo inventário, classificou o nível de ansiedade do indivíduo em mínimo, leve, moderado e grave.

\subsubsection{Períodos de Avaliação}

As voluntárias foram avaliadas em 4 tempos do estudo, já que a avaliação do nível de ansiedade foi baseada no período de avaliações da faculdade, portanto: na semana que antecede as avaliações acadêmicas (T1); na semana das avaliações acadêmicas (T2); na semana subseqüente às avaliações acadêmicas (T3); e 2 dias após voltarem do período de férias anuais (T4). Devido ao grande número de voluntárias avaliadas, o estudo ocorreu em 3 tempos distintos no período de 1 ano. Ou seja, foi utilizado, como referência, 3 semanas de avaliações acadêmicas distintas do ano letivo (T2) e, conseqüentemente, 3 semanas distintas que antecederam semanas de avaliações acadêmicas (T1); 3 semanas distintas subseqüentes as avaliações acadêmicas (T3) e apenas um único tempo de volta de período de férias anuais (T4), já que este momento foi único no estudo que foi desenvolvido em 18 meses.

Além disso, a escolha de T4 ocorrer em apenas 2 dias e não uma semana como T1, T2 e T3 foi devido à possibilidade das avaliações serem aplicadas durante os 3 períodos do dia (manhã, tarde e noite), considerando que os voluntários não haviam iniciado as atividades regulares do ano letivo. Isso não ocorria em T1, T2 e T3 porque as mensurações deveriam ocorrer apenas nos intervalos das atividades acadêmicas dos alunos da Faculdade de Odontologia.

T1: Na semana que antecede as avaliações acadêmicas ou período préprovas, os alunos eram recebidos na Clínica do Departamento de Prótese, inicialmente, pelo examinador 1 (conhecia os grupos) e solicitados a marcar na Escala de Análise Visual (EAV) a intensidade de sua dor naquele momento. Seguidamente, este mesmo examinador confeccionava a matriz de acetato individualizada (Figura 8 ) e registrava os pontos na face do voluntário (Figura 
9). Todos os alunos eram classificados por números, e não por grupo nas fichas pessoais. Após este primeiro contato, o segundo examinador realizava $o$ exame de LDP propriamente dito (Figura 10). Terminado o procedimento de avaliação dos músculos, cada voluntário foi solicitado a comparecer na sala ao lado pra ser avaliado pela psicóloga e classificado quanto ao estresse e ansiedade. Da mesma forma, as avaliações psicológicas ocorriam sem o conhecimento real do grupo ao que o voluntário pertencia.

T2: Na semana das avaliações acadêmicas ou período de provas, os alunos eram recebidos na Clínica do Departamento de Prótese em todos os momentos do dia. Nesta semana os alunos não realizavam nenhuma atividade curricular regular e compareciam apenas para realizar as avaliações bimestrais. A partir deste momento, as matrizes individuais já haviam sido confeccionadas no T1. Os voluntários eram recebidos pelo examinador 1, que registrava em suas faces os pontos a serem palpados através da matriz, que permitia a mensuração sempre no mesmo ponto. Após as marcações as avaliações eram realizadas pelo examinador 2 e subseqüente pelo psicólogo, da mesma forma que no T1.

T3: Este momento ocorria na semana após as avaliações acadêmicas ou período pós-provas e ocorria nos intervalos das atividades curriculares regulares dos alunos da mesma forma que no T2.

T4: Refere-se à volta dos alunos das férias anuais ou período pós-férias e ocorreu nos 2 primeiros dias do retorno dos alunos, quando as atividades da Faculdade ainda não estavam regulares. Este momento foi único no estudo, ou seja, todos os participantes da pesquisa foram avaliados nestes dois dias. Os critérios foram seguidos da mesma forma que T2 e T3.

\subsubsection{Análise estatística dos resultados}

Foi utilizada uma análise de variância a 3 critérios (ANOVA) para mensurações repetidas, com o objetivo de avaliar possíveis diferenças entre os 
grupos (sintomático e assintomático), entre os músculos e entre os diferentes tempos de exame.

Após a constatação de interações estatisticamente significante entre as 3 variáveis, o teste paramétrico de Tukey foi aplicado.

O teste não paramétrico de Friedman foi utilizado para analisar possíveis relações entre a Escala de Análise Visual e os tempos das avaliações em relação ao LDP dos músculos palpados. A comparação entre os grupos foi realizada através do teste de Mann-Whitney.

Ainda, a avaliação do estresse relacionado a cada tempo de avaliação foi verificada através da análise de variância a 2 critérios (ANOVA) para mensurações repetidas. A relação da ansiedade com os diferentes tempos em cada grupo foi analisada através do teste de Mann-Whitney.

Um nível de significância $5 \%$ foi adotado para todos os testes. 
Resultados 


\section{RESULTADOS}

A distribuição da idade média e desvio padrão de todos os indivíduos que participaram deste trabalho estão demonstrados na Tabela 1.

Tabela 1 - Idade média dos grupos de indivíduos analisados em anos

\begin{tabular}{|c|c|c|}
\hline Grupo & Número de Indivíduos & $\begin{array}{c}\text { Idade Média } \pm \text { DP } \\
(\text { anos })\end{array}$ \\
\hline Controle & 16 & $19,5(1,26)$ \\
\hline DTM & 29 & $20(1,69)$ \\
\hline Total & 45 & $19,8(1,55)$ \\
\hline
\end{tabular}

Ao realizar a análise de variância (ANOVA) a um critério, verificou-se que não houve diferença estatisticamente significante entre os grupos $(p>0,05)$.

\subsection{Limiar de dor à pressão}

Os valores médios do Limiar de Dor à Pressão de cada músculo e tendão de Aquiles e seus respectivos desvios-padrão em cada tempo estão apresentados na Tabela 2. Para melhor compreensão dos resultados os tempos T1, T2, T3 e T4 serão descritos, respectivamente, como período de Pré-Provas, Provas, Pós-Provas e Pós-Férias. 
Tabela 2 - Médias e desvio padrão do LDP de cada músculo em cada grupo nos diferentes tempos de avaliação (valores em $\mathrm{Kgf} / \mathrm{cm}^{2}$ )

\begin{tabular}{|c|c|c|c|c|c|c|}
\hline Grupo & Períodos & Masseter & $\begin{array}{c}\text { Temporal } \\
\text { Anterior }\end{array}$ & $\begin{array}{c}\text { Temporal } \\
\text { Médio }\end{array}$ & $\begin{array}{l}\text { Temporal } \\
\text { Posterior }\end{array}$ & $\begin{array}{c}\text { Tendão } \\
\text { de } \\
\text { Aquiles }\end{array}$ \\
\hline \multirow{4}{*}{ DTM } & $\begin{array}{c}\text { Pré- } \\
\text { Provas }\end{array}$ & $\begin{array}{c}1,54 \\
(0,31)\end{array}$ & $\begin{array}{c}1,67 \\
(0,23)\end{array}$ & $\begin{array}{c}2,21 \\
(0,46)\end{array}$ & $\begin{array}{c}2,44 \\
(0,60)\end{array}$ & $\begin{array}{c}5,14 \\
(1,77)\end{array}$ \\
\hline & Provas & $\begin{array}{c}1,28 \\
(0,24)\end{array}$ & $\begin{array}{c}1,64 \\
(0,36)\end{array}$ & $\begin{array}{c}1,83 \\
(0,38)\end{array}$ & $\begin{array}{c}2,05 \\
(0,56)\end{array}$ & $\begin{array}{c}4,19 \\
(1,28)\end{array}$ \\
\hline & $\begin{array}{l}\text { Pós- } \\
\text { Provas }\end{array}$ & $\begin{array}{c}1,53 \\
(0,43)\end{array}$ & $\begin{array}{c}1,95 \\
(0,48)\end{array}$ & $\begin{array}{c}2,30 \\
(0,54)\end{array}$ & $\begin{array}{c}2,44 \\
(0,65)\end{array}$ & $\begin{array}{c}4,92 \\
(1,24)\end{array}$ \\
\hline & $\begin{array}{l}\text { Pós- } \\
\text { Férias }\end{array}$ & $\begin{array}{c}1,54 \\
(0,36)\end{array}$ & $\begin{array}{c}2,06 \\
(0,47)\end{array}$ & $\begin{array}{c}2,35 \\
(0,59)\end{array}$ & $\begin{array}{c}2,47 \\
(0,60)\end{array}$ & $\begin{array}{r}5,46 \\
(1,27)\end{array}$ \\
\hline \multirow{4}{*}{ Controle } & $\begin{array}{c}\text { Pré- } \\
\text { Provas }\end{array}$ & $\begin{array}{c}1,70 \\
(0,33)\end{array}$ & $\begin{array}{c}1,98 \\
(0,33)\end{array}$ & $\begin{array}{c}2,25 \\
(0,47)\end{array}$ & $\begin{array}{c}2,41 \\
(0,53)\end{array}$ & $\begin{array}{c}4,77 \\
(1,77)\end{array}$ \\
\hline & Provas & $\begin{array}{c}1,53 \\
(0,33)\end{array}$ & $\begin{array}{c}1,96 \\
(0,52)\end{array}$ & $\begin{array}{c}2,32 \\
(0,64)\end{array}$ & $\begin{array}{c}2,49 \\
(0,68)\end{array}$ & $\begin{array}{c}5,42 \\
(1,89)\end{array}$ \\
\hline & $\begin{array}{l}\text { Pós- } \\
\text { Provas }\end{array}$ & $\begin{array}{c}1,71 \\
(0,25)\end{array}$ & $\begin{array}{c}2,10 \\
(0,28)\end{array}$ & $\begin{array}{c}2,48 \\
(0,34)\end{array}$ & $\begin{array}{c}2,66 \\
(0,52)\end{array}$ & $\begin{array}{r}5,22 \\
(1,15)\end{array}$ \\
\hline & $\begin{array}{l}\text { Pós- } \\
\text { Férias }\end{array}$ & $\begin{array}{c}1,65 \\
(0,28)\end{array}$ & $\begin{array}{c}1,99 \\
(0,32)\end{array}$ & $\begin{array}{c}2,35 \\
(0,42)\end{array}$ & $\begin{array}{c}2,58 \\
(0,49)\end{array}$ & $\begin{array}{c}5,46 \\
(1,63)\end{array}$ \\
\hline
\end{tabular}

Foi realizada uma análise de variância para mensurações repetidas (ANOVA) a 3 critérios, a fim de se detectar possíveis diferenças significativas entre os grupos (DTM e controle), entre os músculos examinados (masseter, temporal anterior, temporal médio, temporal posterior) e entre os períodos do estudo com nível de significância de 5\% (Tabela 3). 
Tabela 3 - Análise de variância (ANOVA) a 3 critérios para mensurações repetidas dos LDP $(p<0,05)$

\begin{tabular}{|c|c|c|c|c|c|c|}
\hline Fator & GL & QM & GL erro & $\begin{array}{l}\text { QM } \\
\text { erro }\end{array}$ & $F$ & $p$ \\
\hline Grupo & 1 & 8,28 & 43 & 3,59 & 2,30 & 0,13 \\
\hline Tempo & $3^{*}$ & $4,10^{*}$ & $129 *$ & $0,72^{*}$ & $5,65^{*}$ & $<0,00^{*}$ \\
\hline Músculo & $4^{*}$ & $320,58^{*}$ & $172^{*}$ & $0,93^{*}$ & $343,00^{*}$ & $<0,00^{*}$ \\
\hline Grupo X Tempo & $3^{*}$ & $3,08^{*}$ & $129 *$ & $0,72^{*}$ & $4,25^{*}$ & $<0,00^{*}$ \\
\hline Grupo X Músculo & 4 & 0,10 & 172 & 0,93 & 0,11 & 0,97 \\
\hline Tempo X Músculo & 12 & 0,42 & 516 & 0,24 & 1,76 & 0,05 \\
\hline $\begin{array}{c}\text { Grupo X Tempo X } \\
\text { Músculo }\end{array}$ & $12^{*}$ & $0,76^{*}$ & $516^{*}$ & $0,24^{*}$ & $3,18^{*}$ & $<0,00^{*}$ \\
\hline
\end{tabular}

A comparação entre os diferentes períodos do estudo nos 2 grupos mostrou diferença estatisticamente significativa $(p<0,05)$.

Diferenças estatisticamente significativas $(p<0,05)$ foram encontradas também quando considerados os músculos nos diferentes grupos e períodos de avaliação.

Os valores médios do Limiar de Dor à Pressão dos sítios avaliados e seus respectivos desvios-padrão em cada período estão apresentados nas Tabelas 4, 5, 6 e 7. 


\section{PRÉ-PROVAS}

Tabela 4 - Médias e desvio padrão do LDP de cada músculo em cada grupo no período pré-provas (valores em $\mathrm{Kgf} / \mathrm{cm}^{2}$ )

\begin{tabular}{|c|c|c|c|}
\hline Sítio & Grupo DTM & Grupo Controle & $p$ \\
\hline Masseter & $1,54(0,31)$ & $1,70(0,33)$ & 0,10 \\
\hline Temporal Anterior & $1,67(0,23)$ & $1,98(0,33)$ & $<0,001^{*}$ \\
\hline $\begin{array}{c}\text { Temporal Médio } \\
\text { Temporal }\end{array}$ & $2,21(0,46)$ & $2,25(0,47)$ & 0,81 \\
\hline $\begin{array}{c}\text { Posterior } \\
\text { Tendão de }\end{array}$ & $2,44(0,60)$ & $2,41(0,53)$ & 0,87 \\
\hline Aquiles & $5,14(1,77)$ & $4,77(1,77)$ & 0,50 \\
\hline * estatisticamente significativa & & \\
\hline
\end{tabular}

\section{PROVAS}

Tabela 5 - Médias e desvio padrão do LDP de cada músculo em cada grupo no período de provas (valores em $\mathrm{Kgf} / \mathrm{cm}^{2}$ )

\begin{tabular}{|c|c|c|c|}
\hline Sítio & Grupo DTM & Grupo Controle & $p$ \\
\hline $\begin{array}{c}\text { Masseter } \\
\text { Temporal }\end{array}$ & $1,28(0,24)$ & $1,53(0,33)$ & $0,007^{*}$ \\
\hline $\begin{array}{c}\text { Anterior } \\
\text { Temporal Médio }\end{array}$ & $1,64(0,36)$ & $1,96(0,52)$ & $0,020^{*}$ \\
\hline $\begin{array}{c}\text { Temporal } \\
\text { Posterior }\end{array}$ & $2,05(0,56)$ & $2,32(0,64)$ & $0,003^{*}$ \\
\hline $\begin{array}{c}\text { Tendão de } \\
\text { Aquiles }\end{array}$ & $4,19(1,28)$ & $2,49(0,68)$ & $0,027^{*}$ \\
\hline
\end{tabular}

* = estatisticamente significativa 


\section{PÓS-PROVAS}

Tabela 6 - Médias e desvio padrão do LDP de cada músculo em cada grupo no período de pós-provas (valores em $\mathrm{Kgf} / \mathrm{cm}^{2}$ )

\begin{tabular}{|c|c|c|c|}
\hline Sítio & Grupo DTM & Grupo Controle & $p$ \\
\hline $\begin{array}{c}\text { Masseter } \\
\text { Temporal } \\
\text { Anterior }\end{array}$ & $1,53(0,43)$ & $1,71(0,25)$ & 0,12 \\
\hline $\begin{array}{c}\text { Temporal Médio } \\
\text { Temporal }\end{array}$ & $2,30(0,54)$ & $2,10(0,28)$ & 0,26 \\
\hline $\begin{array}{c}\text { Posterior } \\
\text { Tendão de } \\
\text { Aquiles }\end{array}$ & $2,44(0,65)$ & $2,66(0,52)$ & 0,24 \\
\hline
\end{tabular}

\section{PÓS-FÉRIAS}

Tabela 7 - Médias e desvio padrão do LDP de cada músculo em cada grupo no período de pós-férias (valores em $\mathrm{Kgfl} / \mathrm{cm}^{2}$ )

\begin{tabular}{|c|c|c|c|}
\hline Sítio & Grupo DTM & Grupo Controle & $p$ \\
\hline $\begin{array}{c}\text { Masseter } \\
\text { Temporal } \\
\text { Anterior }\end{array}$ & $1,54(0,36)$ & $1,65(0,28)$ & 0,32 \\
\hline $\begin{array}{c}\text { Temporal Médio } \\
\text { Temporal }\end{array}$ & $2,06(0,47)$ & $1,99(0,32)$ & 0,60 \\
\hline $\begin{array}{c}\text { Posterior } \\
\text { Tendão de } \\
\text { Aquiles }\end{array}$ & $2,47(0,59)$ & $2,35(0,42)$ & 0,97 \\
\hline
\end{tabular}

Com exceção do temporal anterior, os resultados demonstraram diferença estatisticamente significativa somente no período de provas para 
todos os músculos e Tendão de Aquiles em ambos os grupos. O músculo temporal anterior, além do período de provas, apresentou diferença estatisticamente significativa no período pré-provas.

Os resultados do LDP de cada músculo avaliado e do Tendão de Aquiles em todos os períodos estão expressos nas tabelas 8, 9, 10,11 e $12 \mathrm{e}$ nas figuras $11,12,13,14$ e 15 . É possível observar uma tendência geral de diminuição do LDP no período de provas para todos os músculos.

\section{MÚSCULO MASSETER}

Tabela 8 - Média dos LDPs do músculo masseter em cada grupo em todos os períodos do estudo (valores em $\mathrm{Kgf} / \mathrm{cm}^{2}$ )

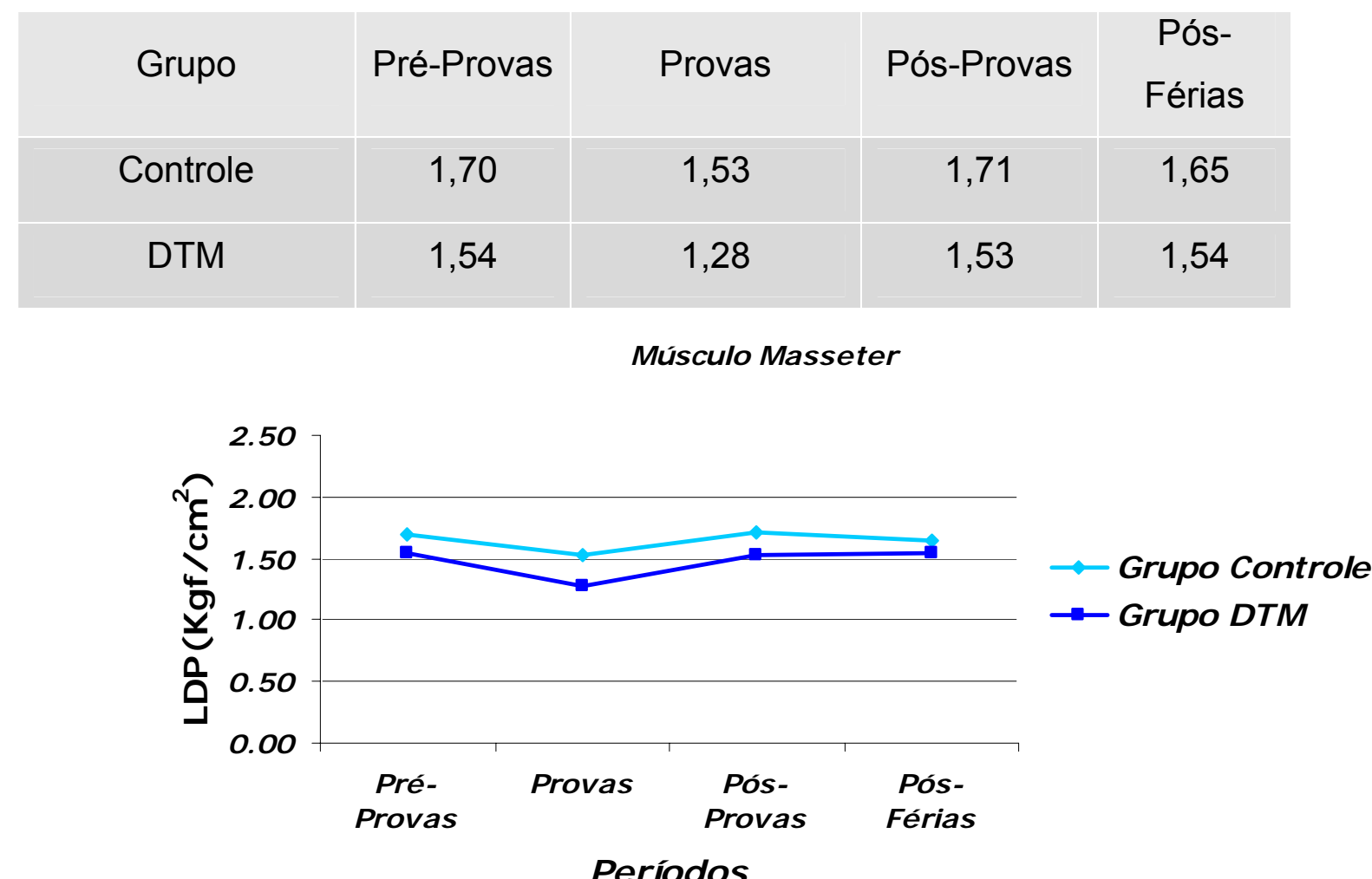

Figura 11 - Valores dos LDPs (valores em $\mathrm{Kgf} / \mathrm{cm}^{2}$ ) do músculo masseter em cada período do estudo (1, 2, 3 e 4) 
O LDP do músculo Masseter demonstrou diferença estatisticamente significativa entre o grupo controle e o grupo com DTM somente no período de provas $(p<0,05)$.

\section{MÚSCULO TEMPORAL ANTERIOR}

Tabela 9 - Média dos LDPs do músculo temporal anterior em cada grupo em todos os períodos do estudo (valores em $\mathrm{Kgf} / \mathrm{cm}^{2}$ )

\begin{tabular}{|c|c|c|c|c|}
\hline Grupo & Pré-Provas & Provas & Pós-Provas & $\begin{array}{c}\text { Pós- } \\
\text { Provas }\end{array}$ \\
\hline Controle & 1,98 & 1,96 & 2,10 & 1,99 \\
\hline DTM & 1,67 & 1,64 & 1,95 & 2,06 \\
\hline
\end{tabular}

Músculo Temporal Anterior

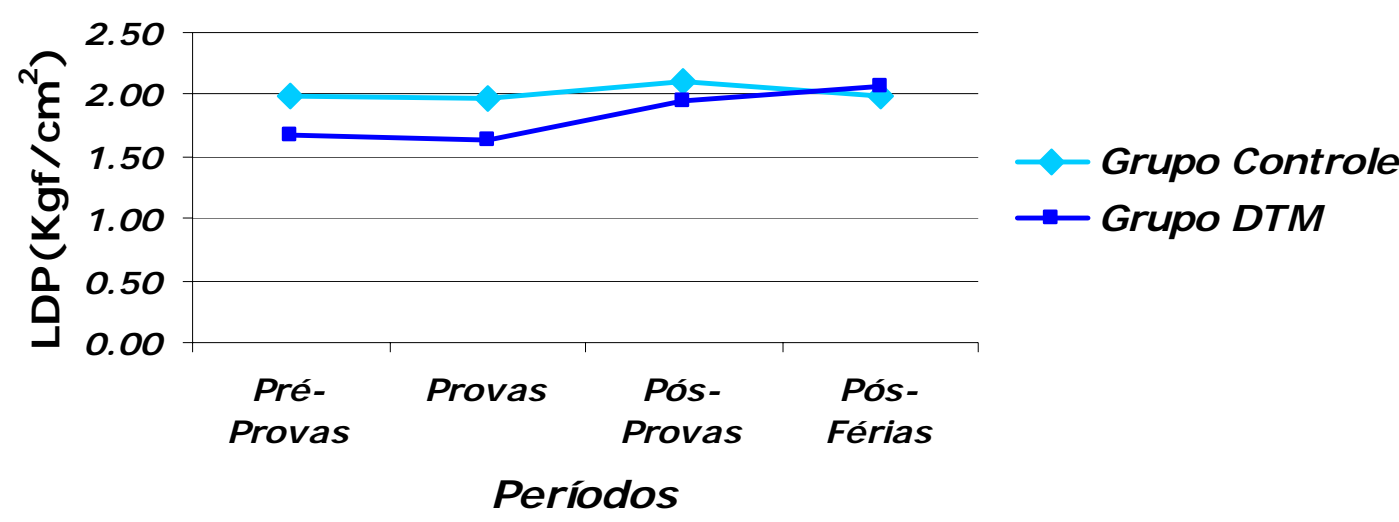

Figura 12 - Valores dos LDPs (valores em $\mathrm{Kgf} / \mathrm{cm}^{2}$ ) do músculo temporal anterior em cada período do estudo (1, 2, 3 e 4)

O LDP do músculo Temporal Anterior apresentou diferença estatisticamente significativa entre os dois grupos nos períodos de pré-provas e de provas $(p<0,05)$. 


\section{MÚSCULO TEMPORAL MÉDIO}

Tabela 10 - Média dos LDPs do músculo temporal médio em cada grupo

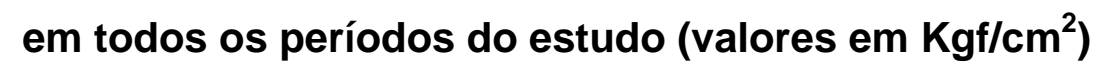

\begin{tabular}{|c|c|c|c|c|}
\hline Grupo & Pré-Provas & Provas & Pós-Provas & $\begin{array}{c}\text { Pós- } \\
\text { Férias }\end{array}$ \\
\hline Controle & 2,25 & 2,32 & 2,48 & 2,35 \\
\hline DTM & 2,21 & 1,83 & 2,30 & 2,35 \\
\hline
\end{tabular}

Músculo Temporal Médio

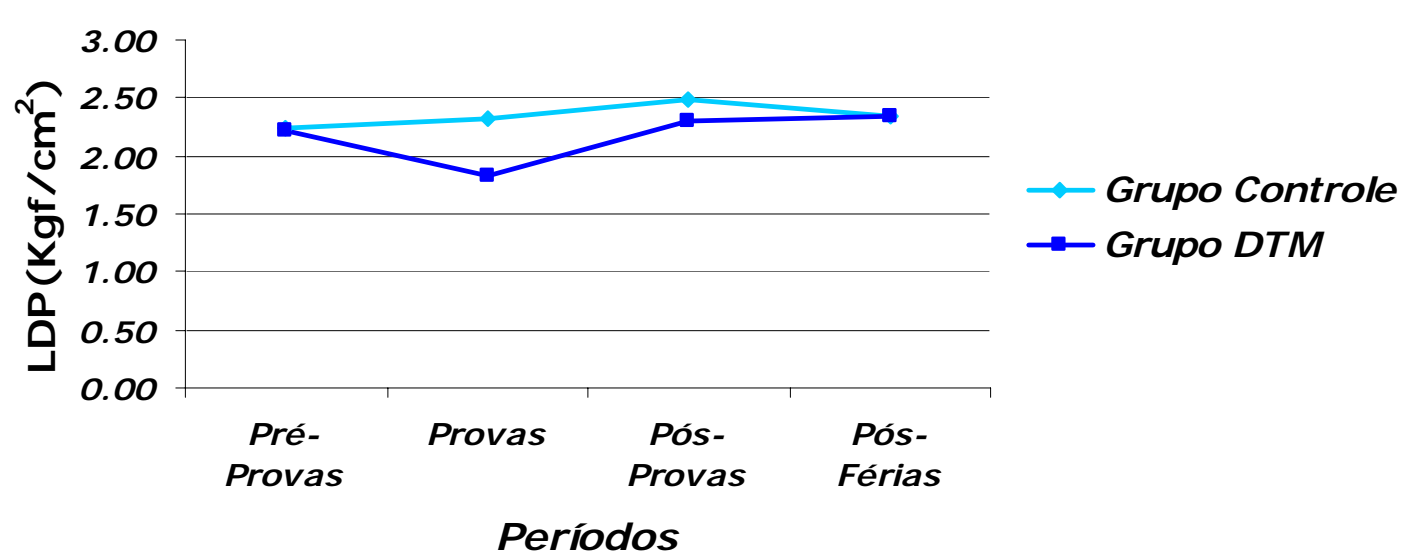

Figura 13 - Valores dos LDPs (valores em $\mathrm{Kgf} / \mathrm{cm}^{2}$ ) do músculo temporal médio em cada período do estudo (1, 2, 3 e 4)

O LDP do músculo Temporal Médio apresentou diferença estatisticamente significativa entre os grupos apenas no período de provas $(p<0,05)$. 


\section{MÚSCULO TEMPORAL POSTERIOR}

Tabela 11 - Média dos LDPs do músculo temporal posterior em cada grupo em todos os períodos do estudo (valores em $\mathrm{Kgf} / \mathrm{cm}^{2}$ )

\begin{tabular}{c|c|c|c|c|} 
Grupo & Pré-Provas & Provas & Pós-Provas & $\begin{array}{c}\text { Pós- } \\
\text { Férias }\end{array}$ \\
\hline Controle & 2,41 & 2,49 & 2,66 & 2,58 \\
\hline DTM & 2,44 & 2,05 & 2,44 & 2,47 \\
\hline
\end{tabular}

Músculo Temporal Posterior

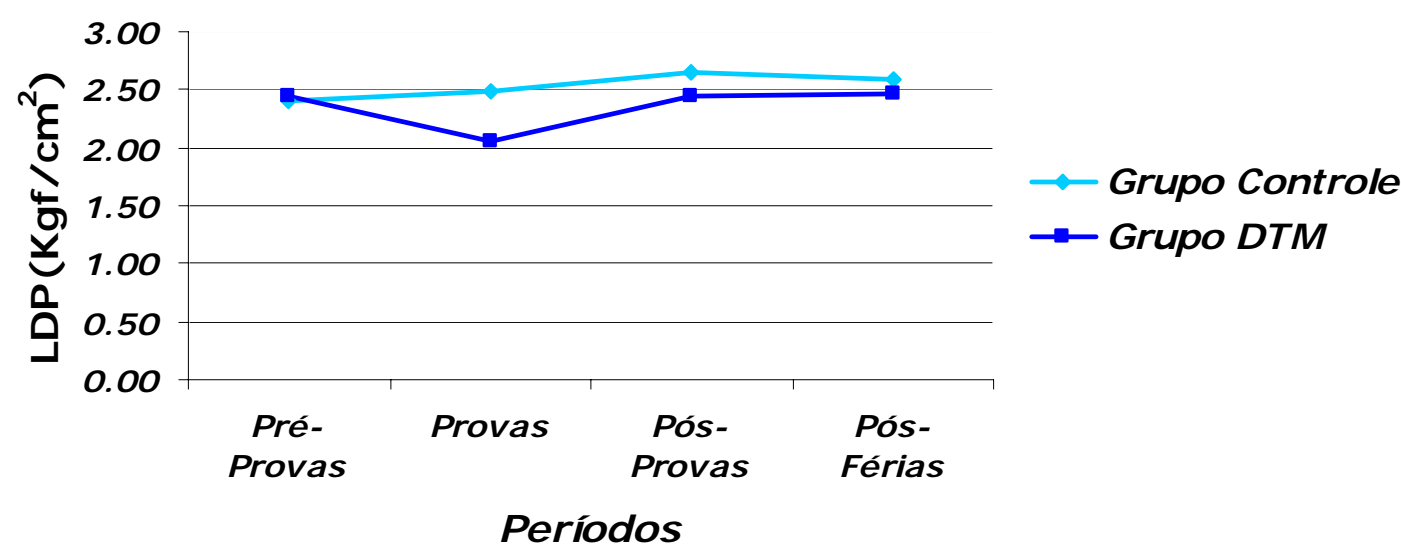

Figura 14 - Valores dos LDPs (valores em $\mathrm{Kgf} / \mathrm{cm}^{2}$ ) do músculo temporal posterior em cada período do estudo $(1,2,3$ e 4)

O LDP do músculo Temporal Posterior apresentou diferença estatisticamente significativa entre os grupos apenas no período de provas $(p<0,05)$. 


\section{TENDÃO DE AQUILES}

Tabela 12 - Média dos LDPs do tendão de Aquiles em cada grupo em todos os períodos do estudo (valores em $\mathrm{Kg} / \mathrm{cm}^{2}$ )

\begin{tabular}{|c|c|c|c|c|}
\hline Grupo & Pré-Provas & Provas & Pós-Provas & $\begin{array}{c}\text { Pós- } \\
\text { Férias }\end{array}$ \\
\hline Controle & 4,77 & 5,42 & 5,22 & 5,46 \\
\hline DTM & 5,14 & 4,19 & 4,92 & 5,46 \\
\hline
\end{tabular}

Tendão Aquiles

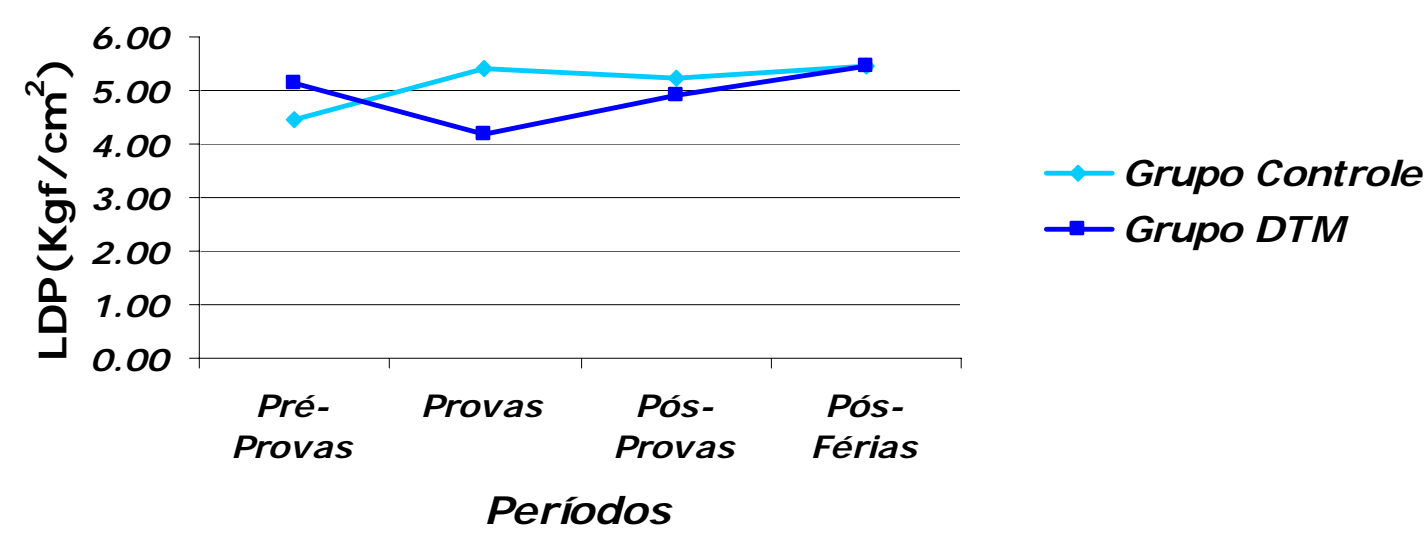

Figura 15 - Valores dos LDPs (valores em $\mathrm{Kgf} / \mathrm{cm}^{2}$ ) do tendão de Aquiles em cada período do estudo (1, 2, 3 e 4)

O LDP do Tendão de Aquiles apresentou diferença estatisticamente significativa entre os grupos apenas no período de provas $(p<0,05)$. 


\subsection{Escala de Análise Visual (EAV)}

Os valores médios da Escala de Análise Visual (EAV) de ambos os grupos (DTM e controle) em cada período, juntamente com seus respectivos desvios-padrão estão apresentados na tabela 13 e representados na figura 16.

Tabela 13 - Média e desvio padrão de dor na Escala de Análise Visual (EAV) de cada grupo em todos os períodos do estudo (valores em $\mathrm{cm}$ )

\begin{tabular}{|c|c|c|c|c|}
\hline Grupo & Pré-Provas & Provas & Pós-Provas & Pós-Férias \\
\hline DTM & $2,07(2,46)$ & $3,24(2,67)$ & $1,59(2,06)$ & $1,27(2,17)$ \\
\hline Controle & $0,11(0,45)$ & $0,27(0,82)$ & $0,06(0,25)$ & $0,0(0)$ \\
\hline$p$ & $0,00012^{*}$ & $0,00007^{*}$ & $0,00776^{*}$ & $0,03701^{*}$ \\
\hline
\end{tabular}

* = estatisticamente significativa

\section{EAV}

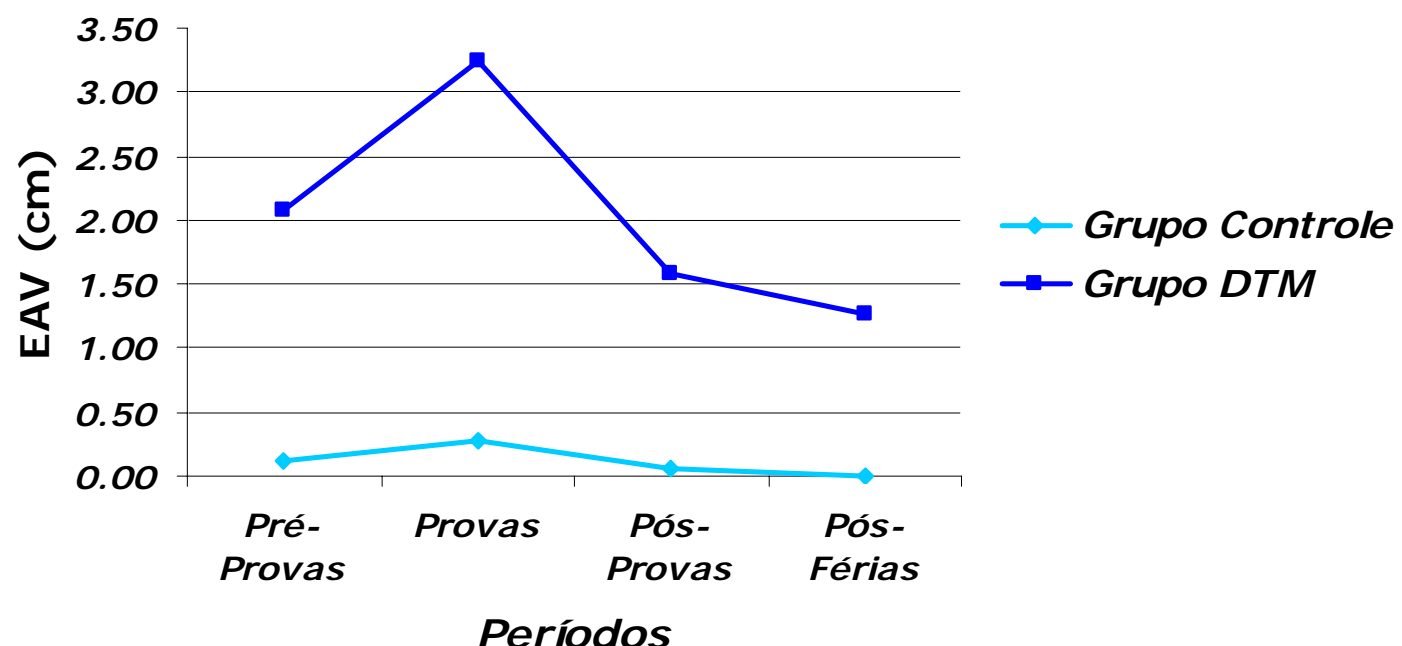

Figura 16 - Valores da EAV (valores em centímetros) de ambos os grupos em cada período do estudo (1, 2, 3 e 4)

Os resultados da Escala de Análise Visual mostraram diferenças estatisticamente significativas entre o grupo com DTM e o grupo controle em todos os períodos da pesquisa (T1, T2, T3 e T4), sendo o maior valor encontrado para o grupo com DTM no período das provas (T2). 


\subsection{Estresse e Ansiedade}

As tabelas 14, 15, 16 e 17 demonstram o número de indivíduos em cada grupo com presença de estresse nos diferentes momentos de avaliações, de acordo com o ISSL. Tais dados estão representados nas figuras 17, 18, 19 e 20, respectivamente. Foi utilizado ANOVA a 2 critérios para obtenção destes dados. Além disso, foi aplicado o teste de Correlação de Pearson com objetivo de avaliar a possível correlação entre o ISSL em cada período com os 2 grupos.

Tabela 14 - Número e valores percentuais de indivíduos com presença ou ausência de estresse segundo o ISSL de cada grupo no período PréProvas do estudo

\begin{tabular}{|c|c|c|c|}
\hline Grupo & ISSL negativo & ISSL positivo & Total \\
\hline Controle & $7(43,75 \%)$ & $9(56,25 \%)$ & 16 \\
\hline DTM & $15(51,72 \%)$ & $14(48,28 \%)$ & 29 \\
\hline$p=0,608$; sem diferença significante & & \\
\hline
\end{tabular}

ISSL Pré-Provas

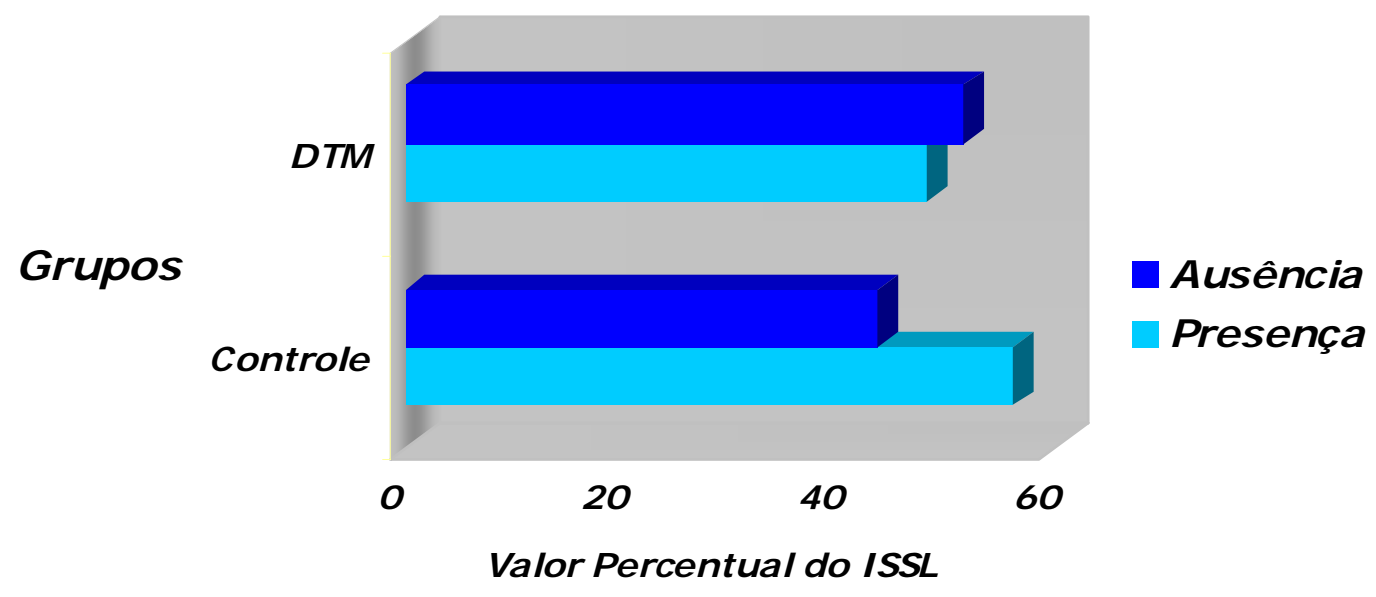

Figura 17 - Gráfico demonstrativo da presença e ausência do estresse (valor percentual), segundo o ISSL, em cada grupo do estudo no período pré-provas 
Tabela 15 - Número e valores percentuais de indivíduos com presença ou ausência de estresse segundo o ISSL de cada grupo no período de Provas do estudo

\begin{tabular}{|c|c|c|c|}
\hline Grupo & ISSL negativo & ISSL positivo & Total \\
\hline Controle & $5(31,25 \%)$ & $11(68,75 \%)$ & 16 \\
\hline DTM & $11(37,93 \%)$ & $18(62,07 \%)$ & 29 \\
\hline$p=0,654$; sem diferença significante & & \\
\hline
\end{tabular}

$p=0,654 ;$ sem diferença significante

ISSL Provas

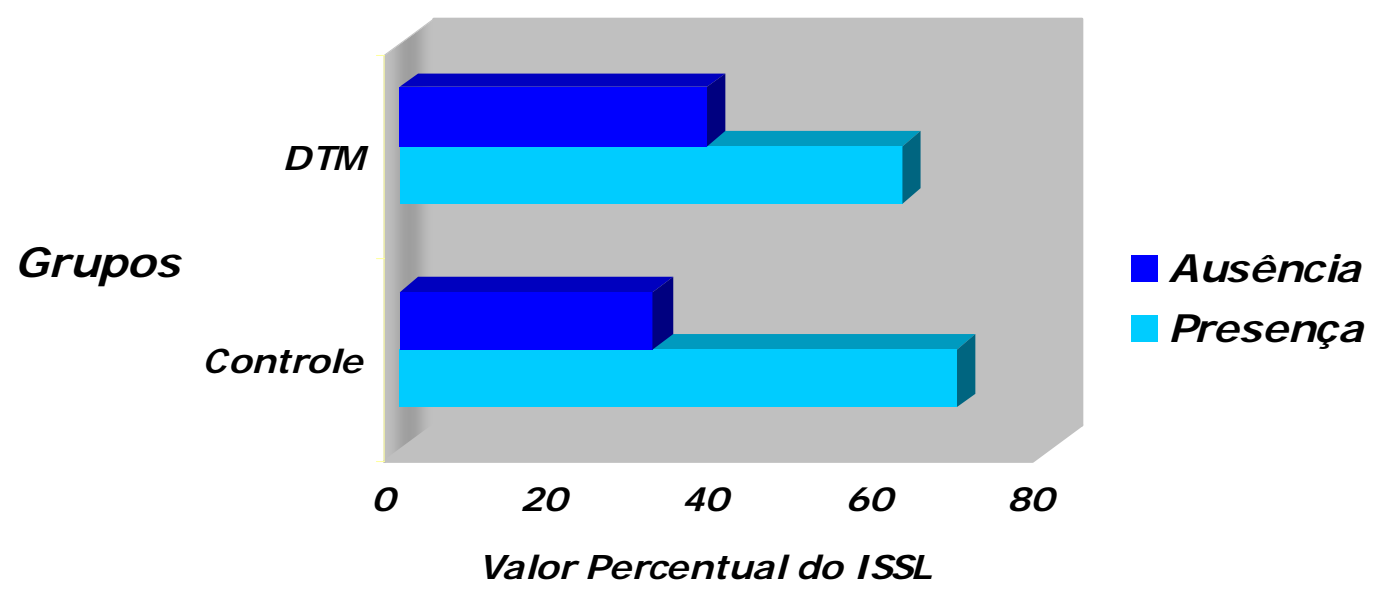

Figura 18 - Gráfico demonstrativo da presença e ausência do estresse (valor percentual), segundo o ISSL, em cada grupo do estudo no período de provas 
Tabela 16 - Número e valores percentuais de indivíduos com presença ou ausência de estresse segundo o ISSL de cada grupo no período PósProvas do estudo

\begin{tabular}{|c|c|c|c|}
\hline Grupo & ISSL negativo & ISSL positivo & Total \\
\hline Controle & $11(68,75 \%)$ & $5(31,25 \%)$ & 16 \\
\hline DTM & $15(51,72 \%)$ & $14(48,28 \%)$ & 29 \\
\hline
\end{tabular}

$p=0,268$; sem diferença significante

\section{ISSL Pós-Provas}

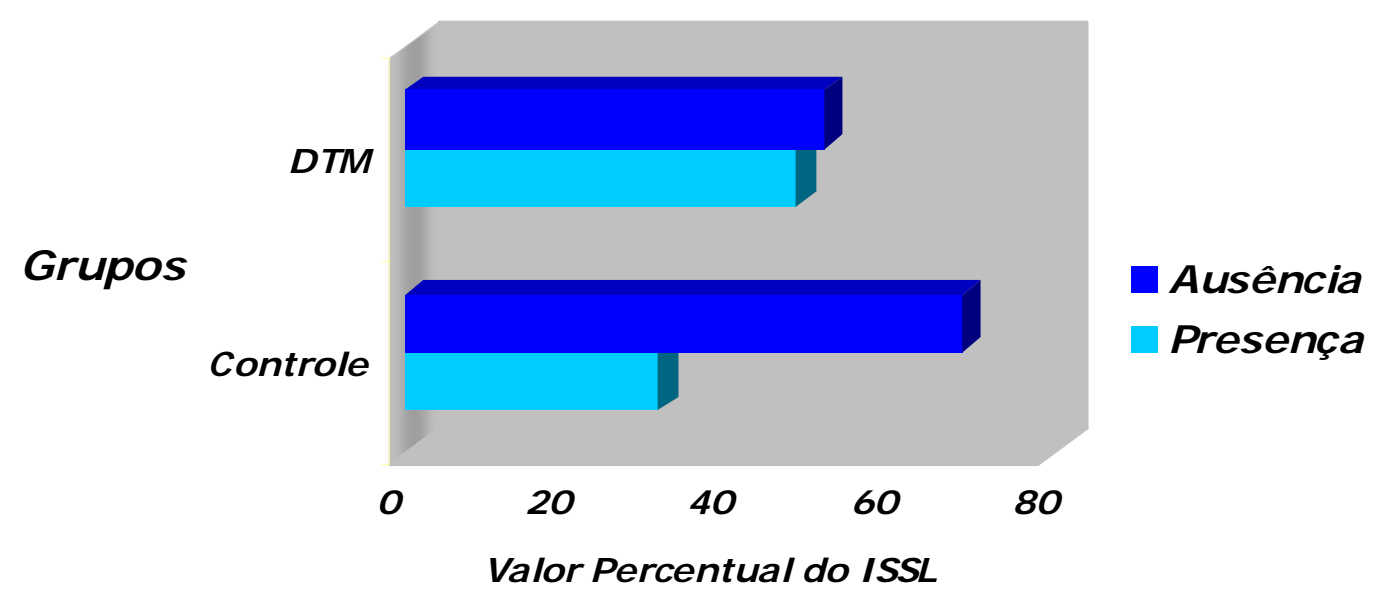

Figura 19 - Gráfico demonstrativo da presença e ausência do estresse (valor percentual), segundo o ISSL, em cada grupo do estudo no período pós-provas 
Tabela 17 - Número e valores percentuais de indivíduos com presença ou ausência de estresse segundo o Inventário de Sintomas de Stress de Lipp (ISSL) de cada grupo no período Pós-Férias do estudo

\begin{tabular}{|c|c|c|c|}
\hline Grupo & ISSL negativo & ISSL positivo & Total \\
\hline Controle & $7(43,75 \%)$ & $9(56,25 \%)$ & 16 \\
\hline DTM & $20(68,97 \%)$ & $9(31,03 \%)$ & 29 \\
\hline$p=0,098$; sem diferença significativa & & \\
\hline
\end{tabular}

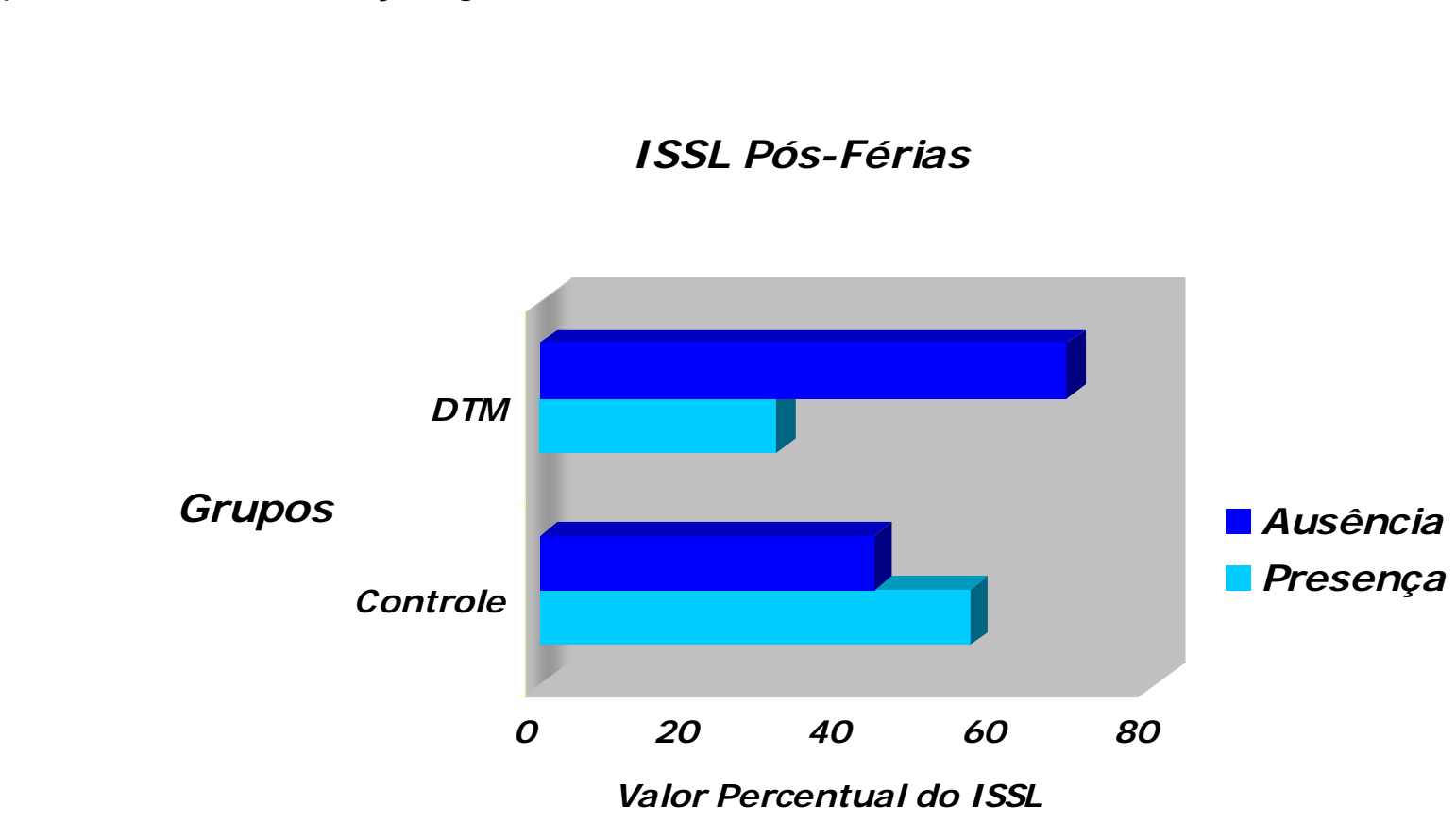

Figura 20 - Gráfico demonstrativo da presença e ausência do estresse (valor percentual), segundo o ISSL, em cada grupo do estudo no período pós-férias 
Tabela 18 - Número e valores percentuais de indivíduos com presença de estresse segundo o Inventário de Sintomas de Stress de Lipp (ISSL) de cada grupo em todos os períodos do estudo

\begin{tabular}{|c|c|c|c|c|}
\hline Grupo & Pré-Provas & Provas & Pós-Provas & Pós-Férias \\
\hline Controle & $14(48,28 \%)$ & $18(62,07 \%)$ & $14(48,28 \%)$ & $9(31,03 \%)$ \\
\hline DTM & $9(56,25 \%)$ & $11(68,75 \%)$ & $5(31,25 \%)$ & $9(56,25 \%)$ \\
\hline
\end{tabular}

\section{Estresse}

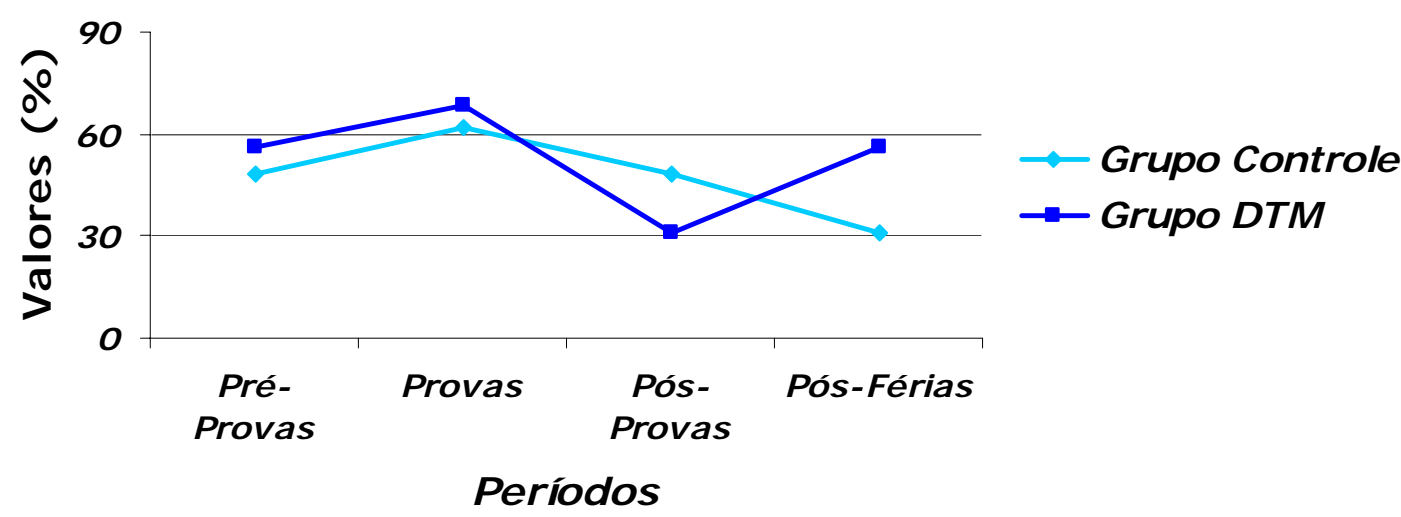

Figura 21 - Valores percentuais de indivíduos com estresse, segundo o ISSL, em cada grupo nos diferentes períodos do estudo

Foi possível observar aumento do estresse no período de provas para ambos os grupos. No houve diferenças estatisticamente significante entre os grupos em cada avaliação ( $p>0,05)$. Porém, houve diferença estatisticamente significante entre os períodos em ambos os grupos $(p<0,05)$, sendo a maior diferença encontrada no grupo com DTM entre o período de provas e o período pós-provas $(p=0,01)$. 


\section{ANSIEDADE}

Na tabela 19 e Figura 22 estão apresentadas as médias dos valores de ansiedade e desvio padrão, segundo o BAI, de cada grupo em todos os períodos do estudo.

Tabela 19 - Médias dos valores de ansiedade e desvio padrão segundo o Inventário de Ansiedade de Beck (BAI) de cada grupo em todos os períodos do estudo (escala numérica de 0 a 63)

\begin{tabular}{|c|c|c|}
\hline Períodos & Grupo Controle & Grupo DTM \\
\hline $\begin{array}{c}\text { Pré- } \\
\text { Provas }\end{array}$ & $10,5(0,81)$ & $12,38(0,81)$ \\
\hline Provas & $10,62(0,81)$ * & $14,28(0,97)$ * \\
\hline $\begin{array}{c}\text { Pós- } \\
\text { Provas }\end{array}$ & $5,62(0,73)$ * & $7,86(1,01)$ \\
\hline $\begin{array}{l}\text { Pós- } \\
\text { Férias }\end{array}$ & $7,93(1,16)$ & $6,90(0,86)$ * \\
\hline
\end{tabular}

\section{Ansiedade}

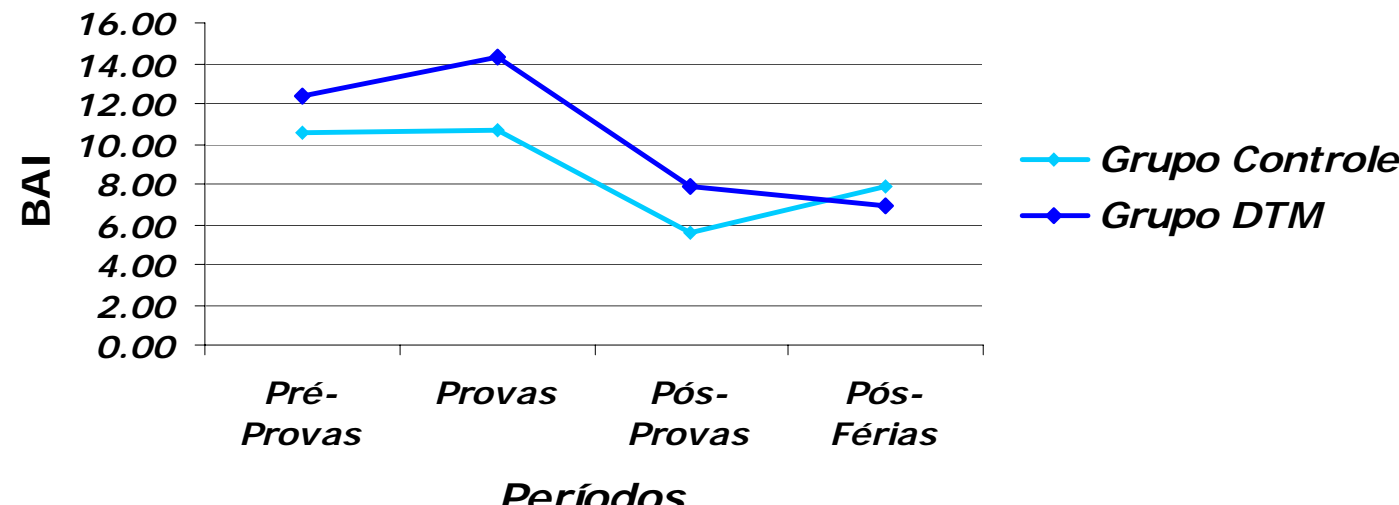

Figura 22 - Valores de ansiedade (escala numérica), segundo o BAI, em cada grupo nos diferentes tempos do estudo 
Quando aplicado o teste de Friedman, observa-se uma maior ansiedade no período de provas para ambos os grupos. No houve diferenças estatisticamente significante entre os grupos em cada avaliação $(p>0,05)$. Porém, houve diferença estatisticamente significante entre os períodos em ambos os grupos $(p<0,05)$, sendo que a maior diferença encontrada foi no grupo com DTM entre o período de provas e o período pós-férias $(p=0,001)$. 


\section{Discussão}




\section{DISCUSSÃO}

A Dor é uma experiência pessoal e complexa, que envolve vários componentes sensoriais, afetivos, cognitivos, sociais e comportamentais ${ }^{142}$. Como uma das principais causas do sofrimento humano, segundo a Associação Internacional do Estudo da Dor (IASP), a dor é uma experiência sensorial e emocional desagradável, associada a um dano tissular real ou potencial, ou descrita em termos desse dano. Ela é uma experiência pessoal e subjetiva e o seu conhecimento só nos é dado pelo relato pessoal daquele que sofre a dor ${ }^{121}$.

Pela vertente psicológica, a concepção de dor pode ser enfaticamente concebida como uma experiência perceptiva, sensível, cuja qualidade e intensidade são influenciadas pela singularidade, história de vida e significado atribuído pelo indivíduo à situação produtora de dor, das condições físicas e emocionais e pelo seu estado de espírito do momento ${ }^{188}$.

MERSKEY ; SPEAR ${ }^{123}$ em 1967, mostraram que na queixa da dor, na maioria dos casos, o paciente já traz componentes psicológicos e físicos entrelaçados, sendo a separação destes inadequada quanto à compreensão da dor. Mostraram também que dores de origem psicogênica podem se tornar físicas. Portanto, a separação dos tipos de dor é menos importante do que a compreensão da complexidade da mesma e da realidade de todas as dores para a pessoa que a sente ${ }^{19}$.

Embora as diferentes definições de dor nos remetam a traços comuns, como o caráter de subjetividade, a natureza sensível, a condição de desprazer, ainda assim há muitas incertezas neste campo, constituindo-se ainda em uma grande incógnita ${ }^{75}$. De maneira igual, a experiência dolorosa tem forte relação com o nível de nocicepção, ou seja, a magnitude do estímulo nocivo e a atitude básica do ser humano diante da vida ${ }^{188}$.

Alguns estudos mostraram a importância de se diferenciar dor aguda de dor crônica. Na dor aguda ocorrem modificações no ritmo cardíaco, na 
sudorese, na pressão sangüínea e na tensão muscular ${ }^{143}$. Há uma resposta da emergência no organismo que é relacionada com o estímulo doloroso tanto quanto com a ansiedade que este provoca, sendo semelhante ao quadro psicológico da ansiedade. Na dor crônica, caracterizada como uma dor que dura vários meses, alterações como: insônia, falta de apetite, irritabilidade, isolamento e libido rebaixada são mais comuns, formando um quadro semelhante ao depressivo. As medicações para ansiedade e as antidepressivas, respectivamente, parecem ser eficientes auxiliares no controle dessas dores. Nos dois casos, a problemática psicológica envolvida leva à necessidade de auxílio psicoterápico ${ }^{19}$.

Dentre as inúmeras diferentes dores que acometem os seres humanos, a dor na região orofacial é um problema de saúde muito comum na sociedade atual ${ }^{30}$, constituindo uma das razões pelas quais as pessoas procuram os consultórios odontológicos. Segundo a Academia Americana de Dor Orofacial, as Disfunções Temporomandibulares (DTM) são definidas como um termo coletivo utilizado para descrever patologias relacionadas à articulação temporomandibular (ATM), às musculaturas mastigatórias ou ambas $^{118}$. Clinicamente, parece estar associada freqüentemente com distúrbios na função somatosensorial e motora dos maxilares, juntamente com alterações

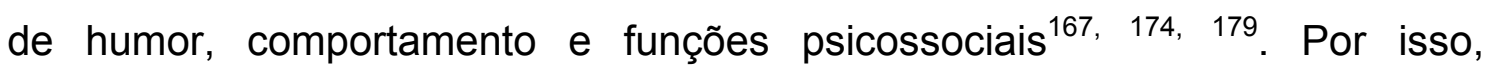
principalmente nos últimos anos, tem sido alvo de vários estudos, na tentativa de elucidar alguns conceitos e relevâncias clínicas importantes, verificando-se o aspecto da influência dos fatores psicossociais no limiar de dor da região orofacial.

Uma das maiores dificuldades encontradas nos trabalhos sobre DTM é a seleção homogênea da amostra. $\mathrm{Na}$ intenção de estudar uma população representativa e adequada de acordo com dados já esclarecidos pela literatura científica, a amostra do presente estudo restringiu-se somente aos indivíduos do gênero feminino. Isso se deve ao fato de que vários estudos epidemiológicos têm revelado a maior prevalência de DTM em mulheres ${ }^{29}$, com uma proporção entre mulheres e homens variando de $3: 1$ a 6:1 12,119, 153. Outros autores, entretanto, argumentam que estas taxas são vistas nas pessoas que 
realmente procuram por tratamento de DTM, e não em uma população em geral ${ }^{35}$. A literatura ainda não é clara a respeito das possíveis razões do porquê de as mulheres procurarem mais freqüentemente tratamento dos sintomas de DTM do que os homens. Fatores hormonais e constitucionais, e uma combinação de variáveis biológicas, psicológicas e sociais, são sustentados como possíveis explicações para este fato ${ }^{41}$.

Além das inúmeras diferenças anatômicas e genéticas entre homens e mulheres, os autores sugerem que as mulheres têm maior consciência ou preocupação com sua saúde do que os homens, e estão em estado de alerta para perceberem sensações físicas, como indicativas de doença ${ }^{32}$. Vários trabalhos sugerem que as mulheres são mais sensíveis a estímulos dolorosos que os homens ${ }^{9}$, 186. Da mesma forma, parecem ter maior sensibilidade e/ou maior resposta fisiológica aos estímulos em outras modalidades sensoriais (visual, auditiva, tátil) ${ }^{187}$. Acredita-se, portanto, que as mulheres possuem um aparato perceptivo mais sensível que os homens, possuem níveis dolorosos mais severos, mais freqüentes e de mais longa duração, o que pode ser atribuído a causas hormonais, que continuam a serem investigadas ${ }^{32}$.

Diferenças entre os gêneros em relação aos níveis de tensão nos músculos mastigatórios e tolerância à dor também têm sido citados como possíveis explicações para a maior prevalência de distúrbios musculoesqueletais nas mulheres ${ }^{38}$. Existem fortes indícios de que as mulheres são menos tolerantes à dor, exibem limiares de dor mais baixos ou podem ser mais sensíveis à dor ${ }^{45,47,153}$. Além disso, outros estudos têm demonstrado que as mulheres relatam mais ruídos nas ATMs, deflexão mandibular, dor à palpação dos músculos e ATM, dor de cabeça, diminuição da amplitude dos movimentos mandibulares, e disfunção articular $^{108,153 .}$

CONTI et al. ${ }^{29}$ investigaram a prevalência de sinais e sintomas de DTM, sua relação quanto ao gênero e associações aos fatores oclusais e psicológicos em um grupo de 310 estudantes pré-universitários e universitários. As avaliações ocorreram por meio de um questionário anamnésico para classificar a severidade dos sintomas associado ao relato de estresse. Os 
resultados mostraram que houve correlação positiva entre DTM, o relato de estresse e hábitos parafuncionais. A avaliação da presença de estresse não ocorreu através de instrumentos de análise psicológica, porém os resultados são semelhantes àqueles encontrados no presente trabalho. Além disso, as mulheres apresentaram significantemente mais sintomas que os homens e com maior gravidade.

Tais fatos explicam a decisão de realizar o presente trabalho somente com universitárias. $\mathrm{O}$ fato de se incluir homens numa pesquisa com o objetivo de ser verificada a participação de fatores psicológicos na manifestação de DTM, poderia levar a mais um fator de confusão. Ainda, a constituição de um grupo de DTM, de gênero masculino, seria difícil de ser obtido.

Com relação aos fatores psicológicos, encontram-se diferenças significantes entre homens e mulheres no relato da dor. Mulheres são muito mais vulneráveis a alterações de humor e apresentam duas vezes mais probabilidade de desenvolver patologias psíquicas que os homens ${ }^{174}$. Descrições mais específicas com relação a participação do estresse e ansiedade nas DTMs das mulheres estão propostas no decorrer deste item.

A respeito dos achados clínicos habituais que compõem a sintomatologia dos pacientes com DTM, a sensibilidade muscular à palpação está entre os mais comuns. Estes dados têm sido verificados tanto em estudos clínicos, quanto em estudos epidemiológicos, onde são encontrados Limiares de Dor à Pressão (LDP) diminuída em músculos comprometidos ${ }^{18,}$ 21, 101, 102. Essas informações são elucidadas com significativa propriedade no relato do estudo epidemiológico de TRUELOVE et al. ${ }^{182}$, 1992. Os autores encontraram, a partir de uma amostra de 350.000 indivíduos, uma alta prevalência de pacientes com sinais e sintomas compatíveis com DTM miogênica, tanto no grupo que buscava tratamento $(88,7 \%)$, quanto no grupo que não buscava tratamento $(77,5 \%)$. 
Considerando esta grande prevalência das patologias musculares em pacientes com DTM, associada ao desenvolvimento dos exames diagnósticos a partir dos anos 70 , os estudos referentes ao exame de palpação

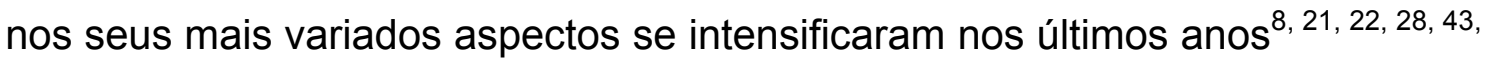
$52,54,76,81,101,116,140,168,180$

Já há algumas décadas, o Limiar de Dor à Pressão é utilizado para avaliar sensibilidade em reumatologia nas artrites, além de ser empregado também na documentação de fibromialgia ${ }^{52}$. Somente a partir da década de 80 , esse termo passou a ser adotado nas DTMs com o objetivo de avaliar sensibilidade muscular e articular à pressão $20,80,81,125,151$.

Tendo como definição para LDP o ponto a partir do qual uma força

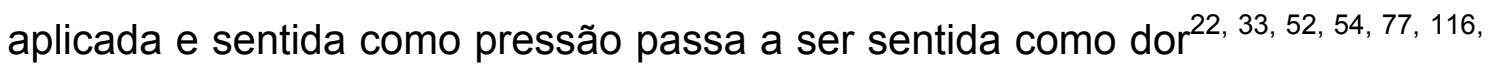
$117,125,131,139$, tornou-se necessária a padronização de um método com mais fidelidade que a palpação manual ${ }^{39,140}$. Com intuito de medir objetivamente o LDP dos músculos em indivíduos sintomáticos e assintomáticos, a algometria tem sido utilizada $51,52,62,81,82,101,140,151$. Dessa forma, tem-se conseguido quantificar a pressão exercida no músculo com grande confiabilidade, obtendose parâmetros objetivos que possam ser usados durante o processo diagnóstico, para pesquisas e para avaliação da eficácia de tratamentos realizados em estudos populacionais ${ }^{54,78,81,82,116,139,169 .}$

A algometria foi utilizada neste estudo com significativa segurança, já que a literatura científica tem descrito o sucesso do método quando avalia a sensibilidade muscular (LDP), tanto em sintomáticos quanto em assintomáticos e nos músculos masseter e temporal, como foi proposto por esta pesquisa ${ }^{21,76,}$ 81, 100, 152, 168 . Segundo GOULET et al. ${ }^{64}$, em 1998, relataram que, nestes dois músculos, o LDP pode ser medido com maior confiabilidade devido à alta reprodutibilidade que apresentaram.

A determinação do LDP com o auxílio de um algômetro pode ser influenciada por alguns fatores, como o tempo de reação do paciente e do examinador, a área da ponta do aparelho, e o próprio aspecto subjetivo do 
relato de dor ${ }^{81}$. Visando suprir estes fatores, este estudo utilizou um algômetro com ponta de $1 \mathrm{~cm}^{2}$, segundo o recomendado pela literatura ${ }^{20-22,51,52,54,58,64,76-}$ $78,101,102,116,117,122,125168$, na qual foi adaptado um adesivo de acetato, para maior conforto da voluntária. Além disso, o algômetro utilizado da marca Kratos $^{\circledR}$ possui um dispositivo que é controlado pelo paciente e este o pressiona para determinar o momento exato do início da dor no exame de pressão muscular, diminuindo, assim, o tempo de reação do paciente.

Estas medidas foram adotadas com objetivo de evitar ao máximo as distorções dos valores obtidos, já que os pacientes com DTM desta amostra não apresentaram níveis de LDP significativamente baixos. Segundo Silva et al. ${ }^{168}$, ao compararem o LDP entre indivíduos assintomáticos e pacientes com sinais e sintomas de DTM miofascial, determinaram que o valor de corte do LDP para o masseter é $1,5 \mathrm{Kgf} / \mathrm{cm}^{2}, 2,47 \mathrm{Kgf} / \mathrm{cm}^{2}$ para o temporal anterior, 2,75 $\mathrm{Kgf} / \mathrm{cm}^{2}$ para o temporal médio e $2,77 \mathrm{Kgf} / \mathrm{cm}^{2}$ para o temporal posterior. A partir desses dados, é possível afirmar que a amostra do presente trabalho apresenta valores médios de LDP que tangenciam os valores de corte descritos na literatura. Este fato se deve, provavelmente, pelas características peculiares da amostra. Em um grupo exclusivamente de alunas universitárias não é comum a prevalência de DTM severa.

Para a obtenção dos LDP, no presente estudo, a pressão foi feita sempre com os músculos relaxados, seguindo a recomendação da literatura ${ }^{64}$, 78, 82, 101, 116. A literatura ressalta, ainda, que esses dois músculos podem ser considerados os mais adequados para diferenciar doentes de não doentes, pela sua alta prevalência de sensibilidade nos casos de DTM miogênica ${ }^{64}$; isso, por serem músculos freqüentemente acometidos por patologias musculares compatíveis com DTM, além de serem relativamente planos e apresentarem um suporte ósseo subjacente uniforme, o que facilita o acesso à palpação ${ }^{21,139}$.

Alguns autores têm questionado, já há décadas, a origem desta dor muscular durante a palpação ${ }^{33,81,152}$. A etiologia da DTM miogênica é ainda indefinida, embora vários fatores estejam nela implicados. Algumas teorias têm atribuído o problema às variáveis de personalidade e estressores 
psicossociais $^{26}$. Atualmente, concorda-se que os fatores psicológicos como estresse e ansiedade têm papel influente na manifestação da patologia, embora sua natureza seja pouco clara ${ }^{26,68}$.

Acredita-se que 0 estresse aumente a atividade de trabalho muscular por diferentes mecanismos hormonais, considerando que, na presença de estresse, ocorram reações orgânicas sistêmicas, e, dentre elas, as relacionadas aos músculos da cabeça e pescoço ${ }^{120}$. Outra teoria ${ }^{17}$ é que a presença de estressores faz com que ocorra uma ativação excessiva do sistema nervoso simpático, contribuindo para uma experiência de intensificação da dor. AUVENSHINE ${ }^{3}$, em 1997, hipotetizou, baseado em pesquisas na área de psiconeuroimunologia, que o estresse pode causar supressão do sistema imunológico, que por sua vez influencia o Sistema Nervoso Central (SNC). Afirma, ainda, que o SNC não diferencia os fatores estruturais anatômicos do sistema mastigatório e os fatores psicológicos. Reage a ambos de uma forma única. Através de mediadores químicos e neurotransmissores, a coordenação entre as estruturas funcionais e componentes psicológicos é basicamente um processo bioquímico. Serotonina, norepinefrina e acetilcolina ativam o hipotálamo. Norepinefrina, epinefrina, corticoesteróides, opiáceos e dopamina conduzem à imunodepressão. Em 1969, LASKIN $^{95}$ já descreveria a teoria psicofisiológica para a etiologia das DTMs, na qual sugere-se que espasmos musculares são o principal fator para a ocorrência dos sinais e sintomas de DTM. Acreditando que a fadiga muscular, devido ao apertamento e ranger de dentes, seja a principal causa de mioespasmos, LASKIN ${ }^{95}$ hipotetizou, então, uma condição auto-perpetuante, onde um padrão anormal de atividade muscular reforçaria o mioespasmo original e a dor, gerando um ciclo vicioso entre um problema funcional (bruxismo) e uma doença orgânica (DTM).

Entretanto, não são todos os autores que acreditam que a dor muscular possa ser devido à hiperatividade dos músculos, mas que seja reflexa, por modificações vasculares, neurais, estruturais e químicas, como resultado ou em associação à sobreatividade simpática generalizada ${ }^{4}$. De acordo com MENSE ${ }^{122}$, não há nenhuma prova experimental de que esse ciclo vicioso de eventos realmente exista. Muito embora a etiologia precisa da DMF 
ainda não seja conhecida, LOBBEZZO; LAVIGNE ${ }^{103}$ sustentam a hipótese de uma etiologia multifatorial, substanciada pela ação conjunta de fatores estruturais (oclusão, anatomia das articulações temporomandibulares e esqueleto); psicológicos e funcionais (neuromuscular).

Da mesma forma, LUND et al. ${ }^{106}$ questionaram a hipótese de que a disfunção (hiperatividade ou espasmos musculares) característica nos vários quadros de dores musculares crônicas (por exemplo, a DTM) seja a causa da dor; propondo tratar-se, a disfunção, de um mecanismo adaptativo normal de proteção. Atribui-se essa hiperatividade a várias causas, sendo as mais comuns a fadiga ou a sobrecarga funcional, anormalidades estruturais e estresse emocional. Os autores expõem a teoria de TRAVELL, ${ }^{181}$ sobre a conversão de uma condição aguda em crônica, a qual hipotetiza que a dor e a hiperatividade estão reciprocamente ligadas: os espasmos musculares causando dor, que por sua vez, reforça a disfunção, compondo um "ciclo vicioso" autoperpetuante. Os autores apresentam evidências de que, embora a dor provoque pequenas mudanças na atividade postural dos músculos, ela modifica a performance muscular reduzindo a ação dos músculos agonistas e aumentando o nível de contrações dos antagonistas. Os autores atribuem, mais provavelmente, a uma resposta geral do paciente à dor, parte da responsabilidade pela hiperatividade muscular. Também se encontrou evidência de que esses pacientes apresentam níveis eletromiográficos dos músculos anteriores significativamente maiores, tanto no repouso quanto durante o movimento, do que o grupo controle com correspondência de idade. A natureza crônica dessas dores pode ser devido à repetição periódica do trauma. Concluem que há evidências de que a dor não causa hiperatividade muscular e de que sua capacidade de contração máxima é reduzida, e não aumentada pela dor.

A partir deste momento, surgiu um grande interesse em registrar a atividade eletromiográfica (EMG) de músculos doloridos. O relato de atividade EMG aumentada passou a ser indicativo de contratura ou espasmos. A sensibilidade muscular à palpação dos portadores de DTM tem sido relacionada ao aumento da atividade muscular postural. Entretanto, estudos 
recentes têm encontrado uma diferença de aproximadamente $2 \mu \mathrm{V}$ na atividade EMG de repouso entre pacientes com DTM e indivíduos controle ${ }^{31,61}$ não sendo um aumento que justifique a condição dolorosa. Por outro lado, são também recentes os estudos ${ }^{10}$ que encontraram aumentos consideráveis na atividade EMG de repouso em uma população com DTM miogênica e dor neuropática em relação a indivíduos controle. Mas os autores atribuíram esse aumento a um mecanismo central e não ao ciclo vicioso.

Dessa forma, a literatura é controversa ao analisar atividade EMG de pacientes com diferentes quadros clínicos de DTM e relacionar os achados à influência da dor. Em geral, diferenças entre as amostras (subgrupo de DTM, severidade e cronicidade da dor) e metodologias são as responsáveis pelos resultados, às vezes, aparentemente contraditórios. Ao analisar a atividade EMG de repouso ou postural em populações com e sem DTM, encontram-se na literatura resultados distintos: 1) ausência de diferenças na atividade EMG entre os grupos ${ }^{144} 2$ ) atividade significativamente aumentada nos grupos com dor $^{10}$ e 3 ) leve aumento nos pacientes com dor ${ }^{61}$.

O aumento de estresse e ansiedade no período de provas da amostra do presente estudo poderia estar relacionado ao aumento de atividade muscular postural (EMG) e, consequentemente, dor. Tal afirmação, no entanto, somente poderia ser feita se mensurações de atividade muscular fossem realizadas, o que não foi objetivo deste trabalho.

Neste estudo, com o objetivo de relacionar os grupos, músculos e tempos (períodos de avaliação), o teste de ANOVA a 3 critérios demonstrou interações estatisticamente significantes entre essas variáveis, ou seja, ao relacioná-las pode-se afirmar que o LDP varia de acordo com o tempo e com o grupo analisado. Os resultados deste estudo concordaram com a literatura, ao constatarem que os músculos masseter, temporal anterior, temporal médio e temporal posterior, em ambos os grupos (DTM e controle) e nos diferentes tempos encontraram diferenças estatisticamente significantes $(p<0,05)$. Este fato era esperado, já que houve rigor na utilização dos critérios de exclusão e inclusão propostos inicialmente, através dos questionários de avaliação 
objetiva, freqüência e intensidade da dor e anamnese com o RDC/TMD, para se fazer a divisão dos grupos deste estudo.

O LDP diminuiu de acordo com o aumento do estresse e da ansiedade nos diferentes momentos de mensuração. Além disso, da mesma forma, houve concordância com o aumento dos valores da Escala de Análise Visual (EAV). Houve diferenças estatisticamente significantes entre os grupos sintomático e assintomático em todos os tempos e, para ambos os grupos. Como o parâmetro de avaliação dos níveis de estresse e ansiedade utilizados neste estudo, foram as avaliações acadêmicas universitárias, os maiores índices foram encontrados no T2, que corresponde à semana de avaliações acadêmicas da amostra estudada.

Segundo CALAIS et al. ${ }^{13}$, em 2003, o estresse é uma reação do organismo frente a qualquer evento, bom ou mau, que altere a vida do indivíduo. Essa reação ocorre, em geral, frente à necessidade de adaptação exigida do indivíduo em momentos de mudança. O processo de estresse passa por três fases: alerta, resistência e exaustão. A fase de alerta se caracteriza por reações do sistema nervoso simpático, quando o organismo percebe o evento estressor. A resistência apresenta-se quando esse estressor permanece presente por períodos prolongados ou se é de grande dimensão. $\mathrm{Na}$ fase de exaustão, o estresse ultrapassou a possibilidade de o indivíduo conviver com ele e está associado a diversos problemas, como úlceras, gengivites, psoríase, hipertensão arterial, depressão, ansiedade e problemas sexuais, entre outros. Cada fase envolve uma sintomatologia diferenciada, que é acompanhada das mudanças hormonais correspondentes.

A hipótese de que a severidade ou presença de eventos de vida estressores são preditivos de severidade ou presença de sintomas de ansiedade ou de transtornos de ansiedade, têm sido alvo de estudos recentes com adultos e adolescentes ${ }^{13,125}$.

Em situações emocionais, o ser humano pode experimentar diferentes reações. Dentre elas o estado de alerta, como descrito anteriormente. Nesta condição, o organismo reage com um comportamento de 
fuga ou de ataque ao agente estressor. Ainda que esta reação seja exacerbada com uma descarga de hormônios mais elevada, poderá ser considerada normal, se logo após esta fase de excitação retornar a seu estado de equilíbrio. No entanto, esta fase pode perdurar, envolvendo outros processos internos, até a exaustão; desenvolve-se, então, uma patologia como, por exemplo, os transtornos de ansiedade ${ }^{14,98}$.

A relação etiológica entre a exposição a eventos de vida estressores e o surgimento de sintomas e transtornos de ansiedade em geral, apesar de plausível, tem sido pouco estudada. Pouco se sabe sobre como as mudanças na carga de estresse ao longo do tempo se relacionam com as mudanças nos sintomas prodrômicos de ansiedade e no desenvolvimento de um transtorno de ansiedade $^{2,59,73}$.

Sabe-se que os sintomas prodrômicos de ansiedade podem surgir anos antes do surgimento de um transtorno definido e completo, em resposta a eventos estressores, como por exemplo, desavenças interpessoais, entre pacientes adultos. Então, estressores desta natureza são co-responsáveis pelo surgimento de transtornos mentais a curto, médio e longo prazo, bem como podem precipitar a recorrência de quadros psiquiátricos ${ }^{98,124}$.

A ansiedade pode ser considerada normal ou patológica. Ansiedade patológica pode estar presente em condições como doenças físicas, vigência de uso de medicamentos ou drogas, abstinência de depressores do sistema nervoso central ou mesmo, primariamente, nos chamados transtornos ansiosos $^{1,98}$.

Como na maioria dos transtornos mentais, a causa do transtorno de ansiedade generalizada não é conhecida. De acordo com sua definição atual, o transtorno, provavelmente, afeta um grupo heterogêneo de pacientes. Talvez porque certo grau de ansiedade seja normal e adaptativo, é difícil a diferenciação entre ansiedade normal e patológica e entre causas biológicas e psicossociais. Os fenômenos biológicos e psicossociais, provavelmente, operam em conjunto ${ }^{85}$. 
Os sintomas associados à ansiedade incluem manifestações fisiológicas, comportamentais e cognitivas. As manifestações fisiológicas refletem atividade do sistema nervoso autonômico (SNA): náuseas, vômitos, palpitações, tremores, sudorese, ondas de calor e frio, sensações de sufocação ou afogamento. Os sintomas comportamentais de ansiedade são mais evidentes. Incluem esquivas de situações ameaçadoras ou comportamentos de fuga. Diante da impossibilidade de fuga de determinada situação, outros comportamentos, como choro, voz trêmula, tremores grosseiros das mãos, ato de roer as unhas podem ocorrer, refletindo um estado ansioso. Já o componente cognitivo da ansiedade envolve a experiência mental. Entre os exemplos de pensamentos ansiosos pode-se citar: "o que vai acontecer comigo agora?"79.

É importante identificar não somente as características da doença, mas as dos doentes. Estabelecer um perfil emocional de pacientes com DTM poderia ser um instrumento útil para identificar os que deveriam ser tratados e aqueles que deveriam ser apenas observados. O estresse é um achado comum em pacientes com e sem DTM e tem sido, da mesma forma, exaustivamente estudado como uma possível causa etiológica da mesma ${ }^{14,18,}$ 41, 48, 75 . Resultados inconclusivos e contraditórios, reportados pela literatura, são pontos comuns entre estes fatores ${ }^{59}$.

Com intuito de otimizar a análise dos dados, o presente estudo utilizou o Inventário de Sintomas de Stress de Lipp (ISSL). O ISSL foi validado em $1994^{99}$ e tem sido utilizado em pesquisas e trabalhos clínicos na área do estresse 13,14,75. Apresenta um modelo quadrifásico do estresse, baseado, inicialmente, no modelo trifásico de Selye ${ }^{166}$. O instrumento é formado por três quadros que contêm sintomas físicos e psicológicos de cada fase do estresse. O número de sintomas físicos é maior do que os psicológicos e varia de fase para fase. No total, o ISSL inclui 34 itens de natureza somática, e 19, de natureza psicológica. 
Os resultados do ISSL demonstraram que na ausência do agente estressor, os limiares aumentaram de uma forma significativa. O estresse diminuiu na semana subseqüente às avaliações acadêmicas (T3) e mantiveram-se baixos no momento de volta de férias anuais (T4), enquanto o LDP de ambos os grupos aumentou neste período. Além disso, apesar de com menor significância, o menor nível de estresse do grupo com DTM foi em T4 enquanto o grupo controle apresentou menores níveis de estresse em T3. Tal manifestação pode ser justificada pelo comportamento específico de cada grupo. Os indivíduos estressados possuem uma menor resposta adaptativa às situações que são consideradas agressivas e não são capazes de interpretar estímulos estressores em relação à homeostasia sistêmica, e a experiências anteriores, desencadeando alterações físicas ${ }^{125,193}$. Por outro lado, cessado o agente estressor, as modificações no comportamento destes indivíduos são infinitamente positivas e relacionadas com sensação de alívio momentâneo e o nível de estresse tende a cair consideravelmente, uma vez que a situação anterior afetava seus equilíbrios emocionais ${ }^{98}$.

De forma semelhante, além do T2, que apresentou menor LDP para ambos os grupos e todos os músculos, o T1 também demonstrou níveis diminuídos de LDP, acompanhando o aumento do estresse. Não houve diferença estatisticamente significativa entre os grupos com relação ao estresse em cada tempo de avaliação, porém a relação intragrupo foi estatisticamente diferente. Ou seja, ao analisar os grupos é possível observar que houve diferenças importantes entre os períodos. O grupo controle apresentou diferenças de estresse entre T2 (provas) e T4 (pós-férias). Já o grupo com DTM apresentou diferenças de estresse entre T2 (provas) e T3 (pós-provas) como descrito anteriormente. Estes achados podem ser justificados pelo tipo de estímulo estressor. Em muitos estudos, o estresse foi induzido experimentalmente em laboratório ${ }^{31,53,87}$ e induzem respostas imediatamente depois do estímulo ${ }^{138,179}$. Da mesma forma, o estímulo é capaz de induzir respostas prévias quando for conhecido, como acontece em situações pré-estabelecidas de avaliações acadêmicas da Faculdade de Odontologia de Bauru ${ }^{125}$. Nesta situação o agente estressor proporcionou uma manifestação semelhante no nível de estresse nos indivíduos doentes e não- 
doentes, por se tratar de uma amostra bastante homogênea sendo submetida a um estressor externo igual. Por outro lado, a manifestação clínica de dor muscular demonstrou o comportamento diferente entre os indivíduos. O grupo sintomático apresentou LDP significativamente menor que o grupo assintomático nos momentos de maior estresse, devido à menor capacidade de adaptação fisiológica diante do momento de mudança ${ }^{13}$.

Sendo assim, apesar de não terem sido constatadas importantes diferenças na presença de estresse entre os grupos, é possível afirmar que o LDP diminui sob influência do aumento do estresse de maneira mais importante no grupo com DTM. Na presença de um evento externo que causou desequilíbrio emocional em ambos os grupos, a diminuição do LDP ocorreu. Porém, o grupo já doente apresenta maior dificuldade de adaptação e exacerbação da doença já estabelecida anteriormente a este evento.

Os níveis de estresse neste estudo não foram quantificados e comparados entre pacientes com DTM e indivíduos assintomáticos, somente quanto à presença ou ausência. Entretanto, alguns estudos demonstraram que os pacientes com DTM apresentam níveis de estresse maiores que pacientes com outras patologias ${ }^{127}$. Além disso, outros autores concluíram que o nível de estresse de pacientes com disfunção é significativamente maior do que os do grupo controle ${ }^{133,173}$. Os resultados encontraram associação positiva entre estresse e disfunções miogênicas, e os autores descrevem a possibilidade de pacientes com distúrbios psicofisiológicos desenvolverem sintomas físicos, enquanto aqueles com DTM freqüentemente apresentarem índices elevados de estresse $^{145,161}$. KUTTILA et al. ${ }^{92}$; SUVINEN et al. ${ }^{178}$, em 1997, discutiram que os pacientes com necessidade ativa de tratamento para disfunções apresentaram índices maiores de estresse e relataram maior gravidade dos sintomas.

Apesar de alguns autores não encontrarem uma relação positiva entre fatores emocionais e DTM ${ }^{159}$, outros se preocupam, além do estresse, com outras patologias psíquicas presentes nos pacientes com DTM ${ }^{48,111}$. A literatura mostra que, independentemente do estresse, as características de personalidade podem demonstrar grupos doentes homogêneos ${ }^{113}$, 
significantemente mais introvertidos que o grupo controle, sugerindo uma personalidade mais vulnerável ao desenvolvimento de patologias ${ }^{170}$. Além disso, o nível de depressão em pacientes com DTM parece ser significantemente maior do que o grupo controle ${ }^{192}$. Da mesma forma, muitos resultados mostraram mais ansiedade nos grupos com DTM e maior tendência à hipocondria ${ }^{162}$.

Existe uma série de testes psicológicos apropriados para a determinação do perfil de personalidade, fatores emocionais, sociais e comportamentais relacionados às condições de dores crônicas e agudas. Embora a maioria desses testes não tenha sido desenvolvida para a utilização específica em pacientes com DTM, são normalmente aceitos ${ }^{173}$. Além disso, a personalidade dentro da psicologia recebe um diferente enfoque, conforme a abordagem que a define. Pode ser definida como padrões de comportamento que dispõem um dado indivíduo, conseqüência de sua história de vida, de sua vivência e interações com o ambiente ${ }^{66,98}$. Na literatura encontramos trabalhos que apontam um perfil de personalidade característico dos pacientes com $\operatorname{DTM}^{17,31,44,60,133,177}$, e outros que demonstram que este perfil não existe ${ }^{128,132}$.

Neste estudo, utiliza-se o Inventário de Ansiedade de Beck (BAI). Este instrumento foi proposto e validado por BECK ${ }^{6}$ em 1961, que descreveu o seu desenvolvimento e forneceu informações sobre suas propriedades psicométricas. A versão utilizada neste trabalho é em português e desenvolvida a partir do Manual de Beck ${ }^{7}$. A escala foi construída com base em vários instrumentos de auto-relato para medir aspectos de ansiedade, dos quais foram selecionados os itens que passaram a compor o Inventário. O BAl é uma escala de auto-relato, que mede a intensidade de sintomas de ansiedade.

A mensuração da ansiedade, reconhecida como uma das emoções humanas básicas, é de extrema importância, já que sintomas de ansiedade, bem como transtornos de ansiedade, podem ser considerados como uma das dificuldades principais enfrentadas pelos seres humanos. Variam as teorias a respeito da natureza da ansiedade e suas diferenças da depressão. Os instrumentos de avaliação de ansiedade e depressão tendem a demonstrar uma relação substancial entre ambas ${ }^{7}$. 
O instrumento, criado originalmente para uso em pacientes psiquiátricos, mostrou-se também adequado para uso na população geral, inclusive estudantes. Essa utilização, no entanto, deve ser feita com cautela.

O Inventário é constituído por 21 itens, que são afirmações descritivas de sintomas de ansiedade, e que devem ser avaliados pelo sujeito com referência a si mesmo, numa escala de 4 pontos, que refletem níveis de gravidade crescente de cada sintoma: 1) "absolutamente não"; 2) "levemente"; 3) "moderadamente: foi muito desagradável, mas pude suportar"; 4)"gravemente: dificilmente pude suportar". O escore total é o resultado da soma dos escores dos itens individuais. O escore permite a classificação em níveis de intensidade da ansiedade. Ainda que as alternativas de resposta oferecidas ao examinador sejam de caráter qualitativo, na realidade constituem uma série escalar, de 0 a 3 pontos. Assim, para cada item, atribui-se um escore individual. A soma dos escores individuais representa o escore total, que pode variar entre 0 e 63. Além disso, o instrumento considera o gênero e a idade da amostra. A média dos escores de pacientes do gênero feminino é quatro pontos mais elevada que a média dos homens. Tal diferença é levada em consideração na interpretação dos resultados. Além disso, com base na amostra estudada, Beck recomenda utilizar o Inventário com pacientes a partir de 17 anos.

Os dados obtidos com o BAl demonstraram que a diminuição do LDP acompanhou o aumento da ansiedade. Da mesma forma que o estresse, a ansiedade não apresentou índices estatisticamente diferentes entre os grupos. Quando é realizada a análise para os dois grupos, nos diferentes períodos, no entanto, há um aumento óbvio na quantidade de alunas estressadas e nos níveis de ansiedade. Tal fato é estatisticamente significante $(p<0,05)$. O grupo controle apresentou diferenças de ansiedade estatisticamente significante entre T2 (provas) e T3 (pós-provas). Já o grupo com DTM apresentou diferenças de ansiedade estatisticamente significante entre T2 (provas) e T4 (pós-férias). 
Ainda, a amostra discutida não apresentou níveis de ansiedade considerados significativamente altos. Não houve nenhuma manifestação de ansiedade grave em qualquer momento para qualquer indivíduo da amostra. Os maiores índices apontados foram encontrados no grupo sintomático e não ultrapassaram o nível moderado. Por esse motivo, a classificação específica em níveis de intensidade de ansiedade não se tornou importante nesta discussão.

A análise estatística empregada demonstrou os escores de ansiedade mais altos no grupo com DTM; porém, a diferença do grupo controle não foi significativa. Apesar da amostra apresentar-se numericamente satisfatória, pode estar ainda aquém de ser estatisticamente suficiente para demonstrar o evento com maior clareza. Estes resultados são semelhantes aos estudos de MOSS, R.A.; ADAMS, H.E. ${ }^{128}$, de 1984, NIEMl et al. $^{132}$, de 1993, MCCREARY et al. ${ }^{115}$, de 1991 e KROGSTAD et al. ${ }^{91}$, de 1996 , nos quais o comportamento da ansiedade nos pacientes com DTM também foi similar aos dos pacientes assintomáticos.

Além disso, as peculiaridades da amostra estudada podem ser responsáveis pelo comportamento semelhante entre os grupos. É importante salientar que as diferenças entre severidade de DTM miogênica neste grupo são pequenas e há homogeneidade em relação à idade, gênero e ambiente de convivência. É possível supor que estes fatores tenham impedido diferenças estatísticas mais evidentes quando os resultados são comparados a outros estudos $^{48,111,125,177 .}$.

De qualquer forma, pode-se afirmar que houve um aumento do relato de dor subjetiva na EAV e diminuição do LDP no momento de aumento de estresse e de ansiedade. Entre as possíveis teorias que justificam essa relação está a possibilidade de que o aumento do estresse e ansiedade poderiam aumentar a prevalência do bruxismo do sono e conseqüentemente a dor ${ }^{5,193}$. Por outro lado, outros autores discutem que altos níveis de atividade de bruxismo podem estar relacionados à menor consciência acerca dos eventos estressantes da vida (maior negação). PIERCE et al. ${ }^{147}$ notaram que 
os bruxômanos que indicaram menores níveis de estresse também eram mais propensos a relatar altos níveis de negação do que a população geral. Os autores lembram que os resultados não significam que a atividade de bruxismo do sono não se relaciona ao estresse, mas que bruxômanos podem não ser muito conscientes da natureza estressante dos eventos diários e ou que eles minimizam o impacto pessoal desses eventos.

Porém, no presente trabalho, tais fatores não puderam ser determinados, pois uma análise específica de presença de bruxismo não foi realizada. A literatura tem rediscutido a real participação dos hábitos parafuncionais nas dores faciais ${ }^{146}$ e a avaliação, através de exames polissonográficos, torna-se necessária para afirmar qualquer relação ${ }^{134,154}$.

Outros autores 59, 87, 191 tentam relacionar o estresse emocional a reações fisiológicas associadas ao sistema nervoso autonômico; dentre elas, o aumento da eletroatividade muscular, como já discutido anteriormente. $\mathrm{O}$ aumento de atividade de fibras eferentes simpáticas pode excitar a liberação de acetilcolina nas terminações nervosas na placa mioneural, aumentando o nível de tensão muscular, fadiga e liberação de substâncias algogênicas, causando dor e diminuição do LDP $18,34,125$.

Foi observado que, sob estresse experimentalmente induzido, os indivíduos com DTM apresentaram respostas eletromiográficas mais ativas que indivíduos assintomáticos ${ }^{87}$, como discutido anteriormente. FLOR et al. ${ }^{53}$; em 1991, demonstraram que pacientes com DTM apresentavam mais estresse e maior atividade eletromiográfica do músculo masseter. HIDAKA ${ }^{73}$ avaliou a influência no estresse induzido na atividade EMG de mulheres saudáveis. Os resultados demonstraram hiperatividade do masseter relacionado ao estresse. WEINER, SHAIKH, SIEGEL 191 estudaram a relação entre atividade eletromiográfica do músculo masseter e comportamentos emocionais através da estimulação elétrica hipotalâmica e estímulos mastigatórios em uma amostra de gatos. Os resultados demonstraram um aumento da atividade eletromiográfica musculares, sugerindo que a estimulação hipotalâmica produz ativação motoneural contínua, resultando em fadiga muscular. Além disso, 
sugerem que a hiperatividade muscular pode ser regulada, principalmente, pelo SNC com pequena influência de receptores periféricos, já que o aumento da atividade EMG ocorreu antes da estimulação mastigatória. Os resultados mostraram relação entre hiperatividade muscular e alterações comportamentais, como por exemplo, ataque e defesa.

Com relação às comparações das modificações fisiológicas, sob estresse induzido experimentalmente em laboratório, entre indivíduos com e sem DTM, a literatura revelou que os pacientes com DTM tiveram freqüência cardíaca e pressão sangüínea superiores aos do grupo controle, e apresentaram mais ansiedade, mais sintomas cognitivos e maior sensação de tensão muscular, mas sem diferenças eletromiográficas ${ }^{17}$. Por outro lado, outros autores concluíram que não houve diferenças significativas entre os grupos com estressores experimentais ${ }^{31}$ e consideram que o estresse experimental não é idêntico ao ambiental, embora as respostas fisiológicas fossem similares ${ }^{156}$.

A etiologia da ansiedade tem sido vinculada a múltiplas causas. Acomete mais mulheres, aumentando em populações com faixa etária acima dos 30 anos e em pacientes com histórico de mais de 6 meses de dor. A idade desempenha um papel importante na etiologia desse distúrbio. Ao contrário de outros transtornos psicológicos, a ansiedade é desenvolvida ao longo da duração da vida ${ }^{89}$.

A literatura a respeito desse assunto é contraditória, existindo trabalhos que mostram que não existem diferenças estatisticamente significantes entre grupos controle e pacientes com DTM ${ }^{128,132}$ quanto ao nível de ansiedade, bem como trabalhos que mostram que a população controle se apresenta relativamente não ansiosa, ao contrário da população com DTM, que se apresenta com nível de ansiedade aumentado ${ }^{17,31,44,60,178 .}$

De qualquer forma, em 1991, MCCREARY et al. ${ }^{115}$ relacionaram mialgia com o estresse e constataram que seu nível é diretamente proporcional à intensidade de dor, entretanto, sem associação positiva com a ansiedade e a 
depressão. Por outro lado, CURRAN et al. ${ }^{31}$, em 1996, estudaram indivíduos com DTM que apresentaram maior ansiedade e sentimento de culpa e tristeza do que o grupo controle. Já KROGSTAD et al. ${ }^{91}$, no mesmo ano, concluíram em seu estudo, que o índice de ansiedade e estresse foi praticamente idêntico nos dois grupos. CIMINO et al. ${ }^{23}$, em 1998, concluíram que em $50 \%$ dos casos, episódios de forte estresse coincidem com o desencadeamento e dor em indivíduos com DTM. Segundo KUTILLA et al. ${ }^{93}$, também em 1998, indivíduos que necessitam de tratamento para DTM mostram índices mais elevados de estresse.

Como já salientado anteriormente, a maior dificuldade que existe nos trabalhos de pesquisa com pacientes com DTM é a homogeneidade da amostra e a falta de padronização dos critérios de diagnóstico ${ }^{141}$. Idealmente, a amostra deveria representar uma parcela significativa da população ${ }^{183}$. Encontramos, no entanto, uma grande heterogeneidade nessas amostras, quando vamos comparar os trabalhos na literatura. Embora pacientes com DTM possam apresentar semelhança clínica, eles podem não constituir um grupo homogêneo diante da variabilidade de fatores etiológicos que os envolvem. Além disso, avaliações comparativas entre vários estudos são praticamente impossíveis, pois, diferentes examinadores fazem diferentes perguntas, concentram-se em diferentes questões psicossociais e usam os mais diferentes tipos de testes psicométricos ${ }^{70}$.

Concordando com os resultados da literatura 18,41, 125, 177 , as alterações encontradas nos limiares de dores musculares no presente estudo coincidiram com a diminuição do índice de relato de dor subjetiva (EAV), descrevendo uma forte relação com o estresse (ISSL) e a ansiedade (BAI). O comportamento de ambos os grupos seguiu um padrão bastante semelhante entre os diferentes tempos. O maior índice de dor foi descrito em T2 (semana de avaliações), seguido pelo T1 (semana antecedente das avaliações), T3 (semana subseqüente às avaliações) e por fim T4 (posterior às férias anuais). Entretanto, os níveis foram expressivamente superiores no grupo experimental e as diferenças entre os tempos também se mostraram maiores neste grupo. 
Dessa forma, pode-se afirmar que o estresse e a ansiedade contribuem nas alterações de percepção da dor do SNC e nas estruturas que envolvem sua regulação 145 191. Este desequilíbrio pode resultar em hipervigilância do sistema, o qual está associado com o aumento dos estímulos nociceptivos. Pode-se considerar a hipótese de que, na amostra deste estudo, o evento de avaliações acadêmicas seria uma condição estressante duradoura, que gera hipervigilância. Esta hipótese é reforçada quando se observa que a diminuição do LDP não ocorreu somente nos músculos masseter e temporais, mas também no grupo controle não muscular representado pelo Tendão de Aquiles. O comportamento do Tendão de Aquiles do grupo sintomático seguiu o mesmo padrão dos músculos avaliados, complementando os resultados. Estes dados demonstram que os estudantes da amostra representam uma ocorrência significativa de um estado de hipervigilância relacionada ao período de avaliações. O comportamento similar dos músculos avaliados e do sítio de controle (Tendão de Aquiles) mantêm a idéia de que a dor orofacial associada à DTM miogênica pode estar relacionada com condições psicológicas ${ }^{43,152}$. A diminuição de LDP no Tendão de Aquiles também demonstra que, além dos fatores estressores poderem exacerbar condições pré-existentes, como a DTM miogênica, alteram de maneira substancial a tonicidade e atividade muscular de uma maneira geral.

Pesquisadores de diversas condições dolorosas têm considerado a sintomatologia, particularmente das disfunções crônicas, como uma síntese complexa de fatores psicológicos e orgânicos 14, 41, 75, 125, 184. A conseqüência desses novos paradigmas reflete-se, inclusive, na reconceituação da dor, antes compreendida apenas como uma sensação e atualmente considerada uma experiência multidimensional e pessoal ${ }^{184}$.

A teoria psicanalítica clássica de Freud defende uma motivação inconsciente como maior determinante do comportamento humano. O modelo psicodinâmico tem sido usado por autores que consideram a DTM como uma reação de transformação de conflitos emocionais inconscientes em sintomas físicos ${ }^{71}{ }^{171}$. Quando o aparelho mental falha, os estados emocionais passariam a se expressar no corpo, ora usando caminhos patológicos já 
existentes, ora contribuindo para criar novas doenças, ora ainda criando dores imaginárias para as quais não se encontra etiologia física. O corpo, assim, sofreria a ansiedade que a mente não suporta ${ }^{71}$.

Os estudos que se preocuparam em avaliar e descrever as características psicológicas dos pacientes com DTM encontraram alta prevalência de distúrbios psicológicos (74\% a $76 \%)$, destacando as reações de ansiedade/depressão como as mais freqüentes ${ }^{60,89}$. Muitos desses estudos têm tentado, geralmente com a aplicação de questionários, identificar um perfil psicológico capaz de caracterizar o paciente próprio de $\mathrm{DTM}^{71}$. Mesmo sem obter sucesso, elevações na ansiedade, na depressão, na somatização e no estresse são relatadas independentemente dos sinais e sintomas clínicos ${ }^{69,} 70$, 171 .

Diante da complexidade dos processos psíquicos do ser humano, muito dos quais ainda são desconhecidos, seria muito simples esperarmos encontrar puramente um componente psicológico que se destacasse. É possível que seja mais comum uma associação de ansiedade e depressão, relacionada ainda a outros fatores emocionais, oscilando de intensidade e freqüência, de indivíduo para individuo e até mesmo no próprio sujeito em momentos diferentes, já que o estado emocional do paciente, no momento do exame, deve ser visto como uma interação de experiências externas e internas que determinarão como cada indivíduo vivencia os sintomas, aceita o tratamento e responde ao mesmo ${ }^{50,145,171 .}$

Estados emocionais devem ser, portanto, considerados em pacientes com dor crônica, pois mesmo que eles não sejam os causadores diretos da dor, podem resultar de uma condição dolorosa persistente, tornar a dor mais difícil de ser tolerada ou impedir o sucesso do tratamento. A avaliação do estresse e ansiedade deve compreender fatores que possam resultar em dores persistentes. Além disso, o reconhecimento e a expressão de sentimentos freqüentemente reprimidos têm auxiliado no alívio dos sintomas ${ }^{55}$, $110,112,148$. 
Embora parte da literatura discutida suporte fortemente a relação do estresse e ansiedade com DTM miogênica, a metodologia deste trabalho não permitiu definir um perfil para o grupo doente. Por outro lado, a relação causa/efeito entre as variáveis estudadas ficou clara, mesmo sem conhecer os exatos mecanismos envolvidos nestes processos. Estudos longitudinais poderiam esclarecer tais fatores ${ }^{89}$. Além disso, sugere-se a utilização de exames laboratoriais complementares para avaliação de níveis de catecolaminas urinárias ${ }^{25,42}$ e níveis de $\beta$-endorfinas sangüínea ${ }^{125}$ na análise de causa/efeito.

De maneira geral, os fatores psicológicos são negligenciados, enquanto os físicos são valorizados no tratamento das DTMs ${ }^{171}$, apesar de muitos estudos destacarem os fatores emocionais como fundamentais na qualidade de resposta do paciente ao tratamento com DTM crônica ${ }^{56}$. A importância da abordagem e do controle dos aspectos psicológicos está no fato de que a falha no tratamento pode estar relacionada à presença de fatores ligados ao estado emocional, como qualidade do sono, auto-estima, motivação e sentimentos de preocupação ${ }^{56}$. Inúmeros trabalhos que testaram diferentes abordagens terapêuticas para DTM encontraram melhores resultados para a dor quando o tratamento associava terapias para DTM com terapia psicológica $^{18,31,97,176}$. A relação entre estresse, ansiedade e dor deve ser observada, pois o alívio da dor parece levar a uma melhora significante do estado emocional destes indivíduos, sugerindo que tantos fatores físicos quanto psicológicos são importantes ${ }^{18,31,98}$.

Pesquisas futuras são necessárias na área de processos psicossomáticos em DTM e dores orofaciais, focando os mecanismos específicos que levam aos sintomas. O que se sabe até o momento é que o estresse e a ansiedade desempenham um papel importante na DTM e devem ser abordados e tratados concomitantemente. Observa-se, além da redução significativa dos sintomas dolorosos e psíquicos, uma maior manutenção do benefício terapêutico quando a combinação de tratamentos é utilizada ${ }^{183}$. Não é possível ainda afirmar o real limite entre causa e conseqüência da DTM e desequilíbrios psicológicos ${ }^{41}$. 
Além disso, é de fundamental importância que o cirurgião-dentista tenha uma concepção do homem como um ser biopsicossocial. Em função dessa concepção, a abordagem dos pacientes deixa de ser usual, considerando somente a doença ou a dor, mas sim, levando em consideração que não se pode separar o biológico do psicológico. Desta forma, a dor passa a ter aspectos psicológicos e aspectos somáticos, sendo que toda conduta deve considerar todas as experiências sensoriais e psicológicas, nos aspectos emocionais, cognitivos e comportamentais, e não somente fatores físicos ou somáticos. 
Conclusões 


\section{CONCLUSÕES}

Tendo em vista os objetivos propostos e os resultados obtidos, segundo a metodologia utilizada, pode-se concluir que:

- O grupo com DTM miogênica apresentou valores de LDP significativamente menores do que o grupo controle;

- Houve uma diminuição nos valores de LDP e aumento dos valores da EAV com o aumento dos níveis de ansiedade e a presença do estresse, ocorridos no período de provas (T2) para ambos os grupos;

- Houve associação entre a diminuição do LDP e o aumento do relato de dor subjetiva (EAV) em ambos os grupos estudados. 
Anexos 


\section{Anexo 1 - Aprovação Comitê de Ética em Pesquisa}

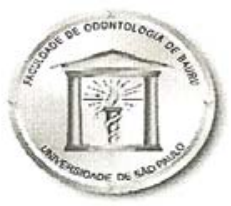

Processo $n^{\circ} 162 / 2004$

\section{Universidade de São Paulo Faculdade de Odontologia de Bauru}

Al. Dr. Octávio Pinheiro Brisolla, 9-75 - Bauru-SP-CEP 17012-901 - C.P. 73

PABX (0XX14)3235-8000 - FAX (0XX14)3223-4679

Comitê de Ética em Pesquisa (3235-8356)

Bauru, 03 de outubro de 2006.

Senhor Professor

Informamos que após o envio da documentaçăo solicitada referente ao projeto de pesquisa encaminhado a este Comitê de Ética em Pesquisa "Participação do estresse e ansiedade na alteração do limiar de dor à pressão (LPD) em pacientes com DTM miogênica: um estudo comparativo" de autoria de Gabriela Modesti Vedolin sob sua orientação, foi novamente analisado e considerado APROVADO em reuniăo deste Comitê realizada no dia $\underline{27}$ de setembro de 2006.

Solicitamos que ao término do trabalho, seja enviado a este Colegiado um relatório final para parecer do trabalho concluído o qual será utilizado para publicação em revista científica.

Atenciosamente,

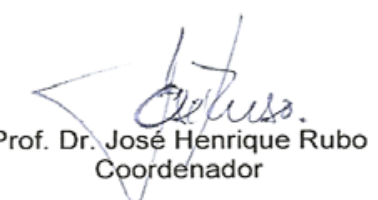

Prof. Dr. Paulo César Rodrigues Conti

Docente do Departamento de Prótese 


\section{Anexo 2 - Termo de Consentimento}

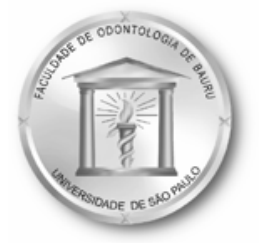

Universidade de São Paulo

Faculdade de Odontologia de Bauru

Al. Dr. Octávio Pinheiro Brisolla, 9-75 - Bauru-SP - CEP 17012-901 - C.P. 73

PABX (0XX14)235-8000 - FAX (0XX14)223-4679

TERMO DE CONSENTIMENTO LIVRE E ESCLARECIDO

Pelo presente instrumento que atende às exigências legais, o Sr. (a) portador da cédula

de identidade após leitura minuciosa da CARTA DE

INFORMAÇÃO AO SUJEITO DA PESQUISA, devidamente explicada pelos profissionais em seus mínimos detalhes, ciente dos serviços e procedimentos aos quais será submetido, não restando quaisquer dúvidas a respeito do lido e explicado, firma seu CONSENTIMENTO LIVRE E ESCLARECIDO concordando em participar da pesquisa proposta.

Fica claro que o indivíduo ou seu representante legal, pode a qualquer momento retirar seu CONSENTIMENTO LIVRE E ESCLARECIDO e deixar de participar desta pesquisa e ciente de que todas as informações prestadas tornaram-se confidenciais e guardadas por força de sigilo profissional (Art. 9 do Código de Ética Odontológica).

Por estarem de acordo assinam o presente termo.

Bauru-SP, de de

Assinatura do sujeito da pesquisa ou responsável

Prof. Dr. Paulo César R. Conti Orientador

\section{Gabriela Modesti Vedolin}

Mestranda em Reabilitação Oral FOB-USP 
ANEXO 3 - Carta de Informação ao Sujeito da Pesquisa

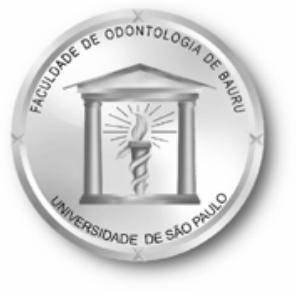

Universidade de São Paulo

Faculdade de Odontologia de Bauru

Al. Dr. Octávio Pinheiro Brisolla, 9-75 - Bauru-SP - CEP 17012-901 -

C.P. 73

PABX (0XX14)235-8000 - FAX (0XX14)223-4679

\section{CARTA DE INFORMAÇÃO AO SUJEITO DA PESQUISA}

Título do Trabalho: Participação do estresse e ansiedade na alteração do limiar de dor à pressão (LDP) em pacientes com DTM miogênica: um estudo comparativo

Autora: Gabriela Modesti Vedolin

Orientador: Prof. Dr. Paulo César Rodrigues Conti

Este trabalho tem como objetivo analisar a influência da ansiedade e do estresse no limiar de dor à pressão (LDP) numa amostra de estudantes universitários em período de avaliações acadêmicas que apresentam disfunção temporomandibular de origem miogênica e voluntários sem sintomas. Para isso serão feitas tomadas bilaterais do LDP, através da palpação utilizando um aparelho capaz de medir pressão (algômetro), possuindo uma ponta circular que fica em contato com determinadas áreas da face do voluntário. A forma dessa ponta não machuca a face. Assim sendo, com o algômetro será efetuado o exame de palpação até o voluntário relatar desconforto e o valor registrado será anotado, bem como o tempo que leva para desencadear o processo de dor referida. Nos casos dos indivíduos que apresentam alguma sintomatologia dolorosa facial (DTM), essa dor pode ser levemente exacerbada após o exame. Vale lembrar que qualquer sujeito que procura tratamento para DTM e apresenta dor miofascial é obrigatoriamente submetido a esse exame e, portanto, não será um incômodo a mais participar dessa pesquisa. A participação nessa pesquisa não proporciona qualquer tipo de risco ao voluntário. Além disso, os participantes serão solicitados a responder questionamentos multidimensionais através de dois questionários denominados ISSL e BAI para medir reações cognitivas, afetivas, psicológicas e comportamentais em situações que causem ansiedade. Todas os exames serão realizados em quatro momentos distintos tendo como parâmetro o período de provas escolares. Os benefícios desta pesquisa serão em verificar se tais testes podem ser utilizados como parâmetros de diagnóstico de indivíduos com disfunção temporomandibulares, e assim concluir qual o melhor tratamento ou a combinação de tratamentos que pode ser mais efetiva na Dor Miofascial, ajudando a encurtar o tempo de tratamento, o que levaria a uma melhora mais rápida do sujeito, planejando melhor o tratamento.

Qualquer dúvida ou questionamento que surgir antes, durante, ou após os testes podem ser esclarecidas diretamente com o examinador ou pelo telefone $32358277 \mathrm{com}$ a pesquisadora e orientador da pesquisa. A qualquer momento você pode retirar seu consentimento de participar do estudo, sem qualquer prejuízo. Uma vez diagnosticada alterações articular ou muscular, o voluntário será encaminhado para tratamento na Clínica de Disfunção Temporomandibular da própria faculdade onde será atendido conforme a rotina de agendamento desta Clínica. Sua identificação e suas informações pessoais ficarão em absoluto sigilo. O voluntário não terá nenhum custo durante a realização dessa pesquisa.

Todas as informações atualizadas serão transmitidas ao voluntário, ainda que estas possam afetar a vontade do indivíduo em continuar participando. Em casos de danos justificáveis, diretamente causados pela pesquisa, com nexo causal comprovado, será disponibilizada a indenização a que legalmente terá direito, por parte da pesquisadora. Assim, esperando contar com sua colaboração, antecipadamente agradecemos.

Atenciosamente,

Prof. Dr. Paulo César Rodrigues Conti 


\section{Anexo 4 - Ficha Inicial Geral Critérios de Inclusão e Exclusão e Questionário de Avaliação Objetiva}

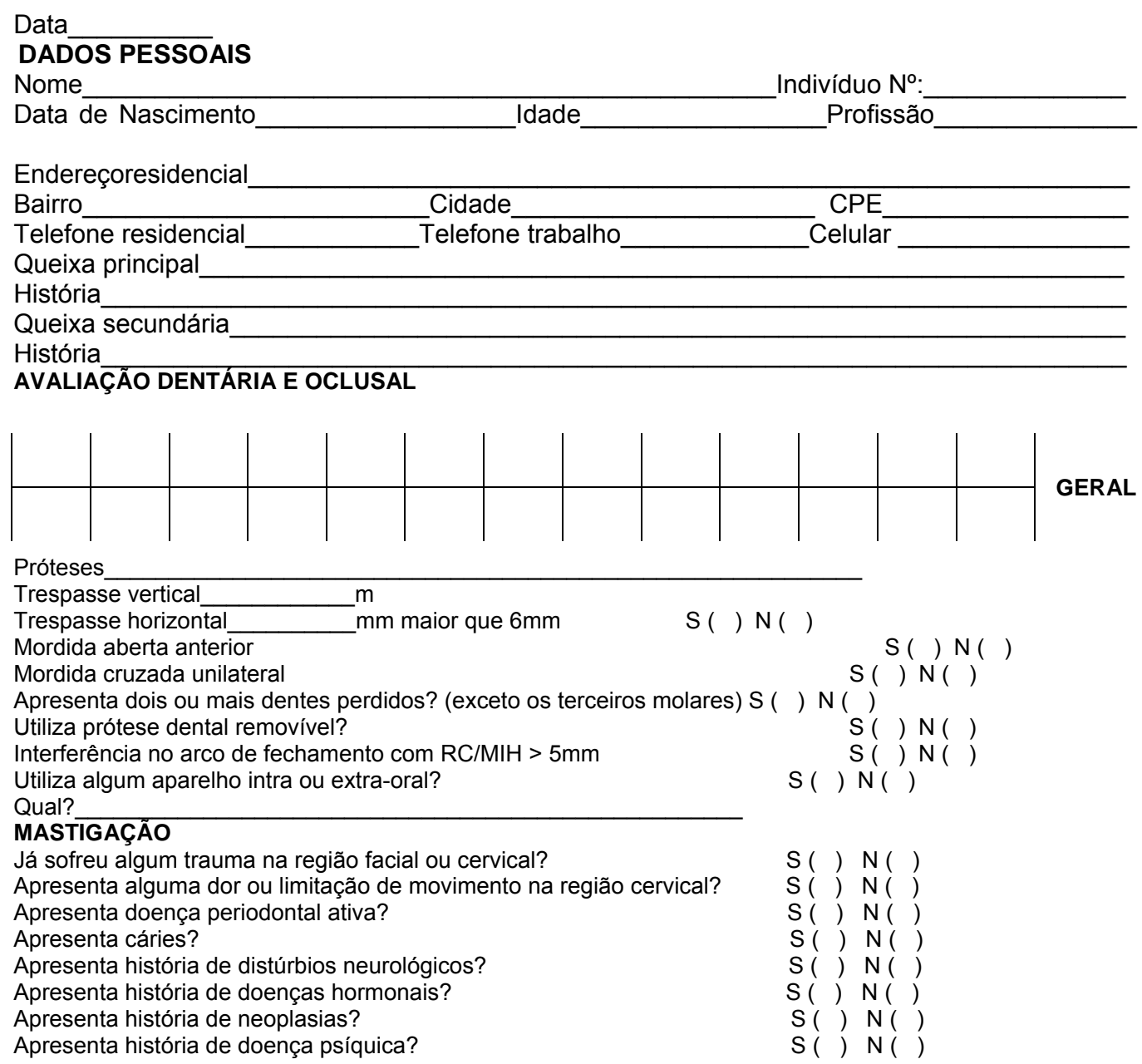

\section{AVALIAÇ̃̃O OBJETIVA}

\section{Escala de análise visual}

Indique a média de seu nível neste momento, marcando com uma linha vertical a escala abaixo. A extremidade esquerda indica ausência total de dor e a extremidade direita indica a pior dor imaginável.

\section{SIM NÃO ÀS VEZES}

1.Você sente dificuldade de abrir a boca?

2. Você sente dificuldade de movimentar sua mandíbula para os lados?

3. Você sente desconforto ou dor muscular quando mastiga?

4. Você sente dores de cabeça com freqüência?

5. Você sente dores no pescoço e/ou ombros?

6. Você sente dores de ouvido ou próximo a ele?

7. Você percebe algum ruído na ATM?

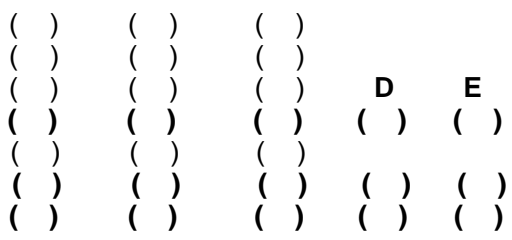


8. Você considera sua mordida "anormal"?

9. Você usa apenas um lado de sua boca para mastigar?

$\begin{array}{llll}\left(\begin{array}{l}1 \\ ()\end{array}\right. & (1) & (1)\end{array}$

10. Você sente dores na face ao acordar?

$($ ) ( )

11. Você toma medicação para qualquer uma das dores questionadas a cima? A quanto tempo?

$($ ) ( ) ( )

Obs.: ATM significa a articulação do seu maxilar

Para o examinador:
NÃO PORTADOR DE DTM
PORTADOR DE DTM LEVE
PORTADOR DE DTM MODERADA
PORTADOR DE DTM SEVERA

As questões 4, 6 e 7 receberão valor 3 para cada resposta "sim" se corresponderem a sintomas bilaterais ou intensos, valor 2 , se corresponderem a sintomas unilaterais ou leves; receberão valor 1 para a resposta "às vezes" e valor 0 para a resposta "não".O somatório dos valores obtidos permitirá a classificação da amostra em relação ao grau de disfunção temporomandibular em:

Valores de 0 a 3: não portador de DTM

Valores de 4 a 8: portador de DTM leve

Valores de 9 a 14: portador de DTM moderada

Valores de 15 a 23: portador de DTM severa. 


\section{Anexo 5 - Questionário de Freqüência e Intensidade da Dor}

\begin{tabular}{|c|c|c|}
\hline $\begin{array}{l}\text { 1. Você diria que você sente dor nos músculos } \\
\text { mandibulares ou nas suas articulações mandibulares } \\
\text { muito freqüentemente, freqüentemente, algumas vezes } \\
\text { ou nunca? }\end{array}$ & $\begin{array}{l}\text { Muito freqüentemente....... } \\
\text { Freqüentemente............. } \\
\text { Algumas Vezes............... } \\
\text { Nunca...................... }\end{array}$ & $\begin{array}{l}3 \\
2 \\
1 \\
0\end{array}$ \\
\hline \multicolumn{3}{|l|}{$\begin{array}{l}\text { Se muito freqüentemente, freqüentemente ou algumas } \\
\text { vezes: }\end{array}$} \\
\hline $\begin{array}{l}\text { a) em geral, você diria que a intensidade de sua dor } \\
\text { é leve, moderada ou severa? }\end{array}$ & 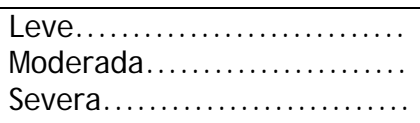 & $\begin{array}{l}1 \\
2 \\
3\end{array}$ \\
\hline $\begin{array}{l}\text { b) em geral, você diria que sua dor é mais presente } \\
\text { logo após acordar, pela manhã, à tarde ou à noite? }\end{array}$ & 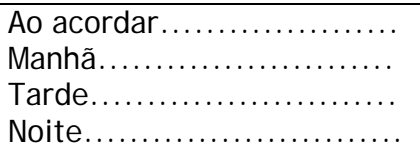 & $\begin{array}{l}1 \\
2 \\
3 \\
4\end{array}$ \\
\hline $\begin{array}{l}\text { 22. Você diria que você tem dificuldade em abrir a boca } \\
\text { amplamente devido à dor na mandíbula ou devido a um } \\
\text { travamento articular, muito freqüente, freqüentemente, } \\
\text { algumas vezes ou nunca? }\end{array}$ & $\begin{array}{l}\text { Muito freqüentemente } \ldots \ldots \\
\text { Freqüentemente.............. } \\
\text { Algumas Vezes............... } \\
\text { Nunca....................... }\end{array}$ & $\begin{array}{l}3 \\
2 \\
1 \\
0\end{array}$ \\
\hline $\begin{array}{l}\text { 3. Você diria que sua articulação da mandíbula estala ou } \\
\text { pula muito freqüentemente, freqüentemente, algumas } \\
\text { vezes ou nunca quando você come ou abre a boca } \\
\text { amplamente? }\end{array}$ & $\begin{array}{l}\text { Muito freqüentemente } \ldots \ldots \ldots \\
\text { Freqüentemente.............. } \\
\text { Algumas Vezes............... } \\
\text { Nunca........................ }\end{array}$ & $\begin{array}{l}3 \\
2 \\
1 \\
0\end{array}$ \\
\hline $\begin{array}{l}\text { 4. Em geral você diria que você sente muito bem } \\
\text { descansado, bem descansado, pouco descansado ou } \\
\text { totalmente sem descanso depois que você dorme? }\end{array}$ & $\begin{array}{l}\text { Totalmente sem descanso... } \\
\text { Pouco descansado............. } \\
\text { Bem descansado.............. } \\
\text { Muito bem descansado....... }\end{array}$ & $\begin{array}{l}0 \\
1 \\
2 \\
3\end{array}$ \\
\hline \multicolumn{3}{|l|}{ Se pouco descansado ou sem nenhum descanso: } \\
\hline $\begin{array}{l}\text { a) Em geral, você diria que seu sono é pobre ou } \\
\text { muito ruim por que você não dorme o suficiente, por que } \\
\text { você toma medicamentos, por causa da sua dor ou por } \\
\text { que você tem estado estressado ou ansioso? }\end{array}$ & $\begin{array}{l}\text { Não dorme o suficiente..... } \\
\text { Toma medicamentos......... } \\
\text { Dor......................... } \\
\text { Angustiado ou Ansioso....... }\end{array}$ & $\begin{array}{l}1 \\
2 \\
3 \\
4\end{array}$ \\
\hline $\begin{array}{l}\text { 5. Nos últimos } 9 \text { meses, você procurou tratamento para } \\
\text { sua dor mandibular, dificuldade de abertura ou estalido } \\
\text { por algum profissional de saúde? }\end{array}$ & $\begin{array}{l}\text { Não } \ldots \ldots \ldots \ldots \ldots \ldots \ldots \ldots \ldots \ldots \\
\text { Sim. } \ldots \ldots \ldots \ldots \ldots \ldots \ldots \ldots \ldots \ldots\end{array}$ & $\begin{array}{l}0 \\
1\end{array}$ \\
\hline $\begin{array}{l}\text { 6. Quais as razões que levaram você a procurar } \\
\text { tratamento? A dor nos maxilares, dor nas articulações da } \\
\text { mandíbula, estalido ou limitação de abertura ou algum } \\
\text { desses sintomas combinados? } \\
\text { Marque o número de opções que achar necessário. }\end{array}$ & $\begin{array}{l}\text { Dor nos maxilares (músc)... } \\
\text { Dor nas articulações......... } \\
\text { Estalido..................... } \\
\text { Limitação de abertura....... }\end{array}$ & $\begin{array}{l}1 \\
2 \\
3 \\
4\end{array}$ \\
\hline
\end{tabular}




\section{Anexo 6 - RDC/TMD}

\section{Anamnese}

Por favor, leia cada questão e responda da seguinte forma: Para cada uma das questões abaixo, circule apenas uma resposta.

Quando se fala em Dor, pode tratar-se também de dor leve ou desconforto.

1) Você diria que sua saúde, em geral, é excelente, muito boa, boa, razoável ou ruim?

2) Você diria que sua saúde oral, em geral, é excelente, muito boa, boa, razoável ou ruim?

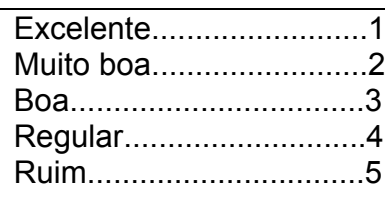

Excelente........................1

Muito boa......................2

Boa.............................

Regular........................ 4

Ruim............................ 5

Não............................. 0

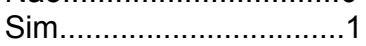
têmporas, em frente aos ouvidos ou nos ouvidos no último mês?

[Se não houver dor, pule para a questão 14]

Se sim:

4) a. Há quantos anos sua dor na face começou?

anos

[Se a 1 ano atrás ou mais, pule para a questão 5]

[Se a menos de 1 ano, escreva 00]

\begin{tabular}{|c|c|c|c|c|c|c|c|c|c|c|c|}
\hline & $\begin{array}{l}\text { b.H } \\
\text { leço }\end{array}$ & os & s a & $\bar{d}$ & a fa & & 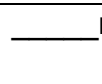 & & & & \\
\hline 5) & $\begin{array}{l}\text { Sua } \\
\text { oco }\end{array}$ & $\begin{array}{l}\text { fac } \\
\text { la }\end{array}$ & $\mathrm{rs}$ & th & cor & ou só & $\begin{array}{l}\text { Persis } \\
\text { Recorr } \\
\text { Uma v } \\
\text { Nenhu }\end{array}$ & $\begin{array}{l}\cdots . . \\
\cdots \cdots \\
\cdots . . \\
\cdots . .\end{array}$ & $\begin{array}{l}\cdots . \\
\cdots . . \\
\cdots .\end{array}$ & & \\
\hline 6) & $\begin{array}{l}\text { Alg } \\
\text { alg } \\
\text { da s }\end{array}$ & $\begin{array}{l}\mathrm{op} \\
\mathrm{fac}\end{array}$ & sior & de & $\begin{array}{l}0, \\
\text { de }\end{array}$ & $\begin{array}{l}\text { a ou } \\
\text { usa }\end{array}$ & $\begin{array}{l}\text { Nunca } \\
\text { Sim, n } \\
\text { Sim, h }\end{array}$ & $\begin{array}{l}\text { nos } \\
\text { de }\end{array}$ & $\begin{array}{l}\text { ese } \\
\text { ese }\end{array}$ & & \\
\hline 7) & $\begin{array}{l}\text { Con } \\
\text { sigr }\end{array}$ & & & & $1 \mathrm{~m}$ & $\begin{array}{l}\text { uma } \\
\text { pior do }\end{array}$ & $\begin{array}{l}\text { cala de } \\
\text { possív }\end{array}$ & & & & \\
\hline $\begin{array}{l}\mathrm{Ne} \\
\mathrm{Do}\end{array}$ & hum & & & & & & & & & jior & possível \\
\hline & 0 & 1 & 2 & 3 & 4 & 5 & 6 & 7 & 8 & 9 & 10 \\
\hline
\end{tabular}

8) Nos últimos 6 meses, quão intensa foi sua pior dor facial, em uma escala de 0 a 10, onde 0 significa "nenhuma dor"e 10 significa "a pior dor possível".

\begin{tabular}{l|l|l|l|l|l|l|l|l|l|l|}
\hline $\begin{array}{l}\text { Nenhuma } \\
\text { Dor }\end{array}$ & \multicolumn{4}{|c|}{ A pior dor possível } \\
\hline 0 & 1 & 2 & 3 & 4 & 5 & 6 & 7 & 8 & 9 & 10 \\
\hline
\end{tabular}

9) Nos últimos 6 meses, em média, quão intensa foi sua dor, em uma escala de 0 a 10, onde 0 significa "nenhuma dor"e 10 significa "a pior dor possível". [ou seja, sua dor usual, nos momentos em que você sente dor]

\begin{tabular}{|l|l|l|l|l|l|l|l|l|l|l|l|}
\hline $\begin{array}{l}\text { Nenhuma } \\
\text { Dor }\end{array}$ & $\begin{array}{r}\text { A pior } \\
\text { dor } \\
\text { possível }\end{array}$ \\
\hline 0 & 1 & 2 & 3 & 4 & 5 & 6 & 7 & 8 & 9 & 10 \\
\hline
\end{tabular}


10) Quantos dias, mais ou menos, nos úlitmos 6 meses, vc deixou de realizar suas atividades rotineiras (trabalho, escola ou trabalho de casa) por causa de sua dor facial?

11) Nos últimos 6 meses, o quanto a sua dor facial tem interferido com suas atividades diárias, em uma escala de 0 a 10, onde 0 significa "nenhuma dor"e 10 significa "a pior dor possível".

Nenhuma

Interferência

$$
0
$$

\begin{tabular}{l|l}
0 & 1
\end{tabular}

\begin{tabular}{|c|c|c|c|c|c|c|c|c|}
\multicolumn{10}{l|}{} & $\begin{array}{c}\text { Incapaz de realizar } \\
\text { qualquer atividade }\end{array}$ \\
\hline
\end{tabular}

12) Nos últimos 6 meses, o quanto a sua dor facial alterou sua capacidade de participar de atividades recreativas, sociais e em família, em uma escala de 0 a 10, onde 0 significa "nenhuma dor"e 10 significa "a pior dor possível".

\begin{tabular}{|c|c|c|c|c|c|c|c|c|c|c|}
\hline \multicolumn{7}{|l|}{$\begin{array}{l}\text { Nenhuma } \\
\text { Mudança }\end{array}$} & \multicolumn{4}{|c|}{ Mudança extrema } \\
\hline 0 & 1 & 2 & 3 & 4 & 5 & 6 & 7 & & 9 & 10 \\
\hline
\end{tabular}

13) Nos últimos 6 meses, o quanto a sua dor facial alterou sua habilidade para o trabalho, (incluindo o trabalho doméstico), em uma escala de 0 a 10, onde 0 significa "nenhuma dor"e 10 significa "a pior dor possível".

Nenhuma

Mudança

\begin{tabular}{|c|c|c|c|c|c|c|c|c|c|c|} 
Mudança \\
extrema
\end{tabular}

14)

a) Alguma vez você já teve sua mandíbula travada ou aderida de forma que ela não se abriria de qualquer forma?

Sim............

[Se não houve qualquer problema de abertura, de qualquer forma, pule para a questão 15]

b) A limitação de abertura foi severa o suficiente para interferir com sua habilidade de comer?

Não.............

Sim............

15)

a) Você percebe algum click ou estalido quando você abre ou fecha sua boca, ou quando você mastiga?

Não. ...0

Você percebe sua mandíbula faz ruído de ranger ou de raspar (como se houvesse areia), quando você abre ou fecha a boca, ou quando você mastiga?

c) Alguém já lhe disse que você range ou aperta seus dentes quando você dorme?

Sim............1

\begin{tabular}{|c|c|c|}
\hline b) & $\begin{array}{l}\text { Você percebe sua mandíbula faz ruído de ranger ou de raspar (como se } \\
\text { houvesse areia), quando você abre ou fecha a boca, ou quando você } \\
\text { mastiga? }\end{array}$ & $\begin{array}{l}\text { Não............. } \\
\text { Sim...........1 }\end{array}$ \\
\hline c) & $\begin{array}{l}\text { Alguém já lhe disse que você range ou aperta seus dentes quando você } \\
\text { dorme? }\end{array}$ & $\begin{array}{l}\text { Não........... } \\
\text { Sim } \ldots \ldots \ldots \ldots .1\end{array}$ \\
\hline d) & Você já notou que range ou aperta seus dentes quando você dorme? & $\begin{array}{l}\text { Não............. } \\
\text { Sim............1 }\end{array}$ \\
\hline e) & Durante o dia, você aperta ou range seus dentes? & $\begin{array}{l}\text { Não............. } \\
\text { Sim............1 }\end{array}$ \\
\hline f) & $\begin{array}{l}\text { Você já sentiu sua mandíbula dolorida ou rígida quando você acorda } \\
\text { pela manhã? }\end{array}$ & $\begin{array}{l}\text { Não............. } \\
\text { Sim............1 }\end{array}$ \\
\hline g) & Você tem ruídos ou zumbidos nos ouvidos? & $\begin{array}{l}\text { Não............. } \\
\text { Sim............1 }\end{array}$ \\
\hline h) & Você sente sua mordida desconfortável ou diferente? & $\begin{array}{l}\text { Não............. } \\
\text { Sim............1 }\end{array}$ \\
\hline 16) & $\begin{array}{l}\text { Você tem artrite reumatóide, lupus, ou qualquer outra doença de artrite } \\
\text { sistêmica? }\end{array}$ & $\begin{array}{l}\text { Não............. } \\
\text { Sim............1 }\end{array}$ \\
\hline b) & Você sabe se alguém da sua família teve qualquer dessas doenças? & $\begin{array}{l}\text { Não............. } \\
\text { Sim............ }\end{array}$ \\
\hline
\end{tabular}




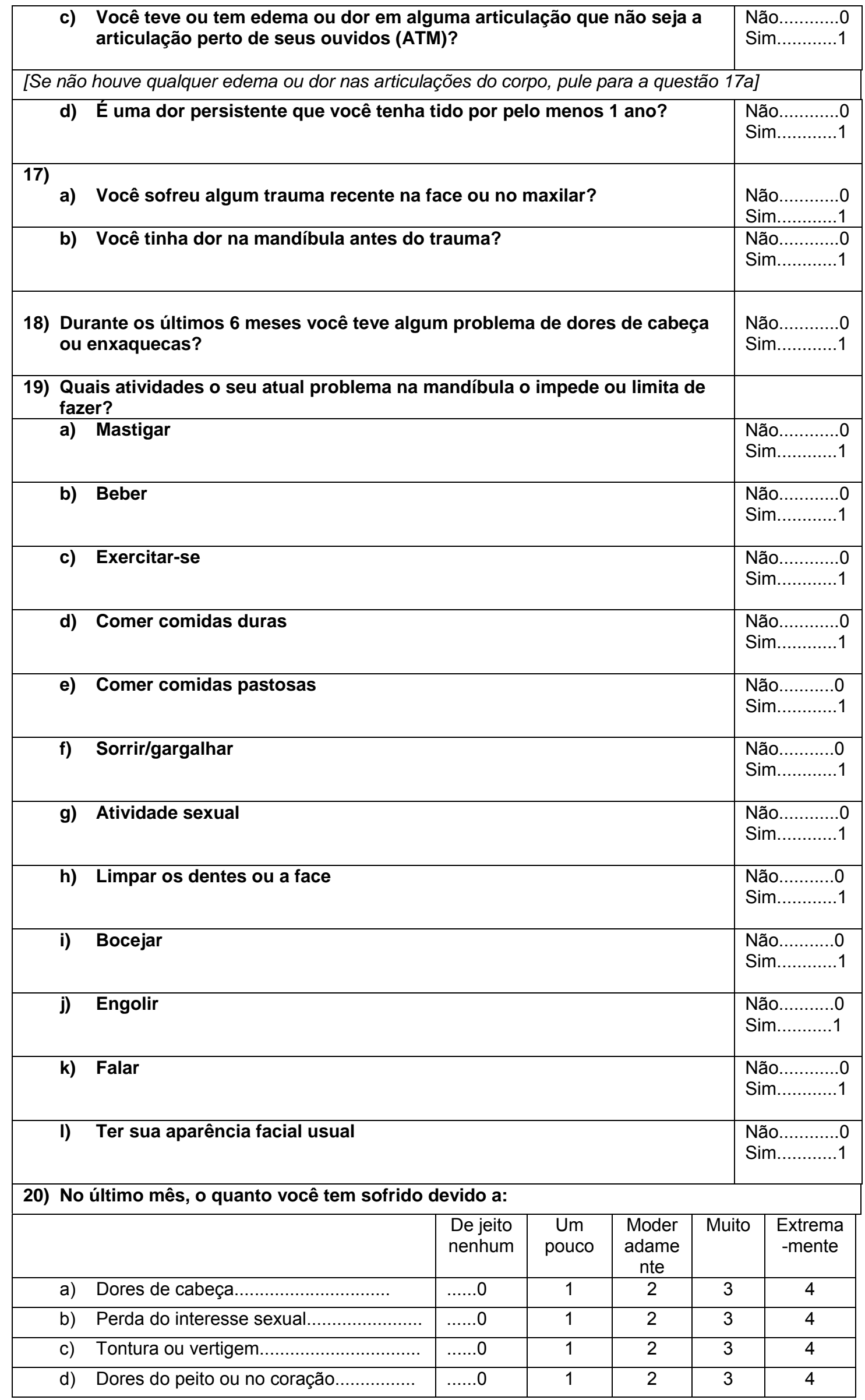




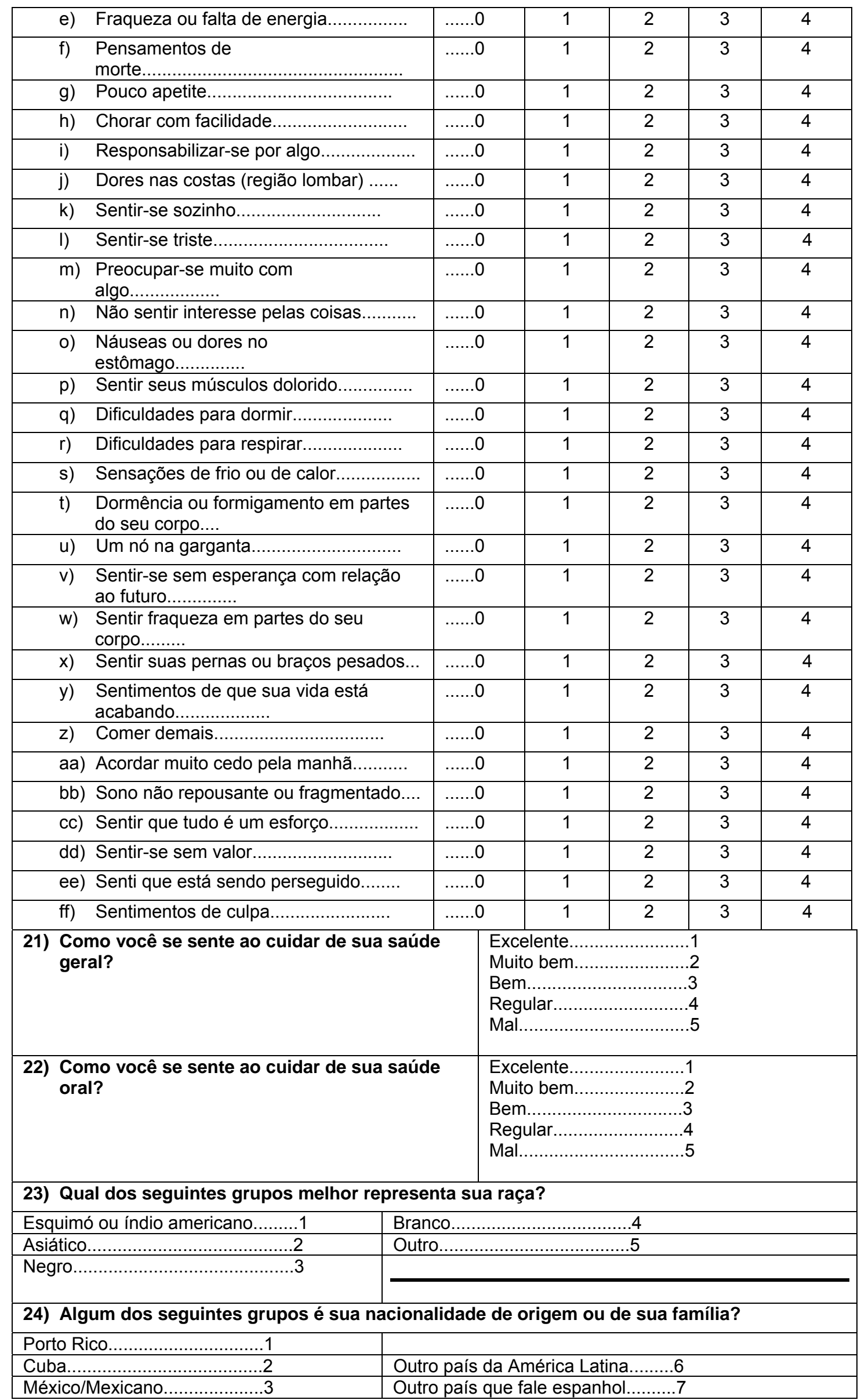




\begin{tabular}{|c|c|c|c|c|c|c|c|c|}
\hline México/Americano..................4 & \multicolumn{8}{|c|}{ Nenhum acima..............................8 } \\
\hline \multicolumn{9}{|c|}{ 25) Qual o grau ou ano mais alto da escola regular que você completou? } \\
\hline $\begin{array}{l}\text { Nunca foi à escola ou freqüentou o pré- } \\
\text { escolar }\end{array}$ & 00 & & & & & & & \\
\hline $1^{\circ}$. Grau ou Ensino Fundamental & 1 & 2 & 3 & 4 & 5 & 6 & 7 & 8 \\
\hline $2^{\circ}$. Grau ou Ensino Médio & 9 & 10 & 11 & 12 & & & & \\
\hline Ensino superior & 13 & 14 & 15 & 16 & 17 & $18+$ & & \\
\hline \multicolumn{7}{|c|}{$\begin{array}{l}\text { 26) Nas duas semanas passadas, você trabalhou ou esteve ocupado em } \\
\text { algum trabalho? (excluindo o trabalho não remunerado doméstico ou } \\
\text { em algum negócio da família) }\end{array}$} & & ........... \\
\hline \multicolumn{9}{|l|}{$\begin{array}{l}\text { [Se sim, pule para a questão 26] } \\
\text { Se não }\end{array}$} \\
\hline \multicolumn{7}{|l|}{$\begin{array}{l}\text { b) Embora você não tenha } \\
\text { algum emprego ou negó }\end{array}$} & \multicolumn{2}{|c|}{$\begin{array}{l}\text { Não............. } \\
\text { Sim............1 }\end{array}$} \\
\hline \multicolumn{9}{|l|}{$\begin{array}{l}\text { [Se sim, pule para a questão 26] } \\
\text { Se não }\end{array}$} \\
\hline \multicolumn{3}{|c|}{$\begin{array}{l}\text { Você estava procurando trabalho ou de } \\
\text { licença do seu trabalho durante essas } 2 \\
\text { semanas? }\end{array}$} & \multicolumn{6}{|c|}{ 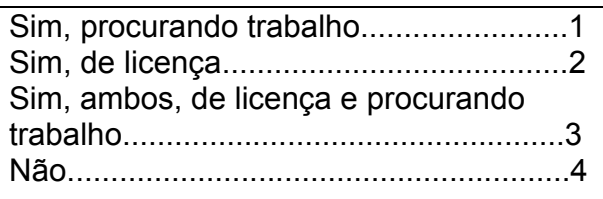 } \\
\hline \multicolumn{3}{|l|}{ 27) Qual seu estado civil? } & \multicolumn{6}{|c|}{ 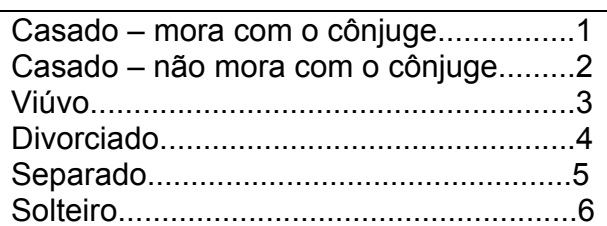 } \\
\hline
\end{tabular}




\section{Exame Físico}

1) Você sente dor no lado direito de sua face, no

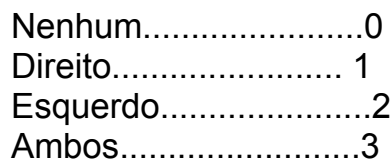

2) Você consegue indicar as áreas onde você sente dor? lado esquerdo, ou em ambos os lados?

[O examinador deve conferir se a área que o paciente indica é indefinida ou se se trata da ATM ou dos músculos]

Lado Direito

Nenhum.......................

ATM ............................ 1

Músculos.....................

Ambos........................

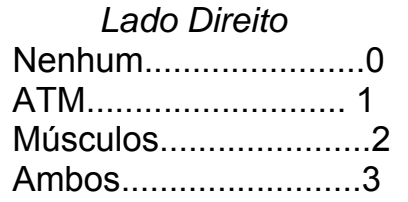

Reto.

Deflexão para a direita .1

Desvio para a direita.....2

Deflexão para a

esquerda...........................

Desvio para a

esquerda......................... 4

Outro..............................

Tipo

(especifique)

Outro significa: abertura não suave ou contínua, se o indivíduo apresentar mais de um padrão de abertura (escreva "mais de um")

4) Amplitude de abertura bucal

\section{a. Abertura não assistida sem dor $\quad \mathbf{m m}$}

-Coloque sua mandíbula em posição confortável, com os dentes se tocando levemente. - Abra sua boca o máximo possível, sem sentir dor.

Se o paciente abrir menos do que $30 \mathrm{~mm}$, peça que repita a abertura a fim de conferir o valor.

b.

Abertura máxima não assistida $\mathrm{mm}$

-Coloque sua mandíbula em posição confortável, com os dentes se tocando levemente. - Abra sua boca o máximo possível, mesmo que seja um pouco desconfortável. -Quando você abriu a boca agora, você sentiu alguma dor?.

Marque se houve ou não dor e a localização, e se foi ou não na ATM. Se o indivíduo indicar sensação de pressão ou apertamento, indique 0 para dor e 9 para Articulação.

c.

- Abertura máxima assistida $\mathrm{mm}$

Coloque sua mandíbula em posição confortável, com os dentes se tocando levemente. - Abra sua boca o máximo possível, mesmo que seja um pouco desconfortável. Depois que o indivíduo tenha aberto o máximo possível, coloque seu polegar sobre os incisivos centrais inferiores do indivíduo. Desta posição você irá ganhar alavanca necessária para forçar o aumento da abertura.

-Eu estou checando para verificar se posso empurrar sua boca um pouco mais e eu paro se você levantar a mão.

-Você sentiu alguma dor quando eu tentei forçar um pouco mais abertura de sua boca?. Marque se houve ou não dor e a localização, e se foi ou não na ATM. (da mesma forma que para a abertura máxima não assistida) 


\begin{tabular}{|c|c|c|c|c|c|c|}
\hline \multicolumn{4}{|c|}{ Presença de Dor } & \multicolumn{3}{|c|}{ Localização: Articulação } \\
\hline Nenhum & Direito & Esquerdo & Ambos & Sim & Não & $\begin{array}{c}\text { Nenhum } \\
\text { a dor }\end{array}$ \\
\hline 0 & 1 & 2 & 3 & 1 & 0 & 9 \\
\hline 0 & 1 & 2 & 3 & 1 & 0 & 9 \\
\hline
\end{tabular}

5) Ruídos Articulares (palpação)

a) Abertura

-Enquanto eu estou com meus dedos sobre sua articulação, abra lentamente sua boca, o máximo possível e depois feche lentamente até que seus dentes estejam se tocando completamente. $(3 x)$

O estalido deve ser registrado apenas se o estalido for reprodutível, em 2 dos 3 movimentos de abertura e fechamento.

\begin{tabular}{|c|c|c|}
\hline & Direito & $\begin{array}{c}\text { Esque } \\
\text { rdo }\end{array}$ \\
\hline \multicolumn{3}{|l|}{ Nenhum... } \\
\hline Estalido....................... & 0 & 0 \\
\hline Crepitação grosseira....... & 1 & 1 \\
\hline \multirow[t]{2}{*}{ Crepitação fina............. } & 2 & 2 \\
\hline & 3 & 3 \\
\hline \multicolumn{3}{|c|}{ estalido de abertura ___ $\mathrm{mm} \_\mathrm{mm}$} \\
\hline iento & Direito & $\begin{array}{c}\text { Esque } \\
\text { rdo }\end{array}$ \\
\hline \multicolumn{3}{|l|}{ Nenhum } \\
\hline Estalido......................... & 0 & 0 \\
\hline Crepitação grosseira....... & 1 & 1 \\
\hline \multirow[t]{2}{*}{ Crepitação fina................... } & 2 & 2 \\
\hline & 3 & 3 \\
\hline
\end{tabular}

Medida do estalido de fechamento $\mathrm{mm}$ $\mathrm{mm}$

c) Estalido recíproco eliminado durante a abertura protrusiva

Definido quando ocorrem dois estalidos (1 na abertura e outro no fechamento) que são eliminados durante a abertura e o fechamento em posição protruída.

\begin{tabular}{|c|c|c|}
\hline & Direito & Esquer \\
\hline Não............................. & 0 & 0 \\
\hline Sim $\ldots \ldots \ldots \ldots \ldots \ldots \ldots \ldots \ldots \ldots \ldots \ldots \ldots$ & 1 & 1 \\
\hline 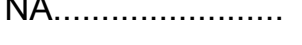 & 9 & 9 \\
\hline
\end{tabular}

\section{6) Movimentos excursivos}

Trace uma linha vertical contínua nos incisivos centrais superior e inferior.

a) - Lateralidade Direita $\mathrm{mm}$

Mova sua mandíbula o máximo possível para a direita, mesmo que isso seja desconfortável e depois volte à posição normal. (3x).

- Você sentiu alguma dor quando moveu sua mandíbula para o lado?

b) Lateralidade Esquerda $\mathbf{m m}$

c) Protrusão $\mathrm{mm}$

$\begin{array}{lll} & \text { Presença de Dor } \\ \text { Nenhum } & \text { Direito } \quad \text { Esquerdo }\end{array}$

Ambos

Localização: Articulação

a. 0

b. 0

1

c. 0

1

2
2
2

3

3

3

Sim Não Nenhuma

12

1
1
1

0 dor

9

9

3


7) Ruídos articulares durante as excursões

\begin{tabular}{|c|c|c|c|c|}
\hline Ruídos Lado Direito & Nenhum & Estalido & $\begin{array}{c}\text { Crepitação } \\
\text { grosseira }\end{array}$ & $\begin{array}{l}\text { Crepitação } \\
\text { fina }\end{array}$ \\
\hline Lateralidade Direita & 0 & 1 & 2 & 3 \\
\hline Lateralidade Esquerda & 0 & 1 & 2 & 3 \\
\hline Protrusão & 0 & 1 & 2 & 3 \\
\hline Ruídos Lado Esquerdo & Nenhum & Estalido & $\begin{array}{c}\text { Crepitação } \\
\text { grosseira }\end{array}$ & $\begin{array}{l}\text { Crepitação } \\
\text { fina }\end{array}$ \\
\hline Lateralidade Direita & 0 & 1 & 2 & 3 \\
\hline Lateralidade esquerda & 0 & 1 & 2 & 3 \\
\hline Protrusão & 0 & 1 & 2 & 3 \\
\hline
\end{tabular}

\section{8) Dor Muscular Extraoral à palpação}

- Caso o paciente sinta dor, pergunte-lhe se a dor é leve, moderada ou severa.

Registre qualquer resposta confusa ou relato de pressão como 0.

Será usado o escore $0=$ sem dor, $1=$ dor leve; $2=$ dor moderada e $3=$ dor severa.

-Mantenha seus músculos relaxados, com os dentes levemente afastados e os lábios se tocando.

a) Temporal anterior (Imediatamente acima do processo zigomático - em frente à têmpora)

b) Temporal médio (Depressão a $2 \mathrm{~cm}$ da extremidade externa da sobrancelha - têmpora)

c) Temporal posterior (fibras diretamente acima do pavilhão auditivo - mova os dedos para anterior até a borda anterior do pavilhão auditivo)

d) Masseter (origem)

e) Masseter (corpo)

f) Masseter (inserção)

g) Masseter (profundo) (Imediatamente anterior à ATM)

h) Digástrico posterior (Área entre a inserção do esternocleidomastóideo e a borda posterior da mandíbula - área imediatamente medial e posterior ao ângulo da mandíbula)

i) Pterigóideo medial

9) Dor articular à palpação
a) Lateral
b) Posterior

10) Dor Muscular Intraoral à palpação

a) Tendão do Temporal

\begin{tabular}{|c|c|c|c|c|c|c|c|}
\hline \multicolumn{4}{|c|}{ Direito } & & \multicolumn{3}{|c|}{ Esquerdo } \\
\hline 0 & 12 & 2 & 3 & 0 & 1 & 2 & 3 \\
\hline 0 & 12 & 2 & 3 & 0 & 1 & 2 & 3 \\
\hline 0 & 12 & & 3 & 0 & 1 & 2 & 3 \\
\hline 0 & 12 & & 3 & 0 & 1 & 2 & 3 \\
\hline 0 & 12 & 2 & 3 & 0 & 1 & 2 & 3 \\
\hline 0 & 12 & & 3 & 0 & 1 & 2 & 3 \\
\hline 0 & 12 & 2 & 3 & 0 & 1 & 2 & 3 \\
\hline 0 & 12 & & 3 & 0 & 1 & 2 & 3 \\
\hline 0 & 12 & & 3 & 0 & 1 & 2 & 3 \\
\hline & Direi & & & & & que & \\
\hline 0 & 1 & 2 & 3 & 0 & 1 & 2 & 3 \\
\hline 0 & 1 & 2 & 3 & 0 & 1 & 2 & 3 \\
\hline & Direi & & & & & que & \\
\hline 0 & 1 & 2 & 3 & 0 & 1 & & 3 \\
\hline
\end{tabular}




\section{Sumário dos Achados do Paciente}

Grupo I. Desordens musculares (circule apenas uma resposta para o Grupo I):

A. Dor Miofascial (la)

( )

a. Queixa de dor na mandíbula, têmporas, face, área preauricular ou dentro dos ouvidos em repouso ou durante a função (Q3); +

b. Dor à palpação em 3 ou mais dos 20 sítios musculares. Pelo menos 1 desses sítios deve ser do mesmo lado da queixa.

B. Dor Miofascial com limitação de abertura (Ib)

a. Diagnóstico la +

b. Abertura não assistida livre de dor $<40 \mathrm{~mm}$ (E 4a); +

c. Abertura máxima assistida (estiramento passivo) com $5 \mathrm{~mm}$ ou mais maior do que a abertura não assistida sem dor (E 4a, 4c)

Grupo II. Deslocamento de disco (circule apenas uma resposta para cada articulação para o Grupo II):

\begin{tabular}{|c|c|}
\hline A. ATM direita & B. ATM es \\
\hline 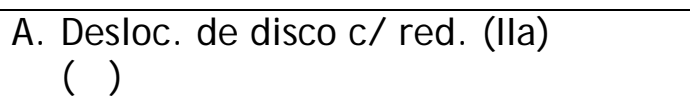 & $\begin{array}{l}\text { A. Desloc. de disco c/ red. (Ila) } \\
(\text { ) }\end{array}$ \\
\hline \multicolumn{2}{|c|}{$\begin{array}{l}\text { a. Estalido recíproco na ATM que ocorre em um ponto da abertura com uma distância } \\
\text { interincisal de pelo menos } 5 \mathrm{~mm} \text { maior do que no fechamento e eliminado pela abertura e } \\
\text { fechamento em posição protruída, reprodutível em } 2 \text { de } 3 \text { aberturas consecutivas (E } 5 \text { ) ou } \\
\text { b. Estalido na ATM na abertura ou no fechamento (reprodutível em } 2 \text { de } 3 \text { aberturas } \\
\text { consecutivas) e estalido durante um dos movimentos excursivos reprodutível em } 2 \text { de três } \\
\text { execuções (E 5a, 5b e 7) }\end{array}$} \\
\hline $\begin{array}{l}\text { B. Desloc. disco s/ red. c/ limitação de } \\
\text { abertura (Ilb) } \\
(\quad)\end{array}$ & $\begin{array}{l}\text { B. Desloc. de disco s/ red. c/ limitação } \\
\text { de abertura (Ilb) } \\
(\text { ) }\end{array}$ \\
\hline \multicolumn{2}{|c|}{$\begin{array}{l}\text { a. História de limitação significativa na abertura (Q } 14 \text {, ambas as partes); + } \\
\text { b. Abertura máxima não assistida } \leq 35 \mathrm{~mm}(\mathrm{E} 4 \mathrm{~b}, 4 \mathrm{~d}) ;+ \\
\text { c. O estiramento passivo aumenta a abertura em } 4 \mathrm{~mm} \text { ou menos além da abertura máxima } \\
\text { não assistida }(\mathrm{E} 4 \mathrm{~b}, 4 \mathrm{c}, 4 \mathrm{~d}) ;+ \\
\text { d. Excursão lateral }<7 \mathrm{~mm} \text { e/ ou deflexão para o lado ipsilateral na abertura }(\mathrm{E} 3,6 \mathrm{a} \text { ou } 6 \mathrm{~b}) ;+ \\
\text { e. Ausência de ruídos articulares ou presença de rú́dos articulares que não preencham o } \\
\text { critério para deslocamento de disco com redução }(E 5,7)\end{array}$} \\
\hline $\begin{array}{l}\text { C. Desloc. de disco s/ redução s/ } \\
\text { limitação de abertura (IIc) } \\
(\quad)\end{array}$ & $\begin{array}{l}\text { B. Desloc. de disco s/ } \\
\text { limitação de abert } \\
(\quad)\end{array}$ \\
\hline $\begin{array}{ll}\text { a. } & \text { História de limitação de abertu } \\
\text { b. } & \text { Abertura máxima não assistida } \\
\text { C. } & \text { Estiramento passivo aumenta e } \\
\text { assistida } & (\text { E } 4 \mathrm{~b}, 4 \mathrm{c}) ;+ \\
\text { d. } & \text { Excurção contralateral } \geq 7 \mathrm{~mm} \text { ( }\end{array}$ & $\begin{array}{l}\text { nificativa ( } Q 14 \text { ambas as } \\
\text { m (E } 4 b) ;+ \\
\text { m ou mais acima da abert }\end{array}$ \\
\hline
\end{tabular}


Grupo III. Outra condição articular (Circule apenas uma resposta para cada articulação pra o Grupo III):

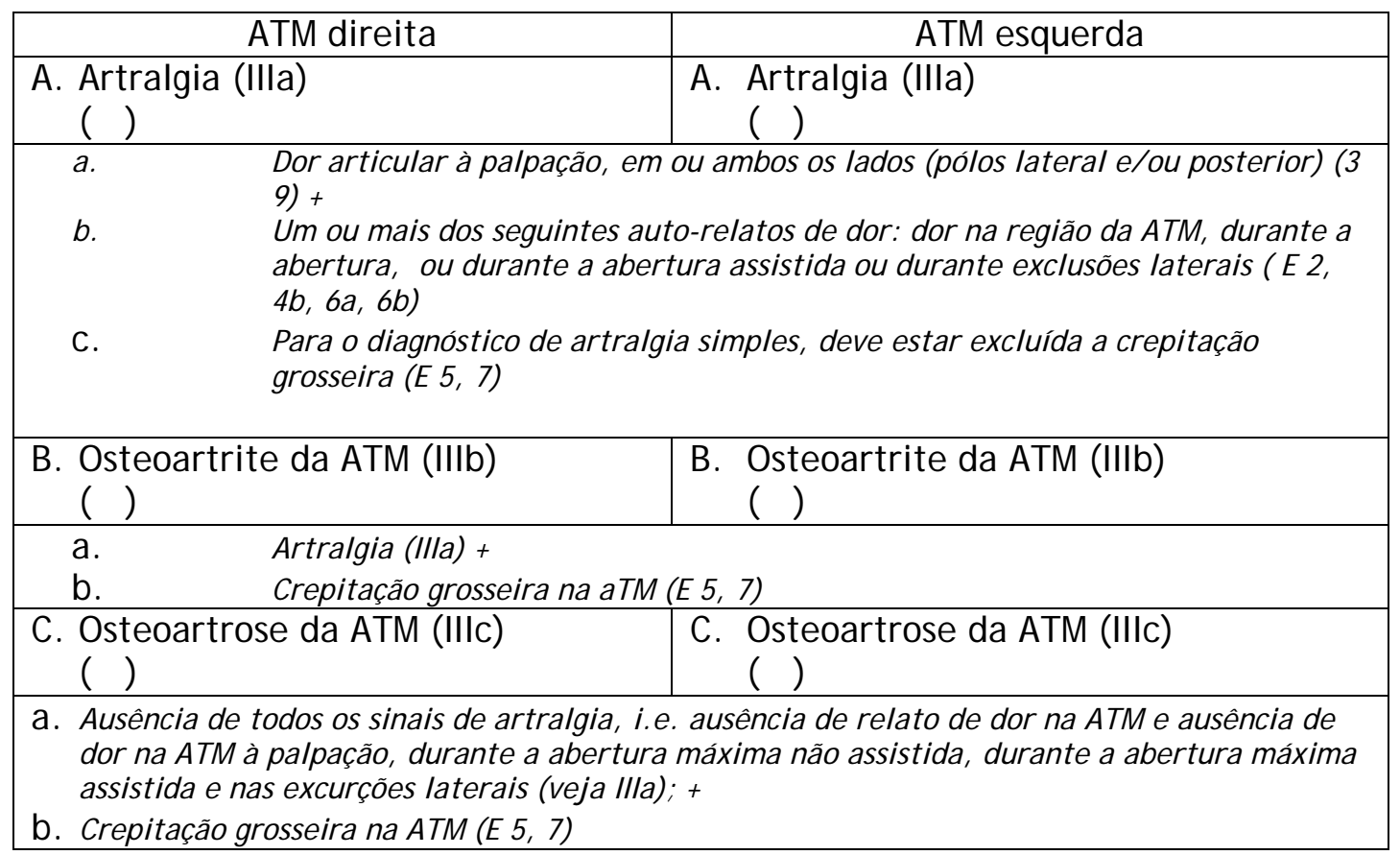

\section{Grupo Controle ( )}

\section{ESPECIFICAÇÕES DO RDC PARA O EXAME DE DTM}

\section{1) Normas Gerais}

a) Todas as medidas devem ser realizadas com os músculos mandibulares em estado passivo, a menos que o exame indique de outra forma. As articulações e os músculos não devem receber carga adicional em qualquer momento.

b) Todas os registros em $\mathrm{mm}$ devem ser feitos com 1 ou 2 dígitos, se a leitura possuir apenas 1 dígito, o mesmo deve ser precedido pelo dígito 0 . Se a medida situar-se entre dois milímetros, deve ser registrada a marca menor.

c) Os indivíduos devem estar sentados confortavelmente na cadeira odontológica a aproximadamente $90^{\circ}$.

d) No item 4 (Amplitude de Abertura Bucal) do Exame Físico, deve-se adicionar ao valor de obtido entre as bordas incisais superiores e inferiores, 0 valor de trespasse vertical. No item 6 (Movimentos excursivos), deve-se traçar duas linhas verticais contínuas (sobre os incisivos centrais superior e inferior) de forma que, ao se realizarem os movimentos de lateralidade direita e esquerda, meça-se 0 deslocamento da linha inferior com relação à inferior. (instruções modificadas, visando maior agilidade durante o exame) 


\section{2) Exame Físico}

a) Circule a resposta apropriada. Se o indivíduo indicar dor na linha média, marque "Ambos".

b) Se não estiver claro ao examinador se o indivíduo está indicando a ATM ou um músculo, pressione a área de forma mais leve possível para identificar corretamente a área anatômica (valerá a área encontrada pelo examinador).

\section{3) Instruções Gerais para a Palpação dos Músculos e da ATM}

a) Deve-se pressionar um sítio específico, usando-se o polegar e o dedo médio com a pressão padronizada de $1.5 \mathrm{~kg}$ para os músculos e 1.0 para a ATM. Devem-se palpar os músculos enquanto se apóia a cabeça do paciente com a outra mão a fim de estabilizá-la. A mandíbula do indivíduo deve estar em posição de repouso, sem que os dentes se toquem. Quando necessário, pode-se pedir ao paciente que aperte os dentes para que se localize melhor a área a ser palpada, em seguida, pede-se ao paciente que torne a relaxar, para que a pressão possa ser exercida. Como o local de dor máxima pode variar de paciente para paciente, é necessário que várias áreas na região especificada sejam pressionadas a fim de determinar se a dor existe. 


\section{ANEXO 7 - Inventário de Ansiedade de Beck (BAI)}

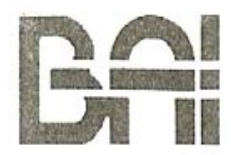

Data:

Nome: Estado Civil:

Idade: Sexo

Ocupaçāo: Escolaridade:

Abaixo está uma lista de sintomas comuns de ansiedade. Por favor, leia cuidadosamente cada item da lista. Identifique o quanto você tem sido incomodado por cada sintoma durante a última semana, incluindo hoje, colocando um " $\mathrm{x}$ " no espaço correspondente, na mesma linha de cada sintoma.

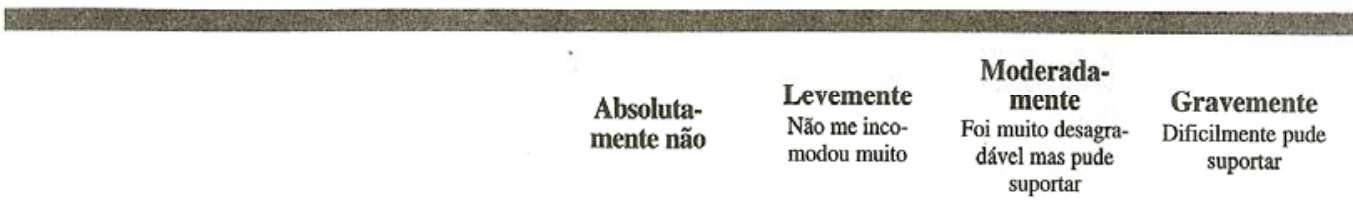

1. Dormência ou formigamento.

2. Sensação de calor.

3. Tremores nas pernas.

4. Incapaz de relaxar.

5. Medo que aconteça o pior.

6. Atordoado ou tonto.

7. Palpitação ou aceleração do coração.

8. Sem equilíbrio.

9. Aterrorizado.

10. Nervoso.

11. Sensação de sufocação.

12. Tremores nas mãos.

13. Trêmulo.

14. Medo de perder o controle.

15. Dificuldade de respirar.

16. Medo de morrer.

17. Assustado.

18. Indigestão ou desconforto no abdômen.

19. Sensação de desmaio.

20. Rosto afogueado.

21. Suor (não devido ao calor).

"Traduzido e adaptado por permissão de The Psychological Corporation, U.S.A. Direitos reservados `1991, a Aaron T. Beck.

Tradução para a língua portuguesa. Direitos reservados ${ }^{\circ} 1993$ a Aaron T. Beck. Todos os direitos reservados."

Tradução e adaptação brasileira, 2001, Casa do Psicólogo ${ }^{\circledR}$ Livraria e Editora Ltda. BAI é um logotipo da Psychological Corporation. 
Anexo 8 - Inventário de Sintomas de Stress de Lipp (ISSL)

Casa do Psicólogo

QUADRO 1a

a) Marque com um F1 os sintomas que tem experimentado nas últimas 24 horas

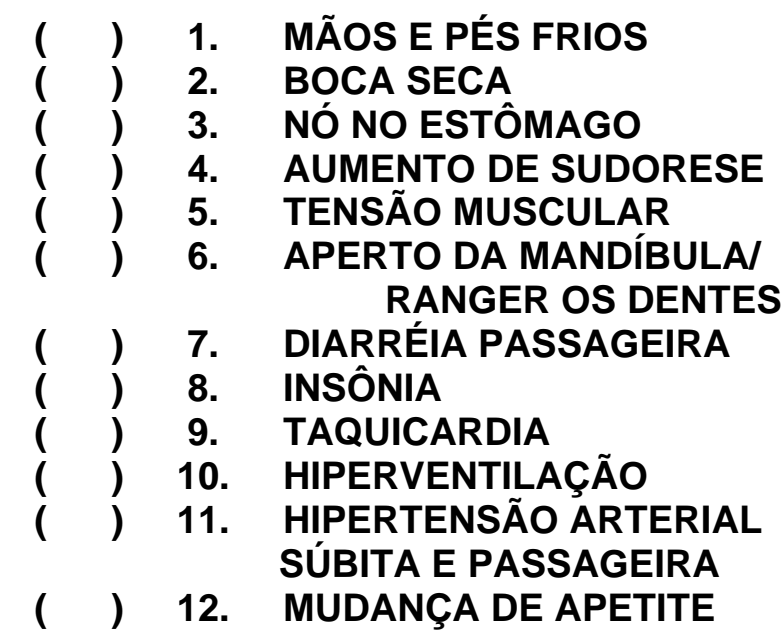

QUADRO $1 b$

b) Marque com um P1 os sintomas que tem experimentado nas últimas 24 horas

13. AUMENTO SÚBITO DE MOTIVAÇÃO

14.. ENTUSIASMO SÚBITO

15. VONTADE SÚBITA DE INICIAR NOVOS PROJETOS 
Inventário de Sintomas de Stress de Lipp Casa do Psicólogo

QUADRO 2a

c) Marque com um F2 os sintomas que tem experimentado na última semana

QUADRO $2 b$

d) Marque com um P2 os sintomas que tem experimentado na última semana

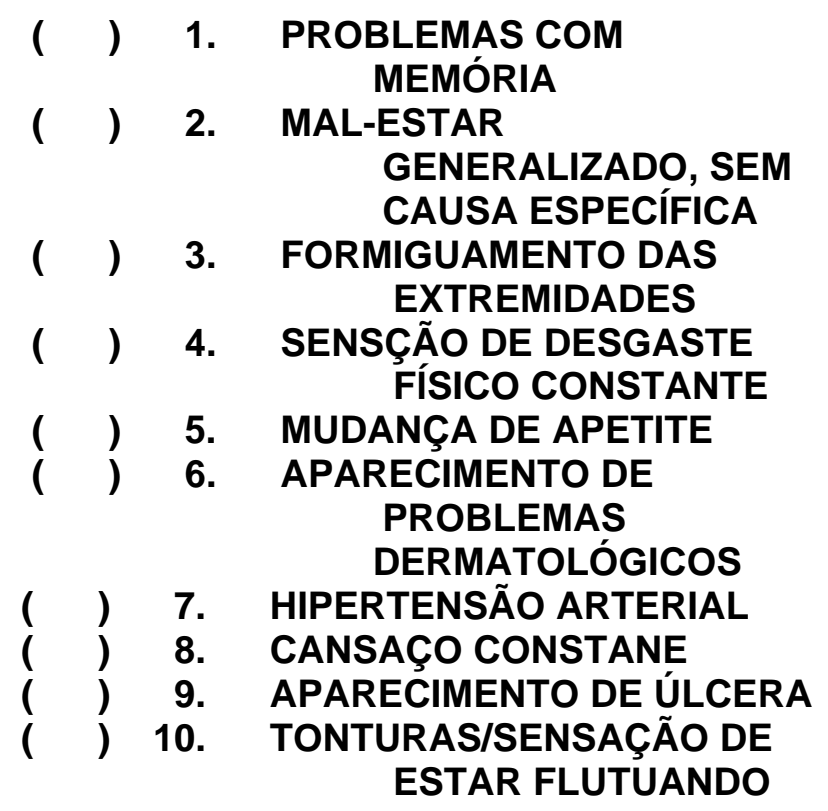

（） 11. SENSIBILIDADE EMOTIVA

（） 12. DÚVIDA QUANTO A SI

PRÓPRIO

( ) 13. PENSAR

CONSTATEMENTE EM UM

SÓ ASSUNTO

（） 14. IRRITABILIDADE

EXCESSIVA

（） 15. DIMINUIÇÃO DA LIBIDO 
Inventário de Sintomas de Stress de Lipp

Casa do Psicólogo

QUADRO 3a

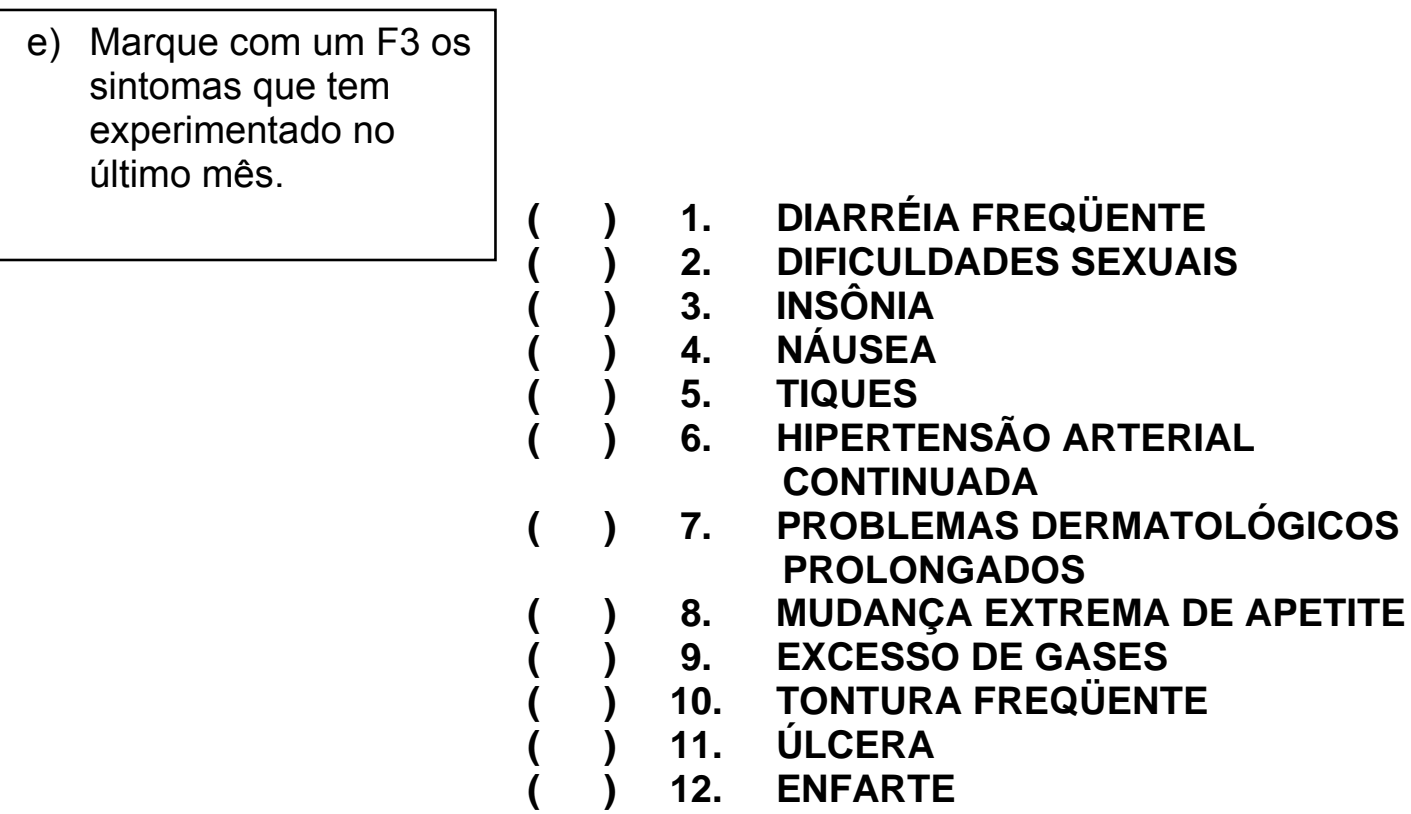

QUADRO $3 b$

f) Marque com um P3 os sintomas que tem experimentado no último mês.

13. IMPOSSIBILIDADE DE TRABALHAR

14.. PESADELOS

15. SENSAÇÃO DE INCOPETÊNCIA

EM TODAS AS ÁREAS

16. VONTADE DE FUGIR DE TUDO

17. APATIA, DEPRESSÃO OU RAIVA PROLONGADA

18. CANSAÇO EXCESSIVO

19. PENSAR/FALAR

CONSTANTEMENTE EM UM SÓ

ASSUNTO

（） 20. IRRITABILIDADE SEM CAUSA

APARENTE

( ) 21. ANGÚSTIAIANSIEDADE

DIÁRIA

( ) 22. HIPERSENSIBILIDADE EMOTIVA

( ) 23. PERDA DO SENSO DE HUMOR 


\section{Anexo 9 - Ficha de exame}

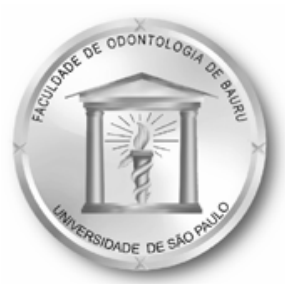

\section{UNIVERSIDADE DE SÃo PAULO}

\section{Faculdade de Odontologia de Bauru}

Al. Dr. Octávio Pinheiro Brisolla, 9-75 - Bauru-SP - CEP 17012-901 - C.P. 73

PABX (0XX14)235-8000 - FAX (0XX14)223-4679

Pesquisa: "Participação do estresse e ansiedade na alteração do limiar de dor à pressão (LDP) em pacientes com DTM miogênica: um estudo comparativo"

Orientador: Prof. Dr. Paulo César Rodrigues Conti

Aluna: Gabriela Modesti Vedolin

\section{Ficha de Exame}

Data do exame: Indivíduo:

Período:

\section{Escala de análise visual}

Indique a média de seu nível neste momento, marcando com uma linha vertical a escala abaixo. A extremidade esquerda indica ausência total de dor e a extremidade direita indica a pior dor imaginável.

\begin{tabular}{|l|l|l|l|}
\hline$\frac{\text { Músculo }}{\text { Afetado }}$ & $\underline{\text { LDP 1 }}$ & $\underline{\text { LDP 2 }}$ & MÉDIA \\
\hline MD & & & \\
\hline TAD & & & \\
\hline TMD & & & \\
\hline TPD & & & \\
\hline TENDÃO & & & \\
\hline ME & & & \\
\hline TAE & & & \\
\hline TME & & & \\
\hline TPE & & & \\
\hline
\end{tabular}


Referências 


\section{REFERÊNCIAS}

1 Alencar Jr. FGP. Fatores psicológicos nas Disfunções Craniomandibulares: Estudo da relação entre graus de disfunção e escalas de ansiedade traço - estado [Dissertação (Doutorado)]. Bauru: USP; 1997.

2 Auerbach SM, Laskin DM, Frantsve LM, Orr T. Depression, pain, exposure to stressful life events, and long-term outcomes in temporomandibular disorder patients. J Oral Maxillofac Surg. 2001 Jun;59(6):628-33; discussion 34.

3 Auvenshine RC. Psychoneuroimmunology and its relationship to the differential diagnosis of temporomandibular disorders. Dent Clin North Am. 1997 Apr;41(2):279-96.

4 Baba K, Haketa T, Sasaki Y, Ohyama T, Clark GT. Association between masseter muscle activity levels recorded during sleep and signs and symptoms of temporomandibular disorders in healthy young adults. J Orofac Pain. 2005 Summer;19(3):226-31.

5 Bader G, Lavigne G. Sleep bruxism; an overview of an oromandibular sleep movement disorder. REVIEW ARTICLE. Sleep Med Rev. 2000 Feb;4(1):27-43.

6 Beck A. The Beck anxiety inventory manual. NY, USA: Harcourt Brace; 1961.

$7 \quad$ Beck A. An Inventory for Measuring Clinical Anxiety: Psychometric Properties. Journal Consulting and Clinical Psychology. 1988;56:893-7.

$8 \quad$ Bendtsen L, Jensen R, Jensen NK, Olesen J. Muscle palpation with controlled finger pressure: new equipment for the study of tender myofascial tissues. Pain. 1994 Nov;59(2):235-9.

9 Berkley KJ. Sex differences in pain. Behav Brain Sci. 1997 Sep;20(3):371-80; discussion 435-513.

10 Bodere C, Tea SH, Giroux-Metges MA, Woda A. Activity of masticatory muscles in subjects with different orofacial pain conditions. Pain. 2005 Jul;116(1-2):33-41.

11 Brand AA, Lloyd PF, Gluckman S. Psychological evaluation of the chronic M.P.D.S. patient. J Dent Assoc S Afr. 1985 May;40(5):229-34.

12 Bush FM, Harkins SW, Harrington WG, Price DD. Analysis of gender effects on pain perception and symptom presentation in temporomandibular pain. Pain. 1993 Apr;53(1):73-80.

13 Calais SL, Andrade LMB, Lipp MEN. Gender and schooling differences in stress symptoms in young adults. Psicol Reflex Crit. 2003;16(2).

14 Camelo SH, Angerami EL. [Symptoms of stress in workers from five family health centers]. Rev Lat Am Enfermagem. 2004 Jan-Feb;12(1):14-21.

15 Cannistraci AJ, Friedrich JA. A multidimensional approach to bruxism and TMD. N Y State Dent J. 1987 Oct;53(8):31-4.

Carey C. Stress: a chain reaction. Cranio. 1992 Oct;10(4):335-6. 
17 Carlson CR, Okeson JP, Falace DA, Nitz AJ, Curran SL, Anderson D. Comparison of psychologic and physiologic functioning between patients with masticatory muscle pain and matched controls. J Orofac Pain. 1993 Winter;7(1):15-22.

18 Carlson CR, Reid KI, Curran SL, Studts J, Okeson JP, Falace D, et al. Psychological and physiological parameters of masticatory muscle pain. Pain. 1998 Jun;76(3):297-307.

19 Carvalho MMMJ. Introdução à Psiconcologia. São Paulo: Livro Pleno; 1994.

20 Chung SC, Kim JH, Kim HS. Reliability and validity of the pressure pain thresholds (PPT) in the TMJ capsules by electronic algometer. Cranio. 1993 Jul;11(3):171-6; discussion 7.

21 Chung SC, Um BG, Kim HS. Evaluation of pressure pain threshold in head and neck muscles by electronic algometer. Intrarater and interrater reliability. J craniomandibular Practice. 1992;10(1):28-34.

22 Cimino R, Farella M, Michelotti A, Pugliese R, Martina R. Does the ovarian cycle influence the pressure-pain threshold of the masticatory muscles in symptom-free women? J Orofac Pain. 2000 Spring;14(2):105-11.

23 Cimino R, Michelotti A, Stradi R, Farinaro C. Comparison of clinical and psychologic features of fibromyalgia and masticatory myofascial pain. $J$ Orofac Pain. 1998 Winter;12(1):35-41.

24 Clark GT, Delcanho RE, Goulet JP. The utility and validity of current diagnostic procedures for defining temporomandibular disorder patients. Adv Dent Res. 1993 Aug;7(2):97-112.

25 Clark GT, Rugh JD, Handelman SL. Nocturnal masseter muscle activity and urinary catecholamine levels in bruxers. J Dent Res. 1980 Oct;59(10):1571-6.

26 Clarke NG. Occlusion and myofacial pain dysfunction - is there relationship? J Am Dent Assoc. 1982;155:565-71.

27 Cohen SR. Follow-up evaluation of 105 patients with myofascial pain-dysfunction syndrome. J Am Dent Assoc. 1978 Nov;97(5):825-8.

28 Conti PC, dos Santos CN, Lauris JR. Interexaminer agreement for muscle palpation procedures: the efficacy of a calibration program. Cranio. 2002 Oct;20(4):289-94.

29 Conti PC, Ferreira PM, Pegoraro LF, Conti JV, Salvador MC. A cross-sectional study of prevalence and etiology of signs and symptoms of temporomandibular disorders in high school and university students. J Orofac Pain. 1996 Summer;10(3):254-62.

30 Crombie IK. Epidemiology of Pain: A report of the task force on epidemiology of the International Association for the Study of Pain. Seatle: IASP; 1999.

31 Curran SL, Carlson CR, Okeson JP. Emotional and physiologic responses to laboratory challenges: patients with temporomandibular disorders versus matched control subjects. J Orofac Pain. 1996 Spring;10(2):141-50. 
32 Dao TT, LeResche L. Gender differences in pain. J Orofac Pain. 2000 Summer;14(3):169-84; discussion 84-95.

33 Davenport JC. Pressure-pain thresholds in the oral cavity in man. Arch Oral Biol. 1969 Nov;14(11):1267-74.

34 De Laat A, Stappaerts K, Papy S. Counseling and physical therapy as treatment for myofascial pain of the masticatory system. J Orofac Pain. 2003 Winter;17(1):42-9.

35 Duckro PN, Tait RC, Margolis RB, Deshields TL. Prevalence of temporomandibular symptoms in a large United States metropolitan area. Cranio. 1990 Apr;8(2):131-8.

36 Duinkerke AS, Luteijn F, Bouman TK, De Jong HP. Relations between TMJ pain dysfunction syndrome (PDS) and some psychologic and biographic variables. Community Dent Oral Epidemiol. 1985 Jun;13(3):185-9.

37 Duinkerke AS, Luteijn F, Bouman TK, De Jong HP. Reproducibility of a palpation test for the stomatognathic system. Community Dent Oral Epidemiol. 1986 Apr;14(2):80-5.

38 Dworkin SF, Huggins KH, LeResche L, Von Korff M, Howard J, Truelove E, et al. Epidemiology of signs and symptoms in temporomandibular disorders: clinical signs in cases and controls. J Am Dent Assoc. 1990 Mar;120(3):273-81.

39 Dworkin SF, Le Resche L, De Rouen T. Reliability of clinical measurement in temporomandibular disorders. Clin J Pain. 1988;4(2).

40 Dworkin SF, LeResche L. Research diagnostic criteria for temporomandibular disorders: review, criteria, examinations and specifications, critique. J Craniomandib Disord. 1992 Fall;6(4):301-55.

41 Eli I. Psychosocial factors in the etiology, diagnosis and management of temporomandibular disorders. Alpha Omegan. 2003 Jul;96(2):20-3.

42 Evaskus DS, Laskin DM. A biochemical measure of stress in patients with myofascial pain-dysfunction syndrome. J Dent Res. 1972 SepOct;51(5):1464-6.

43 Farella M, Michelotti A, Steenks MH, Romeo R, Cimino R, Bosman $F$. The diagnostic value of pressure algometry in myofascial pain of the jaw muscles. J Oral Rehabil. 2000 Jan;27(1):9-14.

44 Farkas KP, Farkas JA. Self-punitive attitudes in myofacial pain syndrome patients. Gen Dent. 1990 Jul-Aug;38(4):286-8.

45 Faucett J, Gordon N, Levine J. Differences in postoperative pain severity among four ethnic groups. J Pain Symptom Manage. 1994 Aug;9(6):383-9.

46 Fearon CG, Serwatka WJ. Stress: a common denominator for nonorganic TMJ pain-dysfunction. J Prosthet Dent. 1983 Jun;49(6):805-8.

47 Feine JS, Bushnell MC, Miron D, Duncan GH. Sex differences in the perception of noxious heat stimuli. Pain. 1991 Mar;44(3):255-62. 
Ferrando M, Andreu Y, Galdon MJ, Dura E, Poveda R, Bagan JV. Psychological variables and temporomandibular disorders: distress, coping, and personality. Oral Surg Oral Med Oral Pathol Oral Radiol Endod. 2004 Aug;98(2):153-60.

49 Figueiró J, Teixeira MJ. Aspectos psicossociais relacionados à dor. In: . In: Teixeira MJ, Côrrea CF, Pimenta CAM, editors. Dor: conceitos gerais. São Paulo: Limay; 1994. p. 42-5.

50 Fine EW. Psychological factors associated with non-organic temporomandibular joint pain dysfunction syndrome. Br Dent J. 1971 Nov 2;131(9):402-4.

51 Fischer AA. Pressure algometry over normal muscles. Standard values, validity and reproducibility of pressure threshold. Pain. 1987 Jul;30(1):115-26.

52 Fischer AA. Pressure threshold measurement for diagnosis of myofascial pain and evaluation of treatment results. Clin J Pain. 1987;v.2:207$14,$.

53 Flor H, Birbaumer N, Schulte W, Roos R. Stress-related electromyographic responses in patients with chronic temporomandibular pain. Pain. 1991 Aug;46(2):145-52.

54 Fredriksson L, Alstergren $\mathrm{P}$, Kopp $\mathrm{S}$. Absolute and relative facial pressure-pain thresholds in healthy individuals. J Orofac Pain. 2000 Spring;14(2):98-104.

55 Fricton JR, Kroening R, Haley D, Siegert R. Myofascial pain syndrome of the head and neck: a review of clinical characteristics of 164 patients. Oral Surg Oral Med Oral Pathol. 1985 Dec;60(6):615-23.

56 Fricton JR, Olsen T. Predictors of outcome for treatment of temporomandibular disorders. J Orofac Pain. 1996 Winter;10(1):54-65.

57 Gale EN. Psychological characteristics of long term female temporomandibular joint pain patients. J dent Res. 1978;57(3):481-3.

58 Gallagher RW, Dal Santo FB, Rugh JD. Design and construction of a pressure algometer. J Craniomandib Disord. 1989 Summer;3(3):159-62.

59 Gameiro GH, da Silva Andrade A, Nouer DF, Ferraz de Arruda Veiga MC. How may stressful experiences contribute to the development of temporomandibular disorders? Clin Oral Investig. 2006 Dec;10(4):261-8.

60 Gatchel RJ, Garofalo JP, Ellis E, Holt C. Major psychological disorders in acute and chronic TMD: an initial examination. J Am Dent Assoc. 1996 Sep;127(9):1365-70, 72, 74.

61 Glaros AG, Williams K, Lausten L. The role of parafunctions, emotions and stress in predicting facial pain. J Am Dent Assoc. 2005 Apr;136(4):451-8.

62 Goulet JP, Clark GT. Clinical TMJ examination methods. J Calif Dent Assoc. 1990 Mar;18(3):25-33.

63 Goulet JP, Clark GT, Flack VF. Reproducibility of examiner performance for muscle and joint palpation in the temporomandibular system 
following training and calibration. Community Dent Oral Epidemiol. 1993 Apr;21(2):72-7.

64 Goulet JP, Clark GT, Flack VF, Liu C. The reproducibility of muscle and joint tenderness detection methods and maximum mandibular movement measurement for the temporomandibular system. J Orofac Pain. 1998 Winter;12(1):17-26.

65 Goulet JP, Lavigne GJ, Lund JP. Jaw pain prevalence among French-speaking Canadians in Quebec and related symptoms of temporomandibular disorders. J Dent Res. 1995 Nov;74(11):1738-44.

66 Graef FG, Brandão, M.L. Neurobiologia das doenças mentais. Sao Paulo: Lemos; 1993.

67 Gray RJ, Davies SJ, Quayle AA. A clinical approach to temporomandibular disorders. 3. Examination of the articulatory system: the muscles. Br Dent J. 1994 Jul 9;177(1):25-8.

68 Greene CS, Olson RE, Laskin DM. Psychological factors in the etiology, progression, and treatment of MPD syndrome. J Amer Dent Ass. 1982 Sept.;105:443-8.

69 Grzesiak RC. The psychologic aspects of chronic orofacial pain, Part I: Psychologic mechanisms. Compendium. 1988 Mar;9(3):222, 4-30.

$70 \quad$ Grzesiak RC. Psychologic aspects of chronic orofacial pain, Part II: Patient characteristics. Compendium. 1988 Apr;9(4):282-3, 6-8, 90-1.

71 Grzesiak RC. Psychologic considerations in temporomandibular dysfunction. A biopsychosocial view of symptom formation. Dent Clin North Am. 1991 Jan;35(1):209-26.

72 Hardy JD, Wolff HG, Goodelli H. Pain sensations and reactions: Baltimore; 1952.

73 Hidaka O, Yanagi M, Takada K. Mental stress-induced physiological changes in the human masseter muscle. J Dent Res. 2004 Mar;83(3):227-31.

74 Hijzen TH, Slangen JL. Myofascial pain-dysfunction: subjective signs and symptoms. J Prosthet Dent. 1985 Nov;54(5):705-11.

75 Hilgert JB, Hugo FN, Bandeira DR, Bozzetti MC. Stress, cortisol, and periodontitis in a population aged 50 years and over. J Dent Res. 2006 Apr;85(4):324-8.

76 Isselee $\mathrm{H}$, De Laat A, Bogaerts $\mathrm{K}$, Lysens $\mathrm{R}$. Short-term reproducibility of pressure pain thresholds in masticatory muscles measured with a new algometer. J Orofac Pain. 1998 Summer;12(3):203-9.

77 Isselee H, De Laat A, De Mot B, Lysens R. Pressure-pain threshold variation in temporomandibular disorder myalgia over the course of the menstrual cycle. J Orofac Pain. 2002 Spring;16(2):105-17.

78 Isselee $H$, De Laat $A$, Lesaffre $E$, Lysens R. Short-term reproducibility of pressure pain thresholds in masseter and temporalis muscles of symptom-free subjects. Eur J Oral Sci. 1997 Dec;105(6):583-7. 
79

Ito LM. Terapia cognitivo-comportamental para transtornos psiquiátricos. 1 ed. Porto Alegre: Artes Médicas; 1998.

80 Jaeger B, Reeves JL. Quantification of changes in myofascial trigger point sensitivity with the pressure algometer following passive stretch. Pain. 1986 Nov;27(2):203-10.

81 Jensen K, Andersen HO, Olesen J, Lindblom U. Pressure-pain threshold in human temporal region. Evaluation of a new pressure algometer. Pain. 1986 Jun;25(3):313-23.

82 Jensen R, Rasmussen BK, Pedersen B, Lous I, Olesen J. Cephalic muscle tenderness and pressure pain threshold in a general population. Pain. 1992 Feb;48(2):197-203.

83 Jimenez AC, Lane ME. Serial determinations of pressure threshold tolerance in chronic pain patients. Arch Phys Med Rehabil. 1985;66:546-6.

84 Johnstone DR, Templeton M. The feasibility of palpating the lateral pterygoid muscle. J Prosthet Dent. 1980 Sep;44(3):318-23.

85 Kaplan HI, Sadock BJ, Grebb JA. Compêndio de Psiquiatria Ciências do Comportamento e Psiquiatria Clínica. 7 ed. Porto Alegre: ArtMed; 2002.

86 Kato T, Thie NM, Montplaisir JY, Lavigne GJ. Bruxism and orofacial movements during sleep. Dent Clin North Am. 2001 Oct;45(4):657-84.

87 Katz JO, Rugh JD, Hatch JP, Langlais RP, Terezhalmy GT, Borcherding $\mathrm{SH}$. Effect of experimental stress on masseter and temporalis muscle activity in human subjects with temporomandibular disorders. Arch Oral Biol. 1989;34(6):393-8.

88 Keele KD. Pain-sensitivity tests; the pressure algometer. Lancet. 1954 Mar 27;266(6813):636-9.

89 Kinney RK, Gatchel RJ, Ellis E, Holt C. Major psychological disorders in chronic TMD patients: implications for successful management. J Am Dent Assoc. 1992 Oct;123(10):49-54.

90 Kleinknecht RA, Mahoney ER, Alexander LD, Dworkin SF. Correspondence between subjective report of temporomandibular disorder symptoms and clinical findings. J Am Dent Assoc. 1986 Aug;113(2):257-61.

91 Krogstad BS, Jokstad A, Dahl BL, Vassend O. The reporting of pain, somatic complaints, and anxiety in a group of patients with TMD before and 2 years after treatment: sex differences. J Orofac Pain. 1996 Summer;10(3):2639.

92 Kuttila M, Kuttila S, Niemi PM, Alanen P, Le Bell Y. Fluctuation of treatment need for temporomandibular disorders and age, gender, stress, and diagnostic subgroup. Acta Odontol Scand. 1997 Dec;55(6):350-5.

93 Kuttila M, Niemi PM, Kuttila S, Alanen P, Le Bell Y. TMD treatment need in relation to age, gender, stress, and diagnostic subgroup. J Orofac Pain. 1998 Winter;12(1):67-74.

94 Kydd WL. [Psychosomatic aspects of temporomandibular joint dysfunction.]. J Am Dent Assoc. 1959 Jul;59(1):31-44. 
95 Laskin DM. Etiology of the pain-dysfunction syndrome. J Am Dent Assoc. 1969 Jul;79(1):147-53.

96 Lavigne GJ, Rompre PH, Montplaisir JY. Sleep bruxism: validity of clinical research diagnostic criteria in a controlled polysomnographic study. $\mathrm{J}$ Dent Res. 1996 Jan;75(1):546-52.

97 Lindroth JE, Schmidt JE, Carlson CR. A comparison between masticatory muscle pain patients and intracapsular pain patients on behavioral and psychosocial domains. J Orofac Pain. 2002 Fall;16(4):277-83.

98 Lipp MEN. Mecanismos Neuropsicofisiológicos do Stress: Teorias e Aplicações Clínicas. 1 ed. São Paulo: Casa do Psicólogo; 2003.

99 Lipp MEN, Guevara AJH. Validação empírica do Inventário de Sintomas de Stress (ISS). Estudos de Psicologia. 1994;11:43-9.

100 List T, Helkimo M. Method for measuring muscle pain with the aid of algometer. Swed Dent J. 1987;11(abstract 69):294.

101 List T, Helkimo M, Falk G. Reliability and validity of a pressure threshold meter in recording tenderness in the masseter muscle and the anterior temporalis muscle. J craniomandibular Practice. 1989 July;11(3):223-9.

102 List T, Helkimo M, Karlsson R. Influence of pressure rates on the reliability of a pressure threshold meter. J Craniomandib Disord. 1991 Summer;5(3):173-8.

103 Lobbezoo F, Lavigne GJ. Do bruxism and temporomandibular disorders have a cause-and-effect relationship? J Orofac Pain. 1997 Winter;11(1):15-23.

104 Locker D, Slade G. Prevalence of symptoms associated with temporomandibular disorders in a Canadian population. Community Dent Oral Epidemiol. 1988 Oct;16(5):310-3.

105 Lowental $U$. Stress, anxiety and the dental patient: the missing specification. Int Dent J. 1981 Sep;31(3):193-7.

106 Lund JP, Donga R, Widmer CG, Stohler CS. The pain-adaptation model: a discussion of the relationship between chronic musculoskeletal pain and motor activity. Can J Physiol Pharmacol. 1991 May;69(5):683-94.

$107 \quad$ Lundeen TF, George JM, Sturdevant JR. Stress in patients with pain in the muscles of mastication and the temporomandibular joints. J Oral Rehabil. 1988 Nov;15(6):631-7.

108 Lundeen TF, Levitt SR, McKinney MW. Discriminative ability of the TMJ scale: age and gender differences. J Prosthet Dent. 1986 Jul;56(1):84-92.

109 Lundin RW. Ansiedade In: Lundin RW, editor. Personalidade: uma análise do comportamento; 1977. p. 329-51.

110 Lupton DE. Psychological aspects of temporomandibular joint dysfunction. J Am Dent Assoc. 1969 Jul;79(1):131-6.

111 Manfredini D, Bandettini di Poggio A, Cantini E, Dell'Osso L, Bosco M. Mood and anxiety psychopathology and temporomandibular disorder: a spectrum approach. J Oral Rehabil. 2004 Oct;31(10):933-40. 
112 Marbach JJ. The 'temporomandibular pain dysfunction syndrome' personality: fact or fiction? J Oral Rehabil. 1992 Nov;19(6):545-60.

113 Marbach JJ, Lennon MC, Dohrenwend BP. Candidate risk factors for temporomandibular pain and dysfunction syndrome: psychosocial, health behavior, physical illness and injury. Pain. 1988 Aug;34(2):139-51.

114 Marbach JJ, Lipton JA. Aspects of illness behavior in patients with facial pain. J Am Dent Assoc. 1978 Apr;96(4):630-8.

115 McCreary CP, Clark GT, Merril RL, Flack V, Oakley ME. Psychological distress and diagnostic subgroups of temporomandibular disorder patients. Pain. 1991 Jan;44(1):29-34.

116 McMillan AS, Blasberg B. Pain-pressure threshold in painful jaw muscles following trigger point injection. J Orofac Pain. 1994 Fall;8(4):384-90.

117 McMillan AS, Lawson ET. Effect of tooth clenching and jaw opening on pain-pressure thresholds in the human jaw muscles. J Orofac Pain. 1994 Summer;8(3):250-7.

118 McNeill C. Temporomandibular Disorders. Guidelines for classification, assessment and management. 2 ed. Chicago; 1993.

119 McNeill C. History and evolution of TMD concepts. Oral Surg Oral Med Oral Pathol Oral Radiol Endod. 1997 Jan;83(1):51-60.

120 McNeill C. Management of temporomandibular disorders: concepts and controversies. J Prosthet Dent. 1997 May;77(5):510-22.

121 Menezes C, Silva E, Passareli P, Silva J. Pain Perception from the vision of doctors and university students. Rev Dor. 2006;7(3):809-18.

122 Mense S, Simons D. Local pain in muscle. Philadelphia Lippincott Williams \& Wilkins; 2001.

123 Merskey H, Spear FG. The concept of pain. J Psychosom Res. 1967 Jun;11(1):59-67.

124 Miceli A, Leite D. Psychoanalysis role on understanding pain. Rev Dor. 2006;7(3):832-40.

125 Michelotti A, Farella M, Tedesco A, Cimino R, Martina R. Changes in pressure-pain thresholds of the jaw muscles during a natural stressful condition in a group of symptom-free subjects. J Orofac Pain. 2000 Fall;14(4):279-85.

126 Moody PM, Calhoun TC, Okeson JP, Kemper JT. Stress-pain relationship in MPD syndrome patients and non-MPD syndrome patients. $J$ Prosthet Dent. 1981 Jan;45(1):84-8.

127 Moody PM, Kemper JT, Okeson JP, Calhoun TC, Packer MW. Recent life changes and myofascial pain syndrome. J Prosthet Dent. 1982 Sep;48(3):328-30.

128 Moss RA, Adams HE. The assessment of personality, anxiety and depression in mandibular pain dysfunction subjects. J Oral Rehabil. 1984 May;11(3):233-5.

129 Moulton RE. Psychiatric considerations in maxillofacial pain. J Am Dent Assoc. 1955 Oct;51(4):408-14. 
130 Moulton RE. Emotional factors in non-organic temporomandibular joint pain. Dent Clin North Am. 1966 Nov:609-20.

131 Murphy GJ, McKinney MW, Gross WG. Temporomandibular-related pressure thresholds: a model for establishing baselines. Cranio. 1992 Apr;10(2):118-23.

132 Niemi P, Le Bell Y, Koskinen-Moffett L. Self-reported symptoms of stress in Finnish patients with craniomandibular disorders. J Orofac Pain. 1993 Fall;7(4):354-8.

133 Niemi PM, Le Bell Y, Kylmala M, Jamsa T, Alanen P. Psychological factors and responses to artificial interferences in subjects with and without a history of temporomandibular disorders. Acta Odontol Scand. 2006 Oct;64(5):300-5.

134 Nunes LMO. Associação entre bruxismo do sono e disfunção temporoandibular [Dissertação (Mestrado)]. Bauru: USP; 2003.

135 Oakley ME, McCreary CP, Clark GT, Holston S, Glover D, Kashima K. A cognitive-behavioral approach to temporomandibular dysfunction treatment failures: a controlled comparison. J Orofac Pain. 1994 Fall;8(4):397-401.

136 Oakley ME, McCreary CP, Flack VF, Clark GT, Solberg WK, Pullinger AG. Dentists' ability to detect psychological problems in patients with temporomandibular disorders and chronic pain. J Am Dent Assoc. 1989 Jun;118(6):727-30.

137 Oakley ME, McCreary CP, Flarck VF, Clark GT. Screening for psychological problems in temporomandibular disorders patients. . J Orofac Pain. 1993;7(2):143-9.

138 Ohrbach R, Blascovich J, Gale EN, McCall WD, Jr., Dworkin SF. Psychophysiological assessment of stress in chronic pain: comparisons of stressful stimuli and of response systems. J Dent Res. 1998 Oct;77(10):184050.

139 Ohrbach R, Gale EN. Pressure pain thresholds in normal muscles: reliability, measurement effects, and topographic differences. Pain. 1989 Jun;37(3):257-63.

140 Ohrbach R, Gale EN. Pressure pain thresholds, clinical assessment, and differential diagnosis: reliability and validity in patients with myogenic pain. Pain. 1989 Nov;39(2):157-69.

141 Okeson JP. The psychology of pain. In: OKESON, J. P. Bell's orofacial pains. 1995;Cap. 5(Carol Stream, Quintessence):93-102.

142 Okeson JP. Orofacial Pain Guidelines for assessment, diagnosis, and management. American Academy of Orofacial Pain. Chicago: Quintessence; 1996.

143 Okeson JP. Management of temporomandibular disorders and occlusion. 4 ed. St. Louis, Mosby; 1998.

144 Paesani DA, Tallents RH, Murphy WC, Hatala MP, Proskin HM. Evaluation of the reproducibility of rest activity of the anterior temporal and 
masseter muscles in asymptomatic and symptomatic temporomandibular subjects. J Orofac Pain. 1994 Fall;8(4):402-6.

145 Parker MW, Holmes EK, Terezhalmy GT. Personality characteristics of patients with temporomandibular disorders: diagnostic and therapeutic implications. J Orofac Pain. 1993 Fall;7(4):337-44.

146 Pergamalian A, Rudy TE, Zaki HS, Greco CM. The association between wear facets, bruxism, and severity of facial pain in patients with temporomandibular disorders. J Prosthet Dent. 2003 Aug;90(2):194-200.

147 Pierce CJ, Chrisman K, Bennett ME, Close JM. Stress, anticipatory stress, and psychologic measures related to sleep bruxism. J Orofac Pain. 1995 Winter;9(1):51-6.

148 Pomp MA. Psychotherapy for the myofascial pain-dysfunction syndrome: a study of factors coinciding with symptom remission. J Amer Dent Ass. 1977 Sept.;89:629-32.

149 Pullinger AG, Seligman DA, Gornbein JA. A multiple logistic regression analysis of the risk and relative odds of temporomandibular disorders as a function of common occlusal features. J Dent Res. 1993 Jun;72(6):968-79.

150 Rappaport CR. Teorias da Personalidade em Freud, Reich e Jung. 1984;2. ed., São Paulo, Editora Pedagógica e Universitária (EPU).

151 Reeves JL, Jaeger B, Graff-Radford SB. Reliability of the pressure algometer as a measure of myofascial trigger point sensitivity. Pain. 1986 Mar;24(3):313-21.

152 Reid KI, Gracely RH, Dubner RA. The influence of time, facial side, and location on pain-pressure thresholds in chronic myogenous temporomandibular disorder. J Orofac Pain. 1994 Summer;8(3):258-65.

153 Rieder CE, Martinoff JT, Wilcox SA. The prevalence of mandibular dysfunction. Part I: Sex and age distribution of related signs and symptoms. J Prosthet Dent. 1983 Jul;50(1):81-8.

154 Rossetti LMN. Associação entre bruxismo do sono e dor miofascial: um estudo polissonográfico: USP; 2006.

155 Rothwell PS. Personality and temporomandibular joint dysfunction. Oral Surg Oral Med Oral Pathol. 1972 Nov;34(5):734-42.

156 Ruf S, Cecere F, Kupfer J, Pancherz H. Stress-induced changes in the functional electromyographic activity of the masticatory muscles. Acta Odontol Scand. 1997 Jan;55(1):44-8.

157 Rugh JD, Solberg WK. Psychological implications in temporomandibular pain and dysfunction. Oral Sci Rev. 1976;7:3-30.

158 Rugh JD, Woods BJ, Dahlstrom L. Temporomandibular disorders: assessment of psychological factors. Adv Dent Res. 1993 Aug;7(2):127-36.

159 Salter M, Brooke RI, Merskey H, Fichter GF, Kapusianyk DH. Is the temporo-mandibular pain and dysfunction syndrome a disorder of the mind? Pain. 1983 Oct;17(2):151-66. 
160 Schiffman EL, Fricton J, Haley D, Tylka D. A pressure algometer for myofascial pain syndrome: reliability and validity. In: Dubner RG, G.F.; Bonds, M.R. , editor. World Congress on Pain. Amsterdam, : Elsevier; 1988. p. 407-13.

161 Schiffman EL, Fricton JR, Haley D. The relationship of occlusion, parafunctional habits and recent life events to mandibular dysfunction in a nonpatient population. J Oral Rehabil. 1992 May;19(3):201-23.

162 Schnurr RF, Brooke RI, Rollman GB. Psychosocial correlates of temporomandibular joint pain and dysfunction. Pain. 1990 Aug;42(2):153-65.

163 Schnurr RF, Rollman GB, Brooke RI. Are there psychologic predictors of treatment outcome in temporomandibular joint pain and dysfunction? Oral Surg Oral Med Oral Pathol. 1991 Nov;72(5):550-8.

164 Scott DS. Treatment of the myofascial pain-dysfunction syndrome: psychological aspects. J Am Dent Assoc. 1980 Oct;101(4):611-6.

165 Seger L. Psicologia aplicada à disfunção da ATM. In: Seger L, editor. Psicologia e odontologia - uma abordagem integradora. São Paulo: Santos; 1992. p. 103-22.

166 Selye HA. Syndrome produced by diverse nervous agents.: Nature; 1936.

167 Sessle BJ. The neural basis of temporomandibular joint and masticatory muscle pain. J Orofac Pain. 1999 Fall;13(4):238-45.

168 Silva RS, Conti PC, Lauris JR, Da Silva RO, Pegoraro LF. Pressure pain threshold in the detection of masticatory myofascial pain: an algometerbased study. J Orofac Pain. 2005 Fall;19(4):318-24.

169 Solberg WK. Temporomandibular disorders: physical tests in diagnosis. Br Dent J. 1986 Apr 19;160(8):273-7.

170 Southwell J, Deary IJ, Geissler P. Personality and anxiety in temporomandibular joint syndrome patients. J Oral Rehabil. 1990 May;17(3):239-43.

171 Speculand B, Goss AN. Psychological factors in temporomandibular joint dysfunction pain. A review. Int J Oral Surg. 1985 Apr;14(2):131-7.

172 Stam HJ, McGrath PA, Brooke RI. The treatment of temporomandibular joint syndrome through control of anxiety. J Behav Ther Exp Psychiatry. 1984 Mar;15(1):41-5.

173 Stein S, Hart DL, Loft G, Davis H. Symptoms of TMJ dysfunction as related to stress measured by the social readjustment rating scale. J Prosthet Dent. 1982 May;47(5):545-8.

174 Stohler CS. Craniofacial pain and motor function: pathogenesis, clinical correlates, and implications. Crit Rev Oral Biol Med. 1999;10(4):504-18.

175 Stratmann U, Mokrys K, Meyer U, Kleinheinz J, Joos U, Dirksen D, et al. Clinical anatomy and palpability of the inferior lateral pterygoid muscle. $\mathrm{J}$ Prosthet Dent. 2000 May;83(5):548-54. 
176 Suvinen TI, Hanes KR, Gerschman JA, Reade PC. Psychophysical subtypes of temporomandibular disorders. J Orofac Pain. 1997 Summer;11(3):200-5.

177 Suvinen TI, Reade PC, Hanes KR, Kononen M, Kemppainen P. Temporomandibular disorder subtypes according to self-reported physical and psychosocial variables in female patients: a re-evaluation. J Oral Rehabil. 2005 Mar;32(3):166-73.

178 Suvinen TI, Reade PC, Kemppainen P, Kononen M, Dworkin SF. Review of aetiological concepts of temporomandibular pain disorders: towards a biopsychosocial model for integration of physical disorder factors with psychological and psychosocial illness impact factors. Eur J Pain. 2005 Dec;9(6):613-33.

179 Svensson P, Arendt-Nielsen L, Houe L. Muscle pain modulates mastication: an experimental study in humans. J Orofac Pain. 1998 Winter;12(1):7-16.

180 Svensson P, Arendt-Nielsen L, Nielsen H, Larsen JK. Effect of chronic and experimental jaw muscle pain on pain-pressure thresholds and stimulus-response curves. J Orofac Pain. 1995 Fall;9(4):347-56.

181 Travell J, Rinzler S, Herman M. Pain and disability of the shoulder and arm: treatment by intramuscular infiltration with procaine hydrochloride. $\mathrm{J}$ Am Dent Ass. 1942;120:417-22.

182 Truelove EL, Sommers EE, LeResche L, Dworkin SF, Von Korff M. Clinical diagnostic criteria for TMD. New classification permits multiple diagnoses. J Am Dent Assoc. 1992 Apr;123(4):47-54.

183 Turk DC. Psychosocial and behavioral assessment of patients with temporomandibular disorders: diagnostic and treatment implications. Oral Surg Oral Med Oral Pathol Oral Radiol Endod. 1997 Jan;83(1):65-71.

184 Turner JA, Dworkin SF. Screening for psychological risk factors in patients with chronic orofacial pain. J Am Dent Assoc. 2004;135:1119-25.

185 Turp JC, Minagi S. Palpation of the lateral pterygoid region in TMD where is the evidence? . Journal of Dentistry. 2001;29(7):475-83.

$186 \quad$ Unruh AM. Gender variations in clinical pain experience. Pain. 1996 May-Jun;65(2-3):123-67.

187 Velle W. Sex differences in sensory functions. Perspect Biol Med. 1987 Summer;30(4):490-522.

188 Vietta E. Dor é uma só: é a dor. Rev Dor. 2006;7(3):805-7.

189 Visscher CM, Lobbezoo F, Naeije M. Comparison of algometry and palpation in the recognition of temporomandibular disorder pain complaints. $\mathrm{J}$ Orofac Pain. 2004 Summer;18(3):214-9.

190 Weinberg LA. An evaluation of stress in temporomandibular joint dysfunction-pain syndrome. J Prosthet Dent. 1977 Aug;38(2):192-207.

191 Weiner S, Shaikh MB, Siegel A. Electromyographic activity in the masseter muscle resulting from stimulation of hypothalamic behavioral sites in the cat. J Orofac Pain. 1993 Fall;7(4):370-7. 
192 Wright J, Deary IJ, Geissler PR. Depression, hassles and somatic symptoms in mandibular dysfunction syndrome patients. J Dent. 1991 Dec;19(6):352-6.

193 Yatani H, Studts J, Cordova M, Carlson CR, Okeson JP. Comparison of sleep quality and clinical and psychologic characteristics in patients with temporomandibular disorders. J Orofac Pain. 2002;16(3):221-8. 
Abstract 


\begin{abstract}
Participation of stress/anxiety on the alteration of PPT values in myogenic TMD patients
\end{abstract}

The aim of this research was to evaluate the influence of stress and anxiety on the Pressure Pain Threshold (PPT) of the masticatory muscles and on the subjective pain report of dental students of the Bauru School of Dentistry (University of São Paulo, Brazil) at different situations. Forty-five females, matched for age, were divided into two groups: 29 presenting with myofascial pain, according to the RDC/TMD criteria, and 16 with no TMD signs or symptoms. PPT measurements were taken bilaterally at the masseter, anterior, middle and posterior temporalis muscles in four different occasions throughout the academic year. The Achilles tendon was used as control. In order to quantify emotional or affective reactions under stress/anxiety situations, the sample were requested to fill out multidimensional questionnaires, such as the Beck Anxiety Inventory (BAI) and the Lipp Inventory for Stress Symptoms (LISS). In addition, pain levels were registered with a Visual Analog Scale (VAS). Data obtained were submitted to statistical analysis (ANOVA, Tukey, Friedman, and Mann-Whitney tests), at a 5\% significance level. The VAS and PPT had a negative correlation, regardless the period, and group studied $(p<.05)$. Higher levels of stress and anxiety were detected at the time of school examinations for both groups, with a strong association with decreased PPT figures $(p<.05)$. Stress and anxiety, however, were not statistically different between groups. It can be concluded that external stressors as academic examinations have a potential impact on the masticatory muscle tenderness, regardless the presence of a previous condition, such as the masticatory myofascial pain.

Keywords: Temporomandibular Disorders. Orofacial Pain. Masticatory Muscle. Experimental Pain. Pressure Pain Threshold. Stress. Anxiety. 
